TOXICOLOGICAL PROFILE FOR TOLUENE DIISOCYANATE AND METHYLENEDIPHENYL DIISOCYANATE

U.S. DEPARTMENT OF HEALTH AND HUMAN SERVICES

Public Health Service

Agency for Toxic Substances and Disease Registry

June 2018 
DISCLAIMER

Use of trade names is for identification only and does not imply endorsement by the Agency for Toxic Substances and Disease Registry, the Public Health Service, or the U.S. Department of Health and Human Services. 


\section{UPDATE STATEMENT}

A Toxicological Profile for Toluene Diisocyanate and Methylenediphenyl Diisocyanate, Draft for Public Comment was released in September 2015. This edition supersedes any previously released draft or final profile.

Toxicological profiles are revised and republished as necessary. For information regarding the update status of previously released profiles, contact ATSDR at:

Agency for Toxic Substances and Disease Registry Division of Toxicology and Human Health Sciences

Environmental Toxicology Branch

1600 Clifton Road NE

Mailstop F-57

Atlanta, Georgia 30329-4027 
This page is intentionally blank. 


\section{FOREWORD}

This toxicological profile is prepared in accordance with guidelines* developed by the Agency for Toxic Substances and Disease Registry (ATSDR) and the Environmental Protection Agency (EPA). The original guidelines were published in the Federal Register on April 17, 1987. Each profile will be revised and republished as necessary.

The ATSDR toxicological profile succinctly characterizes the toxicologic and adverse health effects information for these toxic substances described therein. Each peer-reviewed profile identifies and reviews the key literature that describes a substance's toxicologic properties. Other pertinent literature is also presented, but is described in less detail than the key studies. The profile is not intended to be an exhaustive document; however, more comprehensive sources of specialty information are referenced.

The focus of the profiles is on health and toxicologic information; therefore, each toxicological profile begins with a public health statement that describes, in nontechnical language, a substance's relevant toxicological properties. Following the public health statement is information concerning levels of significant human exposure and, where known, significant health effects. The adequacy of information to determine a substance's health effects is described in a health effects summary. Data needs that are of significance to the protection of public health are identified by ATSDR.

Each profile includes the following:

(A) The examination, summary, and interpretation of available toxicologic information and epidemiologic evaluations on a toxic substance to ascertain the levels of significant human exposure for the substance and the associated acute, subacute, and chronic health effects;

(B) A determination of whether adequate information on the health effects of each substance is available or in the process of development to determine levels of exposure that present a significant risk to human health of acute, subacute, and chronic health effects; and

(C) Where appropriate, identification of toxicologic testing needed to identify the types or levels of exposure that may present significant risk of adverse health effects in humans.

The principal audiences for the toxicological profiles are health professionals at the Federal, State, and local levels; interested private sector organizations and groups; and members of the public.

This profile reflects ATSDR's assessment of all relevant toxicologic testing and information that has been peer-reviewed. Staffs of the Centers for Disease Control and Prevention and other Federal scientists have also reviewed the profile. In addition, this profile has been peer-reviewed by a nongovernmental panel and was made available for public review. Final responsibility for the contents and views expressed in this toxicological profile resides with ATSDR.

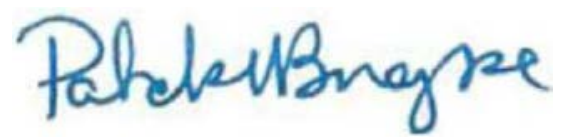

Patrick N. Breysse, Ph.D., CIH

Director, National Center for Environmental Health and

Agency for Toxic Substances and Disease Registry

Centers for Disease Control and Prevention 


\section{*Legislative Background}

The toxicological profiles are developed under the Comprehensive Environmental Response, Compensation, and Liability Act of 1980, as amended (CERCLA or Superfund). CERCLA section 104(i)(1) directs the Administrator of ATSDR to "...effectuate and implement the health related authorities" of the statute. This includes the preparation of toxicological profiles for hazardous substances most commonly found at facilities on the CERCLA National Priorities List and that pose the most significant potential threat to human health, as determined by ATSDR and the EPA. Section 104(i)(3) of CERCLA, as amended, directs the Administrator of ATSDR to prepare a toxicological profile for each substance on the list. In addition, ATSDR has the authority to prepare toxicological profiles for substances not found at sites on the National Priorities List, in an effort to "...establish and maintain inventory of literature, research, and studies on the health effects of toxic substances" under CERCLA Section 104(i)(1)(B), to respond to requests for consultation under section 104(i)(4), and as otherwise necessary to support the site-specific response actions conducted by ATSDR. 


\section{QUICK REFERENCE FOR HEALTH CARE PROVIDERS}

Toxicological Profiles are a unique compilation of toxicological information on a given hazardous substance. Each profile reflects a comprehensive and extensive evaluation, summary, and interpretation of available toxicologic and epidemiologic information on a substance. Health care providers treating patients potentially exposed to hazardous substances may find the following information helpful for fast answers to often-asked questions.

\section{Primary Chapters/Sections of Interest}

Chapter 1: Public Health Statement: The Public Health Statement can be a useful tool for educating patients about possible exposure to a hazardous substance. It explains a substance's relevant toxicologic properties in a nontechnical, question-and-answer format, and it includes a review of the general health effects observed following exposure.

Chapter 2: Relevance to Public Health: The Relevance to Public Health Section evaluates, interprets, and assesses the significance of toxicity data to human health.

Chapter 3: Health Effects: Specific health effects of a given hazardous compound are reported by type of health effect (e.g., death, systemic, immunologic, reproductive), by route of exposure, and by length of exposure (acute, intermediate, and chronic). In addition, both human and animal studies are reported in this section.

NOTE: Not all health effects reported in this section are necessarily observed in the clinical setting. Please refer to the Public Health Statement to identify general health effects observed following exposure.

Pediatrics: Four new sections have been added to each Toxicological Profile to address child health issues:
Chapter 1
Chapter 1
Section 3.7
How Can (Chemical X) Affect Children?
Section 6.6
How Can Families Reduce the Risk of Exposure to (Chemical X)? Children's Susceptibility
Exposures of Children

Other Sections of Interest:

Section $3.8 \quad$ Biomarkers of Exposure and Effect

Section 3.11 Methods for Reducing Toxic Effects

\section{ATSDR Information Center \\ Phone: 1-800-CDC-INFO (800-232-4636) or 1-888-232-6348 (TTY) \\ Internet: http://www.atsdr.cdc.gov}

The following additional materials are available online:

Case Studies in Environmental Medicine are self-instructional publications designed to increase primary health care providers' knowledge of a hazardous substance in the environment and to aid in the evaluation of potentially exposed patients (see https://www.atsdr.cdc.gov/csem/csem.html). 
Managing Hazardous Materials Incidents is a three-volume set of recommendations for on-scene (prehospital) and hospital medical management of patients exposed during a hazardous materials incident (see https://www.atsdr.cdc.gov/MHMI/index.asp). Volumes I and II are planning guides to assist first responders and hospital emergency department personnel in planning for incidents that involve hazardous materials. Volume III-Medical Management Guidelines for Acute Chemical Exposures - is a guide for health care professionals treating patients exposed to hazardous materials.

Fact Sheets (ToxFAQs ${ }^{\mathrm{TM}}$ ) provide answers to frequently asked questions about toxic substances (see https://www.atsdr.cdc.gov/toxfaqs/Index.asp).

\section{Other Agencies and Organizations}

The National Center for Environmental Health (NCEH) focuses on preventing or controlling disease, injury, and disability related to the interactions between people and their environment outside the workplace. Contact: NCEH, Mailstop F-29, 4770 Buford Highway, NE, Atlanta, GA 30341-3724 - Phone: 770-488-7000 - FAX: 770-488-7015 - Web Page: https://www.cdc.gov/nceh/.

The National Institute for Occupational Safety and Health (NIOSH) conducts research on occupational diseases and injuries, responds to requests for assistance by investigating problems of health and safety in the workplace, recommends standards to the Occupational Safety and Health Administration (OSHA) and the Mine Safety and Health Administration (MSHA), and trains professionals in occupational safety and health. Contact: NIOSH, 395 E Street, S.W., Suite 9200, Patriots Plaza Building, Washington, DC 20201 • Phone: 202-245-0625 or 1-800-CDC-INFO (800-232-4636) • Web Page: https://www.cdc.gov/niosh/.

The National Institute of Environmental Health Sciences (NIEHS) is the principal federal agency for biomedical research on the effects of chemical, physical, and biologic environmental agents on human health and well-being. Contact: NIEHS, PO Box 12233, 104 T.W. Alexander Drive, Research Triangle Park, NC 27709 • Phone: 919-541-3212 - Web Page: https://www.niehs.nih.gov/.

\section{Clinical Resources (Publicly Available Information)}

The Association of Occupational and Environmental Clinics (AOEC) has developed a network of clinics in the United States to provide expertise in occupational and environmental issues. Contact: AOEC, 1010 Vermont Avenue, NW, \#513, Washington, DC 20005 • Phone: 202-347-4976 -FAX: 202-347-4950•e-mail: AOEC@AOEC.ORG・Web Page: http://www.aoec.org/.

The American College of Occupational and Environmental Medicine (ACOEM) is an association of physicians and other health care providers specializing in the field of occupational and environmental medicine. Contact: ACOEM, 25 Northwest Point Boulevard, Suite 700, Elk Grove Village, IL 60007-1030 • Phone: 847-818-1800 - FAX: 847-818-9266 - Web Page: http://www.acoem.org/.

The American College of Medical Toxicology (ACMT) is a nonprofit association of physicians with recognized expertise in medical toxicology. Contact: ACMT, 10645 North Tatum Boulevard, 
Suite 200-111, Phoenix AZ 85028 • Phone: 844-226-8333 - FAX: 844-226-8333 • Web Page: http://www.acmt.net.

The Pediatric Environmental Health Specialty Units (PEHSUs) is an interconnected system of specialists who respond to questions from public health professionals, clinicians, policy makers, and the public about the impact of environmental factors on the health of children and reproductive-aged adults. Contact information for regional centers can be found at http://pehsu.net/findhelp.html.

The American Association of Poison Control Centers (AAPCC) provide support on the prevention and treatment of poison exposures. Contact: AAPCC, 515 King Street, Suite 510, Alexandria VA 22314 • Phone: 701-894-1858 • Poison Help Line: 1-800-222-1222 • Web Page:

http://www.aapcc.org/. 
This page is intentionally blank. 


\section{CONTRIBUTORS}

\section{CHEMICAL MANAGER(S)/AUTHOR(S):}

Malcolm Williams, DVM, Ph.D.

G. Daniel Todd, Ph.D.

Hana R. Pohl, M.D., Ph.D.

Jessilynn Taylor, M.S., CDR USPHS

ATSDR, Division of Toxicology and Human Health Sciences, Atlanta, GA

Lisa Ingerman, Ph.D., DABT

Heather Carlson-Lynch, M.S.

Courtney Hard, B.A.

Mario Citra, Ph.D.

SRC, Inc., North Syracuse, NY

THE PROFILE HAS UNDERGONE THE FOLLOWING ATSDR INTERNAL REVIEWS:

1. Health Effects Review. The Health Effects Review Committee examines the health effects chapter of each profile for consistency and accuracy in interpreting health effects and classifying end points.

2. Minimal Risk Level Review. The Minimal Risk Level Workgroup considers issues relevant to substance-specific Minimal Risk Levels (MRLs), reviews the health effects database of each profile, and makes recommendations for derivation of MRLs.

3. Data Needs Review. The Environmental Toxicology Branch reviews data needs sections to assure consistency across profiles and adherence to instructions in the Guidance.

4. Green Border Review. Green Border review assures the consistency with ATSDR policy. 
This page is intentionally blank. 


\section{PEER REVIEW}

A peer review panel was assembled for toluene diisocyanate and methylenediphenyl diisocyanate. The panel consisted of the following members:

1. Dr. Mark Pemberton; Systox, Ltd.; Wilmslow, Cheshire, United Kingdom;

2. Robyn Prueitt, Ph.D., DABT; Gradient Corporation; Cambridge, Massachusetts; and

3. John Weeks, DABT; S.C. Johnson \& Son, Inc.; Racine, Wisconsin.

These experts collectively have knowledge of toluene diisocyanate and methylenediphenyl diisocyanate physical and chemical properties, toxicokinetics, key health end points, mechanisms of action, human and animal exposure, and quantification of risk to humans. All reviewers were selected in conformity with the conditions for peer review specified in Section 104(I)(13) of the Comprehensive Environmental Response, Compensation, and Liability Act, as amended.

Scientists from the Agency for Toxic Substances and Disease Registry (ATSDR) have reviewed the peer reviewers' comments and determined which comments will be included in the profile. A listing of the peer reviewers' comments not incorporated in the profile, with a brief explanation of the rationale for their exclusion, exists as part of the administrative record for this compound.

The citation of the peer review panel should not be understood to imply its approval of the profile's final content. The responsibility for the content of this profile lies with the ATSDR. 
This page is intentionally blank. 


\section{CONTENTS}

DISCLAIMER .ii

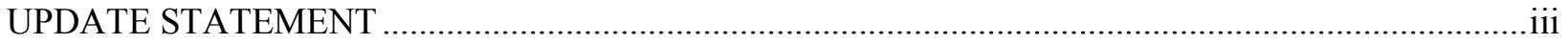

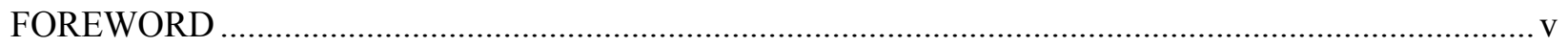

QUICK REFERENCE FOR HEALTH CARE PROVIDERS .............................................................

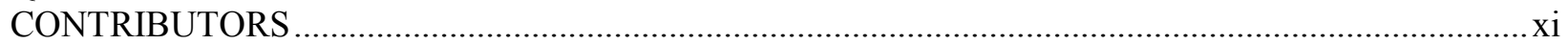

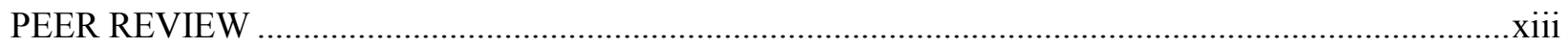

CONTENTS

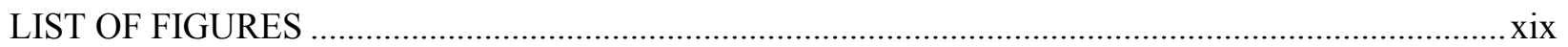

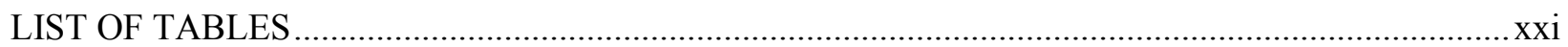

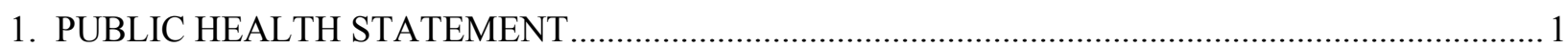

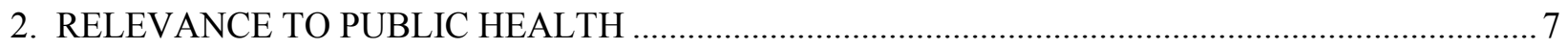

2.1 BACKGROUND AND ENVIRONMENTAL EXPOSURES TO TDI AND MDI IN THE

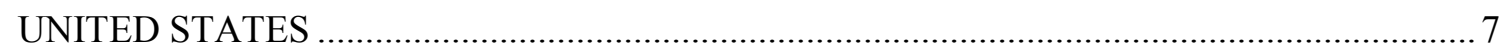

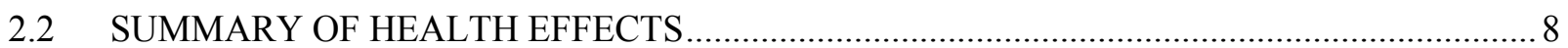

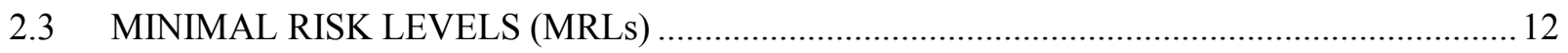

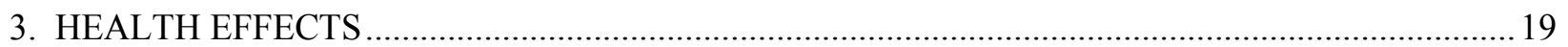

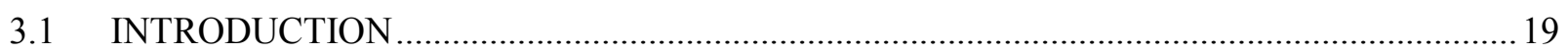

3.2 DISCUSSION OF HEALTH EFFECTS BY ROUTE OF EXPOSURE .................................. 19

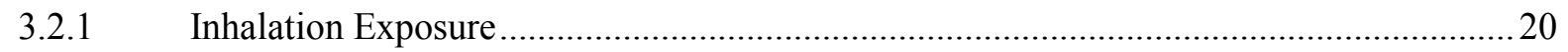

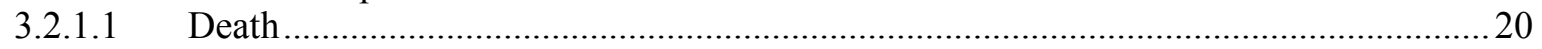

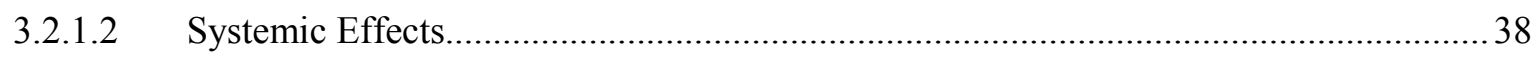

3.2.1.3 Immunological and Lymphoreticular Effects ...................................................5

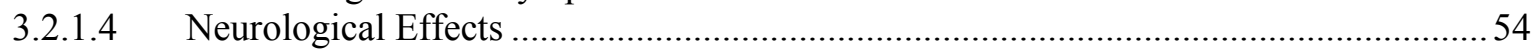

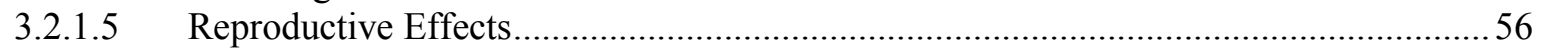

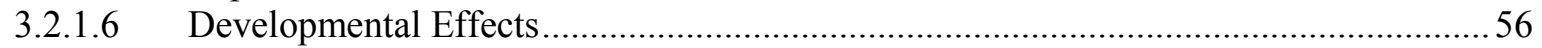

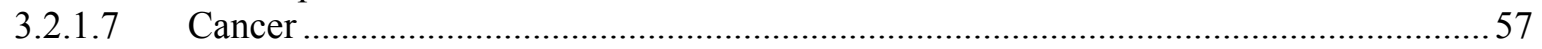

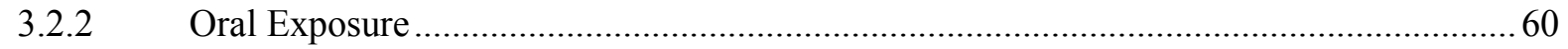

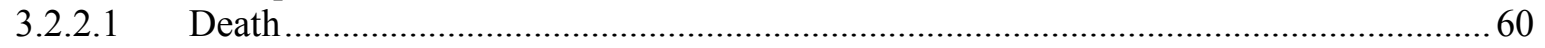

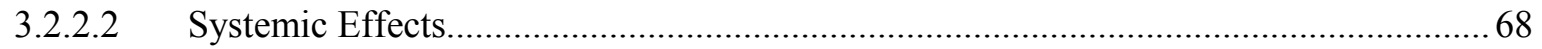

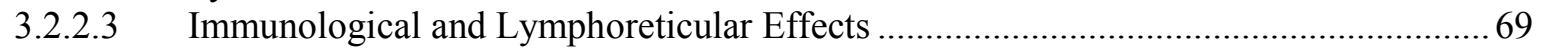

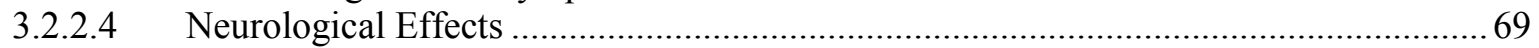

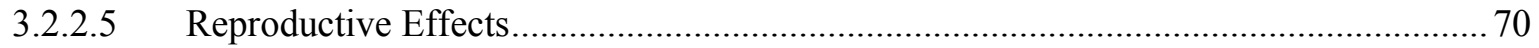

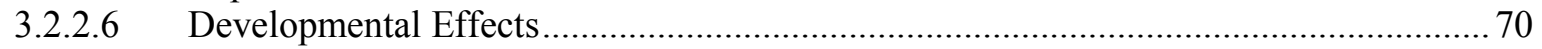

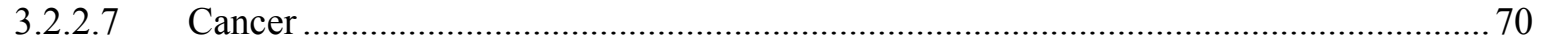

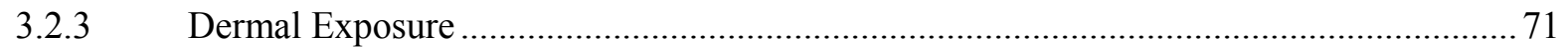

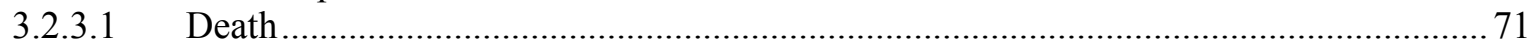

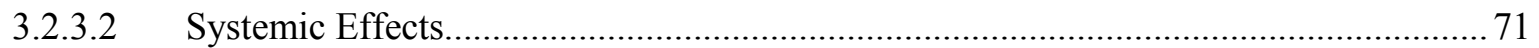

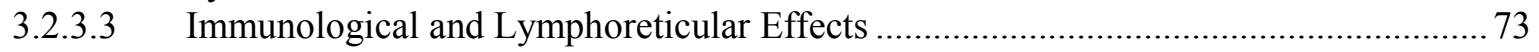

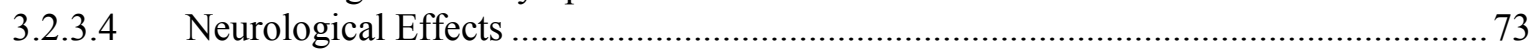

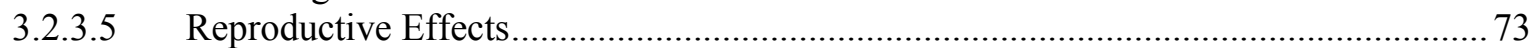

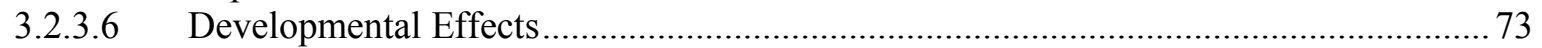

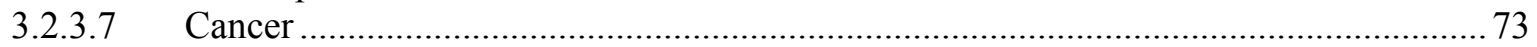

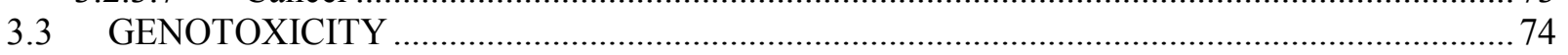

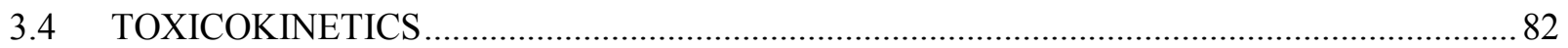

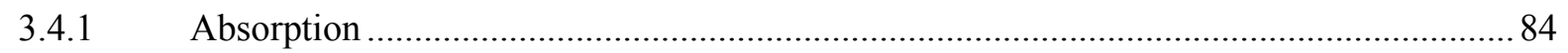

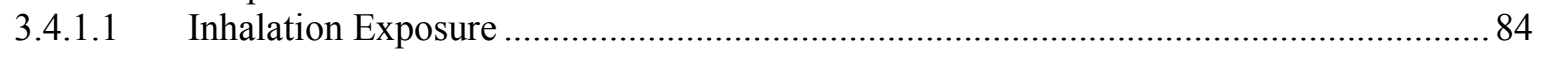




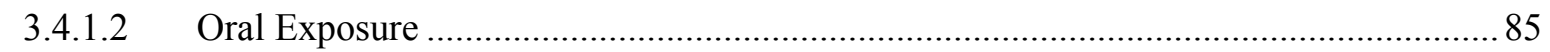

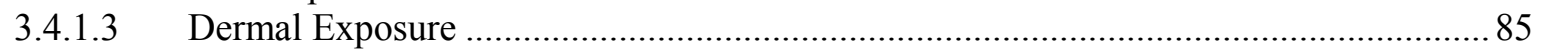

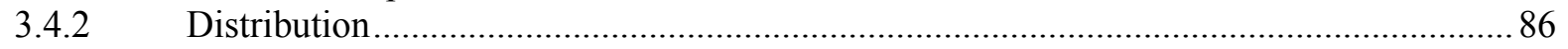

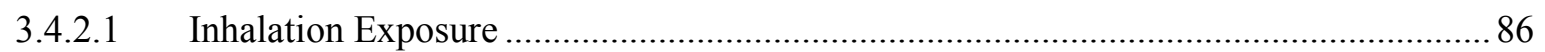

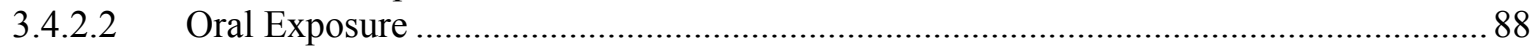

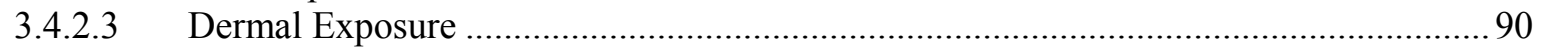

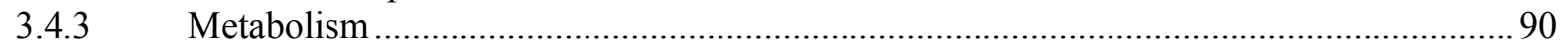

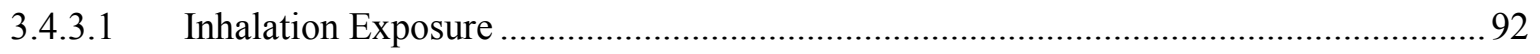

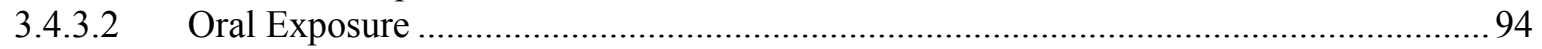

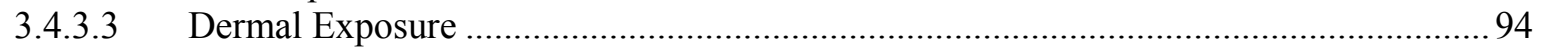

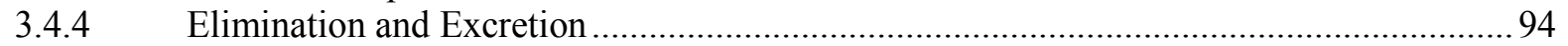

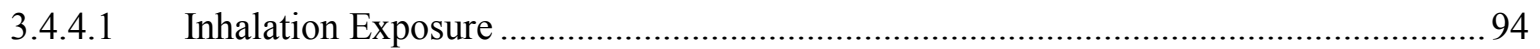

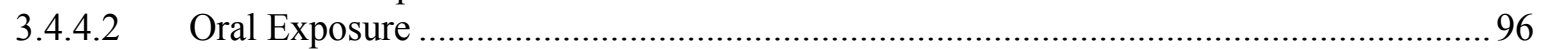

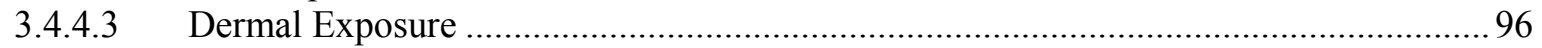

3.4.5 Physiologically Based Pharmacokinetic (PBPK)/Pharmacodynamic (PD) Models......... 98

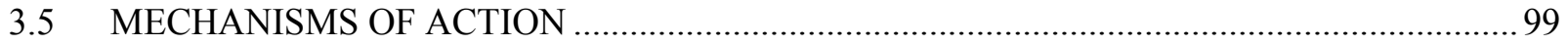

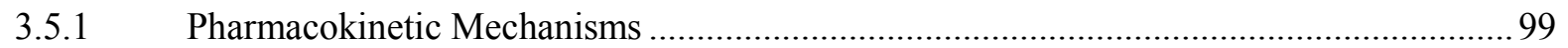

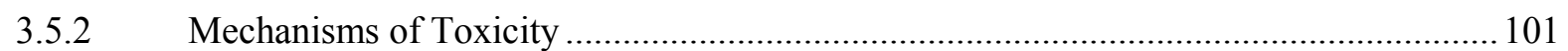

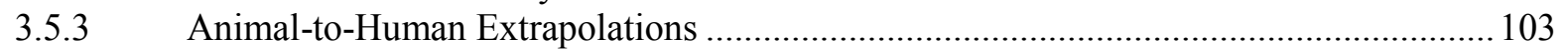

3.6 TOXICITIES MEDIATED THROUGH THE NEUROENDOCRINE AXIS ........................... 104

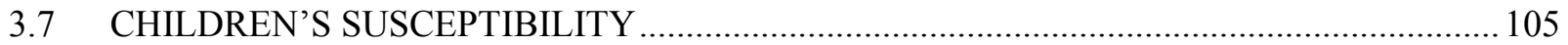

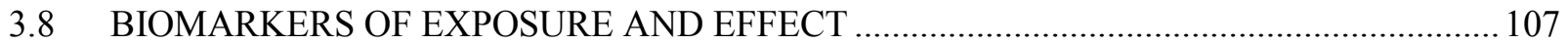

3.8.1 Biomarkers Used to Identify or Quantify Exposure to TDI and MDI........................... 108

3.8.2 Biomarkers Used to Characterize Effects Caused by TDI and MDI ............................ 111

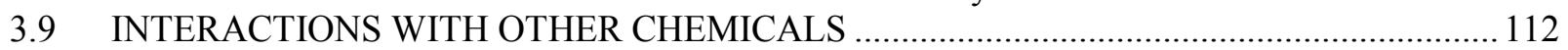

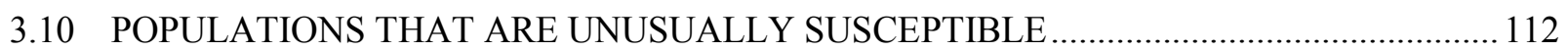

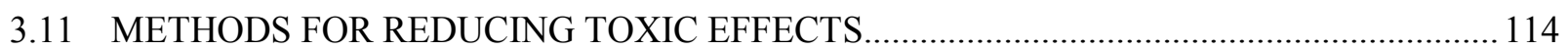

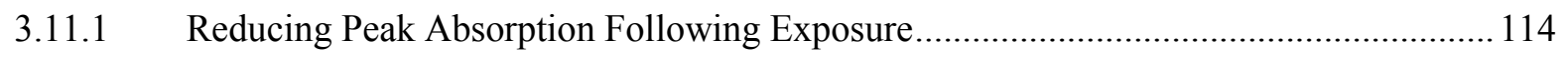

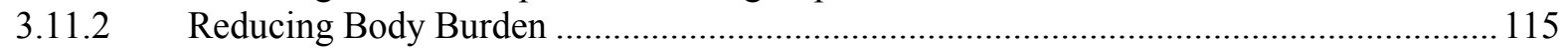

3.11.3 Interfering with the Mechanism of Action for Toxic Effects ..................................... 115

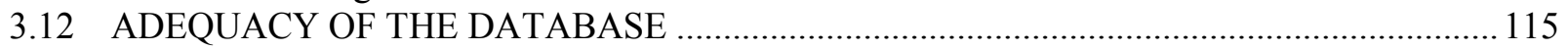

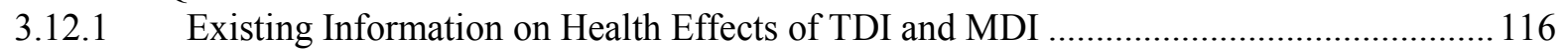

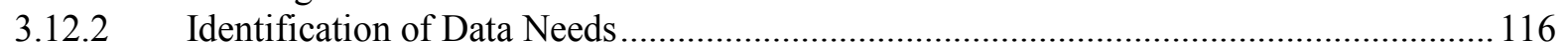

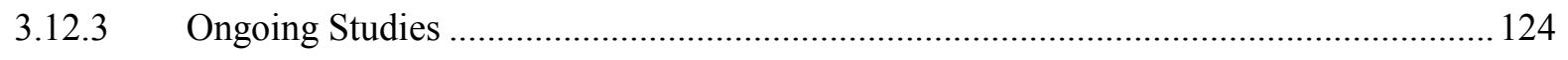

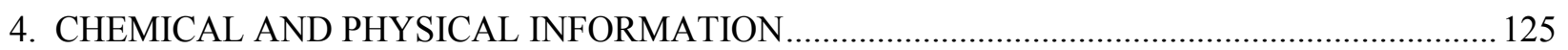

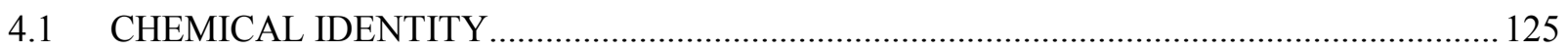

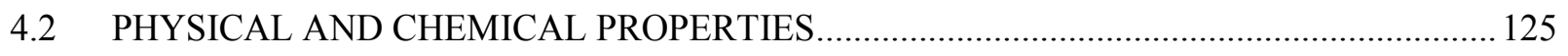

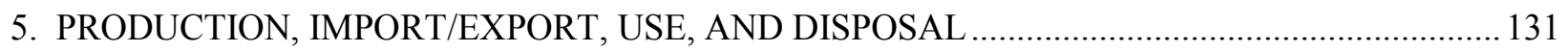

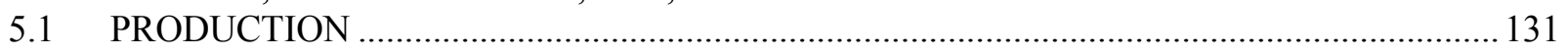

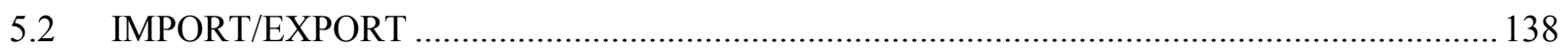

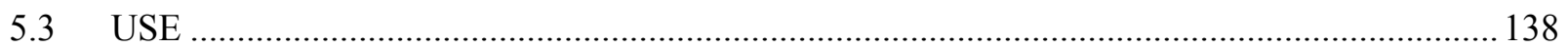

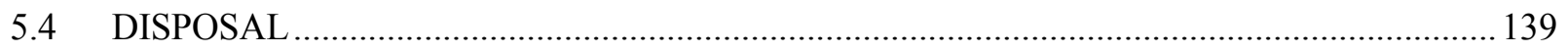

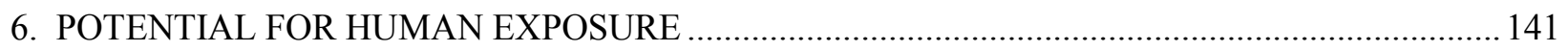

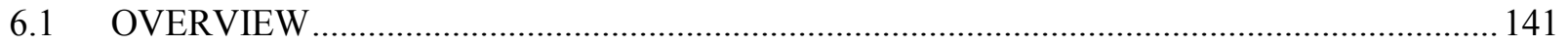

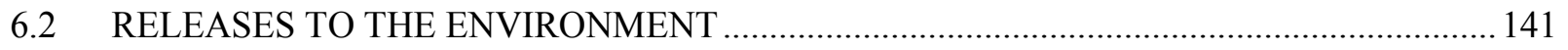

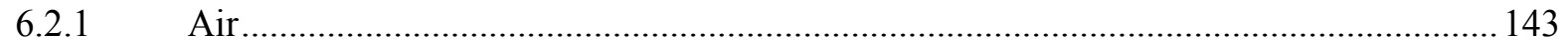

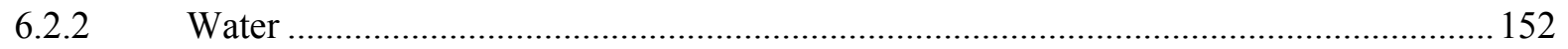

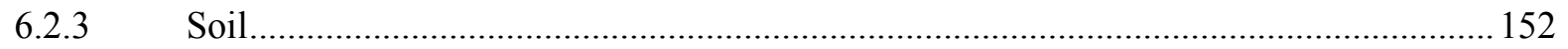




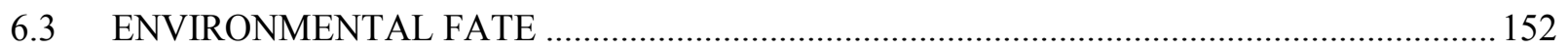

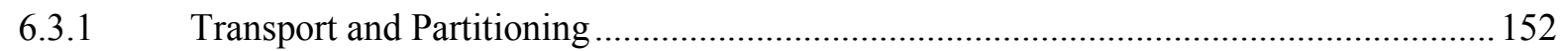

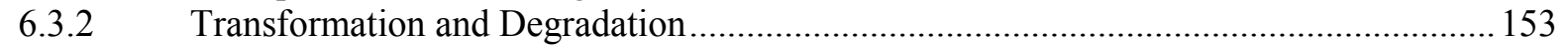

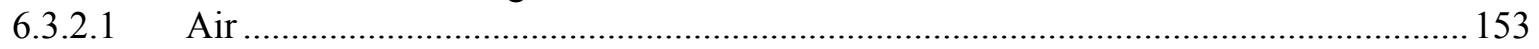

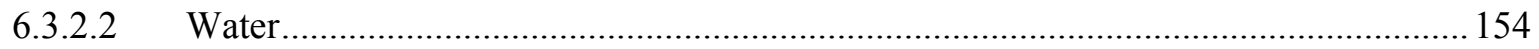

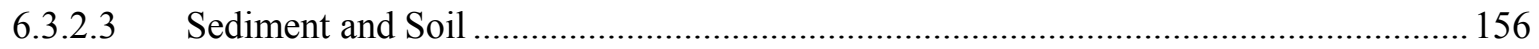

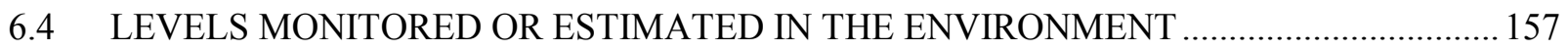

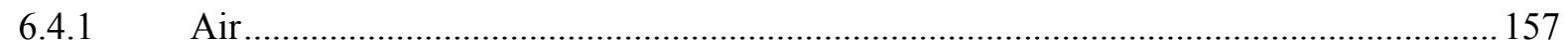

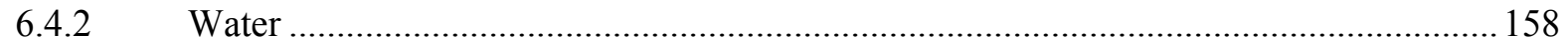

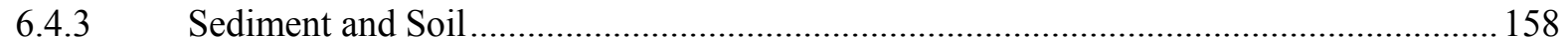

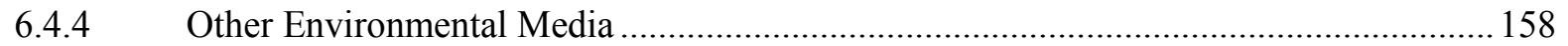

6.5 GENERAL POPULATION AND OCCUPATIONAL EXPOSURE ...................................... 159

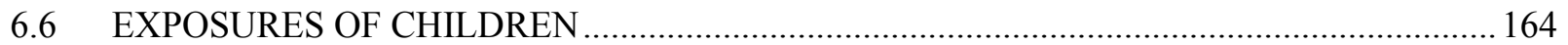

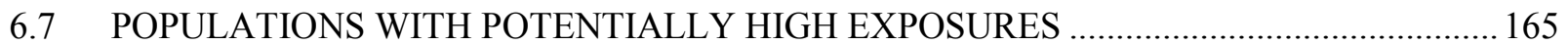

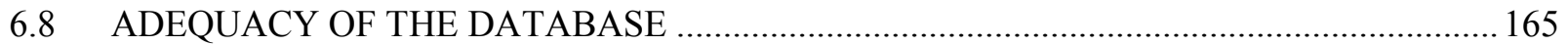

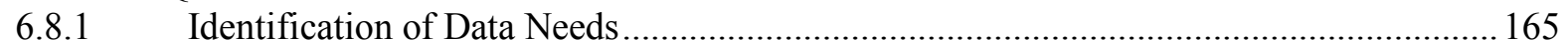

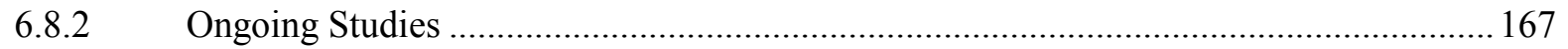

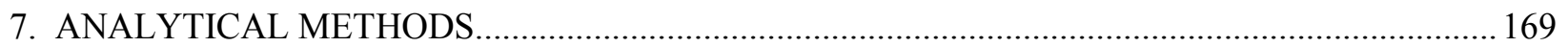

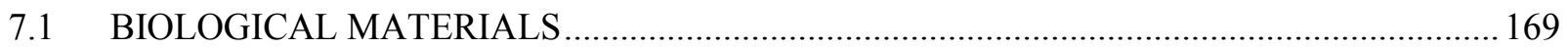

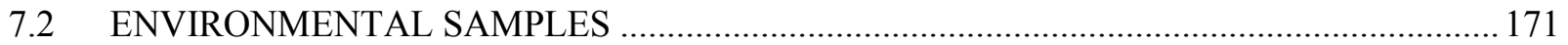

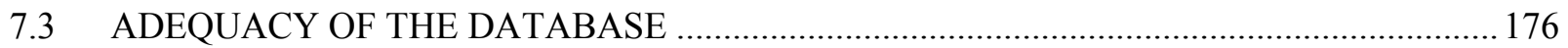

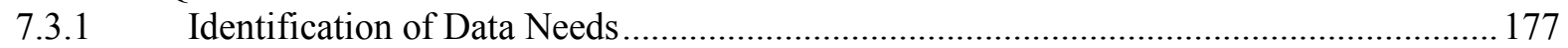

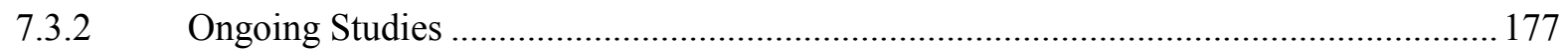

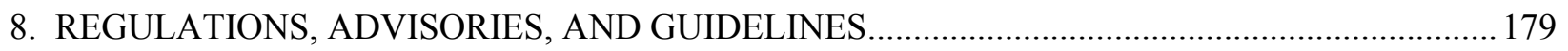

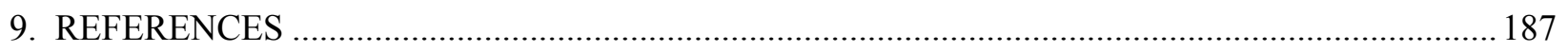

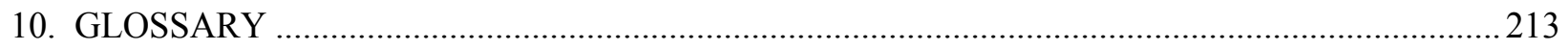

APPENDICES

A. ATSDR MINIMAL RISK LEVELS AND WORKSHEETS …................................................... A-1

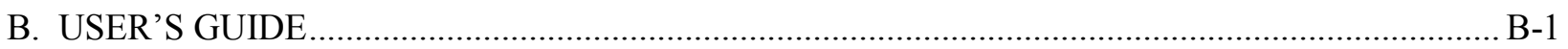

C. ACRONYMS, ABBREVIATIONS, AND SYMBOLS ............................................................ 
This page is intentionally blank. 


\section{LIST OF FIGURES}

3-1. Levels of Significant Exposure to Toluene Diisocyanate - Inhalation ............................................29

3-2. Levels of Significant Exposure to Methylenediphenyl Diisocyanate - Inhalation ........................... 35

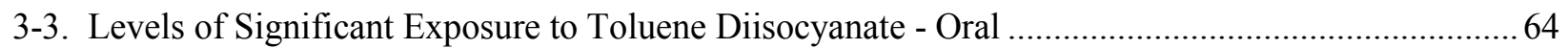

3-4. Proposed Metabolic Scheme for 2,4-Toluene Diisocyanate in the Rat ........................................... 91

3-5. Conceptual Representation of a Physiologically Based Pharmacokinetic (PBPK) Model for a

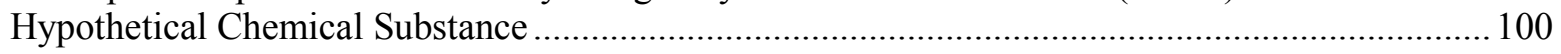

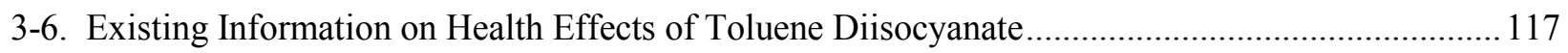

3-7. Existing Information on Health Effects of Methylenediphenyl Diisocyanate................................ 118

6-1. Frequency of NPL Sites with 1,3-Toluene Diisocyanate Contamination...................................... 142 
This page is intentionally blank. 


\section{LIST OF TABLES}

3-1. Levels of Significant Exposure to Toluene Diisocyanate - Inhalation ........................................... 21

3-2. Levels of Significant Exposure to Methylenediphenyl Diisocyanate - Inhalation ........................... 32

3-3. Summary of Occupational Exposure Studies Examining the Effects of TDI on Lung Function ....... 42

3-4. Results of Cohort Studies of Diisocyanate Exposure and Mortality from Specific Cancers.............. 58

3-5. Levels of Significant Exposure to Toluene Diisocyanate - Oral .................................................... 61

3-6. Tumor Incidences in Rats and Mice Exposed to Commercial-Grade Toluene Diisocyanate

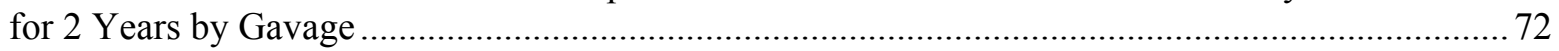

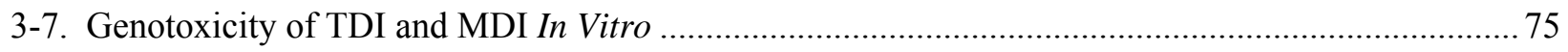

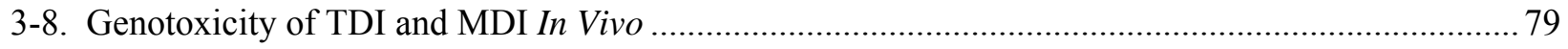

3-9. Tissue Distribution of ${ }^{14} \mathrm{C}$ in Male F344 Rats Exposed to ${ }^{14} \mathrm{C}$ Ring-Labelled 2,4-Toluene Diisocyanate Via Gavage or Inhalation

3-10. Tissue Distribution of ${ }^{14} \mathrm{C}$ in Male Wistar Rats Exposed to ${ }^{14} \mathrm{C}$ Ring-Labelled 4,4'-Methylenediphenyl Diisocyanate Aerosol Via Inhalation

3-11. Metabolites of Methylenediphenyl Diisocyanate (MDI) in Male F344 Rats Exposed to

${ }^{14} \mathrm{C}$ Ring-Labelled 4,4'-MDI Monomer Via Inhalation.

3-12. Kinetics of Urinary Toluene Diamine (TDA) Excretion in Rats Exposed to Toluene Diisocyanate Via Topical Application

3-13. Upper Reference Limits for Biomarkers of Exposure to Toluene Diisocyanate and Methylenediphenyl Diisocyanate 110

4-1. Chemical Identity of Toluene Diisocyanate and Methylenediphenyl Diisocyanate. 126

4-2. Physical and Chemical Properties of Toluene Diisocyanate and Methylenediphenyl Diisocyanate 128

5-1. Facilities that Produce, Process, or Use Toluene Diisocyanate (Mixed Isomers) 132

5-2. Facilities that Produce, Process, or Use 2,4-Toluene Diisocyanate. 134

5-3. Facilities that Produce, Process, or Use 2,6-Toluene Diisocyanate. 135

5-4. Facilities that Produce, Process, or Use Diisocyanates 136

6-1. Releases to the Environment from Facilities that Produce, Process, or Use Toluene Diisocyanate (Mixed Isomers)...... 
6-2. Releases to the Environment from Facilities that Produce, Process, or Use 2,4-Toluene Diisocyanate

6-3. Releases to the Environment from Facilities that Produce, Process, or Use 2,6-Toluene Diisocyanate

6-4. Releases to the Environment from Facilities that Produce, Process, or Use Diisocyanates

7-1. Analytical Methods for Determining TDI and MDI in Biological Materials 170

7-2. Analytical Methods for Determining TDI and MDI in Environmental Samples 172

8-1. Regulations, Advisories, and Guidelines Applicable to TDI and MDI 181 


\section{PUBLIC HEALTH STATEMENT}

This Public Health Statement summarizes the Agency for Toxic Substances and Disease Registry's (ATSDR) findings on toluene diisocyanate (TDI) and methylenediphenyl diisocyanate (MDI), including chemical characteristics, exposure risks, possible health effects from exposure, and ways to limit exposure.

The U.S. Environmental Protection Agency (EPA) identifies the most serious hazardous waste sites in the nation. These sites make up the National Priorities List (NPL) and are sites targeted for long-term federal clean-up activities. The EPA has found TDI in at least 4 of the 1,854 current or former NPL sites. MDI was not found in any of the current or former NPL sites. The total number of NPL sites evaluated for TDI and MDI is not known. But the possibility remains that as more sites are evaluated, the number of sites at which TDI and MDI are found may increase. This information is important because these future sites may be sources of exposure, and exposure to TDI and MDI may be harmful.

If you are exposed to TDI or MDI, many factors determine whether you'll be harmed. These include how much you are exposed to (dose), how long you are exposed (duration), how often you are exposed (frequency), and how you are exposed (route of exposure). You must also consider the other chemicals you are exposed to and your age, sex, diet, family traits, lifestyle, and state of health.

\section{WHAT ARE TDI AND MDI?}

TDI and MDI do not occur naturally in the environment. TDI is a clear, colorless to pale yellow liquid. MDI is a light yellow crystalline solid. There are several forms of TDI and MDI, which are called isomers. The two most common TDI isomers are 2,4-TDI and 2,6-TDI. The most common isomer of MDI is $4,4^{\prime}$-MDI.

TDI and MDI are used to make many household products. They combine with other chemicals to produce various polyurethanes. Some of the products made with these polyurethanes include foam for furniture cushions and carpet padding and waterproof sealants.

\section{WHAT HAPPENS TO TDI AND MDI WHEN THEY ENTER THE ENVIRONMENT?}

TDI and MDI can be released into the air, water, and soil at places where they are produced or used. TDI and MDI are extremely reactive chemicals and are not likely to stay in the environment. In air, TDI and 
MDI have half-lives of less than 1 day (half-life is the amount of time needed for the amount of TDI or MDI in air to be reduced by one-half). TDI and MDI rapidly react with water to form other compounds in a process called hydrolysis. The half-lives of TDI and MDI in water range from a few minutes to a few hours. Significant concentrations are not likely to be found in moist soil or sediment due to the rapid hydrolysis of these compounds; however, small amounts may be detected near point sources such as industrial waste streams and hazardous waste sites. TDI and MDI will not bioaccumulate in the food chain and are therefore not expected to be found in significant concentrations in fish and foods.

\section{HOW MIGHT I BE EXPOSED TO TDI AND MDI?}

TDI and MDI are used to make a number of different types of polyurethane products that are used by consumers ranging from foams for insulation, foam cushions, and sealants. In products such as cushions, the diisocyanates are cured, meaning that they are not reactive. It is unlikely that consumers would be exposed to diisocyanates from cured products. However, you can be exposed to TDI in the air from uncured polyurethane products such as adhesives, sealants, coatings, paints, craft materials, and insulating foams. The percentage of monomeric isocyanates in pre-polymer products is low (generally $<5 \%$ for consumer products). Consumer products that contain low levels of diisocyanates warn against dermal exposure and recommend use of protective gloves. Workers involved in the manufacture of cured and uncured polyurethane products or involved in other industries using uncured diisocyanates may be exposed to higher levels. You are unlikely to be exposed to TDI or MDI in food or water.

\section{HOW CAN TDI AND MDI ENTER AND LEAVE MY BODY?}

When you breathe air containing TDI or MDI, some will enter your body through your lungs, but there is limited information on how much and how fast these compounds enter the body. TDI may enter your body through the digestive tract if you ingest it. There are no data on whether MDI will enter your body after ingestion. If your skin comes in contact with TDI or MDI, it is possible that a small amount may enter the body through the skin.

Once TDI or MDI enters your body, it reacts with large molecules, called macromolecules to form TDIor MDI-conjugates. These conjugates are widely distributed throughout the body. TDI or MDI can also be reactive with itself to form compounds called polyureas, which are not absorbed. TDI and MDI conjugates and polyureas primarily leave the body in the feces; a small amount also leaves the body in the urine. 


\section{HOW CAN TDI AND MDI AFFECT MY HEALTH?}

The health effects of TDI and MDI depend on how much you are exposed to and the length of that exposure. Respiratory effects, including a decrease in lung function, have been reported in workers exposed to TDI or MDI. Some workers have become sensitized to TDI and/or MDI; they are particularly sensitive to the toxicity of TDI and MDI and may experience adverse effects at much lower concentrations than the concentrations that may affect non-sensitized individuals. Asthma and symptoms of asthma, such as wheezing and shortness of breath, have been observed in some individuals who are particularly sensitive to the toxicity of TDI and MDI.

An excess of lung cancer has been observed in some workers at a polyurethane foam manufacturing plant. However, it is not known if exposure to TDI was the cause. A study in animals exposed by gavage to TDI reported increases in tumors in the pancreas, mammary gland, and liver. The Department of Health and Human Services (HHS) considers TDI as reasonably anticipated to be a human carcinogen and the International Agency for Research on Cancer has classified TDI as possibly carcinogenic to humans. EPA has not classified the carcinogenicity of TDI.

There are limited data to determine whether exposure to MDI can cause cancer. An animal study reported an increase in lung tumors in rats exposed by inhalation to polymeric MDI. The exposure levels tested in this study are much higher than concentrations found in work environments. IARC has determined that MDI is not classifiable as to its carcinogenicity in humans. EPA notes that the carcinogenicity of MDI cannot be determined, but there is suggestive evidence that raises concern for carcinogenic effects.

See Chapters 2 and 3 for more information on health effects of TDI and MDI.

\section{HOW CAN TDI AND MDI AFFECT CHILDREN?}

This section discusses potential health effects of TDI and MDI exposure in humans from when they're first conceived to 18 years of age.

We do not have any information on the effects of TDI or MDI in children. We expect that the effects in children will be similar to those seen in adults; exposure to TDI or MDI in the air could result in lung effects. A delay in bone growth has been observed in offspring of animals exposed to high levels of TDI in air that also caused decreases in body weight gain or respiratory effects in the mothers. Exposure to 
high levels of MDI in air during gestation also resulted in bone effects in the offspring; the MDI concentration causing these effects also resulted in decreased food consumption in the mothers.

\section{HOW CAN FAMILIES REDUCE THE RISK OF EXPOSURE TO TDI AND MDI?}

If your doctor finds that you have been exposed to significant amounts of TDI or MDI, ask whether your children might also be exposed. Your doctor might need to ask your state health department to investigate. You may also contact the state or local health department with health concerns.

You are unlikely to be exposed to TDI and MDI from food, drinking water, contaminated groundwater, or soil.

TDI and MDI are used to make many products; however, most of these products are cured and should not have unreacted diisocyanates remaining in them. Primary users and bystanders should be made aware of the potential risks and appropriate precautions to take when uncured TDI or MDI products (such as spray foam or sealants) are being used because use of these professional products can result in exposure to TDI or MDI. Always follow the manufacturers' instruction or product labels when using these products. Wear personal protective equipment (chemical resistant goggles/gloves/ clothing) to prevent direct contact with skin and eyes.

\section{ARE THERE MEDICAL TESTS TO DETERMINE WHETHER I HAVE BEEN EXPOSED TO TDI OR MDI?}

TDI and MDI exposures can be measured in blood and urine by hydrolyzing the TDI and MDI reaction products to the corresponding diamine. However, the detection of the diamine products cannot predict the kind of health effects that might develop from that exposure. Because TDI and MDI reaction products leave the body fairly rapidly (within hours or days), the tests need to be conducted soon after exposure. For more information on the reaction products of TDI and MDI and on tests to detect these substances in the body, see Chapters 3 and 7.

\section{WHAT RECOMMENDATIONS HAS THE FEDERAL GOVERNMENT MADE TO PROTECT HUMAN HEALTH?}

The federal government develops regulations and recommendations to protect public health. Regulations can be enforced by law. Federal agencies that develop regulations for toxic substances include the 
Environmental Protection Agency (EPA), the Occupational Safety and Health Administration (OSHA), and the Food and Drug Administration (FDA). Recommendations provide valuable guidelines to protect public health but are not enforceable by law. Federal organizations that develop recommendations for toxic substances include the Agency for Toxic Substances and Disease Registry (ATSDR) and the National Institute for Occupational Safety and Health (NIOSH).

Regulations and recommendations can be expressed as "not-to-exceed" levels; that is, levels of a toxic substance in air, water, soil, or food that do not exceed a critical value usually based on levels that affect animals; levels are then adjusted to help protect humans. Sometimes these not-to-exceed levels differ among federal organizations. Different organizations use different exposure times (e.g., an 8-hour workday or a 24-hour day), different animal studies, or emphasize some factors over others, depending on their mission.

Recommendations and regulations are also updated periodically as more information becomes available. For the most current information, check with the federal agency or organization that issued the regulation or recommendation.

OSHA has set a legal ceiling limit of 0.02 parts per million (ppm) for TDI and MDI in air; these are "notto-exceed" levels. NIOSH has set a recommended limit of $0.005 \mathrm{ppm}$ for monomeric 4,4'-MDI in air for workers exposed 10 hours/day during a 40 hour/day workweek. The EPA has not recommended any drinking water guidelines for TDI or MDI.

\section{WHERE CAN I GET MORE INFORMATION?}

If you have any questions or concerns, please contact your community or state health or environmental quality department, or contact ATSDR at the address and phone number below. You may also contact your doctor if experiencing adverse health effects or for medical concerns or questions. ATSDR can also provide publicly available information regarding medical specialists with expertise and experience recognizing, evaluating, treating, and managing patients exposed to hazardous substances.

- Call the toll-free information and technical assistance number at 1-800-CDCINFO (1-800-232-4636) or 
- Write to:

\author{
Agency for Toxic Substances and Disease Registry \\ Division of Toxicology and Human Health Sciences \\ 1600 Clifton Road NE \\ Mailstop F-57 \\ Atlanta, GA 30329-4027
}

Toxicological profiles and other information are available on ATSDR's web site:

http://www.atsdr.cdc.gov. 


\section{RELEVANCE TO PUBLIC HEALTH}

\subsection{BACKGROUND AND ENVIRONMENTAL EXPOSURES TO TDI AND MDI IN THE UNITED STATES}

Diisocyanates have widespread commercial use due to their reactivity and versatility. These compounds are predominantly used in the production of polyurethane materials. Two diisocyanates, TDI and MDI, and their related polyisocyanates make up $>90 \%$ of the commercial market. Commercial-grade TDI comprises an 80:20 mixture of isomers 2,4- and 2,6-TDI and represents $>95 \%$ of TDI industrial use. There are several isomers of MDI, including 4,4'-, 2,4'-, and 2,2'-MDI, as well as oligomers and polymeric compounds. The principal commercial product of MDI is made up of a mixture of all of these components, with a typical composition in the range of 40-50\% 4,4'-MDI, 2.5-4.0\% 2,4'-MDI, and 0.1$0.2 \%$ 2,2'-MDI; the remainder is oligomers. $4,4^{\prime}$ '-MDI is the most commercially common isomer and is referred to as pure MDI.

The dominant process affecting the overall environmental fate, transport, and bioaccumulation potential of TDI and MDI is hydrolysis. Diisocyanates react with water forming the respective amines, which in turn may react with more diisocyanates to produce inert, insoluble polyureas. Hydrolysis half-lives of MDI and TDI have been measured to be on the order of a few minutes to a few hours. Due to the rapid hydrolysis of these compounds, they are not expected to persist or bioaccumulate in the environment.

Almost all of the potential exposures to these compounds are associated with the production, handling, use, and disposal of diisocyanates and products containing unreacted diisocyanates. TDI and MDI are most frequently detected in occupational settings, mainly by inhalation of aerosol and vapor (TDI only). Diisocyanates are used in the production of polyurethane foam during foaming, casting, spraying, and other processes. Exposure may also occur after production when the polymer is processed. Thermal degradation of polyurethane foam during processes such as heat cutting of foam blocks, flame lamination with textiles, and welding, cutting, or grinding of polyurethane-coated metal, can also release diisocyanates into the air. Another route is through dermal exposure by contact with uncured polyurethane foams.

Exposure of the general population to diisocyanates could potentially result from industrial exposures, as well as the use of consumer products containing uncured TDI and MDI. There has been an increase in the number of uncured diisocyanate-containing products used by consumers. TDI emissions were not 
detected in a study of polyurethane products such as carpet padding, furniture cushions, and varnishes. However, application of a concrete water solvent did result in elevated TDI levels.

\subsection{SUMMARY OF HEALTH EFFECTS}

TDI. Epidemiology studies and laboratory animal studies have investigated the toxicity of TDI and identified the respiratory tract as the most sensitive target of toxicity. A 6-hour exposure of healthy adults to $0.005 \mathrm{ppm}$ did not result in respiratory symptoms, but did result in slight declines in lung function (specific airway conductance and maximal expiratory flow $[\mathrm{MEF}]$ ). A shorter duration exposure to a higher concentration ( $0.02 \mathrm{ppm}$ for 20 minutes) did not result in alterations in specific airway resistance in healthy or asthmatic subjects. Occupational exposure studies primarily report three types of respiratory effects: occupational asthma, asthma-like symptoms, and declines in lung function. Occupational asthma, which is characterized by airflow limitations and/or airway hyperresponsiveness, is seen in individuals who become hypersensitive to TDI. In sensitized individuals, exposure to low, non-irritating concentrations of TDI can result in wheezing and dyspnea, a marked decrease in lung function, and nonspecific airway hyperresponsiveness. In some workers, removal from TDI exposure can result in improvement in symptoms and a lack of response to a TDI challenge (a brief exposure to a non-irritating concentration); however, a fair percentage of workers still reported asthma symptoms. One study of TDI-sensitized subjects reported an improvement in respiratory symptoms 11 years after removal from TDI exposure; however, $60 \%$ of the workers still complained of asthmatic symptoms. Subjects who are diagnosed with occupational asthma shortly after the onset of symptoms, immediately discontinue TDI exposure after diagnosis, and have a milder degree of airway hyperresponsiveness are more likely to recover from the respiratory symptoms. Recovery has not been reported in workers who continue to be exposed to TDI; continued exposure may result in further declines in lung function. TDI concentrations resulting in sensitization are not known, but the sensitization is believed to be due to a brief exposure to a very high concentration or prolonged exposure to lower concentrations. Prior to 1970 when occupational exposure levels were higher, the prevalence of TDI-induced asthma was 5-6\%; after the mid-1970s when the occupational limit was typically maintained at $0.005 \mathrm{ppm}$, rates of $<1 \%$ have been reported. Some workers report asthma-like symptoms such as wheezing, dyspnea, and chest tightness but do not respond to a TDI challenge; several studies have found that approximately half of the subjects with asthma-like symptoms will have a positive response to a TDI challenge.

The primary health effect observed in nonsensitized workers exposed to TDI is a decline in lung function, particularly the forced expiratory volume in 1 second $\left(\mathrm{FEV}_{1}\right)$. Two longitudinal studies provide 
suggestive evidence that the greatest declines in lung function occur within the first couple of years of exposure to lower TDI concentrations. A decline in $\mathrm{FEV}_{1}$ and forced vital capacity (FVC) was found in workers with no previous history of occupational exposure to TDI who were exposed to an 8-hour timeweighted average (TWA) TDI level of $0.0012 \mathrm{ppm}$. However, no declines in lung function were found in the cohort, which mostly consisted of workers with prior TDI exposure. Additionally, when the naïve workers were followed for another several years, no additional declines in lung function were found. Declines in lung function were observed in workers with an 8-hour TWA TDI exposure level of $0.0082 \mathrm{ppm}$, but no effects were observed in workers with an 8-hour TWA TDI level of $0.0017 \mathrm{ppm}$.

Animal studies have reported histological lesions in the nasal cavity and lungs after acute, intermediate, or chronic TDI exposure. The nasal lesions typically consisted of rhinitis, necrosis, ulceration, and metaplasia; the severity of the lesions and location within the nasal cavity appear to be concentration- and duration-related. Rhinitis was reported at $0.02 \mathrm{ppm}$ in intermediate-duration studies; chronic or necrotic rhinitis was reported at $0.05 \mathrm{ppm}$ in a chronic mouse study. Interstitial pneumonitis and catarrhal bronchitis was observed at slightly higher concentrations in the chronic mouse study. In addition to the histological alterations, airway hyperresponsiveness and increases in respiratory rates have been observed in laboratory animal studies exposed for acute or intermediate durations.

A limited number of other adverse health effects have been reported in humans and animals. A chronic study in rats and mice examined major tissues and organs and only reported adverse effects in the respiratory tract. Dermal irritation and ocular irritation have also been reported in TDI workers. Reproductive and developmental toxicity of TDI has been investigated in rats. No evidence of reproductive toxicity was observed in a 2-generation study in which rats were exposed to concentrations as high as $0.3 \mathrm{ppm}$. An increase in litters with poorly ossified cervical centrum was observed in the offspring of rats exposed to $0.5 \mathrm{ppm}$ on gestation days (GDs) 6-15; this concentration was also associated with significant maternal toxicity, including a $45 \%$ decrease in maternal weight gain and labored breathing.

Although the carcinogenicity of TDI specifically has not been investigated in occupational exposure studies, three studies have examined workers at polyurethane foam manufacturing facilities and found associations between work in the polyurethane foam manufacturing facility and lung cancer in female workers; none of the studies examined associations specifically with TDI exposure. A chronic-duration study in rats and mice did not find significant increases in neoplastic tumors. HHS has classified TDI as reasonably anticipated to be a human carcinogen based on sufficient evidence of carcinogenicity from 
studies in experimental animals. The International Agency for Research on Cancer (IARC) has classified TDI as a Group 2B carcinogen (possibly carcinogenic to humans) based on inadequate evidence of carcinogenicity in humans and sufficient evidence of carcinogenicity in experimental animals. EPA has not classified the carcinogenicity of TDI.

TDI is rapidly hydrolyzed in water and is not likely to be detected in aquatic environments; thus, it is unlikely that the general population will be exposed via this route. The oral toxicity of commercial-grade TDI has been investigated in a series of gavage studies in rats and mice; there is some question regarding the relevance of these data to humans due to likely pharmacokinetic differences between ingestion of TDI and gavage administration directly into the acidic environment of the stomach, which could result in the formation of 2,4-toluene diamine (TDA). Mucoid bronchopneumonia was observed in rats following intermediate exposure to $240 \mathrm{mg} / \mathrm{kg} /$ day, 5 days/week for 13 weeks or following chronic exposure 30 or $60 \mathrm{mg} / \mathrm{kg} / \mathrm{day}, 5$ days/week for 2 years; decreases in survival were also observed at these doses. Bronchopneumonia was not observed in mice; however, an increased incidence of cytomegaly in the renal tubules was observed in male mice administered $120 \mathrm{mg} / \mathrm{kg} /$ day, 5 days/week for 2 years. Decreases in survival were also observed in mice chronically exposed to $240 \mathrm{mg} / \mathrm{kg} / \mathrm{day}$. The chronic study also found clear evidence of carcinogenicity in rats and female mice. In rats, there were increases in the incidence of subcutaneous fibromas and fibrosarcomas, pancreatic acinar cell adenomas and islet cell adenomas, mammary gland fibroadenomas, and neoplastic nodules of the liver. In the female mice, the incidences of hemangiomas or hemangiosarcomas and hepatocellular adenomas were increased.

MDI. Similar to TDI, the respiratory tract is the primary target of toxicity for MDI. Occupational exposure can result in occupational asthma, asthma-like symptoms, and decreases in lung function. Although a number of studies have reported MDI-induced asthma or asthma-like symptoms, no reliable concentration-response data or prevalence data are available. As with TDI, occupational asthma likely results from exposure to very high concentrations of MDI or prolonged exposure to high levels that result in sensitization. Approximately half of workers reporting asthma-like symptoms such as wheezing, dyspnea, and chest tightness have a positive response to a short MDI-challenge. Many MDI-sensitized workers also respond to nonspecific irritants; the prevalence of subjects with asthma-like symptoms exhibiting bronchial hyperresponsiveness following exposure to methacholine was significantly higher than in non-exposed subjects or other MDI workers. Unlike TDI, a small number of workers with asthma-like symptoms also reported chills, fever, and malaise, which are considered symptoms of hypersensitivity pneumonitis. 
Decreases in lung function were observed in MDI workers. Other studies have not found decreases in lung function when pre-shift levels were compared to post-shift levels; one of these studies that examined 27 workers noted that the MDI levels at the facility ranged from 0.0005 to $0.001 \mathrm{ppm}$.

A limited number of studies have been conducted in laboratory animals. A study measuring respiratory rates in mice reported increases in respiratory rates at $7 \mathrm{mg} / \mathrm{m}^{3}$, which were followed by a gradual decline in respiratory rate; the investigators suggested that this pattern was indicative of pulmonary irritation rather than sensory irritation. Airway hyperresponsiveness to acetylcholine was observed in guinea pigs exposed to $0.01 \mathrm{ppm}$ MDI 6 hours/day for 5 days or 6 hours/day, 5 days/week for 4 weeks. A chronicduration study with polymeric MDI containing about 50\% monomeric MDI found increases in nasal lesions (basal cell hyperplasia and Bowman's gland hyperplasia) and lung lesions (localized fibrosis and alveolar duct epithelialization in rats exposed to $1.0 \mathrm{mg} / \mathrm{m}^{3}$ polymeric MDI 6 hours/day, 5 days/week for 2 years. Many of these lesions were observed after 1 year of exposure to $6.0 \mathrm{mg} / \mathrm{m}^{3}$. An unpublished study reported similar lung effects in female rats exposed to $0.23 \mathrm{mg} / \mathrm{m}^{3}$ monomeric MDI 18 hours/day, 5 days/week for 2 years.

The chronic study in rats did not find any other systemic effects. In a rat developmental toxicity study, an increased incidence of litters with fetuses displaying asymmetric sternebrae was observed at $9 \mathrm{mg} / \mathrm{m}^{3}$ MDI administered on GDs 6-15; a decrease in maternal food consumption was also observed at that exposure level.

No occupational exposure studies have examined the possible association between MDI exposure and cancer risk. As discussed in the TDI section, a possible association between lung cancer and employment at polyurethane foam manufacturing facilities was reported in female workers. The chronic inhalation rat study found increases in lung adenomas in male rats exposed to $6.0 \mathrm{mg} / \mathrm{m}^{3}$ polymeric MDI; one incident of lung adenocarcinoma was also found. IARC has classified 4,4'-MDI as a Group 3 carcinogen (not classifiable as to its carcinogenicity to humans) based on inadequate evidence of carcinogenicity in humans and inadequate or limited evidence in experimental animals. EPA has characterized the carcinogenicity of MDI/polymeric MDI as "cannot be determined, but for which there is suggestive evidence that raises concern for carcinogenic effects". 


\subsection{MINIMAL RISK LEVELS (MRLS)}

Estimates of exposure levels posing minimal risk to humans (MRLs) have been established for TDI and MDI. An MRL is defined as an estimate of daily human exposure to a substance that is likely to be without an appreciable risk of adverse effects (noncarcinogenic) over a specified duration of exposure. MRLs are derived when reliable and sufficient data exist to identify the target organ(s) of effect or the most sensitive health effect(s) for a specific duration within a given route of exposure. MRLs are based on noncancerous health effects only and do not consider carcinogenic effects. MRLs can be derived for acute, intermediate, and chronic duration exposures for inhalation and oral routes. Appropriate methodology does not exist to develop MRLs for dermal exposure.

Although methods have been established to derive these levels (Barnes and Dourson 1988; EPA 1990), uncertainties are associated with these techniques. Furthermore, ATSDR acknowledges additional uncertainties inherent in the application of the procedures to derive less than lifetime MRLs. As an example, acute inhalation MRLs may not be protective for health effects that are delayed in development or are acquired following repeated acute insults, such as hypersensitivity reactions, asthma, or chronic bronchitis. As these kinds of health effects data become available and methods to assess levels of significant human exposure improve, these MRLs will be revised.

\section{Inhalation MRLs for TDI}

\section{Acute Duration}

- An MRL of $1 \times 10^{-5} \mathrm{ppm}$ has been derived for acute-duration inhalation exposure ( $\leq 14$ days) to TDI.

A limited number of human studies have evaluated the acute toxicity of TDI. No respiratory symptoms were reported in healthy subjects exposed to 0.005 ppm TDI for 6 hours followed by a 20 -minute exposure to $0.02 \mathrm{ppm}$ TDI; however, slight, but statistically significant, decreases in specific airway conductance and MEF at 25\% of FVC were observed (Vandenplas et al. 1999). No alterations in specific airway resistance were observed in healthy or asthmatic subjects exposed to $0.02 \mathrm{ppm}$ for 20 minutes (Chester et al. 1979). Acute-duration animal inhalation studies have reported rhinitis, lung damage, and airway hyperresponsiveness. The severity of rhinitis was concentration-related; moderate rhinitis was observed in mice exposed to 0.07 ppm 6 hours/day for 4 days (Zissu 1995), moderate-to-severe rhinitis was observed in mice exposed to 0.4 ppm 6 hours/day for 5 days (Buckley et al. 1984), and severe nasal 
lesions were observed in mice exposed to 1 ppm 6 hours/day for 3 days (Arts et al. 2008). Interstitial inflammation, pleural thickening, and goblet cell hyperplasia were observed in the lungs of guinea pigs exposed to $1.4 \mathrm{ppm}$ TDI 3 hours/day for 3 days (Wong et al. 1985). Airway hyperresponsiveness to methacholine or acetylcholine was also observed in guinea pigs and mice exposed to $\geq 0.01 \mathrm{ppm}$ (Gagnaire et al. 1996; Gordon et al. 1985; Marek et al. 1999); a no-observed-adverse-effect level (NOAEL) of $0.005 \mathrm{ppm}$ for airway hyperresponsiveness was identified in guinea pigs exposed to TDI 6 hours/day for 5 days (Marek et al. 1999). An increase in the incidence of litters with poorly ossified cervical centrum was observed in the offspring of rats exposed to $0.5 \mathrm{ppm}$ commercial-grade TDI 6 hours/day on GDs 6-15 (Tyl et al. 1999a); this concentration was also associated with maternal toxicity including a marked decrease in body weight gain and signs of nasal irritation and audible respiration.

The Vandenplas et al. (1999) human study identified the lowest lowest-observed-adverse-effect level (LOAEL) (0.005 ppm) for respiratory effects caused by acute inhalation exposure to TDI; the lowest LOAEL in animals is approximately 10-fold higher. The Vandenplas et al. (1999) study was considered suitable for derivation of an MRL. The LOAEL of $0.005 \mathrm{ppm}$ was adjusted to continuous 24-hour

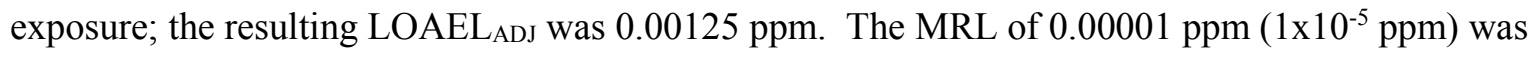
calculated by dividing the LOAEL ADJ $_{\text {by }}$ an uncertainty factor of 100 (10 for the use of a LOAEL and 10 for human variability). There is some uncertainty whether the acute-duration MRL based on the Vandenplas et al. (1999) single exposure study would be protective of continuous exposure to TDI for 14 days. Chronic-duration occupational exposure studies provide some support for this MRL. The lowest LOAEL values identified in longitudinal studies of workers exposed to TDI are 0.0012 and 0.0019 ppm (Clark et al. 1998; Diem et al. 1982); the effects observed at these concentrations included decreases in lung function ( $\mathrm{FEV}_{1}$ and/or FVC). These LOAELs are roughly 2-4 times lower than the LOAEL from the Vandenplas et al. (1999) study. However, since there is uncertainty that the MRL would be protective for continuous exposure for 14 days, it is recommended that measured air concentrations should not exceed the MRL of $1 \times 10^{-5} \mathrm{ppm}$ during a 24-hour period.

Intermediate Duration. No human studies have examined the intermediate-toxicity of TDI; several animal studies have examined the respiratory tract following intermediate-duration exposure. Nasal and lung inflammation were observed in mice exposed to $0.02 \mathrm{ppm}$ commercial-grade TDI 4 hours/day, 5 days/week for 6 weeks (Matheson et al. 2005); increased airway hyperresponsiveness was also observed at this concentration. At a slightly higher concentration $(0.07 \mathrm{ppm})$, severe rhinitis with metaplasia and necrosis of the nasal respiratory epithelium was observed (Zissu 1995). The LOAELs in the animal studies are $>10$ times higher than the LOAELs identified in occupational exposure studies (see Chronic 
Duration section) and may not be protective for declines in lung function. In a study by Clark et al. (1998), lung function declines were observed within the first couple of months of exposure. Thus, the data were not considered suitable for an intermediate-duration inhalation MRL for TDI.

\section{Chronic Duration}

- An MRL of $3 \times 10^{-6} \mathrm{ppm}$ has been derived for chronic-duration inhalation exposure ( $\geq 1$ year) to TDI.

A number of studies of workers at TDI production facilities and polyurethane foam manufacturing facilities have reported respiratory effects consisting of asthma, asthma-like symptoms, and declines in lung function. TDI-induced asthma is a type of occupational asthma characterized as bronchial inflammation and/or airway hyperresponsiveness. The wheezing, dyspnea, and chest tightness observed in individuals with asthma often persists for years after exposure termination (Mapp et al. 1988; Moller et al. 1986; Moscato et al. 1991; Padoan et al. 2003; Paggiaro et al. 1984). Individuals with TDI-induced asthma are considered to be sensitized to TDI, in that brief exposures to nonirritating concentrations can result in a worsening of symptoms and a decline in lung function. Other workers reported asthma-like symptoms of wheezing and dyspnea, but do not respond to a TDI inhalation challenge; although the workers may not have asthma, the observed respiratory effects may still be indicative of TDI sensitization. The exposure level resulting in TDI sensitization is not known; TDI sensitization may result from a brief exposure to very high TDI concentrations or prolonged exposure to lower concentrations. It is believed that $<10 \%$ of workers become sensitized to TDI; lower rates of sensitization $(<1 \%)$ have been found since the occupational exposure limit has been lowered to $0.005 \mathrm{ppm}(\mathrm{Ott}$ et al. 2003).

The available data suggest that the primary effect in non-sensitized workers is a decline in lung function. Several longitudinal studies have evaluated the effect of TDI exposure on the annual decline in lung function (Adams 1975; Bodner et al. 2001; Butcher et al. 1977; Clark et al. 1998, 2003; Diem et al. 1982; Jones et al. 1992; Omae et al. 1992; Ott et al. 2000; Peters et al. 1970; Wegman et al. 1977, 1982). Although the results across studies are not consistent, several factors may contribute to this inconsistency, including differences in peak exposure levels, difference in the length of exposure, exposure to higher TDI levels prior to the start of the study, and inclusion of sensitized workers. A 5-year study of a new TDI manufacturing facility found greater annual declines in $\mathrm{FEV}_{1}$ and forced expiratory flow at 25-50\% of FVC ( $\left.\mathrm{FEF}_{25-50 \%}\right)$ among nonsmoking workers with a cumulative TDI exposure of $\geq 0.0682 \mathrm{ppm}$ months (Diem et al. 1982). Another study that examined workers at a polyurethane foam manufacturing 
facility with no prior TDI exposure found significant annual declines in $\mathrm{FEV}_{1}$ and $\mathrm{FVC}$; however, no significant alterations in lung function were observed in the entire cohort. The mean 8-hour TWA TDI concentration for the entire cohort (naïve workers and workers with prior TDI exposure) was $0.0012 \mathrm{ppm}$ (Clark et al. 1998). When the naïve worker subcohort was examined several years later, the declines in lung function did not significantly vary from predicted levels (Clark et al. 2003). Clark et al. (1998) suggested that the decline in lung function observed in the naïve subcohort may have been due to respiratory irritation. Another study found greater-than-expected declines in maximal midexpiratory flow $(\mathrm{MMF})$, ratio of $\mathrm{FEV}_{1}$ to $\mathrm{FVC}$, and peak expiratory flow (PEF) in polyurethane foam manufacturing workers with an 8-hour TWA TDI level of $0.0082 \mathrm{ppm}$, with peak levels of 0.02-0.03 ppm (Omae et al. 1992). No alterations were found in workers with a TWA level of $0.0017 \mathrm{ppm}$ with peak levels of 0.0003-0.004 ppm. A fourth study found significant declines in $\mathrm{FEV}_{1}$ levels in workers with TDI exposure levels $\geq 0.0035 \mathrm{ppm}$ (Wegman et al. 1977, 1982). No alterations in lung function were observed in other longitudinal studies with TDI levels of 0.0015-0.015 ppm (Bodner et al. 2001; Butcher et al. 1977; Jones et al. 1992; Ott et al. 2000).

Only one study examined the chronic toxicity of airborne TDI in laboratory animals; significant increases in the incidence and severity of chronic or necrotic rhinitis with epithelial atrophy and mucous and squamous metaplasia were observed in mice exposed to $\geq 0.05$ ppm TDI 6 hours/day, 5 days/week for 2 years (Loeser 1983). Interstitial pneumonitis and catarrhal bronchitis was also noted in mice exposed to $0.15 \mathrm{ppm}$; however, the incidence was not reported.

The adverse effect levels for declines in lung function in TDI workers were about 5 times lower than the LOAEL for nasal effects in mice; thus, the occupational exposure studies were selected as the basis of the MRL. The results of the Diem et al. (1982) and Clark et al. (1998) studies suggest that the greatest declines in lung function occur during the first several years of exposure to TDI; thereafter, the declines are not significantly different from predicted levels. Thus, these studies were considered as the basis of the MRL. The Clark et al. (1998) study was selected over the Diem et al. (1982) because it identified a slightly lower adverse effect level (0.0012 versus $0.0019 \mathrm{ppm})$ and did not rely on unpublished monitoring data. The mean daily exposure level of the exposed group of $0.0012 \mathrm{ppm}$ was adjusted for intermittent exposure ( 8 hours/day, 5 days/week). This adjusted adverse effect level of 0.00029 ppm was divided by a total uncertainty factor of 100 (10 for use of an adverse effect level and 10 for human variability) resulting in an MRL $0.000003 \mathrm{ppm}\left(3 \times 10^{-6} \mathrm{ppm}\right.$ or $\left.0.003 \mathrm{ppb}\right)$. 


\section{Oral MRLs for TDI}

TDI is rapidly hydrolyzed in water and is not likely to be detected in aquatic environments. Thus, oral exposure to TDI in humans is unlikely, thereby lessening the need for oral MRLs.

\section{Inhalation MRLs for MDI}

Acute Duration. Several case reports of acute-duration inhalation exposure to MDI have been identified (Banks et al. 1986; Chang and Karol 1984; Stingeni et al. 2008; Suojalehto et al. 2011). The reports described breathing difficulties (Stingeni et al. 2008), asthma (Chang and Karol 1984; Suojalehto et al. 2011), and asthma-like respiratory symptoms (Banks et al. 1986). Although the exposure levels were not reported, they were likely to be relatively high based on the severity of the observed effects. In guinea pigs, exposure to $0.01 \mathrm{ppm}$ MDI 6 hours/day for 5 days resulted in increased airway hyperresponsiveness; a NOAEL of 0.005 ppm was identified for this effect (Marek et al. 1999). The Marek et al. (1999) study was not considered a suitable basis for an MRL because the study did not include a histological examination of the respiratory tract and it is possible that histological alterations, particularly in the nasal cavity, may occur at lower concentrations than airway hyperresponsiveness.

Intermediate Duration. Bascom et al. (1985) reported a case of a male who exhibited dyspnea, fever, malaise, and hypoxemia, effects characteristic of hypersensitivity pneumonitis, 2 months after beginning a job involving the use of a polyurethane foam containing MDI. Malo and Zeiss (1982) also described a case of a foundry worker who developed dyspnea and restrictive breathing 1 month after beginning work. Neither case included information on exposure levels. Exposure of guinea pigs to $0.01 \mathrm{ppm}$ MDI 6 hours/day, 5 days/week for 4 weeks resulted in increased airway hyperresponsiveness to acetylcholine (Marek et al. 1999). This study did not include a histological examination of the respiratory tract. As noted in the discussion for the acute-duration MRL, the lack of a histological examination precludes using the Marek et al. (1999) study as the basis for deriving an MRL.

\section{Chronic Duration}

- An MRL of $0.001 \mathrm{mg} / \mathrm{m}^{3}$ has been derived for chronic-duration inhalation exposure ( $\geq 1$ year) to polymeric MDI.

The primary effects of MDI observed in occupational exposure studies include occupational asthma in sensitized individuals and decreases in lung function. Asthma and/or asthma-like symptoms were 
reported by several investigators (Hur et al. 2008; Wang and Petsonk 2004; Woellner et al. 1997; Zammit-Tabona et al. 1983); none of these studies provided exposure information. Symptoms of hypersensitivity pneumonitis (e.g., chills, fever, malaise) have also been reported in a study of workers with asthma-like symptoms (Baur 1995). Liss et al. (1988) found a significant decrease in FEV levels $_{1}$ when pre-shift levels were compared to post-shift levels in workers at a steel foundry using MDI; the study did not provide monitoring data. Comparison of pre- and post-shift lung function levels did not reveal significant differences in a study of 27 polyurethane foam workers (Sulotto et al. 1990); the MDI levels ranged from 0.0005 to $0.001 \mathrm{ppm}$. Musk et al. (1982) also found no differences in lung function when pre- and post-shift values were compared in workers at two polyurethane plastic manufacturing facilities. Monitoring data were provided by the facilities and were measured by the investigators; however, there was a large discrepancy between the values.

The chronic toxicity of inhaled MDI has been investigated in rats exposed to an aerosol of polymeric MDI, which contained 44.8-50.2\% monomeric MDI 6 hours/day, 5 days/week for 2 years (Reuzel et al. 1994). Exposure to $1.0 \mathrm{mg} / \mathrm{m}^{3}$ resulted in significant increases in the incidence of basal cell hyperplasia and Bowman's gland hyperplasia in the nasal cavity and mild to moderate localized fibrosis in the lungs and alveolar duct epithelialization. Localized alveolar bronchiolization was also observed at $6.0 \mathrm{mg} / \mathrm{m}^{3}$. The study identified a NOAEL of $0.2 \mathrm{mg} / \mathrm{m}^{3}$. An unpublished study conducted by Hoyemann and associates and reviewed by Feron et al. (2001) found similar results in female rats exposed to monomeric MDI 18 hours/day, 5 days/week for 2 years. In this study, an increased incidence of bronchiolo-alveolar hyperplasia and fibrosis were observed at $\geq 0.23 \mathrm{mg} / \mathrm{m}^{3}$. After adjusting for intermittent exposure, the LOAEL value identified in the Reuzel et al. (1994) study $\left(0.178 \mathrm{mg} / \mathrm{m}^{3}\right)$ is very similar to the LOAEL from the Hoyemann study $\left(0.123 \mathrm{mg} / \mathrm{m}^{3}\right)$.

The NOAELs from the Sulotto et al. (1990) occupational exposure study and the Reuzel et al. (1994) rat study were both considered as possible points of departure for the chronic-duration inhalation MRL (the Hoyemann study was not considered as the basis of the MRL because the study was not available to ATSDR for review). Two TDI studies (Clark et al. 1998; Diem et al. 1982) showed that the greatest declines in lung function occurred within the first year of exposure to TDI. Sulotto et al. (1990) is not a prospective study, so it is possible that exposure to $0.005-0.001 \mathrm{ppm}$ might have resulted in a decline in lung function in naïve workers that would have gone undetected. Due to this uncertainty, the Reuzel et al. (1994) study was selected as the basis of the MRL. The incidence data for basal cell hyperplasia in the nasal cavity, Bowman's duct hyperplasia in the nasal cavity, and lung fibrosis were fit to all available dichotomous models in EPA's Benchmark Dose Software (BMDS, version 2.4.0) using the extra risk 
option. The $\mathrm{BMCL}_{10}$ values predicted from the selected models for basal cell hyperplasia and lung fibrosis were 0.48 and $0.70 \mathrm{mg} / \mathrm{m}^{3}$, respectively; none of the models provided an adequate fit to the incidence data for Bowman's gland hyperplasia. The BMCL $\mathrm{BM}_{10}$ of $0.48 \mathrm{mg} / \mathrm{m}^{3}$ was selected as the point of departure for the MRL and was adjusted for intermittent exposure (6 hours/day, 5 days/week) resulting in a $\mathrm{BMCL}_{\mathrm{ADJ}}$ of $0.086 \mathrm{mg} / \mathrm{m}^{3}$. A human equivalent concentration $\left(\mathrm{BMCL}_{\mathrm{HEC}}\right.$ ) was calculated by multiplying the BMCL $\mathrm{BDJ}_{\mathrm{AJ}}$ by a regional deposited dose ratio (RDDR) of 0.453 . The chronic-duration inhalation MRL of $0.001 \mathrm{mg} / \mathrm{m}^{3}$ for polymeric MDI was derived by dividing the BMCL $L_{H E C}$ of $0.039 \mathrm{mg} / \mathrm{m}^{3}$ by a total uncertainty factor of 30 (3 for extrapolation from animals to human with dosimetric adjustments and 10 for human variability).

\section{Oral MRLs for MDI}

MDI is rapidly hydrolyzed in water and is not likely to be detected in aquatic environments. Thus, oral exposure to MDI in humans is unlikely, thereby lessening the need for oral MRLs. 


\section{HEALTH EFFECTS}

\subsection{INTRODUCTION}

The primary purpose of this chapter is to provide public health officials, physicians, toxicologists, and other interested individuals and groups with an overall perspective on the toxicology of TDI and MDI. It contains descriptions and evaluations of toxicological studies and epidemiological investigations and provides conclusions, where possible, on the relevance of toxicity and toxicokinetic data to public health.

A glossary and list of acronyms, abbreviations, and symbols can be found at the end of this profile.

\subsection{DISCUSSION OF HEALTH EFFECTS BY ROUTE OF EXPOSURE}

To help public health professionals and others address the needs of persons living or working near hazardous waste sites, the information in this section is organized first by route of exposure (inhalation, oral, and dermal) and then by health effect (e.g., death, systemic, immunological, neurological, reproductive, developmental, and carcinogenic effects). These data are discussed in terms of three exposure periods: acute (14 days or less), intermediate (15-364 days), and chronic (365 days or more).

Levels of significant exposure for each route and duration are presented in tables and illustrated in figures. The points in the figures showing no-observed-adverse-effect levels (NOAELs) or lowestobserved-adverse-effect levels (LOAELs) reflect the actual doses (levels of exposure) used in the studies. LOAELs have been classified into "less serious" or "serious" effects. "Serious" effects are those that evoke failure in a biological system and can lead to morbidity or mortality (e.g., acute respiratory distress or death). "Less serious" effects are those that are not expected to cause significant dysfunction or death, or those whose significance to the organism is not entirely clear. ATSDR acknowledges that a considerable amount of judgment may be required in establishing whether an end point should be classified as a NOAEL, "less serious" LOAEL, or "serious" LOAEL, and that in some cases, there will be insufficient data to decide whether the effect is indicative of significant dysfunction. However, the Agency has established guidelines and policies that are used to classify these end points. ATSDR believes that there is sufficient merit in this approach to warrant an attempt at distinguishing between "less serious" and "serious" effects. The distinction between "less serious" effects and "serious" effects is considered to be important because it helps the users of the profiles to identify levels of exposure at which major health effects start to appear. LOAELs or NOAELs should also help in determining whether or not 
the effects vary with dose and/or duration, and place into perspective the possible significance of these effects to human health.

The significance of the exposure levels shown in the Levels of Significant Exposure (LSE) tables and figures may differ depending on the user's perspective. Public health officials and others concerned with appropriate actions to take at hazardous waste sites may want information on levels of exposure associated with more subtle effects in humans or animals (LOAELs) or exposure levels below which no adverse effects (NOAELs) have been observed. Estimates of levels posing minimal risk to humans (Minimal Risk Levels or MRLs) may be of interest to health professionals and citizens alike.

Levels of exposure associated with carcinogenic effects (Cancer Effect Levels, CELs) of TDI and MDI are indicated in Tables 3-2 and 3-5 and Figures 3-2, and 3-3.

A User's Guide has been provided at the end of this profile (see Appendix B). This guide should aid in the interpretation of the tables and figures for Levels of Significant Exposure and the MRLs.

\subsubsection{Inhalation Exposure}

The highest NOAEL values and all LOAEL values from each reliable study for each end point in each species and duration category are recorded in Tables 3-1 and 3-2 and plotted in Figures 3-1 and 3-2 for TDI and MDI, respectively.

\subsubsection{Death}

Available literature did not include human studies evaluating lethality after inhalation exposure to TDI or MDI.

TDI. Acute-duration exposure to commercial-grade TDI at concentrations up to $1.0 \mathrm{ppm}$ did not result in any deaths when groups of eight pregnant CD rats were exposed during GDs 6-15 in a dose-range finding study (Tyl et al. 1999a). Likewise, exposure concentrations up to $0.5 \mathrm{ppm}$ did not result in maternal deaths in the main developmental toxicity study (Tyl et al. 1999a) or in F0 or F1 parental animals in a 2-generation reproductive toxicity study using rats (Tyl et al. 1999b). Chronic (2-year) exposure to $0.15 \mathrm{ppm}$ production-grade TDI (80:20 mix of 2,4- and 2,6-TDI) did not affect survival rates of SpragueDawley rats (Loeser et al. 1983). In CD-1 mice, a significantly increased rate of mortality was seen with 
3. HEALTH EFFECTS

Table 3-1. Levels of Significant Exposure to Toluene Diisocyanate - Inhalation

\begin{tabular}{|c|c|c|c|c|c|c|c|c|}
\hline \multirow[b]{2}{*}{$\begin{array}{l}\text { Key to } \\
\text { Figure }\end{array}$} & \multirow[b]{2}{*}{$\begin{array}{l}\text { Species } \\
\text { (Strain) }\end{array}$} & \multirow{2}{*}{$\begin{array}{c}\text { Exposurel } \\
\text { Duration/ } \\
\text { Frequency } \\
\text { (Route) }\end{array}$} & & \multirow[b]{2}{*}{ NOAEL } & \multicolumn{3}{|c|}{ LOAEL } & \multirow[b]{2}{*}{ Comments } \\
\hline & & & System & & $\begin{array}{c}\text { Less Serious } \\
(\mathrm{ppm})\end{array}$ & $\begin{array}{r}\text { Serious } \\
(\mathrm{ppm})\end{array}$ & $\begin{array}{l}\text { Reference } \\
\text { Chemical Form }\end{array}$ & \\
\hline
\end{tabular}

ACUTE EXPOSURE

Systemic

1 Human

$6 \mathrm{hr}$

Resp

$0.005^{b}$ (slight decrease in

specific airway

conductance)

2

$\begin{array}{lll}\text { Rat } & 4 \text { hours/day } & \text { Resp } \\ \text { (Wistar) } & 5 \text { days } & \end{array}$

3

Rat $\quad 6 \mathrm{hr} / \mathrm{d}$

(CD) Gd 6-15

Hepatic

$0.5 \mathrm{~F}$

$\mathrm{Bd} \mathrm{Wt}$

Resp

$\begin{array}{lll}\text { (CD) } & \text { Gd 6-15 } & \text { Resp }\end{array}$

$\mathrm{Bd} \mathrm{Wt}$

\section{$0.41 \mathrm{~F}$ (hypersensitivity}

airway eosinophil

infiltration)

$5 / 21$ dams) symptoms, central airway

goblet cell metaplasia,

central and peripheral

$0.02 \mathrm{~F}$ (red nasal discharge in

Tyl et al. 1999a

2,4/2,6-TDI

Kouadio et al. 2014

2,4-TDI

Vandenplas et al. 1999

TDI, not specified

Tyl et al. 1999a

2,4/2,6-TDI

80: 20 mixture of 2,4-

and 2,6-TDI
80: 20 mixture of 2,4 and 2,6-TDI
$0.5 \mathrm{~F}(45 \%$ decrease in

maternal body weight gain during exposure)

discharge and labored respiration; blood gas changes indicative of respiratory acidosis) 
Table 3-1. Levels of Significant Exposure to Toluene Diisocyanate - Inhalation

(continued)

\begin{tabular}{|c|c|c|c|}
\hline $\begin{array}{l}\text { Key to } \\
\text { Figure }\end{array}$ & $\begin{array}{c}\text { Species } \\
\text { (Strain) }\end{array}$ & $\begin{array}{l}\text { Exposurel } \\
\text { Duration/ } \\
\text { Frequency } \\
\text { (Route) }\end{array}$ & Syste \\
\hline 5 & $\begin{array}{l}\text { Mouse } \\
\text { (BALB/c) }\end{array}$ & $\begin{array}{l}45,90,180, \text { or } \\
360 \mathrm{~min} / \mathrm{d} \\
3 \mathrm{~d}\end{array}$ & Resp \\
\hline
\end{tabular}

$6 \quad$ Mouse $6 \mathrm{hr} / \mathrm{d}$

(Swiss-

$5 \mathrm{~d}$

Webster)

7 Mouse $4 \mathrm{hr} / \mathrm{d}$

(C57BL/6N) $12 \mathrm{~d}$

Resp

Mouse $\quad 2 \mathrm{hr}$

(C57BL/6N)

$\begin{array}{ll}\text { Mouse } & 3 \mathrm{hr} / \mathrm{d} \\ \text { (Swiss- } & 5 \mathrm{~d} \\ \text { Webster) } & \end{array}$

Resp

NOAEL

(ppm)

LOAEL

\begin{tabular}{ll} 
& LOAEL \\
\hline Less Serious & Seri
\end{tabular}

(ppm)

(ppm)

Reference

Chemical Form

Comments

Arts et al. 2008

$2,4 / 2,6-\mathrm{TDI}$

80: 20 mixture of 2,4 and 2,6-TDI

Buckley et al. 1984

TDI, not specified

Johnson et al. 2007

TDI, not specified

Matheson et al. 2005

2,4/2,6-TDI

80: 20 mixture of 2,4 and 2,6-TDI

Resp

$$
\begin{array}{ll}
\text { F } & \text { (nasal and lung } \\
\text { inflammation, airway } \\
\text { hyperresponsiveness) }
\end{array}
$$

Resp

$0.031 \mathrm{M}$

$0.018 \mathrm{M}$
$0.25 \mathrm{M}$ (histological damage to
nasal respiratory

epithelium)

$0.023 \mathrm{M}$ (decreased respiratory rate)
Sangha and Alarie 1979

2,4-TDI 
Table 3-1. Levels of Significant Exposure to Toluene Diisocyanate - Inhalation

(continued)

\begin{tabular}{|c|c|c|c|c|c|c|c|c|}
\hline \multirow[b]{2}{*}{$\begin{array}{l}\text { Key to } \\
\text { Figure } \\
\end{array}$} & \multirow[b]{2}{*}{$\begin{array}{l}\text { Species } \\
\text { (Strain) }\end{array}$} & \multirow{2}{*}{$\begin{array}{l}\text { Exposurel } \\
\text { Durationl } \\
\text { Frequency } \\
\text { (Route) }\end{array}$} & \multirow[b]{2}{*}{ System } & \multirow[b]{2}{*}{$\begin{array}{l}\text { NOAEL } \\
(p p m)\end{array}$} & \multicolumn{2}{|c|}{ LOAEL } & \multirow[b]{2}{*}{$\begin{array}{l}\text { Reference } \\
\text { Chemical Form }\end{array}$} & \multirow[b]{2}{*}{ Comments } \\
\hline & & & & & $\begin{array}{l}\text { Less Serious } \\
\text { (ppm) }\end{array}$ & $\begin{array}{r}\text { Serious } \\
(\mathrm{ppm}) \\
\end{array}$ & & \\
\hline 10 & $\begin{array}{l}\text { Mouse } \\
\text { (Swiss) }\end{array}$ & $\begin{array}{l}6 \mathrm{hr} / \mathrm{d} \\
4 \mathrm{~d}\end{array}$ & Resp & & $\begin{array}{r}0.07 \mathrm{M} \text { (moderat } \\
\text { metaplas } \\
\text { in the nas } \\
\text { epitheliur }\end{array}$ & & $\begin{array}{l}\text { Zissu } 1995 \\
\text { 2,4/2,6-TDI }\end{array}$ & $\begin{array}{l}80: 20 \text { mixture of } 2,4- \\
\text { and } 2,6-\text { TDI }\end{array}$ \\
\hline 11 & $\begin{array}{l}\text { Gn Pig } \\
\text { (Hartley) }\end{array}$ & $\begin{array}{l}3 \mathrm{hr} / \mathrm{d} \\
5 \mathrm{~d}\end{array}$ & Resp & $0.02 \mathrm{~F}$ & $0.2 \mathrm{~F}$ (pulmona & & $\begin{array}{l}\text { Aoyama et al. } 1994 \\
\text { 2,4/2,6-TDI }\end{array}$ & \\
\hline 12 & $\begin{array}{l}\text { Gn Pig } \\
\text { (Dunkin-H }\end{array}$ & rtle $^{1 \mathrm{hr}}$ & Resp & & $\begin{array}{l}3 \mathrm{~F} \text { (airway } \\
\text { hyperres }\end{array}$ & & $\begin{array}{l}\text { Gagnaire et al. } 1996 \\
\text { 2,4/2,6-TDI }\end{array}$ & $\begin{array}{l}80: 20 \text { mixture of } 2,4- \\
\text { and } 2,6-\text { TDI }\end{array}$ \\
\hline 13 & $\begin{array}{l}\text { Gn Pig } \\
\text { (Dunkin-H }\end{array}$ & $\begin{array}{l}\text { continuously } \\
\text { rtle } 48 \mathrm{hr}\end{array}$ & Resp & & $\begin{array}{r}0.1 \mathrm{~F} \text { (airway } \\
\text { hyperres }\end{array}$ & & $\begin{array}{l}\text { Gagnaire et al. } 1996 \\
\text { 2,4/2,6-TDI }\end{array}$ & $\begin{array}{l}\text { 80: } 20 \text { mixture of } 2,4- \\
\text { and } 2,6-T D I\end{array}$ \\
\hline 14 & $\begin{array}{l}\text { Gn Pig } \\
\text { (Dunkin-H }\end{array}$ & $\begin{array}{l}\text { continuously } \\
\text { rtle } 1 \mathrm{wk}\end{array}$ & Resp & & 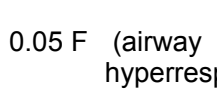 & & $\begin{array}{l}\text { Gagnaire et al. } 1996 \\
\text { 2,4/2,6-TDI }\end{array}$ & $\begin{array}{l}80: 20 \text { mixture of } 2,4- \\
\text { and } 2,6-\text { TDI }\end{array}$ \\
\hline 15 & $\begin{array}{l}\text { Gn Pig } \\
\text { (Hartley) }\end{array}$ & $1 \mathrm{hr}$ & Resp & & 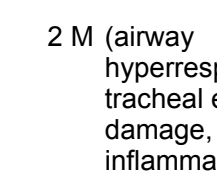 & & $\begin{array}{l}\text { Gordon et al. } 1985 \\
\text { TDI, not specified }\end{array}$ & \\
\hline
\end{tabular}


Table 3-1. Levels of Significant Exposure to Toluene Diisocyanate - Inhalation

(continued)

\begin{tabular}{|c|c|c|c|c|c|}
\hline $\begin{array}{l}\text { Key to } \\
\text { Figure } \\
\end{array}$ & $\begin{array}{l}\text { Species } \\
\text { (Strain) }\end{array}$ & $\begin{array}{l}\text { Exposurel } \\
\text { Durationl } \\
\text { Frequency } \\
\text { (Route) }\end{array}$ & System & $\begin{array}{l}\text { NOAEL } \\
(p p m) \\
\end{array}$ & $\begin{array}{c}\text { Less Serious } \\
\text { (ppm) }\end{array}$ \\
\hline 16 & $\begin{array}{l}\text { Gn Pig } \\
\text { (Dunkin } \\
\text { Hartley) }\end{array}$ & $\begin{array}{l}6 \mathrm{hr} / \mathrm{d} \\
5 \mathrm{~d}\end{array}$ & Resp & $0.005 \mathrm{~F}$ & $\begin{array}{c}0.01 \mathrm{~F} \\
\text { (increased airway } \\
\text { responsiveness) }\end{array}$ \\
\hline 17 & $\begin{array}{l}\text { Gn Pig } \\
\text { (English } \\
\text { smooth } \\
\text { haired) }\end{array}$ & $\begin{array}{l}3 \mathrm{hr} / \mathrm{d} \\
5 \mathrm{~d}\end{array}$ & Resp & & $\begin{array}{l}1.4 \mathrm{~F} \text { (diminished response to } \\
\text { CO2, pulmonary } \\
\text { hypersensitivity, } \\
\text { interstitial inflammation, } \\
\text { pleural thickening and } \\
\text { goblet cell hyperplasia in } \\
\text { the lungs) }\end{array}$ \\
\hline
\end{tabular}

LOAEL

\section{Developmental}

$18 \begin{array}{ll}\text { Rat } & 6 \mathrm{hr} / \mathrm{d} \\ \text { (CD) } & \text { Gd 6-15 }\end{array}$

0.5 (increased incidence of litters with poorly ossified cervical centrum no. 5)
0.02 (rhinitis in F1 parental animals)

Marek et al. 1999

2,4/2,6-TDI

Wong et al. 1985 2,4/2,6-TDI

Tyl et al. 1999a

2,4/2,6-TDI

Tyl et al. 1999b 2,4/2,6-TDI
Comments

80: 20 mixture of 2,4 and 2,6-TDI

80: 20 mixture of 2,4 and 2,6-TDI

80: 20 mixture of 2,4 and 2,6-TDI 80: 20 mixture of $2,4-$
and $2,6-T D I$

\section{Systemic}

19

$\begin{array}{ll}\text { Rat } & \text { 2-generation, } \\ \text { (CD) } & 19 \mathrm{wk} \\ & 5 \text { or } 7 \mathrm{~d} / \mathrm{wk} \\ & 6 \mathrm{hr} / \mathrm{d}\end{array}$

Hepatic

Endocr 
Table 3-1. Levels of Significant Exposure to Toluene Diisocyanate - Inhalation

(continued)

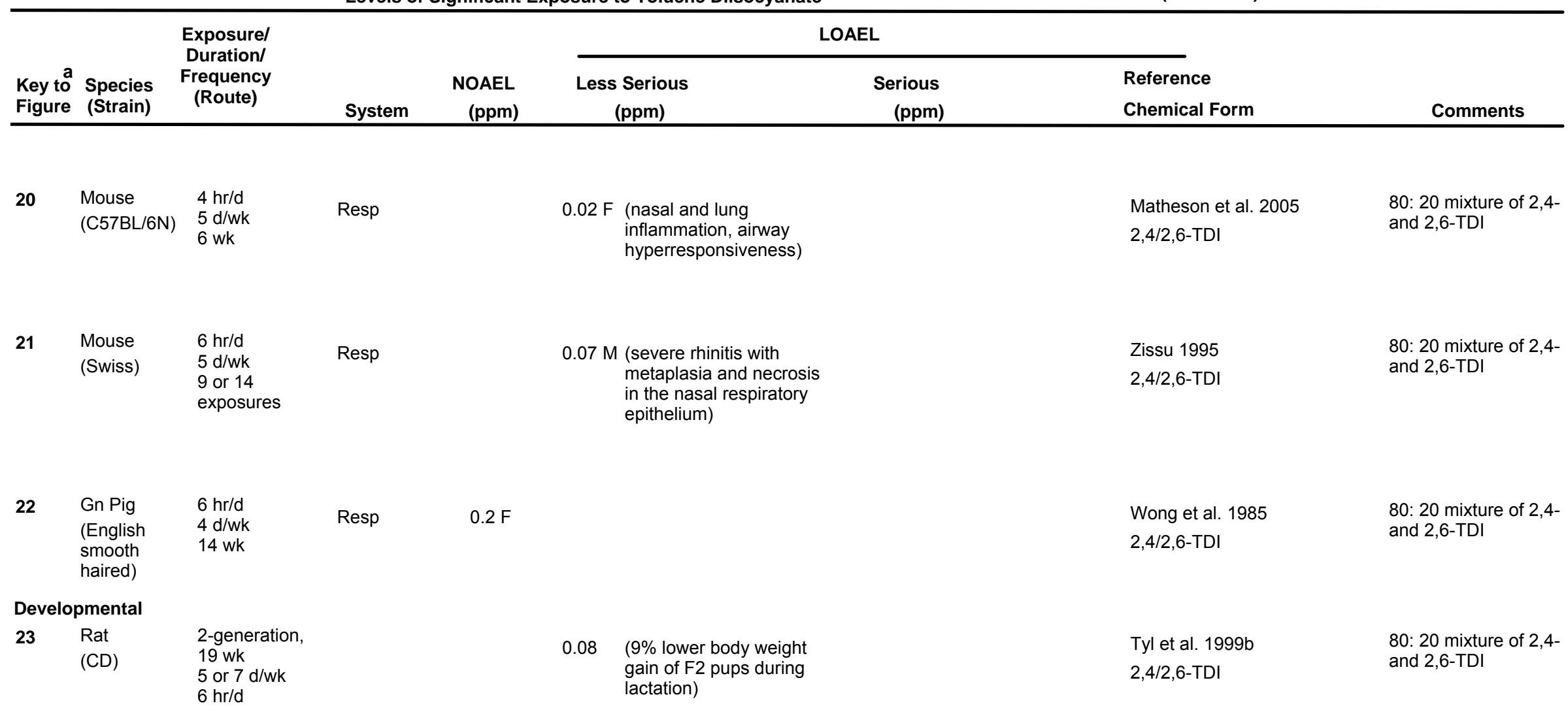

\section{CHRONIC EXPOSURE}

Death

$24 \begin{array}{ll}\text { Mouse } & 104 \mathrm{wk} \\ \text { (CD-1) } & 5 \mathrm{~d} / \mathrm{wk} \\ & 6 \mathrm{hr} / \mathrm{d}\end{array}$

Systemic

25 Human $\begin{aligned} & \text { occupational Resp } \\ & \text { exposure }\end{aligned}$

$0.05 \mathrm{~F}$ (significantly increased Loeser 1983

mortality, $77 \%$ vs $60 \%$ in $2,4 / 2,6$-TDI

controls)
80: 20 mixture of $2,4-$ and 2,6-TDI 
Table 3-1. Levels of Significant Exposure to Toluene Diisocyanate - Inhalation

(continued)

\begin{tabular}{|c|c|c|c|c|c|c|}
\hline $\begin{array}{l}\text { Key to } \\
\text { Figure } \\
\end{array}$ & $\begin{array}{l}\text { Species } \\
\text { (Strain) }\end{array}$ & $\begin{array}{l}\text { Exposurel } \\
\text { Durationl } \\
\text { Frequency } \\
\text { (Route) }\end{array}$ & System & $\begin{array}{l}\text { NOAEL } \\
(p p m)\end{array}$ & Les & $\begin{array}{l}\text { Serious } \\
\text { (ppm) }\end{array}$ \\
\hline 26 & Human & $\begin{array}{l}\text { occupational } \\
\text { exposure }\end{array}$ & Resp & & 0.015 & (respiratory symptoms) \\
\hline 27 & Human & $\begin{array}{l}\text { occupational } \\
\text { exposure }\end{array}$ & Resp & & $0.0012^{c}$ & $\begin{array}{l}\text { (decline in FEV1 in naive } \\
\text { subjects) }\end{array}$ \\
\hline 28 & Human & $\begin{array}{l}\text { occupational } \\
\text { exposure }\end{array}$ & Resp & & 0.00105 & $\begin{array}{l}\text { (increased reporting of } \\
\text { wheezing) }\end{array}$ \\
\hline 29 & Human & $\begin{array}{l}\text { occupational } \\
\text { exposure }\end{array}$ & Resp & & 0.0082 & (decreased lung function) \\
\hline 30 & Human & $\begin{array}{l}\text { occupational } \\
\text { exposure }\end{array}$ & Resp & 0.0042 & & \\
\hline 31 & Human & $\begin{array}{l}\text { occupational } \\
\text { exposure }\end{array}$ & Resp & & 0.0035 & (decreased lung function) \\
\hline
\end{tabular}

Reference

Chemical Form

Comments
Butcher et al. 1977

2,4/2,6-TDI

Clark et al. 1998

2,4/2,6-TDI

Clark et al. 2003

2,4/2,6-TDI

Omae et al. 1992

$2,4 / 2,6-$ TDI

Ott et al. 2000

$2,4 / 2,6-T D I$

Wegman et al. 1977, 1982

$2,4 / 2,6-$ TDI 
Table 3-1. Levels of Significant Exposure to Toluene Diisocyanate - Inhalation

(continued)

\begin{tabular}{|c|c|c|c|c|}
\hline $\begin{array}{l}\text { Key to } \\
\text { Figure }\end{array}$ & $\begin{array}{l}\text { Species } \\
\text { (Strain) }\end{array}$ & $\begin{array}{l}\text { Exposurel } \\
\text { Duration/ } \\
\text { Frequency } \\
\text { (Route) }\end{array}$ & System & $\begin{array}{l}\text { NOAE } \\
\text { (ppr }\end{array}$ \\
\hline \multirow[t]{8}{*}{32} & $\begin{array}{l}\text { Rat } \\
\text { (Sprague- } \\
\text { Dawley) }\end{array}$ & $\begin{array}{l}108-110 \mathrm{wk} \\
5 \mathrm{~d} / \mathrm{wk} \\
6 \mathrm{hr} / \mathrm{d}\end{array}$ & Cardio & 0.15 \\
\hline & & & Gastro & 0.15 \\
\hline & & & Hemato & 0.15 \\
\hline & & & Musc/skel & 0.15 \\
\hline & & & Hepatic & 0.15 \\
\hline & & & Renal & 0.15 \\
\hline & & & Endocr & 0.15 \\
\hline & & & $\mathrm{Bd} \mathrm{Wt}$ & 0.15 \\
\hline
\end{tabular}

$\begin{array}{llll}\text { Mouse } & \begin{array}{l}104 \mathrm{wk} \\ \text { (CD-1) }\end{array} & \text { Resp } & \\ 6 \mathrm{dr} / \mathrm{wk} & & \\ & & \\ & & \\ & \text { Cardio } & 0.15 \\ & \text { Gastro } & 0.15 \\ & \text { Hemato } & 0.15 \\ & \text { Musc/skel } & 0.15 \\ & \text { Hepatic } & 0.15 \\ & & \\ & \text { Renal } & 0.15 \\ & & \\ & & \end{array}$

0.05 (chronic or necrotic rhinitis)
Reference

Chemical Form

Comments

Loeser 1983

2,4/2,6-TDI

80: 20 mixture of 2,4 and 2,6-TDI

Loeser 1983

2,4/2,6-TDI
80: 20 mixture of 2,4and $2,6-\mathrm{TDI}$ 
Table 3-1. Levels of Significant Exposure to Toluene Diisocyanate - Inhalation

(continued)

\begin{tabular}{lllll}
\hline Key to Species & $\begin{array}{c}\text { Exposurel } \\
\text { Duration/ } \\
\text { Frequency } \\
\text { Figure }\end{array}$ & System & $\begin{array}{c}\text { NOAEL } \\
(\text { (Spm) }\end{array}$ & $\begin{array}{c}\text { Less Serious } \\
\text { (ppm) }\end{array}$ \\
\hline & Bd Wt & & 0.15 & $\begin{array}{l}\text { (significantly reduced } \\
\text { weight gain) }\end{array}$
\end{tabular}

a The number corresponds to entries in Figure 3-1.

b Used to derive an acute-duration inhalation MRL of $0.00001 \mathrm{ppm}$. The LOAEL was adjusted for intermittent exposure (6 hours/day) and divided by an uncertainty factor of 100 (10 for the use of a LOAEL and 10 for human variability).

c Used to derive a chronic-duration inhalation MRL of $0.000003 \mathrm{ppm}$. The mean daily exposure level was adjusted for intermittent exposure and divided by an uncertainty factor of 100 (10 for the use of a LOAEL and 10 for human variability)

$\mathrm{Bd} \mathrm{Wt}=$ body weight; Cardio = cardiovascular; $\mathrm{d}=$ day $(\mathrm{s}) ;$ Endocr $=$ endocrine; $\mathrm{F}=$ Female; FEV1 $=$ forced expiratory volume in 1 second; Gastro $=$ gastrointestinal; Gd $=$ gestational day; $\mathrm{Gn}$ Pig = guinea pig; Hemato = hematological; hr = hour(s); LOAEL = lowest-observed-adverse-effect level; $\mathrm{M}=$ male; min = minute(s); Musc/skel = musculoskeletal; NOAEL = no-observed-adverse-effect level; Resp = respiratory; wk = week $(\mathrm{s})$ 
Figure 3-1. Levels of Significant Exposure to Toluene Diisocyanate - Inhalation

Acute ( $\leq 14$ days)

ppm
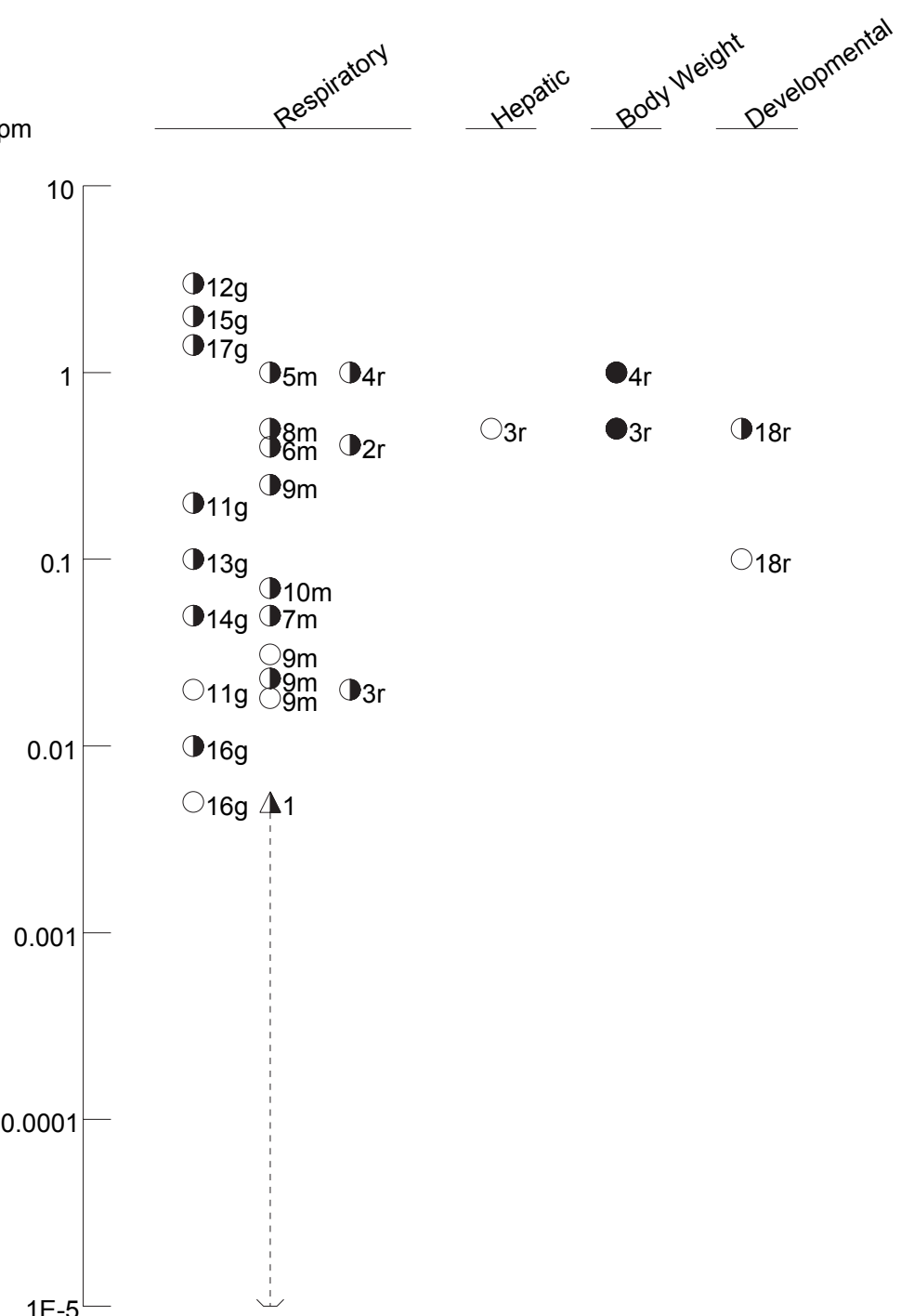

$\begin{array}{ll}\text { c-Cat } & \text { k-Monkey } \\ \text { d-Dog } & \text { m-Mouse } \\ \text { r-Rat } & \text { h-Rabbit } \\ \text { p-Pig } & \text { a-Sheep } \\ \text { q-Cow } & \end{array}$


Figure 3-1. Levels of Significant Exposure to Toluene Diisocyanate - Inhalation (Continued) Intermediate (15-364 days)

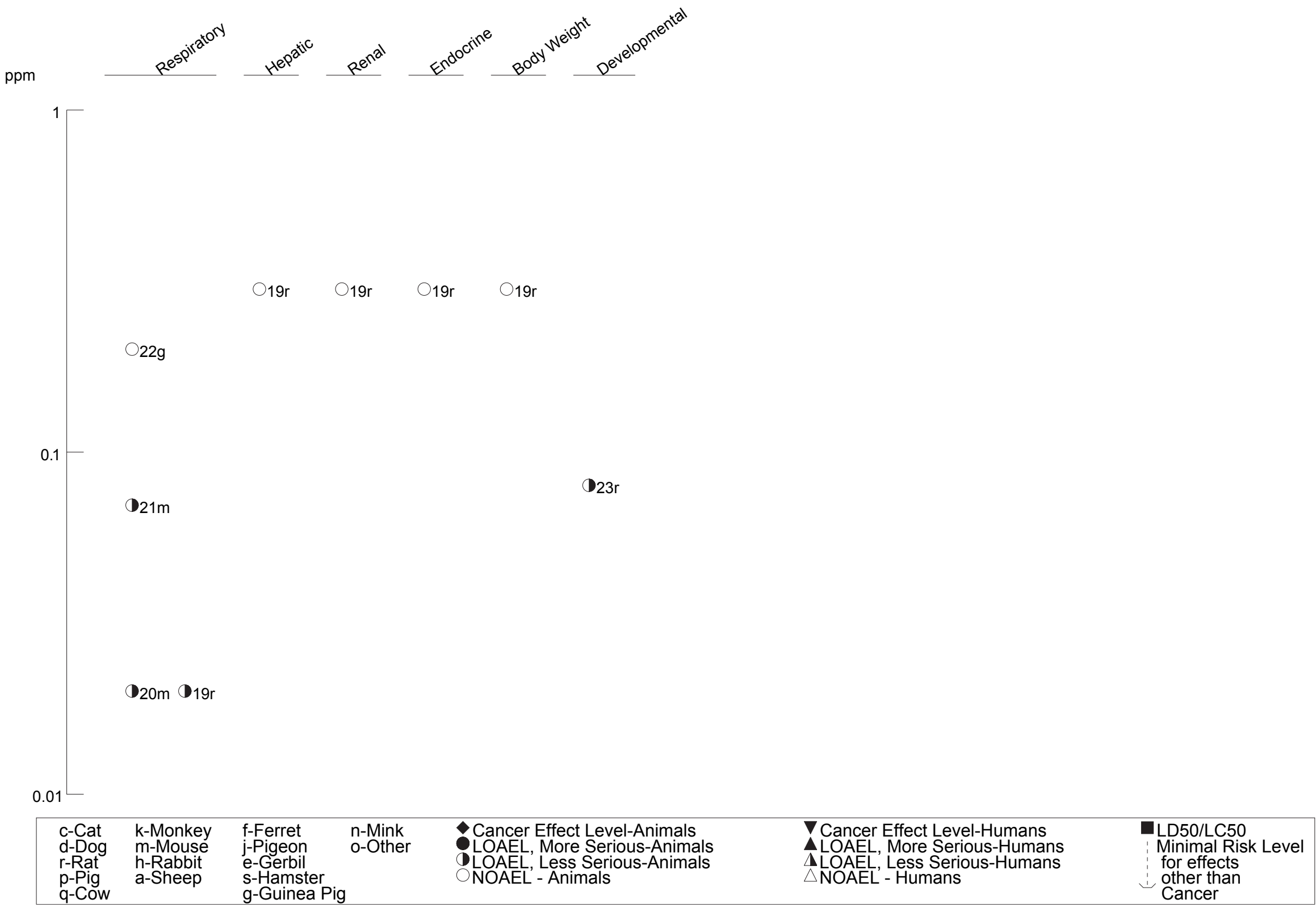


Figure 3-1. Levels of Significant Exposure to Toluene Diisocyanate - Inhalation (Continued)

Chronic ( $\geq 365$ days)

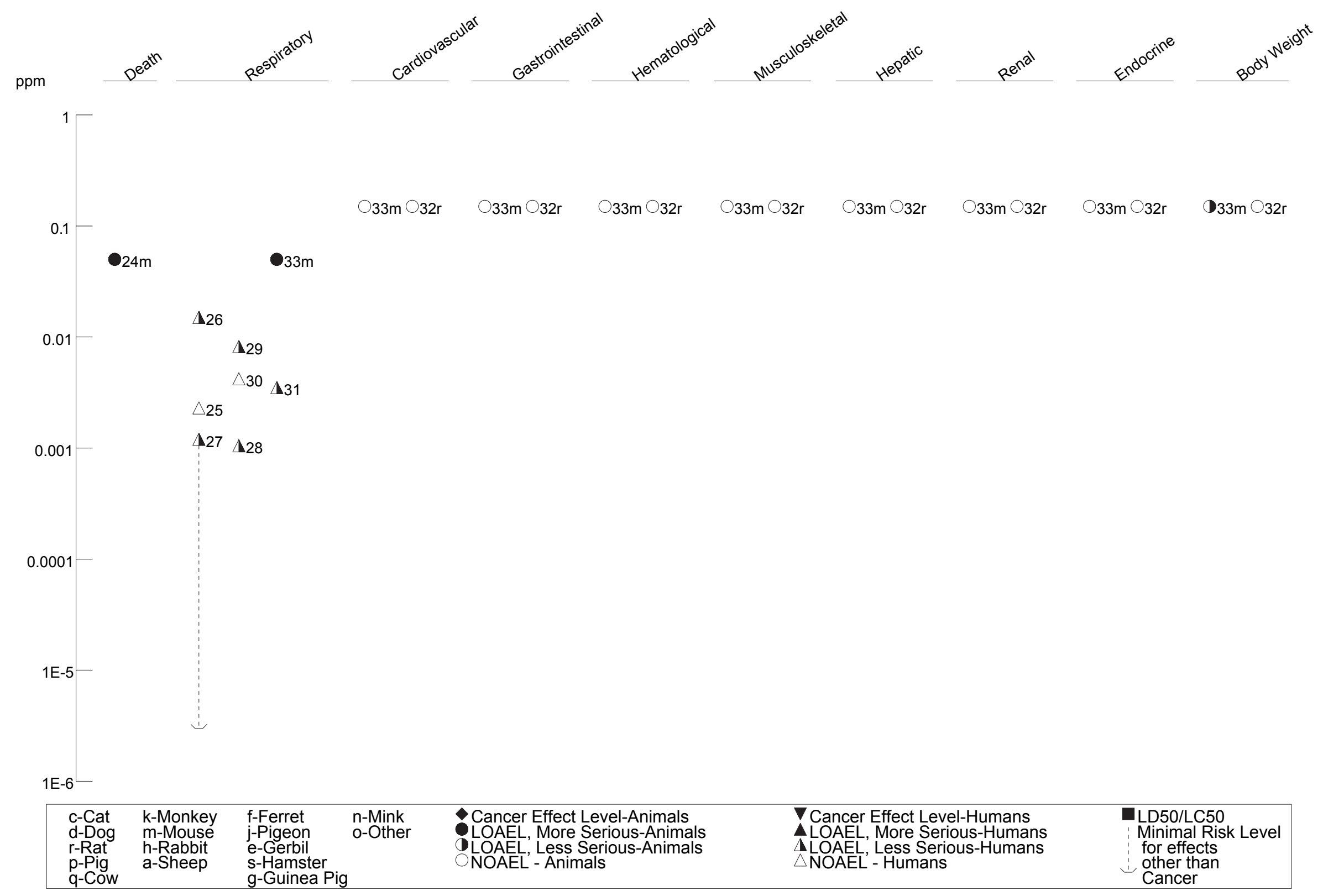


3. HEALTH EFFECTS

Table 3-2. Levels of Significant Exposure to Methylene Diphenyl Diisocyanate - Inhalation

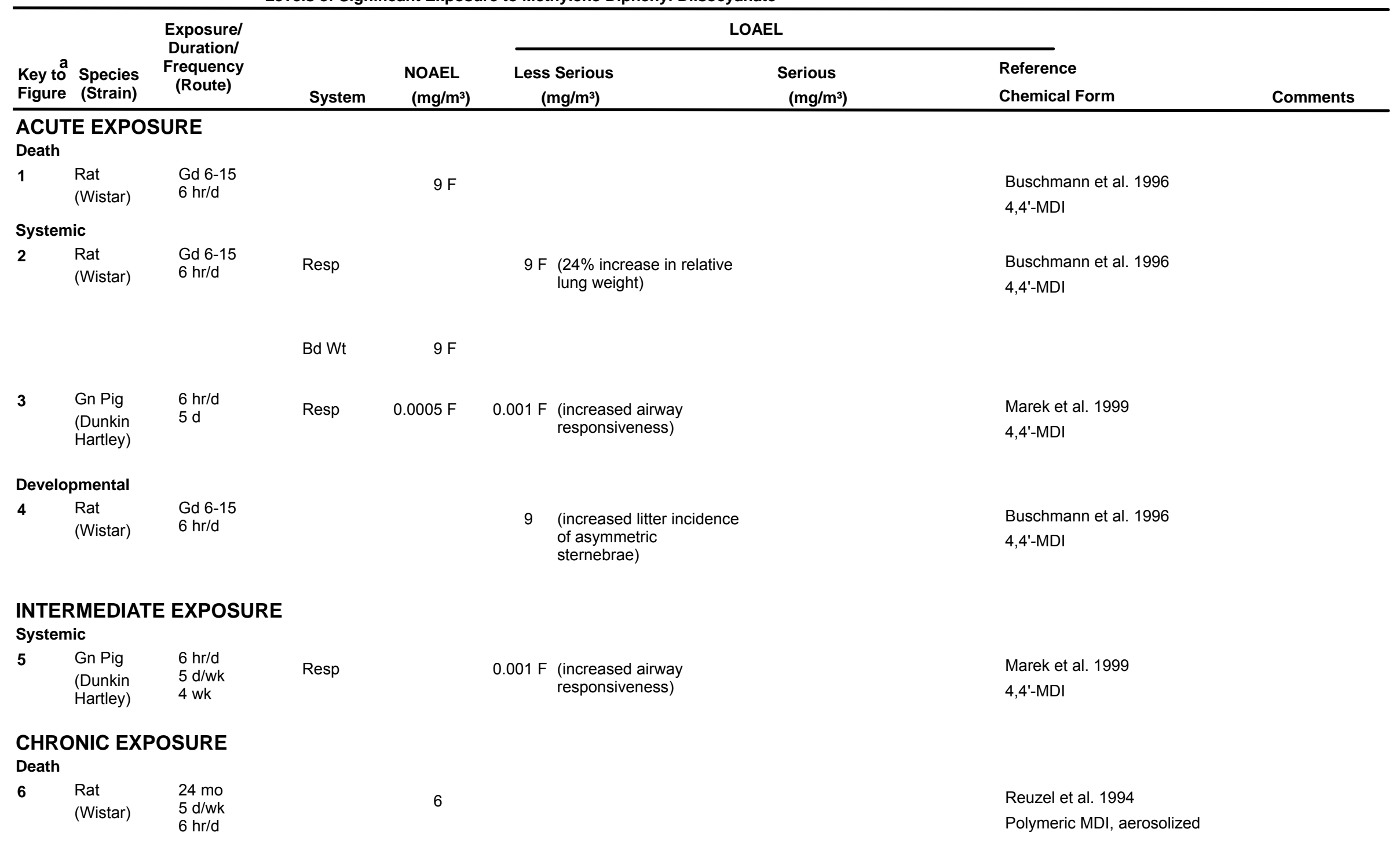


3. HEALTH EFFECTS

Table 3-2. Levels of Significant Exposure to Methylene Diphenyl Diisocyanate - Inhalation

(continued)

\begin{tabular}{|c|c|c|c|c|c|c|c|c|}
\hline \multirow[b]{2}{*}{$\begin{array}{l}\text { Key to } \\
\text { Figure }\end{array}$} & \multirow[b]{2}{*}{$\begin{array}{c}\text { Species } \\
\text { (Strain) }\end{array}$} & \multirow{2}{*}{$\begin{array}{l}\text { Exposurel } \\
\text { Durationl } \\
\text { Frequency } \\
\text { (Route) }\end{array}$} & \multicolumn{5}{|c|}{ LOAEL } & \multirow[b]{2}{*}{ Comments } \\
\hline & & & System & $\begin{array}{l}\text { NOAEL } \\
\left(\mathrm{mg} / \mathrm{m}^{3}\right)\end{array}$ & $\begin{array}{l}\text { Less Serious } \\
\left(\mathrm{mg} / \mathrm{m}^{3}\right)\end{array}$ & $\begin{array}{l}\text { Serious } \\
\left(\mathrm{mg} / \mathrm{m}^{3}\right)\end{array}$ & $\begin{array}{l}\text { Reference } \\
\text { Chemical Form }\end{array}$ & \\
\hline
\end{tabular}

\section{Systemic}

7 Human

occupational exposure

Resp

0.0005

8 Rat

$24 \mathrm{mo}$

$5 \mathrm{~d} / \mathrm{wk}$

Immunol Lymphoret

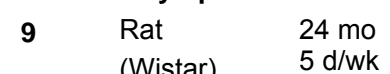

$\begin{array}{ll}\text { (Wistar) } & 5 \mathrm{~d} / \mathrm{wk} \\ 6 \mathrm{hr} / \mathrm{d}\end{array}$

Neurological

10 Rat (Wistar)

$24 \mathrm{mo}$

$5 \mathrm{~d} / \mathrm{wk}$

$6 \mathrm{hr} / \mathrm{d}$
Resp

(minimal to mild

pulmonary fibrosis and

macrophage

accumulation; alveolar

duct epithelialization;

basal cell and Bowman's

gland hyperplasia in the

nasal cavity)

$\begin{array}{ll}\text { Cardio } & 6 \\ \text { Hemato } & 6 \\ \text { Hepatic } & 6 \\ \text { Renal } & 6 \\ \text { Endocr } & 6 \\ \text { Bd Wt } & 6\end{array}$

$0.2 \mathrm{M}$
$1 \mathrm{M}$ (minimal to mild
macrophage
accumulation in
mediastinal lymph nodes)

Chemical Form

Comments
Sulotto et al. 1990

4,4'-MDI

Reuzel et al. 1994

Polymeric MDI, aerosolized
Reuzel et al. 1994

Polymeric MDI, aerosolized

Reuzel et al. 1994

Polymeric MDI, aerosolized 
Table 3-2. Levels of Significant Exposure to Methylene Diphenyl Diisocyanate - Inhalation

(continued)

\begin{tabular}{|c|c|c|}
\hline $\begin{array}{l}\text { Key to } \\
\text { Figure }\end{array}$ & $\begin{array}{c}\text { Species } \\
\text { (Strain) }\end{array}$ & $\begin{array}{r}\text { Exposur } \\
\text { Duratio } \\
\text { Frequen } \\
\text { (Route }\end{array}$ \\
\hline \multicolumn{3}{|c|}{ Reproductive } \\
\hline 11 & $\begin{array}{l}\text { Rat } \\
\text { (Wistar) }\end{array}$ & $\begin{array}{l}24 \mathrm{mo} \\
5 \mathrm{~d} / \mathrm{wk} \\
6 \mathrm{hr} / \mathrm{d}\end{array}$ \\
\hline \multicolumn{3}{|l|}{ Cancer } \\
\hline 12 & $\begin{array}{l}\text { Rat } \\
\text { (Wistar) }\end{array}$ & $\begin{array}{l}24 \mathrm{mo} \\
5 \mathrm{~d} / \mathrm{wk} \\
6 \mathrm{hr} / \mathrm{d}\end{array}$ \\
\hline
\end{tabular}

LOAEL

urationl

LOAEL

Route)

System $\quad\left(\mathrm{mg} / \mathrm{m}^{3}\right)$

$\left(\mathrm{mg} / \mathrm{m}^{3}\right)$

Serious

$\left(\mathrm{mg} / \mathrm{m}^{3}\right)$

Reference

Chemical Form

Comments

a The number corresponds to entries in Figure 3-2.

b Used to derive a chronic-duration inhalation MRL of $0.001 \mathrm{mg} / \mathrm{m} 3$ for polymeric MDI based on a BMDL of $0.48 \mathrm{mg} / \mathrm{m} 3$. The BMDL was adjusted for intermittent exposure and multiplied by the regional deposited dose ratio for extrathoracic effects to calculate the human equivalent concentration (HEC). The BMDL(HEC) of $0.039 \mathrm{mg} / \mathrm{m} 3 \mathrm{was}$ divided by an uncertainty factor of 30 ( 3 for extrapolation from animals to humans with dosimetric adjustment and 10 for human variability).

$\mathrm{Bd} \mathrm{Wt}=$ body weight; Cardio = cardiovascular; $\mathrm{CEL}=$ cancer effect level; $\mathrm{d}=$ day $(\mathrm{s}) ;$ Endocr = endocrine; $\mathrm{F}=$ female; $\mathrm{Gd}=$ gestational day; $\mathrm{Gn}$ Pig = guinea pig; Hemato = hematological; hr = hour(s); Immuno/Lymphoret = immunological/lymphoreticular; LOAEL = lowest-observed-adverse-effect level; $\mathrm{M}=$ male; $\mathrm{mo}=$ month(s); NOAEL =

no-observed-adverse-effect level; Resp = respiratory; wk = weeks(s) 
Figure 3-2. Levels of Significant Exposure to Methylene Diphenyl Diisocyanate - Inhalation Acute ( $\leq 14$ days)

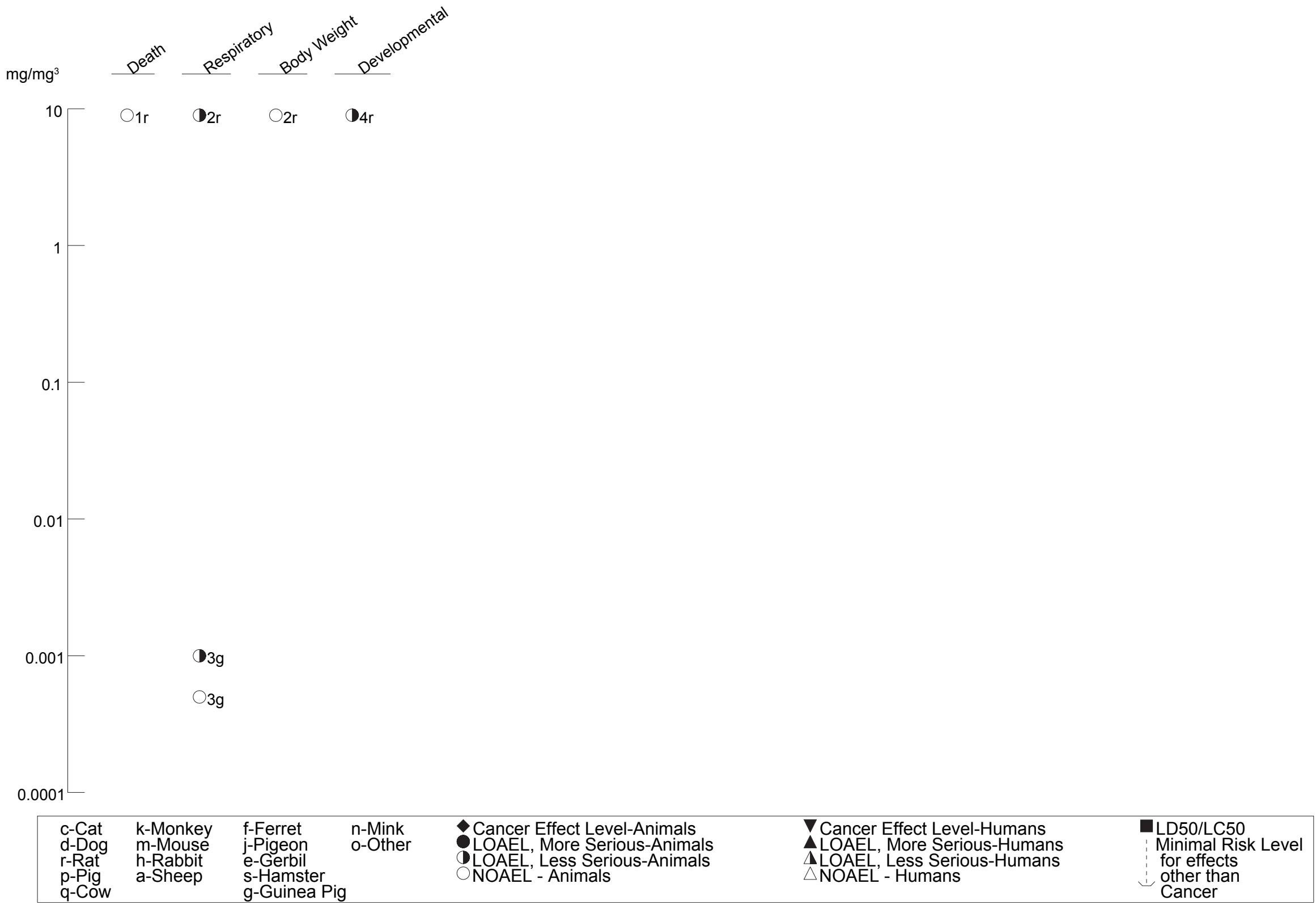


Figure 3-2. Levels of Significant Exposure to Methylene Diphenyl Diisocyanate - Inhalation (Continued) Intermediate (15-364 days)

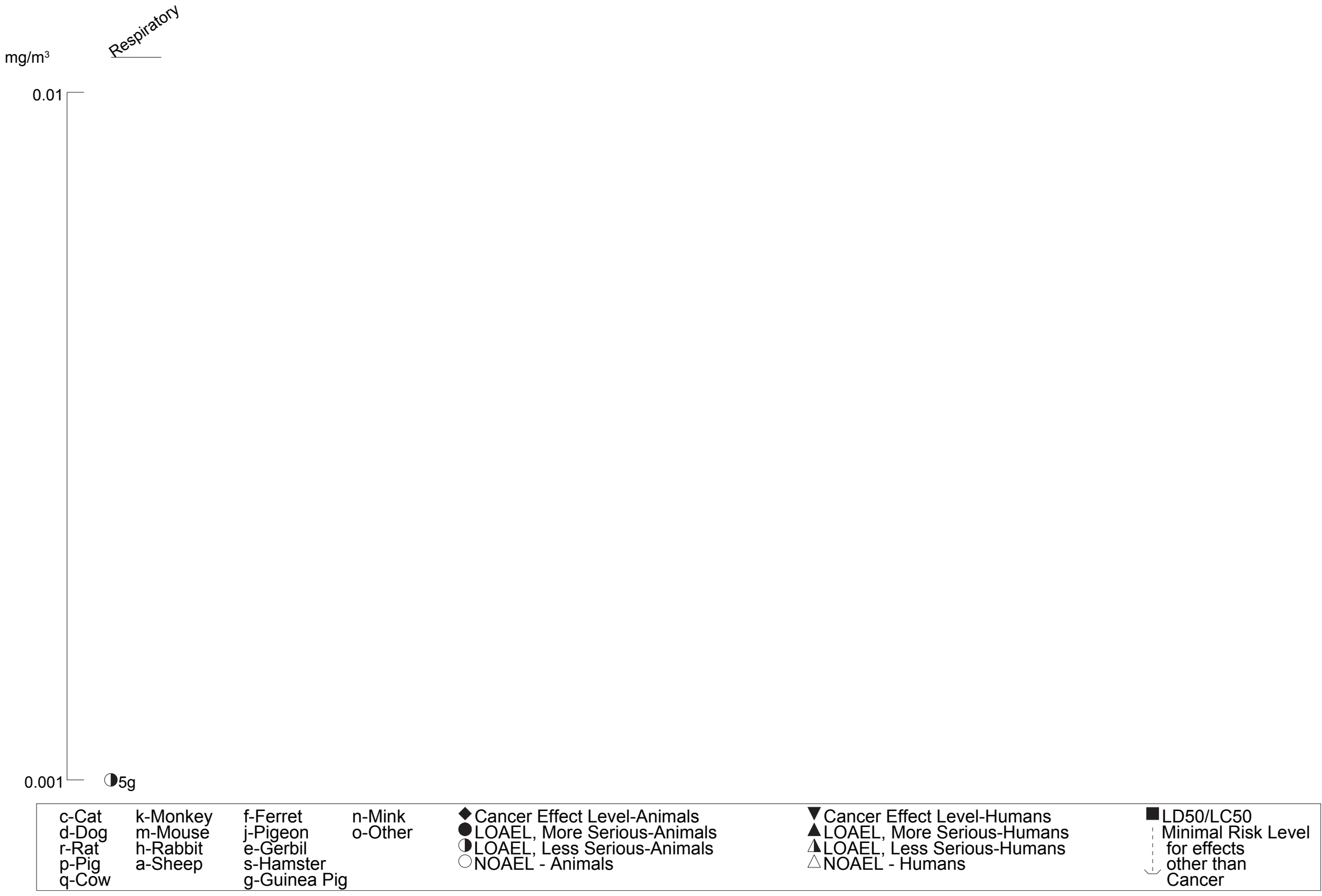


Figure 3-2. Levels of Significant Exposure to Methylene Diphenyl Diisocyanate - Inhalation (Continued)

Chronic ( $\geq 365$ days)

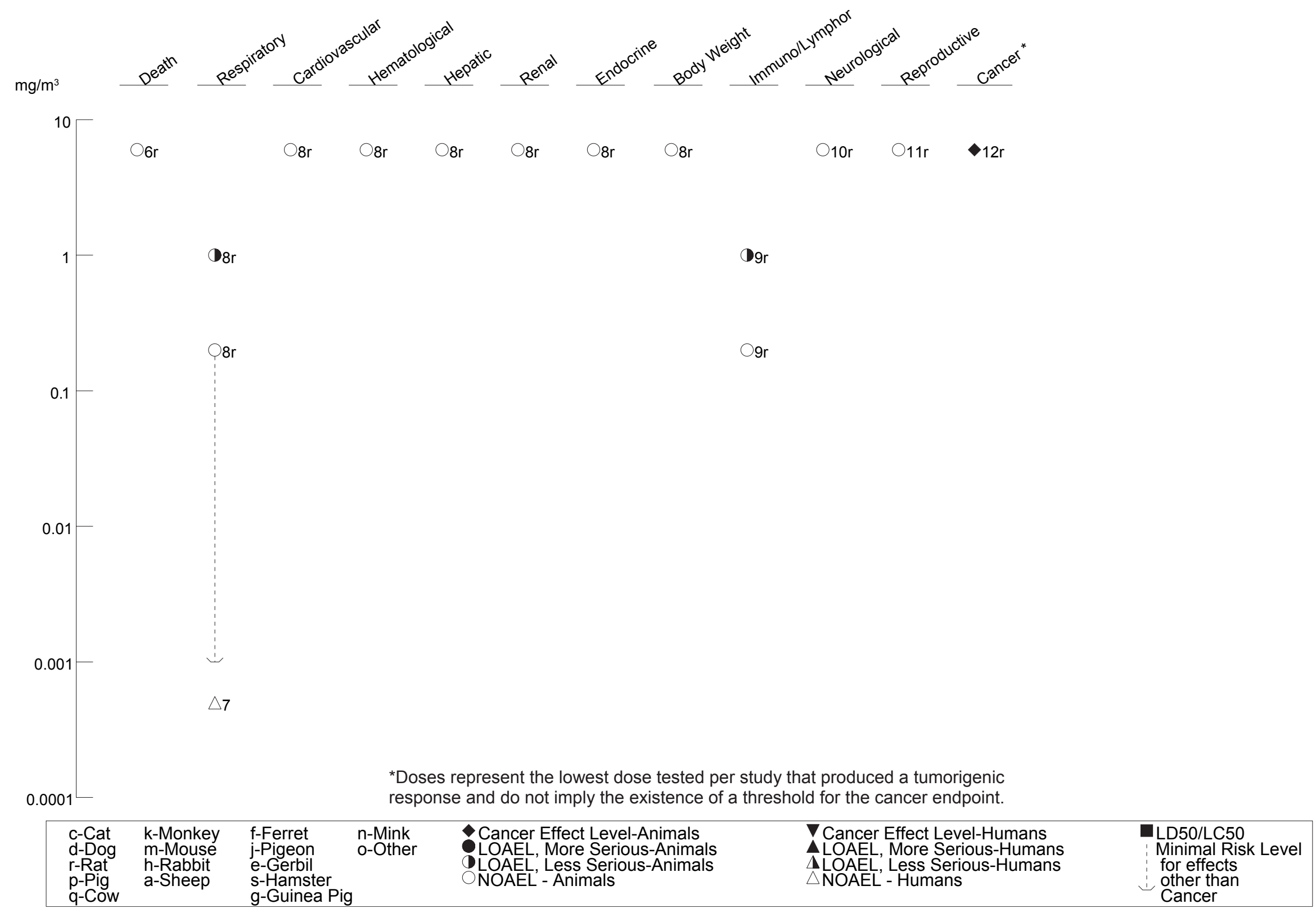


chronic exposure to $\geq 0.05$ ppm production-grade TDI; deaths occurred in $60 \%$ of controls and in 77 and $74 \%$ of low- and high-exposure females, respectively (Loeser et a. 1983).

MDI. No deaths were observed in acute- or intermediate-duration studies in guinea pigs exposed up to 20 ppb 4,4'-MDI (Marek et al. 1999), in a developmental toxicity study in which rats were exposed to $9 \mathrm{mg} / \mathrm{m}^{3}$ 4,4'-MDI aerosol on GDs 6-15 (Buschmann et al. 1996), or in a chronic-duration study in which rats were exposed to $6.0 \mathrm{mg} / \mathrm{m}^{3}$ for 2 years (Reuzel et al. 1994).

\subsubsection{Systemic Effects}

\section{Respiratory Effects.}

TDI. A large number of epidemiology and experimental studies have examined the toxicity of TDI to the respiratory tract. Data from a limited number of acute-duration studies identify respiratory irritation as the primary effect at low concentrations and severe respiratory symptoms and possibly asthma occurring after exposure to high concentrations. As reviewed by Ott et al. (2003), a 30-minute exposure to TDI resulted in the following effects in healthy subjects: ocular irritation at $0.050 \mathrm{ppm}$, nasal irritation at $0.080 \mathrm{ppm}$, eye, nose, and throat irritation, which was considered tolerable, at $0.100 \mathrm{ppm}$; tearing and burning in the throat at $0.50 \mathrm{ppm}$, and nasal discharge and severe cough after several minutes of exposure to $1.3 \mathrm{ppm}$. Another study reviewed by Ott et al. (2003) reported chest tightness, cough, and burning of the throat in asthmatics (asthma was not due to occupational exposure to TDI) exposed to 0.01 or $0.02 \mathrm{ppm}$ TDI for 1 hour. By comparison, another study reported a mild cough in 1/10 healthy subjects exposed to $0.02 \mathrm{ppm}$ TDI for 2 hours. A longer study in healthy subjects exposed to $0.005 \mathrm{ppm}$ TDI for 6 hours followed by a 20 -minute exposure to $0.02 \mathrm{ppm}$ did not result in respiratory symptoms (Vandenplas et al. 1999). However, slight, but statistically significant, decreases in specific airway conductance $\left(\mathrm{sG}_{\mathrm{AW}}\right)$ and $\mathrm{MEF}$ at $25 \%$ of $\mathrm{FVC}\left(\mathrm{MEF}_{25 \%}\right)$ were observed. The decreases in $\mathrm{sG}_{\mathrm{AW}}$ and $\mathrm{MEF}_{25 \%}$ started within the first 60 minutes of exposure. Another study (Chester et al. 1979) did not find alterations in specific airway resistance ( $\left.\mathrm{sR}_{\mathrm{AW}}\right)$ in healthy or asthmatic (not TDI-induced) subjects exposed to $0.02 \mathrm{ppm}$ TDI for 20 minutes.

The primary respiratory effects observed following longer-term occupational exposure are TDI-induced bronchial asthma, asthma-like respiratory symptoms, and a decline in pulmonary function. TDI-induced asthma is a type of occupational asthma that can be characterized as bronchial inflammation and/or airway hyperresponsiveness. Respiratory symptoms often reported in workers with TDI-induced asthma 
include wheezing, dyspnea, coughing, and chest tightness, which often persist after TDI exposure has ceased (Mapp et al. 1988; Moller et al. 1986; Moscato et al. 1991; Padoan et al. 2003; Paggiaro et al. 1984). Individuals with TDI-induced asthma are considered to be sensitized to TDI, in that brief exposures to nonirritating concentrations can result in a worsening of symptoms and a decline in lung function. TDI exposure can result in four types of asthmatic reactions in sensitized individuals: an immediate response, a late response, a dual response (individuals having immediate and late responses), or an irregular response. Two studies, each examining about 100 workers suspected of having TDIinduced asthma based on respiratory symptoms (e.g., wheezing, dyspnea, chest tightness, or dry cough), found that more workers ( 41 or $44 \%$ of responders) had a late response to a TDI challenge $(0.011 \mathrm{ppm}$ for 30 minutes or $0.015-0.025 \mathrm{ppm}$ for $10-15$ minutes) than had a dual response ( 35 or $41 \%$ ) or immediate response (28 or 21\%) (Moscato et al. 1991; Paggiaro et al. 1986). A smaller scale study of 10 subjects reported that $8 / 10$ workers had a late reaction to a TDI challenge $(0.005-0.006 \mathrm{ppm})$ and $2 / 10$ had a dual reaction (Saetta et al. 1995). Siracuse et al. (1978) reported a case of a worker who had recurrent nocturnal asthma as a result of TDI exposure. Although the cause of the different responses is not known, Paggiaro et al. (1986) noted that subjects who had a dual response to a TDI challenge had a significantly longer duration of symptoms before diagnosis than the immediate or late responders.

The prevalence of TDI-induced asthma among TDI workers has not been well established. A comparison of the prevalence of TDI-induced asthma across studies is difficult due to differences in the criteria used to define asthma. Some studies define asthma as removal from workplace or job due to respiratory symptoms, particularly wheezing and dyspnea, and others as a decrease in lung function following a TDI-challenge. Ott et al. (2003) calculated annual induction rates of TDI-induced asthma using data from a number of cross-sectional and longitudinal studies and found rates of approximately $5-6 \%$ prior to the 1970 s and rates of $<1 \%$ since the mid-1970s when TDI levels were typically maintained at $\leq 0.005 \mathrm{ppm}$ and many of the cases were attributable to incidents involving exposure to TDI levels well above $0.02 \mathrm{ppm}$. In a study of 49 workers at a new TDI polyurethane foam manufacturing facility, new symptoms of asthma were observed in $7.1 \%$ of the workers after 6 months of exposure (Gui et al. 2014). The investigators noted that $90 \%$ of the air samples were less than the $0.0001 \mathrm{ppm}$ detection limit, with a maximum exposure level of $0.01 \mathrm{ppm}$.

Inhalation challenge testing in which subjects with respiratory symptoms characteristic of asthma are exposed to a non-irritating concentration of TDI (typically $\leq 0.02 \mathrm{ppm}$ ) for a short period is often used to diagnose TDI-induced asthma. However, not all subjects have a positive reaction, such as a decline in $\mathrm{FEV}_{1}$, to the challenge test (Banks et al. 1989; Burge 1982; Mapp et al. 1988; Moller et al. 1986; Moscato 
et al. 1991; O’Brien et al. 1979). For example, a study of 58 workers reporting wheezing and dyspnea found that only $43 \%$ had a positive response in the TDI challenge test (Banks et al. 1989). Another study of 51 workers with respiratory symptoms found a positive reaction to the TDI challenge in $52 \%$ of the workers (Burge 1982).

The mechanism of TDI sensitization has not been elucidated; some investigators have suggested that immune mechanisms may be involved. Specific IgG antibodies to TDI-human serum albumin (HSA) conjugates (Park et al. 1999) or IgE antibodies to TDI-HSA (Baur and Fruhmann 1981; Cvitanovic et al. 1989; Park and Nahm 1996; Park et al. 1999; Pezzini et al. 1984; Sharifi et al. 2013) have been found in workers with TDI-induced asthma. However, TDI-HSA-specific IgG or IgE antibodies were typically found in less than half of the sensitized workers (16-57\%).

A number of studies have tracked the prognosis of workers with probable TDI-induced asthma. Some recovery from respiratory symptoms and/or an absence of a response to a TDI challenge have been observed (Banks and Rando 1988; Banks et al. 1990; Lemiere et al. 1996; Mapp et al. 1998; Moller et al. 1986; Padoan et al. 2003; Paggiora et al. 1984, 1993; Park and Nahm 1997; Saetta et a. 1995). A small improvement in the prevalence of respiratory symptoms was observed 2 years after exposure termination in workers with verified TDI-induced asthma (Paggiaro et al. 1984). Dyspnea and wheezing were reported by $8 / 12$ subjects, as compared to $12 / 12$ subjects at the initial examination. In 16 asthmatic subjects who left the workplace, $56 \%$ did not respond to a TDI challenge administered 4 years after leaving the workforce (Paggiaro et al. 1993). Padoan et al. (2003) also reported a decline in the prevalence of respiratory symptoms of asthma and hyperresponsiveness to methacholine in subjects who ceased TDI exposure for an average of 11 years. However, $60 \%$ of the subjects removed from TDI exposure for $>10$ years still complained of asthmatic symptoms. Improvement in respiratory symptoms or response to a TDI challenge was not observed in workers who continued TDI exposure (Banks et al. 1990; Mapp et al. 1988; Padoan et al. 2003; Paggiaro et al. 1984). A study of 35 subjects with TDIinduced asthma monitored for 2 years after cessation of exposure found that $49 \%$ were no longer hyperresponsive to methacholine, $31 \%$ had significant improvements in the first year, and $20 \%$ did not show evidence of improvement. Subjects who recovered had a shorter duration of asthmatic symptoms before diagnosis, immediately ceased TDI exposure after diagnosis, had a milder degree of airway hyperresponsiveness, and had specific IgE antibodies to TDI-HSA (Park and Nahm 1997). A case report suggested that re-exposure to TDI may result in a reversal of the recovery (Banks and Rando 1988). Eleven years after a worker with asthma ceased TDI exposure, there were no respiratory symptoms and 
no response when challenged with a subirritant concentration of TDI. However, within 5 months of returning to work, the subject developed asthma and had a positive response to a TDI challenge.

TDI-induced asthma is typically associated with acute exposure to very high concentrations or prolonged exposure to lower concentrations. Two studies have examined communities near a polyurethane foam manufacturing facility in Finland (Nuorteva et al. 1987) or TDI-emitting sources in North Carolina (Wilder et al. 2011). In the Finnish study of 3,153 adults living near the facility, asthma was diagnosed in $2.2 \%$ of the subjects, compared to $2.4 \%$ of the 1,029 subjects living in a referent area. In the subjects with asthma, IgE antibodies specific to TDI, MDI, or hexamethylene diisocyanate (HDI) were only found in one subject who was occupationally exposed. No differences in the prevalence of respiratory symptoms were found. Wilder et al. (2011) did not find a significant increase in the prevalence of asthma or asthma-like respiratory symptoms in the residents living near TDI sources compared to the referent communities. Of the 161 residents living near TDI sources, only 1 had IgG antibodies specific to TDI and none had IgE antibodies specific to TDI.

The primary effect in workers not sensitized to TDI is a decline in lung function. Ott et al. (2003) noted that the decline in lung function, particularly airflow limitations, may be due to increased airway wall thickness, subepithelial fibrosis, obstruction of airway lumen by exudate or mucus, and changes in elastic properties of airway walls or loss of the interdependence between airways and surrounding parenchyma. Longitudinal studies, summarized in Table 3-3, have examined possible changes in lung function in TDI workers over time and found mixed results based on reported 8-hour TWA TDI levels (Adams 1975; Bodner et al. 2001; Butcher et a. 1977; Clark et al. 1998, 2003; Diem et al. 1982; Jones et al. 1992; Omae et al. 1992; Ott et al. 2000; Peters et al. 1970; Wegman et al. 1977, 1982). Conflicting results may be due to differences in peak exposure levels, length of exposure, historical TDI exposure, or inclusion of subjects with possible TDI-induced asthma. Diem et al. (1982) conducted a 5-year study of a new TDI manufacturing facility and found a greater decline in $\mathrm{FEV}_{1}$ and $\mathrm{FEF}_{25-50 \%}$ among workers with a cumulative TDI exposure of $\geq 0.0682 \mathrm{ppm}$-months and who never smoked. A greater decline in $\mathrm{FEV}_{1}$ was also observed in smokers with high cumulative exposure; however, the mean annual decline was similar to expected values from cross-sectional studies of normal populations. Based on unpublished information from Janet Hughes, EPA (IRIS 2003) reported a mean 8-hour TWA TDI level in the high cumulative exposure, never-smoking group of $0.0019 \mathrm{ppm}$; the mean 8-hour TWA TDI level for the low cumulative exposure, never-smoking group was $0.0009 \mathrm{ppm}$. Clark et al. (1998) found a significant 


\section{Table 3-3. Summary of Occupational Exposure Studies Examining the Effects of TDI on Lung Function}

\begin{tabular}{l}
\hline Study \\
\hline Adams 1975 \\
Longitudinal study \\
565 TDI workers at two TDI \\
manufacturing facilities examined \\
between 1961 and 1972
\end{tabular}

\section{Bodner et al. 2001}

Longitudinal study

305 TDI manufacturing workers

employed for at least

3 consecutive months; referent group consisted of 581 workers in hydrocarbon departments at the same facility; workers were examined every $1-2$ years for 26 years

\section{Butcher et al. 1977}

Longitudinal study

166 TDI manufacturing workers examined prior to working in TDIrelated job and at 6-month intervals for a total of 2.5 years

\section{Clark et al. 1998}

Longitudinal study 644 workers at 12 polyurethane foam manufacturing facilities and 136 referents examined over a 5 -year period

\section{Clark et al. 2003}

Longitudinal study 251 polyurethane foam manufacturing workers (217 workers were part of the Clark et al. 1988 cohort)

\section{Diem et al. 1982}

Longitudinal study 114 TDI workers and 54 referents working at a new TDI manufacturing facility; workers divided in to low, medium, and high exposure groups and into high and low cumulative exposure groups; workers examined 9 times in 5-year period

Exposure
Exposure levels not reported; the
percentage of TDI levels that
exceeded $0.02 \mathrm{ppm}$ was $58-67 \%$ in
$1962-1964$ (most readings between
0.05 and $0.1 \mathrm{ppm}$ ) in plant $1,21 \%$
and $13 \%$ in 1965 in plants 1 and 2 ,
and $1-4$ and $2-8 \%$ in $1966-1970$ in
plants 1 and 2
Mean TDI level at the last study
examination was 0.0023 ppm
Effect

No association between exposure and decline in FVC and $\mathrm{FEV}_{1}$ levels

No correlations between lung function (FEV 1 and $F V C)$ and TDI exposure

The TWA TDI level was estimated to be $0.015 \mathrm{ppm}$ based on area monitoring; a comparison between some area monitoring and personal monitoring data suggests that the area monitoring may overestimate the worker's exposure levels The mean daily 8-hour TWA was $0.0012 \mathrm{ppm}$

Workers divided into three groups; mean 8-hour TWA TDI levels were $0.00105,0.0006$, and 0.00029 ppm

No exposure-related decline in lung function

No exposure-related decline in lung function; in a subset of 157 workers who entered the study after the first year, longitudinal analysis showed a significant decline in $\mathrm{FEV}_{1}$ and FVC

No effect of exposure on FEV 1 levels for the full cohort

Mean 8-hour TWA TDI levels were $0.0016,0.0032$, and $0.0068 \mathrm{ppm}$

TDI levels in the low and high cumulative exposure groups were $<0.0682$ and $\geq 0.0682$ ppm-months
Greater decline in $\mathrm{FEV}_{1}$ and $\mathrm{FEF}_{25-50 \%}$ in never-smokers in the high cumulative exposure group, as compared to low cumulative exposure group; no effect on $F V_{1}$ when TDI was expressed as a continuous variable 


\section{Table 3-3. Summary of Occupational Exposure Studies Examining the Effects of TDI on Lung Function}

\begin{tabular}{l}
\hline Study \\
\hline Gui et al. 2014 \\
Longitudinal study \\
49 workers at a new TDI \\
manufacturing facility \\
Huang et al. 1991a \\
Cross-sectional study \\
15 painters applying polyurethane \\
varnish; included 7 workers with \\
chronic bronchitis and 4 workers \\
with dyspnea and wheezing
\end{tabular}

Huang et al. 1991b

Cross-sectional study

48 workers at spraying

polyurethane varnish at three

facilities included workers at

facilities $A$ and $B$ with chronic

bronchitis (46.7 and 15\%),

dyspnea and wheezing (26.7 and $15 \%)$

Jones et al. 1992

Longitudinal study

386 workers at polyurethane foam

manufacturing facility examined $\geq 1$ time in a 2-year period;

227 examined at least 3 times and initial lung function testing performed on 294 workers

\section{Olsen et al. 1989}

Cross-sectional study

57 workers at TDI manufacturing facility and 89 referents

\section{Omae et al. 1992}

Longitudinal study

57 polyurethane foam

manufacturing workers and

24 referents followed for 4 years

Ott et al. 2000

Longitudinal study

219 TDI manufacturing workers

and 77 referents examined over a 16-year period (average duration

of employment was 4.7-5.7 years)

\begin{tabular}{|c|c|}
\hline Exposure & Effect \\
\hline $\begin{array}{l}90 \% \text { air samples had TDI levels } \\
\text { below the detection limit of } \\
0.0001 \mathrm{ppm}\end{array}$ & $\begin{array}{l}\text { No significant alteration in } \\
\mathrm{FEV}_{1}, \mathrm{FVC} \text {, or } \mathrm{FEV} \mathrm{V}_{1} / \mathrm{FVC} \text {; } \\
\text { decline in } \mathrm{FEV} \mathrm{V}_{1} \text { levels of }>15 \% \\
\text { in } 9.1 \% \text { workers after } 12 \\
\text { months of exposure }\end{array}$ \\
\hline $\begin{array}{l}\text { TDI levels ranged from } 0.07 \text { to } 0.17 \\
\text { ppm }\end{array}$ & $\begin{array}{l}\text { Decreased FVC, } \mathrm{FEV}_{1} \text {, and } \\
\mathrm{FEV}_{1} \%\end{array}$ \\
\hline
\end{tabular}

Mean TDI levels at facilities $A, B$, and Decreased $F E V_{1}$, and MMF at $C$ were $0.11,0.043$, and $0.015 \mathrm{ppm}$, facilities $A$ and $B$ respectively Mean TDI levels ranged from
0.00117 to $0.00447 \mathrm{ppm}$

Exposure levels not reported; TDI levels did not exceed the permissible level of $0.02 \mathrm{ppm}$

Mean TWA TDI levels in low and high Larger than expected annual exposure groups were 0.0001 and $0.0057 \mathrm{ppm}$

High exposure group further divided into high-1 and high-2 groups; TWA TDI concentrations were $0.0082 \mathrm{ppm}$ (maximum TWA TDI level of 0.02$0.03 \mathrm{ppm}$ ) and $0.0017 \mathrm{ppm}$ (maximum TWA TDI level of $0.003-$ $0.004 \mathrm{ppm})$

TWA TDI level across jobs and times No association between FVC was $0.0042 \mathrm{ppm}$

No association between TDI exposure (current, highest career, or cumulative) and $\mathrm{FEV}_{1}$ levels.

losses of MMF, ratio of $\mathrm{FEV}_{1} \%, \mathrm{FEF}_{25 \%}$, and PEF in high-1 group; MMF, $\mathrm{FEV}_{1} \%$, and $\mathrm{PEF}_{25 \%}$ in the high-1 than low exposure group and $F E V_{1}$ and exposure
No relationship between TDI exposure and decline in FVC or $\mathrm{FEV}_{1}$ (excluded workers with TDI-induced asthma) group were significantly higher (annual or cumulative exposure measures) in smokers or nonsmokers 


\section{Table 3-3. Summary of Occupational Exposure Studies Examining the Effects of TDI on Lung Function}

\begin{tabular}{|c|c|c|}
\hline Study & Exposure & Effect \\
\hline $\begin{array}{l}\text { Peters et al. } 1970 \\
\text { Longitudinal study } \\
28 \text { workers at a polyurethane foam } \\
\text { manufacturing facility examined } \\
\text { every } 6 \text { months for } 2 \text { years }\end{array}$ & $\begin{array}{l}\text { Maximum TDI levels at examinations } \\
1,2,3 \text {, and } 4 \text { were } 0.003,0.012 \text {, } \\
0.0015 \text {, and } 0.0145 \mathrm{ppm} \text {, respectively }\end{array}$ & $\begin{array}{l}\text { FEV } 1 \text { levels on Monday } \\
\text { morning were significantly } \\
\text { lower at the second } \\
\text { examination than first } \\
\text { examination }\end{array}$ \\
\hline $\begin{array}{l}\text { Peters et al. } 1968 \\
\text { Cross-sectional study } \\
38 \text { workers at a polyurethane foam } \\
\text { manufacturing facility }\end{array}$ & $\begin{array}{l}\text { TDI levels ranged from } 0.0001 \text { to } \\
0.003 \text { ppm (levels were } \\
\text { approximately } 10 \text {-fold higher the } \\
\text { previous year) }\end{array}$ & $\begin{array}{l}\text { Decreased FVC, } \mathrm{FEV}_{1}, \mathrm{FR}_{50 \%} \text {, } \\
\text { and } \mathrm{FR}_{25 \%} \text { during the workday }\end{array}$ \\
\hline $\begin{array}{l}\text { Świerczyńska-Machura et al. } \\
2015 \\
\text { Cross sectional study } \\
30 \text { workers at polyurethane foam } \\
\text { manufacturing facility }\end{array}$ & $\begin{array}{l}\text { Arithmetic mean TDI levels at } \\
\text { different work areas ranged from } \\
0.0005 \text { to } 0.0037 \mathrm{ppm}\end{array}$ & $\begin{array}{l}\text { Changes indicative of mild } \\
\text { bronchial obstruction noted in } \\
17 \% \text { of workers }\end{array}$ \\
\hline $\begin{array}{l}\text { Wegman et al. } 1977 \\
\text { Longitudinal study } \\
57 \text { polyurethane foam } \\
\text { manufacturing workers originally } \\
\text { examined in } 1972 \text { were re- } \\
\text { examined in } 1974\end{array}$ & $\begin{array}{l}\text { TDI levels were } \leq 0.0015,0.0025 \text { - } \\
0.0030 \text {, and } \geq 0.0035 \mathrm{ppm}\end{array}$ & $\begin{array}{l}\text { Decline in } \mathrm{FEV}_{1} \text { was dose- } \\
\text { related and exceeded } \\
\text { predicted levels in the highest } \\
\text { two groups }\end{array}$ \\
\hline $\begin{array}{l}\text { Wegman et al. } 1982 \\
\text { Longitudinal study } \\
48 \text { TDI workers from Wegman et } \\
\text { al. (1977) re-examined in } 1976\end{array}$ & $\begin{array}{l}\text { TDI levels were } \leq 0.0015,0.0025 \text { - } \\
0.0030 \text {, and } \geq 0.0035 \mathrm{ppm}\end{array}$ & $\begin{array}{l}\text { 4-Year change in } F E V_{1} \text { was } \\
\text { significantly greater in } \\
\geq 0.0035 \text { ppm group than low } \\
\text { exposure group; most of the } \\
\text { decline occurred in the first } \\
2 \text { years of the study }\end{array}$ \\
\hline $\begin{array}{l}\text { White et al. } 1980 \\
\text { Cross-sectional study } \\
147 \text { machinists making seat } \\
\text { covers with a fabric backed with } \\
\text { flame-bonded polyurethane foam; } \\
30 \% \text { workers reported wheezing } \\
\text { and/or dyspnea }\end{array}$ & $\begin{array}{l}\text { TDI levels ranged from } 0.0003 \text { to } \\
0.003 \mathrm{ppm}\end{array}$ & $\begin{array}{l}\text { Higher prevalence of peak } \\
\text { flow rates }<90 \% \text { of predicted, } \\
\text { as compared to } 45 \text { workers } \\
\text { who never machined } \\
\text { polyurethane foam }\end{array}$ \\
\hline
\end{tabular}

$\mathrm{FEF}_{25-75 \%}=$ forced expiratory flow between 25 and $75 \%$ of FVC; FEV 1 = forced expiratory volume in 1 second; $\mathrm{FEV}_{1} \%=$ ratio of $\mathrm{FEV}_{1}$ to $\mathrm{FVC} ; \mathrm{FR}_{50 \%}=$ flow rate at $50 \%$ vital capacity; $\mathrm{FR}_{25} \%$ = flow rate at $25 \%$ vital capacity; FVC = forced vital capacity; MMF = maximal mid-expiratory flow; PEF = peak expiratory flow; TDI = toluene diisocyanate; TWA = time-weighted average 
increase in annual declines in $\mathrm{FEV}_{1}$ and $\mathrm{FVC}$ among workers at a polyurethane foam manufacturing facility who entered the study with no prior exposure to TDI (naïve group). It was noted that the greatest decline in lung function occurred during the first few months of employment. The mean 8-hour TWA TDI level for the entire cohort of exposed workers was $0.0012 \mathrm{ppm}$. No exposure-related effects on lung function were found in the whole cohort of exposed workers. A follow-up of this cohort (Clark et al. 2003) did not find significant increases in annual declines in lung function in the whole cohort or the naïve group in subsequent years. Another study of polyurethane manufacturing workers found largerthan-expected annual losses of MMF, ratio of $\mathrm{FEV}_{1}$ to $\mathrm{FVC}\left(\mathrm{FEV}_{1} \%\right)$, and PEF in workers with an 8-hour TWA TDI level of $0.0082 \mathrm{ppm}$ with maximal TWA peak concentrations of 0.02-0.03 ppm (Omae et al. 1992). Annual declines in lung function parameters were not observed in workers with an 8-hour TWA TDI level of $0.0017 \mathrm{ppm}$ with maximal TWA peak concentrations of 0.0003-0.004 ppm. In another study of a new polyurethane foam production facility, no significant alterations in $\mathrm{FEV}_{1}, \mathrm{FVC}$, or $\mathrm{FEV}_{1} / \mathrm{FVC}$ ratio were found after 6 or 12 months of exposure (Gui et al. 2014). However, it was noted that in $9.1 \%$ of the 33 workers, there was a decrease in $\mathrm{FEV}_{1}$ of $>15 \%$ between 6 and 12 months of exposure. TWA TDI levels were not reported; the investigators noted that the TDI levels in $>90 \%$ of the air samples were below the detection limit of $0.0001 \mathrm{ppm}$.

Other longitudinal studies of workers at TDI manufacturing facilities (Adams 1975; Bodner et al. 2001; Butcher et al. 1977; Ott et al. 2000) or polyurethane foam manufacturing facilities (Clark et al. 2003; Jones et al. 1992) have not found significant associations between TDI exposure and declines in lung function (Table 3-3). In longitudinal analysis of FVC and $\mathrm{FEV}_{1}$ levels and TDI exposure, Ott et al. (2000) did not find statistically significant associations in TDI manufacturing workers with a TWA TDI level of $0.0042 \mathrm{ppm}$. Similar findings were reported in another study of TDI manufacturing workers with a mean TDI exposure level of 0.0023 ppm (Bodner et al. 2001). Ott et al. (2003) concluded that among nonsensitized TDI workers, exposure to $\leq 5 \mathrm{ppb}$ (8-hour TWA) was not associated with decreases in $\mathrm{FEV}_{1}$. However, it is noted that the investigators did not consider the possibility of increased toxicity among naïve workers, as found by Clark et al. (1998) and Diem et al. (1982).

Cross-sectional studies, summarized in Table 3-3, also examined declines in lung function due to TDI exposure (Huang et al. 1991a, 1991b; Olsen et al. 1989; Peters et al. 1968; Świerczyńska-Machura et al. 2015; White et al. 1989). The interpretation of the results of some of the studies is limited by the inclusion of workers with asthma-like respiratory symptoms (Huang et al. 1991a, 1991b; White et al. 1980) or the lack of controls (Świerczyńska-Machura et al. 2015). Olsen et al. (1989) did not find associations between TDI exposure (current exposure, highest career exposure, cumulative exposure, or 
cumulative highest-to-date exposure) and $\mathrm{FEV}_{1}$ levels in a study of TDI manufacturing workers. Although the TDI levels were not reported, the investigators noted that TDI levels at the facility did not exceed the permissible level of $0.02 \mathrm{ppm}$; the investigators did not provide definitions of highest career exposure, cumulative exposure, or cumulative highest-to-date exposure or information on how they were calculated. In a study of polyurethane foam manufacturing workers, Peters et al. (1968) reported significant decreases in $\mathrm{FVC}, \mathrm{FEV}_{1}$, flow rate at $50 \%$ vital capacity $\left(\mathrm{FR}_{50 \%}\right)$, and $\mathrm{FR}_{25} \%$ when end-of-shift values were compared to start-of-shift values. Further declines in FVC, peak flow rate (PFR), $\mathrm{FR}_{50 \%}$, and $\mathrm{FR}_{25} \%$ were found when Monday afternoon values were compared to Monday morning values. The TDI levels ranged from 0.0001 to $0.003 \mathrm{ppm}$.

Animal studies support the findings from human studies that the respiratory tract is a sensitive target of TDI toxicity. Signs of irritation and histological damage have been observed following acute-, intermediate-, and chronic-duration exposure. Acute studies in mice and rats demonstrated that TDI was a sensory irritant and that the level of response was related to the concentration and the duration of exposure (Pauluhn 2014; Sangha and Alarie 1979). $\mathrm{RD}_{50}$ values (concentration resulting in a 50\% decrease in respiration rate) in mice exposed for 10, 30, 60, 120, 180, or 240 minutes were $0.813,0.498$, $0.386,0.249,0.199$, and $0.199 \mathrm{ppm}$, respectively (Sangha and Alarie 1979). When the animals were repeatedly exposed, the $\mathrm{RD}_{50}$ values were lower on subsequent days; after 3 days of exposure to $0.023-$ $1.18 \mathrm{ppm}$, pre-exposure respiratory rates were lower than day 1 , indicating an incomplete recovery.

Histological alterations have been observed in the nasal cavity (Arts et al. 2008; Buckley et al. 1984; Johnson et al. 2007; Loeser 1983; Matheson et al. 2005; Sangha and Alarie 1979; Zissu 1995), trachea (Gordon et al. 1985), and lung (Loeser 1983; Wong et al. 1985) in laboratory animals. The nasal lesions consist of inflammation, hyperplasia, degeneration, ulceration, and metaplasia; the severity and the location of the damage appear to be concentration and duration related. At lower concentrations and shorter durations, only the nares (most anterior region of the nasal cavity) are affected; at high concentrations, the damage extends to the olfactory epithelium. The only NOAEL identified for nasal effects is $0.031 \mathrm{ppm}$ in mice exposed 3 hours/day for 5 days (Sangha and Alarie 1979). When the duration was extended to at least 6 weeks (4 hours/day, 5 days/week), exudate, goblet cell metaplasia, and inflammation were observed in the nares of mice exposed to $0.02 \mathrm{ppm}$ (Matheson et al. 2005). Rhinitis was also observed in rats exposed to $0.02 \mathrm{ppm}$ in a 2-generation study (Tyl et al. 1999b). Exposure to $0.05 \mathrm{ppm} 4$ hours/day for 12 days resulted in extensive inflammatory cell infiltration into the lamina propria in the nasoturbinates and maxilloturbinates of mice; goblet cell metaplasia was also observed in the maxilloturbinates (Johnson et al. 2007). Extending exposure to 0.07 ppm from 4 to 9 days resulted in 
an increase in the severity of the rhinitis and respiratory epithelia metaplasia and necrosis observed in mice (Zissu 1995). The TDI concentration associated with olfactory epithelial damage was $0.4 \mathrm{ppm}$ (6 hours/day for 5 days), which resulted in moderate olfactory epithelial ulceration and necrosis and slight degeneration of the olfactory nerve (Buckley et al. 1984). Concentration-related increases in the incidence and severity of chronic or necrotic rhinitis with epithelial atrophy and mucous and squamous metaplasia were observed in mice exposed to $\geq 0.05$ ppm TDI for 2 years (Loeser 1983).

Slight laryngeal epithelial hyperplasia was observed in mice exposed to $1.0 \mathrm{ppm}$ TDI for 6 hours (Arts et al. 2008). Exposure of guinea pigs to $2 \mathrm{ppm}$ for 1 hour resulted in patchy loss of cilia and disruption of the surface epithelium in the trachea (Gordon et al. 1985). Matheson et al. (2005) reported goblet cell inflammation, epithelial hyperplasia, regeneration, and loss of structure in the lungs of mice exposed to $0.5 \mathrm{ppm}$ for 2 hours. However, other acute studies at similar (0.4 ppm 6 hours/day for 5 days) or higher (1 ppm for 6 hours) concentrations did not find histological alterations in the lungs (Arts et al. 2008; Buckley et al. 1984). Interstitial inflammation, localized pleural thickening, and goblet cell hyperplasia were observed in the lungs of guinea pigs 50 days after exposure to $1.4 \mathrm{ppm} 3$ hours/day for 5 days (Wong et al. 1985). Similarly, goblet cell metaplasia in the central airway mucosa and eosinophil infiltration in the central and peripheral airways were observed in rats exposed to $0.41 \mathrm{ppm} 2,4-\mathrm{TDI}$ 4 hours/day for 5 days (Kouadio et al. 2014); the severity of the lesions increased with exposure concentration. In a chronic mouse study, interstitial pneumonitis and catarrhal bronchitis were observed in "some mice," with a higher incidence at 0.15 ppm (Loeser 1983).

In addition to the histological alterations, studies in guinea pigs, rats, and mice have demonstrated TDI sensitization (Aoyama et al. 1994), bronchial hyperresponsiveness (Gagnaire et al. 1996; Gordon et al. 1985; Kouadio et al. 2014; Marek et al. 1999; Matheson et al. 2005), and nasal hyperresponsiveness (Kouadio et al. 2014). An increase in respiratory rate was observed in guinea pigs exposed to $0.2 \mathrm{ppm}$ TDI 3 hours/day for 5 days and challenged with 0.02 ppm TDI (15-minute exposure) 26 days after the initial exposure (Aoyama et al. 1994). The TDI challenge concentration did not elucidate a response in guinea pigs previously exposed to $0.02 \mathrm{ppm}$ for 5 days. Challenge tests with acetylcholine or methacholine resulted in airway hyperresponsiveness in guinea pigs and mice previously exposed to a TDI concentration as low as $0.01 \mathrm{ppm}$ (6 hours/day for 5 days) (Marek et al. 1999); a NOAEL of $0.005 \mathrm{ppm}$ was identified in the same study. Airway hyperresponsiveness was also observed following a 1-hour exposure to a relatively high concentration (3 ppm) (Gagnaire et al. 1996). The effects were observed 30 minutes after exposure and persisted for 48 hours. A TDI challenge following 4-hour/day exposure to 2,4-TDI resulted in severe labored breathing as evidenced by gasping and breathing with an 
open mouth after 4 days of exposure to 1.14 ppm (Kouadio et al. 2014); the severity of the labored breathing was less severe after 2 or 3 exposure days. Labored breathing was also observed in rats similarly exposed to $0.41 \mathrm{ppm}$ for 4 or 5 days. Symptoms of nasal hyperresponsiveness (sneezing and hyperrhinorrhea) were also observed at both concentrations (Kouadio et al. 2014).

MDI. The toxicity of MDI to the respiratory tract has not been as well investigated as TDI, but the effects appear to be similar. The primary effects observed include occupational asthma in sensitized individuals and decreased lung function. MDI-induced asthma has been reported in occupational exposure studies and case reports (Bonauto et al. 2005; Burge 1982; Chang and Karol 1984; Helaskoski et al. 2015; Hur et al. 2008; Liss et al. 1988; Suojalehto et al. 2011; Woellner et al. 1997; Zammit-Tabona et al. 1983); however, no reliable dose-response data are available. Asthma symptoms were noted in 18 of the 106 workers at a wood products plant using heated MDI in the manufacture of synthetic wood (Woellner et al. 1997). Symptoms occurred within the first 12 months of operation; half reported symptoms within the first 7 months of operation when operational problems would likely have resulted in MDI levels that exceeded the permissible level of $0.02 \mathrm{ppm}$. Bonauto et al. (2005) used worker's compensation claims to estimate the rate of asthma in the spray-on truck bed lining industry. A rate of 200 per 10,000 full-time employees was found; however, no testing was done on any of the claims to determine whether MDI was causative agent. Approximately half of subjects reporting asthma-like symptoms (wheezing, dyspnea, and/or cough) had a positive response in a methacholine-challenge test. A study of 11 foundry workers with asthma-like symptoms found that 6 had a positive response in a MDI-challenge test (Zammit-Tabona et al. 1983). Another study of 40 MDI workers found that 24 responded to MDI challenge at test atmospheres of up to $0.02 \mathrm{ppm}$ (Burge 1982). A third study (Hur et al. 2008) diagnosed MDI-induced asthma or eosinophilic bronchitis in 6 of 13 car upholstery factory workers with lower respiratory symptoms. The incidence of nonspecific bronchial hyperresponsiveness to a challenge with methacholine was significantly higher among MDI workers with asthma-like symptoms, as compared to controls and TDI workers (Jang et al. 2000). Several case reports of MDI workers (Bascom et al. 1985; Baur et al. 1984; Malo and Zeiss 1982; Zeiss et al. 1980) and a study of MDI workers (Baur 1995) with asthma-like symptoms also reported chills, fever, and malaise, which are consistent with symptoms of hypersensitivity pneumonitis.

Several occupational exposure studies have examined the effect of MDI exposure on lung function (Liss et al. 1988; Musk et al. 1982; Sulotto et al. 1990). Lung function was examined in 27 polyurethane foam workers who were asymptomatic for asthma; the MDI concentrations ranged from 0.0005 to $0.001 \mathrm{ppm}$. A comparison of lung function values of the workers to an age-matched control group of 27 clerks did not 
show statistically significant differences between the groups. Additionally, no differences in the change in lung function over a work week (Monday values compared to Friday values) or over the work shift were found. Musk et al. (1982) examined 107 workers at two polyurethane plastic manufacturing facilities over a 5-year period; 25 of the subjects were only exposed to MDI, 17 to only TDI, 6 to MDI and TDI, and 42 were not exposed to diisocyanates. The geometric mean MDI levels reported by the plants during the last year of the study were 0.0006 and $0.0003 \mathrm{ppm}$ at plants 1 and 2 , respectively; however, the mean MDI levels measured by the investigators ranged from 0.001 to $0.003 \mathrm{ppm}$. It should be noted that MDI exists as an aerosol; thus, the method used to measure MDI air levels (impinged method) may have underestimated MDI levels (EPA 1998a). Lung function tests were conducted on Monday morning and afternoon and on Monday morning and afternoon following a 2-week vacation. No significant alterations in $\mathrm{FEV}_{1}$ or FVC levels were found over the 5-year period, over a workday, or after a 2-week non-exposure period among the MDI-only exposed group.

Several studies of MDI workers have examined the possible association between specific immunoglobulin antibodies to MDI and MDI-induced asthma (Hur et al. 2008; Pezzini et al. 1984; Tse et al. 1985; Zeiss et al. 1980). In a study of 76 foundry workers (10 with asthma-like symptoms and bronchial hyperreactivity, 40 with respiratory symptoms but no evidence of bronchial hyperreactivity, and 26 with no respiratory symptoms), specific IgE antibodies to MDI-HSA conjugates were found in 2 workers ( 1 with asthma-like symptoms and one with other symptoms) and specific IgG antibodies to MDI-HSA conjugates were found in 5 workers ( 3 with asthma-like symptoms, 1 with other symptoms, and 1 with no symptoms) (Tse et al. 1985). Another study of car upholstery factory workers found specific IgG antibodies to MDI-HSA conjugates in $20.7 \%$ of the 58 workers (4/12 of the responders were diagnosed with MDI-induced asthma or eosinophilic bronchitis) and specific IgE antibodies to MDI-HSA conjugates in $8.6 \%$ of the workers ( $2 / 5$ of the responders were diagnosed with MDI-induced asthma or eosinophilic bronchitis) (Hur et al. 2008).

A limited number of laboratory animal studies have examined the toxicity of MDI to the respiratory tract. An $\mathrm{RD}_{50}$ of $32 \mathrm{mg} / \mathrm{m}^{3}$ in mice exposed to $4,4^{\prime}$-MDI for 4 hours was calculated (Weyel and Schaffer 1985). Exposure to concentrations as low as $7 \mathrm{mg} / \mathrm{m}^{3}$ initially resulted in increases in respiratory rate followed by a gradual decline in respiratory rate; a similar respiratory pattern was observed in mice administered 4,4'-MDI via tracheal cannulation. The investigators suggested that this respiratory pattern was indicative of a pulmonary irritant rather than a sensory irritant. Increases in airway hyperresponsiveness to acetylcholine were observed in guinea pigs exposed to $0.01 \mathrm{ppm}$ MDI 6 hours/day for 
5 days or 6 hours/day, 5 days/week for 4 weeks (Marek et al. 1999); a NOAEL of 0.005 ppm was identified in the 5-day study.

In a chronic-duration study (Reuzel et al. 1994), rats were exposed to polymeric MDI (containing 44.8$50.2 \%$ monomeric MDI) for 1 or 2 years. After 2 years of exposure, nasal and pulmonary lesions were observed at 1.0 and $6.0 \mathrm{mg} / \mathrm{m}^{3}$ and no alterations were observed at $0.2 \mathrm{mg} / \mathrm{m}^{3}$. The nasal lesions consisted of basal cell hyperplasia and Bowman's gland hyperplasia in males at $\geq 1.0 \mathrm{mg} / \mathrm{m}^{3}$ (basal cell hyperplasia was also observed in females at $6.0 \mathrm{mg} / \mathrm{m}^{3}$ ) and minimal to severe olfactory epithelial degeneration in males and females at $6.0 \mathrm{mg} / \mathrm{m}^{3}$; after 1 year of exposure, the only nasal lesion with a significantly increased incidence was minimal to moderate olfactory epithelial disarrangement in males exposed to $6.0 \mathrm{mg} / \mathrm{m}^{3}$. The lung lesions in rats exposed to 1.0 or $6.0 \mathrm{mg} / \mathrm{m}^{3}$ for 2 years consisted of mild to moderate localized fibrosis and alveolar duct epithelialization; exposure to $6.0 \mathrm{mg} / \mathrm{m}^{3}$ also resulted in localized alveolar bronchiolization. Additionally, an accumulation of macrophages with yellow pigment was observed at 1.0 and $6.0 \mathrm{mg} / \mathrm{m}^{3}$. After 1 year of exposure, minimal to moderate localized fibrosis, alveolar duct epithelialization, and localized alveolar bronchiolization were observed at $6.0 \mathrm{mg} / \mathrm{m}^{3}$; alveolar duct epithelialization was also observed in the females exposed to $1.0 \mathrm{mg} / \mathrm{m}^{3}$.

An unpublished study conducted by Hoyemann and associates in 1995 also evaluated the chronic toxicity of MDI in rats; this study was reviewed by Feron et al. (2001). Groups of 80 female Wistar rats were exposed to $0,0.23,0.70$, or $2.05 \mathrm{mg} / \mathrm{m}^{3}$ monomeric MDI aerosols (mass median aerodynamic diameter [MMAD] of approximately $1.0 \mu \mathrm{m}) 18$ hours/day, 5 days/week for approximately 2 years. As reviewed by Feron et al. (2001), significant increases in absolute and relative lung weight were observed at $2.05 \mathrm{mg} / \mathrm{m}^{3}$. A number of histological alterations were observed at $0.23 \mathrm{mg} / \mathrm{m}^{3}$ including bronchioloalveolar hyperplasia, mononuclear cell infiltration, and fibrosis; the incidence and severity of the lesions appeared to be concentration related. These effects are similar to those observed in Reuzel et al. (1994). The LOAELs from the two studies are similar after adjusting for intermittent exposure: $0.178 \mathrm{mg} / \mathrm{m}^{3}$ for the Reuzel et al. (1994) study and $0.123 \mathrm{mg} / \mathrm{m}^{3}$ for the Hoyemann study.

\section{Cardiovascular Effects.}

TDI. No histological alterations were observed in the aorta or heart of rats or mice exposed to $0.15 \mathrm{ppm}$ commercial-grade TDI for 2 years (Loeser 1983). 
MDI. No histological alterations were observed in the heart of rats exposed to $6.0 \mathrm{mg} / \mathrm{m}^{3}$ polymeric MDI for 2 years (Reuzel et al. 1994).

\section{Gastrointestinal Effects.}

TDI. Workers with accidental exposure to unknown quantities of TDI spilled from tanks have reported nausea and vomiting during exposure (Axford et al. 1976; Singer and Scott 1987).

Shadnia et al. (2013) reported a case of intestinal obstruction in a 16-year-old male worker in an Iranian sponge production factory. The subject's symptoms began after he was exposed to TDI for 2 hours; details of his exposure prior to this incident, or coexposures during the incident, were not provided. The authors noted that the subject had a past history of surgery for stomach lymphoma, and during surgery to correct the obstruction, mild adhesions from the previous surgery were seen. However, the authors noted that the surgery did not identify any possible causes of the obstruction; they postulated several possible mechanisms by which TDI may have induced the effect, including triggering an inflammatory response, interrupting parasympathetic nervous system function, or decreasing bowel motility via an effect on intestinal smooth muscle.

No gastrointestinal lesions were observed in rats or mice exposed to $0.15 \mathrm{ppm}$ commercial-grade TDI for 2 years (Loeser 1983).

MDI. No histological alterations were observed in the gastrointestinal tract of rats exposed to $6.0 \mathrm{mg} / \mathrm{m}^{3}$ polymeric MDI for 2 years (Reuzel et al. 1994).

\section{Hematological Effects.}

TDI. No hematological alterations were noted in rats or mice exposed to $0.15 \mathrm{ppm}$ commercial-grade TDI for 2 years (Loeser 1983).

MDI. No hematological alterations were observed in rats exposed to $6.0 \mathrm{mg} / \mathrm{m}^{3}$ polymeric MDI for 2 years (Reuzel et al. 1994). 


\section{Musculoskeletal Effects.}

TDI. No histological alterations were observed in the femur or skeletal muscle (quadriceps) of rats or mice exposed to 0.15 ppm commercial-grade TDI for 2 years (Loeser 1983).

MDI. Reuzel et al. (1994) examined 43 organs and tissues, which likely included bones and skeletal muscles, of rats exposed to $6.0 \mathrm{mg} / \mathrm{m}^{3}$ polymeric MDI for 2 years and did not find histological alterations outside of the respiratory tract.

\section{Hepatic Effects.}

TDI. No histological alterations in the liver or alterations in serum chemistry parameters were observed in rats or mice exposed to 0.15 ppm commercial-grade TDI for 2 years (Loeser 1983).

MDI. No histological alterations were observed in the liver of rats exposed to $6.0 \mathrm{mg} / \mathrm{m}^{3}$ polymeric MDI for 2 years (Reuzel et al. 1994); additionally, no alterations in serum clinical chemistry parameters were observed.

\section{Renal Effects.}

TDI. No histological alterations were observed in the kidneys in rats or mice exposed to $0.15 \mathrm{ppm}$ commercial-grade TDI for 2 years (Loeser 1983).

MDI. No histological alterations in the kidneys or alterations in urinalysis parameters were observed in rats exposed to $6.0 \mathrm{mg} / \mathrm{m}^{3}$ polymeric MDI for 2 years (Reuzel et al. 1994).

\section{Dermal Effects.}

TDI. In a study of 114 workers at a flexible foam manufacturing facility (Daftarian et al. 2002), production workers who were exposed to TDI reported skin conditions such as dermatitis, eczema, or other red rash in the previous 12 months more than twice as often as unexposed non-production workers (prevalence rate ratio of $2.66 ; 95 \%$ confidence interval $[\mathrm{CI}] 1.14-16.32, \mathrm{p}<0.02$ ). Skin patch testing and blood samples for specific IgG or IgE antibodies to TDI were largely negative (only 2/100 workers had a 
positive result to any of these tests, and only for specific $\operatorname{IgG})$; thus, the effects were considered to be related to irritation rather than an immune response.

MDI. Stingeni et al. (2008) reported a case of facial urticaria in a worker using a polyurethane glue containing MDI.

\section{Ocular Effects.}

TDI. In a case series of ocular effects in humans or animals exposed to diisocyanates, Luckenbach and Kielar (1980) evaluated visual acuity and ophthalmologic status in nine workers exposed to TDI during the production of polyurethane foam. No information on exposure levels was provided; the various cases had worked in the facility for durations ranging from 10 days to 2 years. All nine workers reported ocular symptoms such as "smoky" or "foggy" vision or eye irritation, usually resolving during weekends or overnight. In all nine, microcystic edema of the corneas and conjunctival injection (dilation of conjunctival blood vessels leading to appearance of redness) were observed upon ophthalmologic examination, with more severe cases associated with diminished visual acuity. None of the cases exhibited abnormal Schirmer I tear test or tear break-up time (Luckenbach and Kielar 1980).

Littorin et al. (2007) noted a significant association between self-reported eye symptoms and continuous measures of TDI exposure in workers. When the 2,4-TDI and 2,6-TDI levels were examined separately, a stronger association was found between eye symptoms and 2,4-TDI levels than with 2,6-TDI levels.

MDI. No information was located regarding ocular effects in humans or animals following inhalation exposure to MDI.

\section{Body Weight Effects.}

TDI. Significant decreases (45\% relative to controls) in maternal body weight gain were seen in CD rats during exposure (6 hours/day on GDs 6-15) to $0.5 \mathrm{ppm}$ commercial-grade TDI in a developmental toxicity study (Tyl et al. 1999a); in a range-finding study, significant weight loss was observed at $1 \mathrm{ppm}$. In a 2-generation reproductive toxicity study, intermediate-duration exposure (19 weeks including premating, mating, gestation, and lactation) to $0.3 \mathrm{ppm}$ commercial-grade TDI did not alter body weight of male or female F0 or F1 parental CD rats (Tyl et al. 1999b). Chronic exposure of rats to $0.15 \mathrm{ppm}$ commercial-grade TDI resulted in significant reductions in body weight gain (Loeser et al. 1983). 
However, the magnitude of change was not reported; the investigators did not report any changes in body weight gain at $0.05 \mathrm{ppm}$.

MDI. Acute-duration exposure of Wistar rats to 4,4'-MDI during gestation (6 hours/day on GDs 6-15) did not alter maternal body weight or body weight gain at exposure concentrations up to $9 \mathrm{mg} / \mathrm{m}^{3}$ (Buschmann et al. 1996). No significant alterations in body weight gain were observed in rats exposed to $6.0 \mathrm{mg} / \mathrm{m}^{3}$ polymeric MDI for 2 years (Reuzel et al. 1994).

\subsubsection{Immunological and Lymphoreticular Effects}

Although the exact mechanism of toxicity of TDI and MDI has not been elucidated, there is some indication that occupational asthma observed in some workers has an immune component, and several studies have reported alterations in TDI or MDI specific IgG and IgE antibodies in workers with asthma (Baur and Fruhmann 1981; Cvitanovic et al. 1989; Hur et al. 2008; Park and Nahm 1996; Park et al. 1999; Pezzini et al. 1984; Sharifi et al. 2013; Tse et al. 1985; Zeiss et al. 1980). These findings are discussed in detail in the Respiratory Effects section.

\subsubsection{Neurological Effects}

TDI. Le Quesne et al. (1976) described the immediate and long-term neurological effects in 23 firefighters who were "heavily exposed" during a fire at a polyurethane foam factory; approximately 4,500 $\mathrm{L}$ of TDI had spilled from storage tanks during the fire (Axford et al. 1976). The firefighters were exposed via inhalation, and some also had dermal contact. Other chemicals were stored at the factory, but the spillage was apparently limited to TDI; however, exposure to other chemicals cannot be ruled out. Additionally, exposure to carbon monoxide or anoxia may have contributed to the observed effects; the investigators noted that there was no evidence that the fumes were sufficiently dense for the firefighters to become anoxic. Five of the exposed men reported symptoms during the fire including euphoria, ataxia, and transient loss of consciousness; two reported headache the next day. Seventeen of the firefighters were medically evaluated 3 weeks later and 14 of these men reported symptoms of confusion, poor memory, headache, irritability, difficulty concentrating, or depression. Neurological examination showed slight changes including ataxia and mild sensory loss; electroencephalography recordings on nine men were unremarkable. At follow-up of 18 men 4 years later, memory problems were still reported by most of the subjects, and some reported persistence of concentration difficulty, irritability, and depression. No abnormalities were seen on neurological examination; however, a statistically significant $(\mathrm{p}<0.02)$ impairment in long-term recall was noted in the Wechsler memory scale when tests in exposed men who 
reported persistent effects were compared with unexposed firemen from another area (Le Quesne et al. 1976).

Singer and Scott (1987) reported neurological symptoms and neuropsychological and electrophysiology test results for three male wharf workers who were exposed to spilled TDI. Both dermal contact and inhalation exposure were described, and the total duration of exposure was about 4 hours for all three workers. The workers reported feeling dizzy during exposure. The workers were evaluated 2 and 16 months after exposure using neuropsychological tests and nerve conduction velocity measurements. Test results showed statistically significant decreases $(p<0.0003)$ in verbal, performance, and full-scale IQ at 16 months postexposure compared with 2 months postexposure (full scale IQ dropped between 20 and 26 points in all three subjects); while the tests administered at each time were slightly different (WAIS at 2 months versus WAIS-R at 16 months), on average, these tests differ only by 7-8 points (Singer and Scott 1987). In addition to IQ change, statistically significant impairments in both the Benton Visual Retention and Wechsler Memory Scale: Logical Memory were observed. Two of the three subjects exhibited significantly reduced nerve conduction velocities, one in the median sensory nerve and the other in the sural nerve, while the third showed no change in nerve conduction. The study authors also reported that testing at 16 months postexposure showed severe deficits in manual dexterity, visuomotor tracking, mental flexibility, ability to detect figure-ground relationships, and word fluency (additional details of these findings were not provided). The small number of subjects, lack of a control group, and small magnitude of the effects limit the interpretation of the results.

Hughes et al. (2014) recently evaluated the available data on the neurotoxicity of diisocyanates to determine whether a causal association could be established between diisocyanate exposure (the studies involved exposure to TDI, MDI, HDI, or unspecified diisocyanates) and neurotoxicity. Using the Hill criteria for causality, Hughes et al. (2014) concluded that there was limited evidence for strength of association and consistency, and the data were inadequate to establish a casual association between diisocyanates and neurotoxicity. The investigators noted several limitations of the studies included in their systematic review such as limited exposure information (including the lack of objective exposure measures and no dose-response assessment), co-exposure to known neurotoxicants, and lack of objective measures of neurotoxicity. Additionally, they noted that no plausible mechanisms of toxicity were identified. 
No animal studies have examined the potential of TDI to induce neurological effects. No histological alterations were observed in the brain, sciatic nerve, or spinal cord of rats or mice exposed to $0.15 \mathrm{ppm}$ commercial-grade TDI for 2 years (Loeser 1983).

MDI. Information on the neurotoxicity of MDI is limited to a chronic study that did not find histological alterations in the brain of rats exposed to $6.0 \mathrm{mg} / \mathrm{m}^{3}$ polymeric MDI for 2 years (Reuzel et al. 1994).

\subsubsection{Reproductive Effects}

TDI. No information was located regarding reproductive effects in humans following inhalation exposure to TDI. When groups of $28 \mathrm{CD}$ rats were exposed via inhalation to commercial-grade TDI (80:20 mix of 2,4- and 2,6-TDI), no effects on reproductive toxicity parameters (including mating, fecundity, or fertility indices; gestation length; numbers of live litters or live birth indices; gross necropsy findings; or histopathology of reproductive organs) were seen at exposures up to $0.3 \mathrm{ppm}, 6$ hours/day, 5 days/week for 2 generations (Tyl et al. 1999b). A 2-year study in rats and mice did not find histological alterations in the gonads of male and female rats and mice (Loeser 1983).

MDI. No information was located regarding reproductive effects in humans following inhalation exposure to MDI. A 2-year study in male and female rats did not find histological alterations in the gonads at $6.0 \mathrm{mg} / \mathrm{m}^{3}$ polymeric MDI (Reuzel et al. 1994).

\subsubsection{Developmental Effects}

TDI. No information was located regarding developmental effects in humans following inhalation exposure to TDI. Exposure of rats to $0.5 \mathrm{ppm}$ TDI (80:20 mix of 2,4- and 2,6-TDI) during GDs 6-15 resulted in an increased incidence of litters with poorly ossified cervical centrum no. 5, but no other treatment-related increases in anomalies or variations (Tyl et al. 1999a). Maternal toxicity, including markedly reduced body weight gain and respiratory symptoms, was seen at $0.5 \mathrm{ppm}$, and the observed developmental effects may have been secondary to the maternal toxicity.

MDI. No information was located regarding developmental effects in humans following inhalation exposure to MDI. After exposure of rats to $9 \mathrm{mg} / \mathrm{m}^{3} 4,4^{\prime}-\mathrm{MDI}$ aerosol for 6 hours/day on GDs 6-15, there was an increase in the incidence of litters with fetuses displaying asymmetric sternebrae (10/23 litters versus $2 / 25$ control litters, $p<0.05$ ); no effects of treatment were seen on other gestational parameters or on malformation or variation incidences at lower exposure concentrations (Buschmann et 
al. 1996). The investigators noted that the incidence was within the limits of biological variability. Apart from reduced food consumption, dams did not exhibit signs of toxicity at any exposure concentration in this study; an increase in lung weight was also observed in the dams.

\subsubsection{Cancer}

Human data on the potential association between inhalation exposure to diisocyanates and cancer are available from studies of three cohorts of workers engaged in polyurethane foam manufacture. Studies of these cohorts (Mikoczy et al. 2004; Schnorr et al. 1996; Sorahan and Nichols 2002) have suggested an association between work in the polyurethane foam manufacturing industry and lung cancer in female workers, but an association with diisocyanate exposure was not established. Significant limitations of all three studies included lack of control for confounding factors such as smoking and alcohol consumption and coexposure to mixtures of compounds including those other than diisocyanates.

Cohort studies of cancer and diisocyanate exposure include: a cohort of 4,611 workers from 4 plants in the United States (Schnorr et al. 1996); a cohort of 4,175 workers from 9 plants in Sweden (Mikoczy et al. 2004; Hagmar et al. 1993a, 1993b); and a cohort of 8,288 workers in 11 plants in the United Kingdom (Sorahan and Nichols 2002; Sorahan and Pope 1993). Sorahan and Nichols (2002) reported data on the largest number of person-years at risk (200,262); Schnorr et al. (1996) reported on 90,393 person-years at risk, and Mikoczy et al. (2004) reported on 83,023 person-years at risk. None of the studies provided quantitative estimates of individual exposures. Workers in all three cohorts were exposed to a mixture of TDI isomers, and those at some plants were also exposed to unspecified isomers of MDI. In addition, all of the cohorts included workers who may have been exposed to other airborne contaminants such as methylene chloride, aliphatic amines, acrolein, acrylonitrile, styrene, amine accelerators such as bis(2-dimethylaminoethyl) ether, and others (Mikoczy et al. 2004; Schnorr et al. 1996).

Table 3-4 shows the results of the most recent studies in the three cohorts. Increased standardized mortality ratios (SMRs) for lung cancer were reported for women in all three cohorts; the increases were statistically significant in the U.K. (Sorahan and Nichols 2002) and Swedish (Mikoczy et al. 2004) cohorts, but not the U.S. cohort (Schnorr et al. 1996). Mikoczy et al. (2004) also reported a significantly increased incidence of lung cancer in females (standardized incidence ratio [SIR] of 3.0; 95\% CI 1.555.24) compared with the expected incidence in the general Swedish population. However, when stratified 


\section{Table 3-4. Results of Cohort Studies of Diisocyanate Exposure and Mortality from Specific Cancers}

\begin{tabular}{|c|c|c|c|c|c|c|}
\hline & \multicolumn{2}{|c|}{ U.S. cohort } & \multicolumn{2}{|l|}{ U.K. cohort } & \multicolumn{2}{|c|}{ Swedish cohort } \\
\hline Reference & \multicolumn{2}{|c|}{ Schnorr et al. 1996} & \multicolumn{2}{|c|}{$\begin{array}{l}\text { Sorahan and Nichols } \\
2002\end{array}$} & \multicolumn{2}{|c|}{ Mikoczy et al. 2004} \\
\hline $\begin{array}{l}\text { Cohort size (number of } \\
\text { plants) }\end{array}$ & \multicolumn{2}{|l|}{$4,611(4)$} & \multicolumn{2}{|l|}{$8,288(11)$} & \multicolumn{2}{|l|}{$4,175(9)$} \\
\hline Time period of follow-up & \multicolumn{2}{|c|}{ 1958-1993 } & \multicolumn{2}{|l|}{$1958-1998$} & \multicolumn{2}{|c|}{ 1959-1998 } \\
\hline Person-years at risk & \multicolumn{2}{|l|}{90,393} & \multicolumn{2}{|l|}{200,262} & \multicolumn{2}{|l|}{83,023} \\
\hline Cancer site & $\begin{array}{l}\text { Number } \\
\text { of cases }\end{array}$ & $\begin{array}{l}\text { SMR }(95 \% \\
\mathrm{CI})\end{array}$ & $\begin{array}{l}\text { Number of } \\
\text { cases }\end{array}$ & $\begin{array}{l}\text { SMR }(95 \% \\
\mathrm{CI})\end{array}$ & $\begin{array}{l}\text { Number } \\
\text { of cases }\end{array}$ & $\operatorname{SMR}(95 \% \mathrm{Cl})$ \\
\hline \multicolumn{7}{|l|}{ Females } \\
\hline Lung & 8 & 173 & 35 & $\begin{array}{l}181^{a}(126- \\
251)\end{array}$ & 10 & $\begin{array}{l}352^{\mathrm{a}}(169- \\
648)\end{array}$ \\
\hline Rectum & 0 & NA & 2 & $53(6-192)$ & - & - \\
\hline Non-Hodgkin's lymphoma & - & - & 3 & $110(23,321)$ & - & - \\
\hline Hodgkin's disease & - & - & 0 & NA & - & - \\
\hline \multicolumn{7}{|l|}{ Males } \\
\hline Lung & 12 & 79 & 134 & $107(90-127)$ & 7 & $49(20-101)$ \\
\hline Rectum & 3 & 390 & 10 & $65(31-120)$ & - & - \\
\hline Non-Hodgkin's lymphoma & - & - & 6 & $65(24-142)$ & - & - \\
\hline Hodgkin's disease & - & - & 1 & $44(1-243)$ & - & - \\
\hline \multicolumn{7}{|c|}{ Females and males (combined) } \\
\hline Lung & $20^{b}$ & $101(62-156)$ & & - & 17 & $99(58-159)$ \\
\hline Rectum & 3 & $278(57-813)$ & - & - & - & - \\
\hline Non-Hodgkin's lymphoma & 4 & $154(42-395)$ & - & - & - & - \\
\hline Hodgkin's disease & 2 & $232(28-838)$ & - & - & - & - \\
\hline
\end{tabular}

aSignificantly different from null hypothesis at $p<0.05$.

bIncludes tumors of the lung, trachea, and bronchus.

- = not reported; $\mathrm{Cl}=$ confidence interval; $\mathrm{SMR}=$ standardized mortality ratio 
by "apparent" versus "no or low" exposure to TDI or MDI, women with "apparent" exposure did not exhibit a higher risk of lung cancer. In addition, Mikoczy et al. (2004) conducted a nested case-referent study of the 12 lung cancer cases among female workers, and observed no greater prevalence of exposure to polyurethane dust in cases compared with referents. Similarly, Sorahan and Nichols (2002) observed a statistically significant increased incidence of lung and bronchus cancer in women (standardized registration ratios [SRR] 199; 95\% CI 135-282), but reported that all of the female lung cancers in the cohort were in women who did not work for any period in an isocyanate-exposed setting. Schnorr et al. (1996) did not evaluate the effect of isocyanate exposure duration on lung cancer risk in women alone, but in both male and female workers, there was no trend of increased lung cancer mortality by duration of exposure or time since first exposure.

Schnorr et al. (1996) reported nonsignificant increases in the SMRs for rectal cancer, Hodgkin's disease, and non-Hodgkin's lymphoma in the U.S. cohort; however, studies of the Swedish and U.K. cohorts (Mikoczy et al. 2004 and Sorahan and Nichols 2002, respectively) did not support these findings, as SMRs for these neoplasms were reduced in the exposed workers of these cohorts (Table 3-4).

TDI. When groups of 126/sex Sprague-Dawley rats and 120/sex CD-1 mice were exposed to vapors of commercial-grade TDI via whole-body inhalation on 6 hours/day, 5 days/week for 108-110 weeks (Loeser 1983), there were no treatment-related increased tumor incidences in rats or mice.

The authors noted that histopathology of the nasal turbinates in rats was still in progress, but that there were no grossly visible effects of treatment on the upper respiratory tract. No follow-up study was identified in the literature search. This study lacked some details in methodology, and did not describe the approach to statistical analysis.

MDI. Groups of $60 \mathrm{Wistar}$ rats per sex were exposed to aerosolized polymeric MDI at nominal concentrations of $0,0.2,1.0$, or $6.0 \mathrm{mg} / \mathrm{m}^{3}$ via whole-body inhalation 6 hours/day, 5 days/week for 2 years (Reuzel et al. 1994). A significantly increased incidence (6/60) of lung adenoma, as well as one lung adenocarcinoma, was observed in male rats exposed to $6.0 \mathrm{mg} / \mathrm{m}^{3}$ polymeric MDI. No lung tumors occurred in control, 0.2 , or $1.0 \mathrm{mg} / \mathrm{m}^{3}$ exposure groups of male or female rats. In female rats exposed to $6.0 \mathrm{mg} / \mathrm{m}^{3}, 2 / 59$ animals developed lung adenomas; there were no adenocarcinomas (Reuzel et al. 1994).

In a second study conducted by Hoyemann and associates (reviewed by Feron et al. 2001) in which female Wistar rats were exposed to monomeric MDI 18 hours/day, 5 days/week for 2 years, the 
occurrence of lung tumors was limited to a bronchiolo-alveolar adenoma observed in 1/80 rats exposed to $2.05 \mathrm{mg} / \mathrm{m}^{3}$.

\subsubsection{Oral Exposure}

It is noted that TDI and MDI are rapidly hydrolyzed in aqueous environments and it is unlikely that humans will be exposed to these compounds in water. The only available information on the toxicity of TDI administered via the oral route comes from gavage studies in which rats and mice were administered TDI in corn oil for 14 days, 13 weeks, or 2 years (NTP 1986). There is some question regarding the applicability of the results of the gavage studies to humans due to likely differences in the metabolism of ingested TDI compared to gavage administered TDI. Direct instillation of TDI into the acidic stomach could result in the formation of 2,4-TDA, which is unlikely to occur following ingestion because TDI is likely to react with itself and macromolecules to form urea and polyurea in the neutral $\mathrm{pH}$ milieu of the mouth. No information was located regarding health effects in humans or animals following oral exposure to MDI.

The highest NOAEL values and all LOAEL values for TDI from each reliable study for each end point in each species and duration category are recorded in Table 3-5 and plotted in Figure 3-3.

\subsubsection{Death}

No information was located regarding death in humans following oral exposure to TDI. In acute-duration gavage studies of commercial-grade TDI administered in corn oil (NTP 1986), treatment-related deaths occurred at doses $\geq 240 \mathrm{mg} / \mathrm{kg} /$ day in rats and $\geq 500 \mathrm{mg} / \mathrm{kg} /$ day in mice exposed for up to 14 consecutive days; however, because sporadic deaths among male mice at lower doses (as low as $30 \mathrm{mg} / \mathrm{kg} / \mathrm{day}$ ), it is difficult to identify a clear and reliable effect level for death in mice. Data on effect levels for death of mice and rats exposed for intermediate durations are also uncertain as a consequence of sporadic deaths occurring at low doses; however, based on the study authors' determinations, treatment-related deaths of female rats and mice occurred at doses of 240 and $120 \mathrm{mg} / \mathrm{kg} /$ day, respectively (NTP 1986). In 2-year studies of commercial-grade TDI, doses $\geq 30 \mathrm{mg} / \mathrm{kg} /$ day reduced survival of male and female rats, while the high dose of $240 \mathrm{mg} / \mathrm{kg}$ /day reduced the survival of male mice (NTP 1986). Importantly, NTP (1986) reported that analysis of the test material in the chronic study showed that the TDI had reacted with the corn oil vehicle, yielding actual gavage doses $77-90 \%$ of nominal doses. It is reasonable to assume that similar reactions occurred in the acute- and intermediate-duration studies. 


\section{HEALTH EFFECTS}

Table 3-5. Levels of Significant Exposure to Toluene Diisocyanate - Oral

\begin{tabular}{|c|c|c|}
\hline $\begin{array}{l}\text { Key to } \\
\text { Figure }\end{array}$ & $\begin{array}{l}\text { Species } \\
\text { (Strain) }\end{array}$ & $\begin{array}{l}\text { Exposurel } \\
\text { Durationl } \\
\text { Frequency } \\
\text { (Route) }\end{array}$ \\
\hline \multicolumn{3}{|c|}{$\begin{array}{l}\text { ACUTE EXPOSURE } \\
\text { Death }\end{array}$} \\
\hline 1 & $\begin{array}{l}\text { Rat } \\
(\mathrm{F} 344 / \mathrm{N})\end{array}$ & $\begin{array}{l}\text { single dose } \\
\text { (G) }\end{array}$ \\
\hline 2 & $\begin{array}{l}\text { Rat } \\
\text { (F344) }\end{array}$ & $\begin{array}{l}14 \mathrm{~d}, 1 \times / \mathrm{d} \\
(\mathrm{G})\end{array}$ \\
\hline
\end{tabular}

3 Mouse single dose (B6C3F1) (G)

Systemic

$4 \quad$ Rat

(F344)

$14 \mathrm{~d}, 1 \mathrm{x} / \mathrm{d}$

(G)

$\mathrm{Bd} \mathrm{Wt}$

$60 \mathrm{M}$

$120 \mathrm{M}(12 \%$ decrease in body weight)

$\begin{array}{ll}\text { NOAEL } & \\ \text { System } \quad(\mathrm{mg} / \mathrm{kg} / \mathrm{day})\end{array}$

(mg/kg/day)
LOAEL

Serious
(mg/kg/day)

2150 M (2/5 M died)

NTP 1986

2,4/2,6-TDI

$240 \quad(1 / 5$ males and $1 / 5$ females died)

NTP 1986

2,4/2,6-TDI

$4640 \quad(4 / 5 \mathrm{M}$ and $1 / 5 \mathrm{~F}$ died $)$

NTP 1986

2,4/2,6-TDI

NTP 1986

2,4/2,6-TDI

NTP 1986

2,4/2,6-TDI

NTP 1986

2,4/2,6-TDI

in body weight)

$30 \quad \begin{aligned} & \text { (significantly decreased } \\ & \text { survival) }\end{aligned}$

NTP 1986

2,4/2,6-TDI

240 M (significantly decreased

NTP 1986 survival)

2,4/2,6-TD

Comments

80: 20 mixture of 2,4 and 2,6-TDI

80: 20 mixture of 2,4 and 2,6-TDI

80: 20 mixture of 2,4 and 2,6-TDI

80: 20 mixture of 2,4 and 2,6-TDI

80: 20 mixture of 2,4 and 2,6-TDI

80: 20 mixture of 2,4and 2,6-TDI

80: 20 mixture of 2,4and 2,6-TDI

$80: 20$ mixture of $2,4-$ and 2,6-TDI 


\section{HEALTH EFFECTS}

Table 3-5. Levels of Significant Exposure to Toluene Diisocyanate - Oral

(continued)

\begin{tabular}{|c|c|c|c|c|c|c|c|c|}
\hline \multirow[b]{2}{*}{$\begin{array}{l}\text { Key to } \\
\text { Figure }\end{array}$} & \multirow[b]{2}{*}{$\begin{array}{c}\text { Species } \\
\text { (Strain) }\end{array}$} & \multirow{2}{*}{$\begin{array}{l}\text { Exposurel } \\
\text { Duration/ } \\
\text { Frequency } \\
\text { (Route) }\end{array}$} & \multirow[b]{2}{*}{ System } & \multirow[b]{2}{*}{$\begin{array}{l}\text { NOAEL } \\
\text { (mg/kg/day) }\end{array}$} & \multicolumn{2}{|c|}{ LOAEL } & \multirow[b]{2}{*}{$\begin{array}{l}\text { Reference } \\
\text { Chemical Form }\end{array}$} & \multirow[b]{2}{*}{ Comments } \\
\hline & & & & & $\begin{array}{r}\text { Less Serious } \\
\text { (mg/kg/day) }\end{array}$ & $\begin{array}{l}\text { Serious } \\
\text { (mg/kg/day) }\end{array}$ & & \\
\hline \multicolumn{9}{|c|}{ Systemic } \\
\hline \multirow[t]{7}{*}{9} & $\begin{array}{l}\text { Rat } \\
(\mathrm{F} 344 / \mathrm{N})\end{array}$ & $\begin{array}{l}105 \mathrm{wk}, 5 \mathrm{~d} / \mathrm{wk} \\
\text { (G) }\end{array}$ & Resp & & 30 M (bronchopneumonia) & & NTP 1986 & $\begin{array}{l}\text { 80: } 20 \text { mixture of } 2,4- \\
\text { and } 2,6-\text { TDI }\end{array}$ \\
\hline & & & Cardio & $120 \mathrm{~F}$ & & & & \\
\hline & & & Gastro & $120 \mathrm{~F}$ & & & & \\
\hline & & & Musc/skel & $120 \mathrm{~F}$ & & & & \\
\hline & & & Hepatic & $120 \mathrm{~F}$ & & & & \\
\hline & & & Renal & $120 \mathrm{~F}$ & & & & \\
\hline & & & $\mathrm{Bd} W \mathrm{t}$ & & $\begin{array}{l}30 \mathrm{M} \text { ( } 12 \% \text { decrease in } \\
\text { terminal body weight) }\end{array}$ & & & \\
\hline
\end{tabular}


Table 3-5. Levels of Significant Exposure to Toluene Diisocyanate - Oral

(continued)

\begin{tabular}{|c|c|c|c|c|c|}
\hline $\begin{array}{l}\text { Key to } \\
\text { Figure }\end{array}$ & $\begin{array}{l}\text { Species } \\
\text { (Strain) }\end{array}$ & $\begin{array}{l}\text { Exposurel } \\
\text { Duration/ } \\
\text { Frequency } \\
\text { (Route) }\end{array}$ & System & $\begin{array}{l}\text { NOAEL } \\
\text { (mg/kg/day) }\end{array}$ & $\begin{array}{r}\text { Less Serious } \\
(\mathrm{mg} / \mathrm{kg} / \mathrm{day}) \\
\end{array}$ \\
\hline \multirow[t]{7}{*}{10} & $\begin{array}{l}\text { Mouse } \\
\text { (B6C3F1) }\end{array}$ & $\begin{array}{l}105 \mathrm{wk}, 5 \mathrm{~d} / \mathrm{wk} \\
\text { (G) }\end{array}$ & Resp & $240 \mathrm{~F}$ & \\
\hline & & & Cardio & $240 \mathrm{~F}$ & \\
\hline & & & Musc/skel & $240 \mathrm{~F}$ & \\
\hline & & & Hepatic & $240 \mathrm{~F}$ & \\
\hline & & & Renal & $120 \mathrm{M}$ & $\begin{array}{c}240 \text { M (cytomegaly of tubular } \\
\text { epithelium) }\end{array}$ \\
\hline & & & Endocr & $240 \mathrm{~F}$ & \\
\hline & & & $\mathrm{Bd} W \mathrm{Wt}$ & $120 \mathrm{M}$ & $\begin{array}{l}240 \mathrm{M} \text { (body weight decrement } \\
\text { of } \sim 10 \% \text { throughout most } \\
\text { of the study) }\end{array}$ \\
\hline
\end{tabular}

LOAEL

(mg/kg/day) Chemical Form

Comments

\section{Cancer}


3. HEALTH EFFECTS

Figure 3-3. Levels of Significant Exposure to Toluene Diisocyanate - Oral

Acute ( $\leq 14$ days)

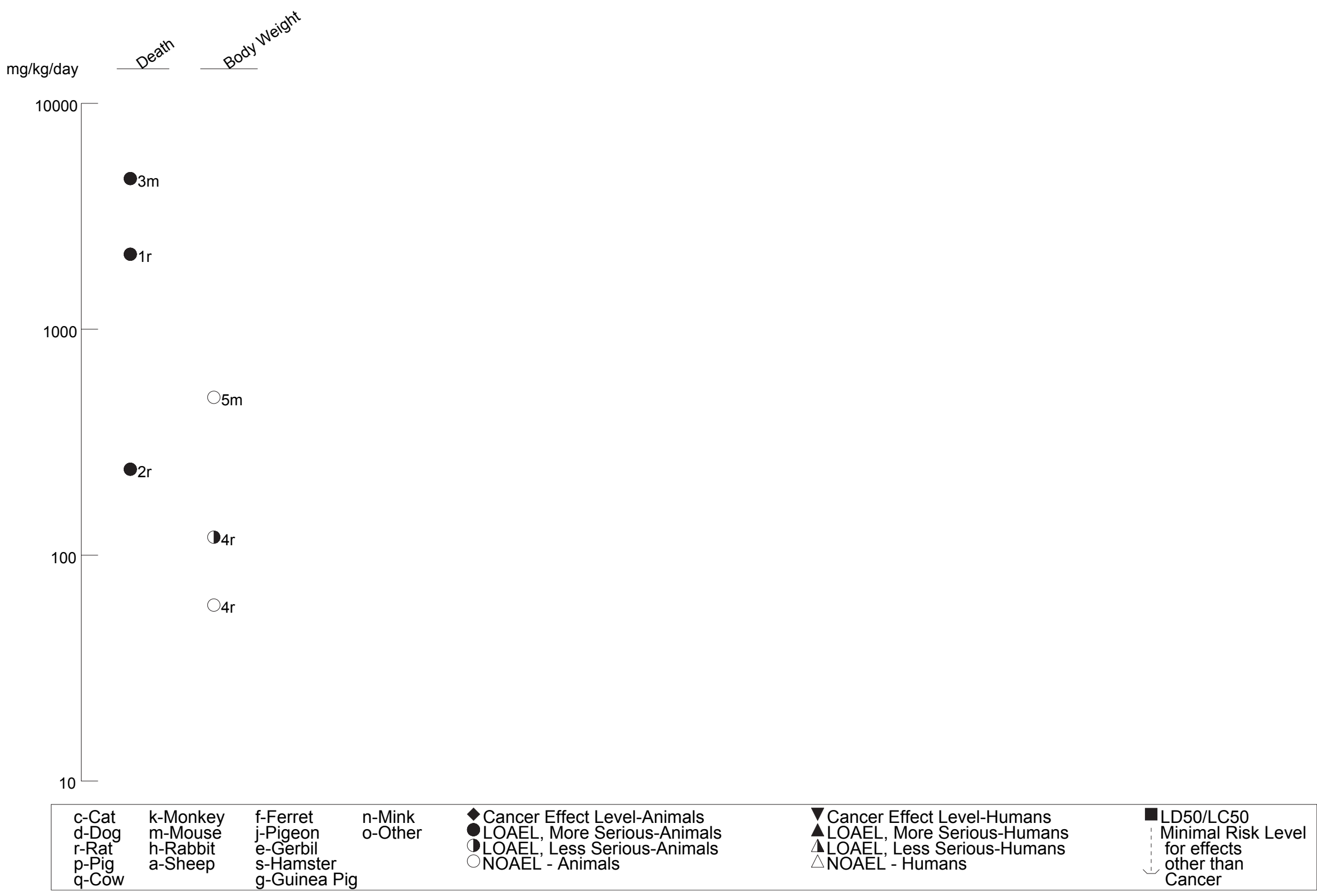


Figure 3-3 Levels of Significant Exposure to Toluene Diisocyanate - Oral (Continued) Intermediate (15-364 days)

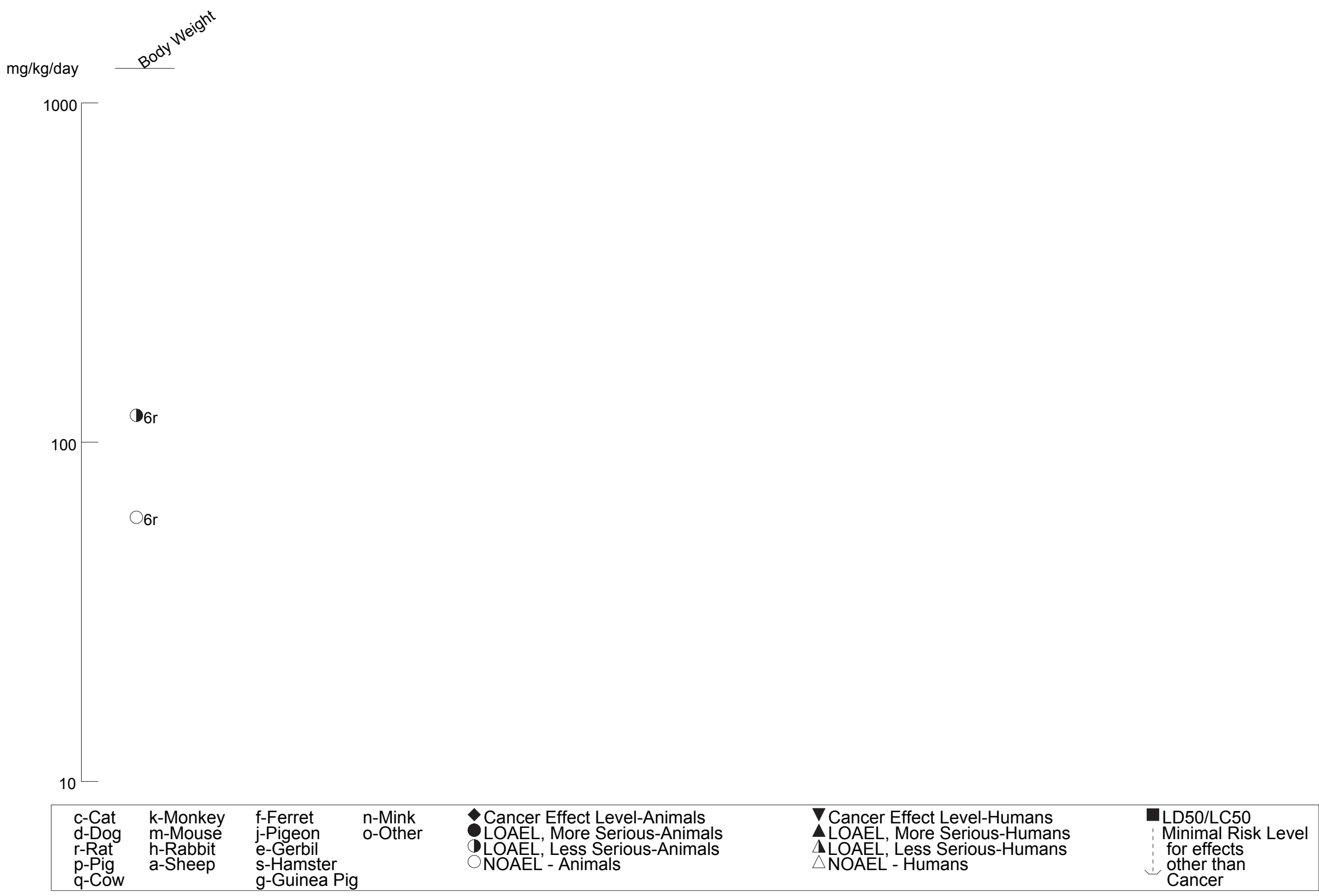


Figure 3-3 Levels of Significant Exposure to Toluene Diisocyanate - Oral (Continued)

Chronic ( $\geq 365$ days)

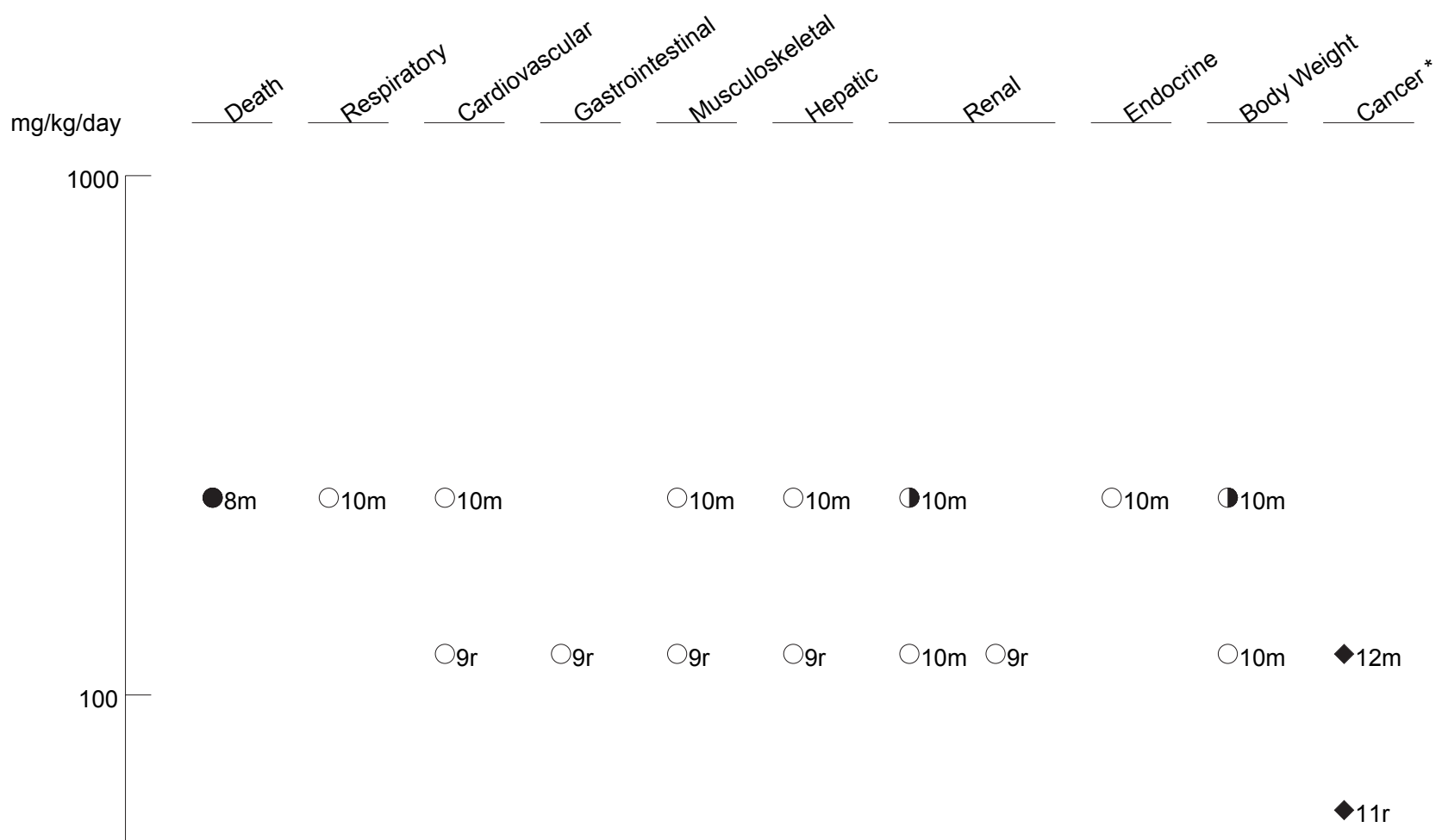

Or $9 \mathrm{r}$

(1r

*Doses represent the lowest dose tested per study that produced a tumorigenic response and do not imply the existence of a threshold for the cancer endpoint.

\begin{tabular}{|c|c|c|c|c|c|c|}
\hline $\begin{array}{l}\text { c-Cat } \\
\text { d-Dog } \\
\text { r-Rat } \\
\text { p-Pig } \\
\text { q-Cow }\end{array}$ & $\begin{array}{l}\text { k-Monkey } \\
\text { m-Mouse } \\
\text { h-Rabbit } \\
\text { a-Sheep }\end{array}$ & $\begin{array}{l}\text { f-Ferret } \\
\text { j-Pigeon } \\
\text { e-Gerbil } \\
\text { s-Hamster } \\
\text { g-Guinea Pic }\end{array}$ & $\begin{array}{l}\text { n-Mink } \\
\text { o-Other }\end{array}$ & $\begin{array}{l}\text { Cancer Effect Level-Animals } \\
\text { LOAEL, More Serious-Animals } \\
\text { LOAEL, Less Serious-Animals } \\
\text { NOAEL - Animals }\end{array}$ & $\begin{array}{l}7 \text { Cancer Effect Level-Humans } \\
\Delta \text { LOAEL, More Serious-Humans } \\
\Delta \text { LOAEL, Less Serious-Humans } \\
\triangle \text { NOAEL - Humans }\end{array}$ & $\begin{array}{l}\text { LD50/LC50 } \\
\text { Minimal Risk Level } \\
\text { for effects } \\
\text { other than } \\
\text { Cancer }\end{array}$ \\
\hline
\end{tabular}


In an acute lethality study using five animals/sex/dose, two of five male F344 rats given a single gavage dose of $2,150 \mathrm{mg} / \mathrm{kg}$ (the lowest dose tested) commercial-grade TDI in corn oil died on days 5 and 9 of the observation period (NTP 1986). No females died at this dose, but at 3,160 mg/kg, two of five female rats died. Dose-related increases in mortality were observed in both sexes at higher doses. There were no untreated controls in this study. In a 14-day gavage study of rats by NTP (1986), there were clear doserelated increases in mortality at doses $\geq 500 \mathrm{mg} / \mathrm{kg} / \mathrm{day}$. A second study by this group reported that one male and one female each in the 30 and $240 \mathrm{mg} / \mathrm{kg} /$ day dose groups, and one female in the $500 \mathrm{mg} / \mathrm{kg} / \mathrm{day}$ group died prematurely, but there were no deaths at 60 or $120 \mathrm{mg} / \mathrm{kg} /$ day. Taken together with the first study, these data suggest a severe LOAEL of $240 \mathrm{mg} / \mathrm{kg} /$ day for death in rats (NTP 1986).

In the acute lethality study of mice performed by NTP (1986), a dose-related increase in mortality was observed at doses $\geq 4,640 \mathrm{mg} / \mathrm{kg}$. At 4,640 mg/ $\mathrm{kg}$, one of five female mice and four of five male mice died between days 2 and 8 of the observation period. No deaths occurred at doses of $2,150 \mathrm{mg} / \mathrm{kg}$ (males only were exposed to this dose) or 3,160 mg/ $/ \mathrm{kg}$ (males and females). As with the rat study, there were no untreated controls in this study. In 14-day gavage studies of commercial-grade TDI in mice (NTP 1986), all animals died in the first study using doses $500 \mathrm{mg} / \mathrm{kg} /$ day. A second study using doses of 30$500 \mathrm{mg} / \mathrm{kg} /$ day was performed, and deaths of one to two male mice per group were seen at all doses. Two females died at $240 \mathrm{mg} / \mathrm{kg} / \mathrm{day}$, but there were no female deaths at any other dose. An effect level for death is difficult to ascertain from this study due to the lack of a dose-response relationship in the male deaths at doses between 30 and $500 \mathrm{mg} / \mathrm{kg} / \mathrm{day}$ in the second study and the deaths of all animals at $\geq 500 \mathrm{mg} / \mathrm{kg} / \mathrm{day}$ in the first study.

Intermediate-duration (13 weeks, 5 days/week) gavage studies of commercial-grade TDI in rats and mice were performed by NTP (1986). In both species, the 13-week studies were repeated due to mortality in the first study. As with the 14-day studies, deaths occurred at various doses without a clear dose-response relationship. The study authors considered a single female rat death at $240 \mathrm{mg} / \mathrm{kg} /$ day, and deaths of $1 / 10$ and 2/10 female mice exposed to 120 and $240 \mathrm{mg} / \mathrm{kg} /$ day (respectively), to be treatment-related (NTP 1986).

Chronic (2-year) exposure to gavage doses $\geq 30 \mathrm{mg} / \mathrm{kg} /$ day TDI for 5 days/ week significantly decreased survival of F344 rats (NTP 1986). At termination, survival of male rats was 36/50, 14/50, and 8/50 at 0 , 30 , and $60 \mathrm{mg} / \mathrm{kg} /$ day, respectively; survival of female rats was $36 / 50,19 / 50$, and $6 / 50$ at 0,60 , and $120 \mathrm{mg} / \mathrm{kg} /$ day, respectively. In the chronic study of mice (NTP 1986), survival of high-dose (240 mg/kg/day) male mice was significantly lower than controls; at termination, 46/50 controls, 40/50 in 
the $120 \mathrm{mg} / \mathrm{kg} /$ day group, and $26 / 50$ in the $240 \mathrm{mg} / \mathrm{kg}$ /day group remained. Survival of female mice was not diminished by treatment.

\subsubsection{Systemic Effects}

No information was located regarding systemic effects in humans following oral exposure to TDI.

Respiratory Effects. No information on respiratory effects of acute-duration oral exposure to TDI in animals was located. In rats exposed via gavage to commercial-grade TDI for 13 weeks (5 days/week), mucoid bronchopneumonia was reported in one of 2 male rats that received $120 \mathrm{mg} / \mathrm{kg} / \mathrm{day}$ and died prematurely; this effect was also seen in 8/10 males and 2/10 females exposed to $240 \mathrm{mg} / \mathrm{kg} /$ day (NTP 1986). Histopathology examination was not performed on other rats in the $120 \mathrm{mg} / \mathrm{kg} /$ day group or in any rats of the lower dose groups; thus, an effect level cannot be determined for this end point. In the 13-week study of mice, few results of the histopathology examination of high dose animals were reported, but results that were reported did not indicate lesions of the respiratory tract at $240 \mathrm{mg} / \mathrm{kg} / \mathrm{day}$.

When F344 rats were exposed via gavage to commercial-grade TDI on 5 days/week for 2 years, acute bronchopneumonia was seen in both sexes (NTP 1986). The incidences of bronchopneumonia in male rats were 2/50,6/50, and 14/50 (control, 30, and $60 \mathrm{mg} / \mathrm{kg} /$ day groups, respectively) and incidences in female rats were $1 / 50,10 / 50$, and 25/49 (control, 60 , and $120 \mathrm{mg} / \mathrm{kg} /$ day groups, respectively). In contrast, $\mathrm{B} 6 \mathrm{C} 3 \mathrm{~F} 1$ mice exhibited no respiratory effects when exposed for 2 years to commercial-grade TDI doses up to $120 \mathrm{mg} / \mathrm{kg} /$ day in females and $240 \mathrm{mg} / \mathrm{kg} /$ day in males (NTP 1986).

Cardiovascular Effects. No histological alterations were observed in the hearts of rats or mice administered doses up to 120 or $240 \mathrm{mg} / \mathrm{kg}$ /day commercial-grade TDI 5 days/week for 2 years (NTP 1986).

Gastrointestinal Effects. Chronic gavage studies with TDI in rats and mice did not result in gastrointestinal lesions (NTP 1986).

Hematological Effects. No information was located regarding hematological effects in animals following oral exposure to TDI. 
Musculoskeletal Effects. No histological alterations were observed in the musculoskeletal system of rats or mice administered doses up to 120 or $240 \mathrm{mg} / \mathrm{kg} /$ day commercial-grade TDI 5 days/week for 2 years (NTP 1986).

Hepatic Effects. No non-neoplastic lesions resulted from a 2-year administration of commercialgrade TDI to rats and mice (NTP 1986).

Renal Effects. No histological alterations were observed in the kidneys of administered doses up to $120 \mathrm{mg} / \mathrm{kg} /$ day commercial-grade TDI 5 days/week for 2 years (NTP 1986). An increased incidence of cytomegaly of tubular epithelium was observed in male mice administered $240 \mathrm{mg} / \mathrm{kg} /$ day commercialgrade TDI 5 days/week for 2 years (NTP 1986); no alterations were observed in male or female mice exposed to $120 \mathrm{mg} / \mathrm{kg} /$ day.

Dermal Effects. Administration of commercial-grade TDI for 2 years did not result in dermal lesions in rats or mice (NTP 1986).

Ocular Effects. Administration of commercial-grade TDI for 2 years did not result in ocular lesions in rats or mice (NTP 1986).

Body Weight Effects. Decreases in body weight gain were observed in male and female rats administered via gavage $\geq 30 \mathrm{mg} / \mathrm{kg}$ /day commercial-grade TDI 5 days/week for 2 years (NTP 1986). A similar exposure of mice resulted in decreases in body weight gain at $240 \mathrm{mg} / \mathrm{kg} / \mathrm{day}$ (males only); no alterations in weight gain were observed in male or female mice at $120 \mathrm{mg} / \mathrm{kg} /$ day (NTP 1986).

\subsubsection{Immunological and Lymphoreticular Effects}

No information was located regarding immunological and lymphoreticular effects in humans or animals following oral exposure to TDI.

\subsubsection{Neurological Effects}

No information was located regarding neurological effects in humans or animals following oral exposure to TDI. 


\subsubsection{Reproductive Effects}

No information was located regarding reproductive effects in humans or animals following oral exposure to TDI.

\subsubsection{Developmental Effects}

No information was located regarding developmental effects in humans or animals following oral exposure to TDI.

\subsubsection{Cancer}

Data on cancer effects of diisocyanates in humans and animals orally exposed to diisocyanates are limited to bioassays in rats and mice exposed to commercial-grade TDI via gavage (NTP 1986). Based on the bioassays, NTP (1986) concluded that there was clear evidence that commercial-grade TDI in corn oil was carcinogenic to female mice and to rats of both sexes. Tumor types occurring at increased incidences in the exposed rats included subcutaneous fibromas and fibrosarcomas, pancreatic acinar cell adenomas and islet cell adenomas, mammary gland fibroadenomas, and neoplastic nodules of the liver. In exposed female mice, the following tumor types occurred at increased incidences: hemangiomas or hemangiosarcomas and hepatocellular adenomas. The findings of the study are limited by reduced survival in rats and high dose male mice, as well as instability of the test material in the vehicle.

NTP (1986) administered commercial-grade TDI in corn oil via gavage to groups of 50/sex F344 rats and B6C3F1 mice on 5 days/week for 104 weeks. Doses were 0,60 , or $120 \mathrm{mg} / \mathrm{kg} /$ day in female rats and mice; 0,30 , or $60 \mathrm{mg} / \mathrm{kg} /$ day in male rats; and 0, 120, or $240 \mathrm{mg} / \mathrm{kg} /$ day in male mice. Analysis of the administered material indicated that the TDI had reacted with corn oil, yielding actual gavage doses 77$90 \%$ of nominal doses. In rats, survival was significantly lower than controls in all exposed groups; NTP (1986) concluded that the maximum tolerated dose had been exceeded. Statistically significant increases in the incidence of neoplasia were observed in both male and female rats; the data are shown in Table 3-6. Increased incidences of subcutaneous tissue fibromas or fibrosarcomas and pancreatic acinar cell adenomas occurred in male rats. In female rats, mammary gland fibroadenomas, pancreatic islet cell adenomas, and neoplastic nodules of the liver were observed; mammary gland and pancreatic tumor incidences were significantly higher than controls at both doses, while the incidence of hepatic neoplastic nodules was significantly increased only at the high dose in female rats (NTP 1986). Survival of highdose male mice was significantly lower than controls, but survival of female mice was not diminished by 
treatment (NTP 1986). Statistically significant increases in the incidence of neoplasia were observed only in high dose female mice, and included hemangiosarcomas or hemangiomas and hepatocellular adenomas or carcinomas (Table 3-6). NTP (Dieter et al. 1990) noted that the liver, mammary gland, and subcutaneous tissue tumors observed in rats and hemangiomas and liver tumors observed in mice were the same types of tumors observed in rats and mice exposed to 2,4-diaminotoluene, a known carcinogen. Dieter et al. (1990) suggested that the carcinogenic activity observed in the NTP (1986) study could be attributed to the metabolism of 2,4-TDI to products identical to those of 2,4-diaminotoluene metabolism. An industry-sponsored statistical analysis of the results of the NTP TDI study and NTP 2,4-diaminotoluene study concluded that hydrolyzation of 5\% of the TDI dose to form 2,4-aminotoluene could explain carcinogenic responses observed in the NTP TDI study (Sielken et al. 2012).

\subsubsection{Dermal Exposure}

\subsubsection{Death}

No information was located regarding deaths in humans or animals following dermal exposure to TDI or MDI.

\subsubsection{Systemic Effects}

No information was located regarding systemic effects in humans or animals following dermal exposure to TDI. Data on the dermal toxicity of MDI are limited to a human study that reported respiratory effects.

\section{Respiratory Effects.}

MDI. Workers at a newly established wood products facility with no prior exposure to MDI were asked to complete symptom questionnaires prior to beginning work and 2, 9, 14, and 20 months after production began (Petsonk et al. 2000; Wang and Petsonk 2004); the workers were exposed to liquid MDI resin.

Asthma-like symptoms were reported by 15 of the 56 workers with the highest potential for exposure to liquid MDI and prepolymer, as compared to 0 of 43 workers with the lowest exposure potential. MDIexposed workers had significantly increased odds of dyspnea with wheezing, dyspnea or cough at rest, chest tightness, and phlegm after adjusting for age, smoking, and wood dust exposure (Wang and Petsonk 2004). There were no increases in the prevalence of eye or nasal symptoms. MDI exposure was likely via the inhalation and dermal routes of exposure. The workers wore respirators; however, the incidence 
3. HEALTH EFFECTS

\section{Table 3-6. Tumor Incidences in Rats and Mice Exposed to Commercial-Grade Toluene Diisocyanate for 2 Years by Gavage ${ }^{a, b}$}

\begin{tabular}{|c|c|c|c|c|}
\hline & Control & $30 \mathrm{mg} / \mathrm{kg} / \mathrm{day}$ & $60 \mathrm{mg} / \mathrm{kg} / \mathrm{day}$ & $120 \mathrm{mg} / \mathrm{kg} / \mathrm{day}$ \\
\hline \multicolumn{5}{|l|}{ Male rats } \\
\hline Subcutaneous fibroma or fibrosarcoma & $3 / 50(6 \%)$ & $6 / 50^{\mathrm{b}}(12 \%)$ & $12 / 50^{\mathrm{b}}(24 \%)$ & Not tested \\
\hline Pancreatic acinar cell adenoma & $1 / 47(2 \%)$ & $3 / 47(6 \%)$ & $7 / 49^{b}(14 \%)$ & Not tested \\
\hline $\begin{array}{l}\text { Pancreatic islet cell adenoma or } \\
\text { carcinoma }\end{array}$ & $1 / 47(2 \%)$ & $0 / 47(0 \%)$ & $4 / 49^{b}(8 \%)$ & Not tested \\
\hline \multicolumn{5}{|l|}{ Female rats } \\
\hline Subcutaneous fibroma or fibrosarcoma & $2 / 50(4 \%)$ & Not tested & $1 / 50(2 \%)$ & $5 / 50^{\mathrm{b}}(10 \%)$ \\
\hline Mammary gland tumors & $\begin{array}{l}17 / 50 \\
(34 \%)\end{array}$ & Not tested & $25 / 50^{\mathrm{b}}(50 \%)$ & $21 / 50^{\mathrm{b}}(42 \%)$ \\
\hline Pancreatic islet cell adenoma & $0 / 50(0 \%)$ & Not tested & $6 / 49^{b}(12 \%)$ & $2 / 47(4 \%)$ \\
\hline Hepatic neoplastic nodules & $3 / 50(6 \%)$ & Not tested & $8 / 50^{\mathrm{b}}(16 \%)$ & $8 / 48^{b}(17 \%)$ \\
\hline \multicolumn{5}{|l|}{ Female mice } \\
\hline Hemangioma or hemangiosarcoma & $0 / 50(0 \%)$ & Not tested & $1 / 50(2 \%)$ & $5 / 50^{\mathrm{b}}(10 \%)$ \\
\hline Hepatocellular adenoma or carcinoma & $4 / 50(8 \%)$ & Not tested & $5 / 50(10 \%)$ & $15 / 50^{\mathrm{b}}(30 \%)$ \\
\hline
\end{tabular}

aData are presented as the number of animals with tumor per total number of animals examined in each exposure group (percentages in parentheses).

bSignificantly different from control by either life table or incidental tumor test or both, $\mathrm{p}<0.05$.

Source: NTP 1986 
of asthma symptoms was significantly higher among those who reported removing their respirator during work. The incidence of asthma symptoms was also significantly higher in workers reporting skin or clothing MDI staining (Petsonk et al. 2000).

\subsubsection{Immunological and Lymphoreticular Effects}

No information was located regarding immunological and lymphoreticular effects in humans following dermal exposure to TDI or MDI.

In mice, dermal exposure to 2,4-TDI or MDI followed by an oral challenge dose resulted in airway hyperreactivity, lung tissue hyperreactivity, and increases in serum IgE levels (Pollaris et al. 2016). However, no evidence of cross-reactivity was observed in mice exposed to 2,4-TDI and challenged with MDI or exposed to MDI and challenged with 2,4-TDI.

\subsubsection{Neurological Effects}

No information was located regarding neurological effects in humans or animals following dermal exposure to TDI or MDI.

\subsubsection{Reproductive Effects}

No information was located regarding reproductive effects in humans or animals following dermal exposure to TDI or MDI.

\subsubsection{Developmental Effects}

No information was located regarding developmental effects in humans or animals following dermal exposure to TDI or MDI.

\subsubsection{Cancer}

No information was located regarding cancer in humans or animals following dermal exposure to TDI or MDI. 


\subsection{GENOTOXICITY}

TDI. Results of in vitro genotoxicity testing of TDI are shown in Table 3-7. 2,4-TDI, 2,6-TDI, and the commercial-grade mixture (80:20 mixture of 2,4- and 2,6-TDI) have all been tested for mutagenicity in various strains of Salmonella typhimurium (Anderson and Styles 1978; Anderson et al. 1980; NTP 1986; Seel et al. 1999; Zeiger et al. 1987). All of the studies have shown negative results in the absence of metabolic activation.

All of the studies other than Seel et al. (1999) used dimethylsulfoxide (DMSO) as a solvent for the test compounds, and these studies suggested that each of the individual isomers and the mixture was mutagenic with metabolic activation in at least one strain of S. typhimurium (NTP 1986; Zeiger et al. 1987). Seel et al. (1999) showed that 2,4-TDI is not stable in DMSO (a hygroscopic solvent that increases reaction of TDI with water), and that use of this solvent yielded a variety of degradation products, including 2,4-TDA (a known mutagen), in the reaction medium. To assess the role of toluene diamines in the observed responses of TDI in these tests, Seel et al. (1999) conducted parallel mutagenicity tests using DMSO and ethylene glycol dimethylether (EGDE) as solvents and quantifying levels of TDI and TDA in the first 45 seconds after the test was started. These tests showed that 2,6-TDI was relatively more stable in EGDE than in DMSO; when DMSO was used as a solvent, only $12.3 \%$ of dose of 2,6-TDI remained at the start of mutagenicity testing, while $9.1 \%$ of the dose existed as 2,6-TDA (other reaction products were not analyzed). In contrast, when EGDE was used, 99.5\% of the dose existed as 2,6-TDI at the start of testing, with only $0.5 \%$ as 2,6-TDA (Seel et al. 1999). Analyses over time showed formation of TDA in mixtures using either DMSO or EGDE; levels of TDA were lower when EGDE was used, but not substantially lower after the first 45 seconds (2,6-TDA was 5.6\% of the TDI dose in the EGDE mixture, compared with $8.3 \%$ of the TDI dose in the DMSO mixture). These experiments indicated that mutagenicity testing of TDI using DMSO as a solvent yields unreliable results due to the conversion of TDI to TDA prior to plating.

In mutagenicity tests using EGDE as the solvent (Seel et al. 1999) and with metabolic activation, all three test materials tested positive in TA98 and TA100 and all three tested negative in TA1535. 2,4-TDI was also positive in strain TA1537, and the 80:20 mixture was weakly positive in this strain, while 2,6-TDI was negative. The authors attributed the positive and weakly positive results to the TDA formed over time even when EGDE was used. 
Table 3-7. Genotoxicity of TDI and MDI In Vitro

\begin{tabular}{|c|c|c|c|c|c|c|}
\hline \multirow[b]{2}{*}{ Species (test system) } & \multirow[b]{2}{*}{ End point } & \multicolumn{2}{|l|}{ Results } & \multirow[b]{2}{*}{ Purity } & \multirow[b]{2}{*}{ Vehicle } & \multirow[b]{2}{*}{ Reference } \\
\hline & & $\begin{array}{l}\text { With } \\
\text { activation }\end{array}$ & $\begin{array}{l}\text { Without } \\
\text { activation }\end{array}$ & & & \\
\hline \multicolumn{7}{|l|}{$2,6-T D I$} \\
\hline \multicolumn{7}{|l|}{ Prokaryotic organisms: } \\
\hline $\begin{array}{l}\text { Salmonella } \\
\text { typhimurium (TA100, } \\
\text { TA98) }\end{array}$ & $\begin{array}{l}\text { Gene } \\
\text { mutation }\end{array}$ & + & - & $94 \%$ & DMSO & $\begin{array}{l}\text { NTP 1986; Zeiger } \\
\text { et al. } 1987\end{array}$ \\
\hline $\begin{array}{l}\text { S. typhimurium } \\
\text { (TA98) }\end{array}$ & $\begin{array}{l}\text { Gene } \\
\text { mutation }\end{array}$ & + & - & NR & EGDE & Seel et al. 1999 \\
\hline $\begin{array}{l}\text { S. typhimurium } \\
\text { (TA1535, TA1537a) }\end{array}$ & $\begin{array}{l}\text { Gene } \\
\text { mutation }\end{array}$ & - & - & $94 \%$ & DMSO & $\begin{array}{l}\text { NTP 1986; Zeiger } \\
\text { et al. } 1987\end{array}$ \\
\hline $\begin{array}{l}\text { S. typhimurium } \\
\text { (TA1537) }\end{array}$ & $\begin{array}{l}\text { Gene } \\
\text { mutation }\end{array}$ & - & - & NR & EGDE & Seel et al. 1999 \\
\hline \multicolumn{7}{|l|}{ Mammalian cells: } \\
\hline $\begin{array}{l}\text { L5178Y mouse } \\
\text { lymphoma cells }\end{array}$ & $\begin{array}{l}\text { Gene } \\
\text { mutation }\end{array}$ & + & + & NR & DMSO & $\begin{array}{l}\text { McGregor et al. } \\
1991\end{array}$ \\
\hline $\begin{array}{l}\text { Chinese hamster } \\
\text { ovary cells }\end{array}$ & $\begin{array}{l}\text { Sister } \\
\text { chromatid } \\
\text { exchange }\end{array}$ & - & + & $99 \%$ & DMSO & Gulati et al. 1989 \\
\hline $\begin{array}{l}\text { Chinese hamster } \\
\text { ovary cells }\end{array}$ & $\begin{array}{l}\text { Chromosomal } \\
\text { aberrations }\end{array}$ & - & + & $99 \%$ & DMSO & Gulati et al. 1989 \\
\hline \multicolumn{7}{|l|}{ 2,4-TDI } \\
\hline \multicolumn{7}{|l|}{ Prokaryotic organisms: } \\
\hline $\begin{array}{l}\text { S. typhimurium } \\
\text { (TA100, TA98) }\end{array}$ & $\begin{array}{l}\text { Gene } \\
\text { mutation }\end{array}$ & + & - & $99 \%$ & DMSO & Zeiger et al. 1987 \\
\hline $\begin{array}{l}\text { S. typhimurium } \\
\text { (TA1535, TA97) }\end{array}$ & $\begin{array}{l}\text { Gene } \\
\text { mutation }\end{array}$ & $(+/-)$ & - & $99 \%$ & DMSO & Zeiger et al. 1987 \\
\hline $\begin{array}{l}\text { S. typhimurium } \\
\text { (TA98, TA100, } \\
\text { TA1535, TA1538) }\end{array}$ & $\begin{array}{l}\text { Gene } \\
\text { mutation }\end{array}$ & - & NT & NR & DMSO & $\begin{array}{l}\text { Anderson and } \\
\text { Styles } 1978\end{array}$ \\
\hline $\begin{array}{l}\text { S. typhimurium } \\
\text { (TA1537, TA98) }\end{array}$ & $\begin{array}{l}\text { Gene } \\
\text { mutation }\end{array}$ & + & - & NR & EGDE & Seel et al. 1999 \\
\hline \multicolumn{7}{|l|}{ Mammalian cells: } \\
\hline $\begin{array}{l}\text { L5178Y mouse } \\
\text { lymphoma cells }\end{array}$ & $\begin{array}{l}\text { Gene } \\
\text { mutation }\end{array}$ & + & + & NR & DMSO & $\begin{array}{l}\text { McGregor et al. } \\
1991\end{array}$ \\
\hline $\begin{array}{l}\text { Chinese hamster } \\
\text { ovary cells }\end{array}$ & $\begin{array}{l}\text { Sister } \\
\text { chromatid } \\
\text { exchange }\end{array}$ & - & $(+/-)$ & $94 \%$ & DMSO & Gulati et al. 1989 \\
\hline $\begin{array}{l}\text { Chinese hamster } \\
\text { ovary cells }\end{array}$ & $\begin{array}{l}\text { Chromosomal } \\
\text { aberrations }\end{array}$ & - & - & $94 \%$ & DMSO & Gulati et al. 1989 \\
\hline
\end{tabular}


Table 3-7. Genotoxicity of TDI and MDI In Vitro

\begin{tabular}{|c|c|c|c|c|c|c|}
\hline \multirow[b]{2}{*}{ Species (test system) } & \multirow[b]{2}{*}{ End point } & \multicolumn{2}{|l|}{ Results } & \multirow[b]{2}{*}{ Purity } & \multirow[b]{2}{*}{ Vehicle } & \multirow[b]{2}{*}{ Reference } \\
\hline & & $\begin{array}{l}\text { With } \\
\text { activation }\end{array}$ & $\begin{array}{l}\text { Without } \\
\text { activation }\end{array}$ & & & \\
\hline \multicolumn{7}{|c|}{ Commercial-grade 2,4- and 2,6-TDI (80:20 mixture) } \\
\hline \multicolumn{7}{|l|}{ Prokaryotic organisms: } \\
\hline $\begin{array}{l}\text { S. typhimurium } \\
\text { (TA100, TA98) }\end{array}$ & $\begin{array}{l}\text { Gene } \\
\text { mutation }\end{array}$ & + & - & $\begin{array}{l}\text { Commercial } \\
\text { grade }\end{array}$ & DMSO & $\begin{array}{l}\text { NTP 1986; Zeiger } \\
\text { et al. } 1987\end{array}$ \\
\hline $\begin{array}{l}\text { S. typhimurium } \\
\text { (TA100, TA98, } \\
\text { TA1537) }\end{array}$ & $\begin{array}{l}\text { Gene } \\
\text { mutation }\end{array}$ & + & - & $\begin{array}{l}\text { Commercial } \\
\text { grade }\end{array}$ & EGDE & Seel et al. 1999 \\
\hline $\begin{array}{l}\text { S. typhimurium } \\
\text { (TA100, TA98, } \\
\text { TA1538) }\end{array}$ & $\begin{array}{l}\text { Gene } \\
\text { mutation }\end{array}$ & + & - & $\begin{array}{l}\text { Commercial } \\
\text { grade }\end{array}$ & DMSO & $\begin{array}{l}\text { Anderson et al. } \\
1980\end{array}$ \\
\hline $\begin{array}{l}\text { S. typhimurium } \\
\text { (TA1537) }\end{array}$ & $\begin{array}{l}\text { Gene } \\
\text { mutation }\end{array}$ & - & - & $\begin{array}{l}\text { Commercial } \\
\text { grade }\end{array}$ & DMSO & $\begin{array}{l}\text { Anderson et al. } \\
1980\end{array}$ \\
\hline $\begin{array}{l}\text { S. typhimurium } \\
\text { (TA1535, TA1537) }\end{array}$ & $\begin{array}{l}\text { Gene } \\
\text { mutation }\end{array}$ & - & - & $\begin{array}{l}\text { Commercial } \\
\text { grade }\end{array}$ & DMSO & $\begin{array}{l}\text { NTP 1986; Zeiger } \\
\text { et al. } 1987\end{array}$ \\
\hline \multicolumn{7}{|l|}{ Mammalian cells: } \\
\hline $\begin{array}{l}\text { F-344 rat hepatocyte } \\
\text { primary cultures }\end{array}$ & $\begin{array}{l}\text { Unscheduled } \\
\text { DNA } \\
\text { synthesis }\end{array}$ & - & - & $N R$ & DMSO & $\begin{array}{l}\text { Shaddock et al. } \\
1990\end{array}$ \\
\hline \multicolumn{7}{|l|}{ 4,4'-MDI (monomer) } \\
\hline \multicolumn{7}{|l|}{ Prokaryotic organisms: } \\
\hline $\begin{array}{l}\text { S. typhimurium } \\
\text { (TA100, TA98) }\end{array}$ & $\begin{array}{l}\text { Gene } \\
\text { mutation }\end{array}$ & + & - & NR & DMSO & Herbold et al. 1998 \\
\hline $\begin{array}{l}\text { S. typhimurium } \\
\text { (TA100, TA98) }\end{array}$ & $\begin{array}{l}\text { Gene } \\
\text { mutation }\end{array}$ & + & - & $98 \%$ & DMSO & Shimizu et al. 1985 \\
\hline $\begin{array}{l}\text { S. typhimurium } \\
\text { (TA100, TA98) }\end{array}$ & $\begin{array}{l}\text { Gene } \\
\text { mutation }\end{array}$ & + & - & $\begin{array}{l}\text { Commercial } \\
\text { grade }\end{array}$ & DMSO & $\begin{array}{l}\text { Anderson et al. } \\
1980\end{array}$ \\
\hline $\begin{array}{l}\text { S. typhimurium } \\
\text { (TA100, TA98) }\end{array}$ & $\begin{array}{l}\text { Gene } \\
\text { mutation }\end{array}$ & - & - & NR & EGDE & Herbold et al. 1998 \\
\hline $\begin{array}{l}\text { S. typhimurium } \\
\text { (TA1535, TA1537, } \\
\text { TA1538) }\end{array}$ & $\begin{array}{l}\text { Gene } \\
\text { mutation }\end{array}$ & - & - & $98 \%$ & DMSO & Shimizu et al. 1985 \\
\hline $\begin{array}{l}\text { S. typhimurium } \\
\text { (TA1535, TA1537) }\end{array}$ & $\begin{array}{l}\text { Gene } \\
\text { mutation }\end{array}$ & - & - & NR & $\begin{array}{l}\text { DMSO, } \\
\text { EGDE }\end{array}$ & Herbold et al. 1998 \\
\hline $\begin{array}{l}\text { S. typhimurium } \\
\text { (TA1537) }\end{array}$ & $\begin{array}{l}\text { Gene } \\
\text { mutation }\end{array}$ & - & - & $\begin{array}{l}\text { Commercial } \\
\text { grade }\end{array}$ & DMSO & $\begin{array}{l}\text { Anderson et al. } \\
1980\end{array}$ \\
\hline \multicolumn{7}{|l|}{ Mammalian cells: } \\
\hline $\begin{array}{l}\text { Human lung } \\
\text { epithelial cells } \\
\text { (A549) }\end{array}$ & $\begin{array}{l}\text { DNA double- } \\
\text { strand breaks }\end{array}$ & NT & $-(c)$ & NR & EGDE & Vock et al. 1998 \\
\hline
\end{tabular}


Table 3-7. Genotoxicity of TDI and MDI In Vitro

\begin{tabular}{|c|c|c|c|c|c|c|}
\hline \multirow[b]{2}{*}{ Species (test system) } & \multirow[b]{2}{*}{ End point } & \multicolumn{2}{|l|}{ Results } & \multirow[b]{2}{*}{ Purity } & \multirow[b]{2}{*}{ Vehicle } & \multirow[b]{2}{*}{ Reference } \\
\hline & & $\begin{array}{l}\text { With } \\
\text { activation }\end{array}$ & $\begin{array}{l}\text { Without } \\
\text { activation }\end{array}$ & & & \\
\hline \multicolumn{7}{|l|}{$2,4-M D I$} \\
\hline $\begin{array}{l}\text { S. typhimurium } \\
\text { (TA98, TA1538) }\end{array}$ & $\begin{array}{l}\text { Gene } \\
\text { mutation }\end{array}$ & + & - & NR & DMSO & Herbold et al. 1998 \\
\hline $\begin{array}{l}\text { S. typhimurium } \\
\text { (TA98, TA1538) }\end{array}$ & $\begin{array}{l}\text { Gene } \\
\text { mutation }\end{array}$ & - & - & NR & EGDE & Herbold et al. 1998 \\
\hline $\begin{array}{l}\text { S. typhimurium } \\
\text { (TA100) }\end{array}$ & $\begin{array}{l}\text { Gene } \\
\text { mutation }\end{array}$ & - & - & NR & $\begin{array}{l}\text { DMSO, } \\
\text { EGDE }\end{array}$ & Herbold et al. 1998 \\
\hline \multicolumn{7}{|c|}{ Mixture of isomers monomeric MDI (4,4'-, 2,4'-, and 2,2'-) } \\
\hline $\begin{array}{l}\text { S. typhimurium } \\
\text { (TA100, TA98) }\end{array}$ & $\begin{array}{l}\text { Gene } \\
\text { mutation }\end{array}$ & + & - & NR & DMSO & Herbold et al. 1998 \\
\hline $\begin{array}{l}\text { S. typhimurium } \\
\text { (TA100, TA98, } \\
\text { TA1535, TA1537) }\end{array}$ & $\begin{array}{l}\text { Gene } \\
\text { mutation }\end{array}$ & - & - & NR & EGDE & Herbold et al. 1998 \\
\hline $\begin{array}{l}\text { S. typhimurium } \\
\text { (TA1535, TA1537) }\end{array}$ & $\begin{array}{l}\text { Gene } \\
\text { mutation }\end{array}$ & - & - & NR & DMSO & Herbold et al. 1998 \\
\hline \multicolumn{7}{|l|}{ Polymeric MDI } \\
\hline $\begin{array}{l}\text { S. typhimurium } \\
\text { (TA100, TA98) }\end{array}$ & $\begin{array}{l}\text { Gene } \\
\text { mutation }\end{array}$ & + & - & $N R$ & DMSO & Herbold et al. 1998 \\
\hline $\begin{array}{l}\text { S. typhimurium } \\
\text { (TA100, TA98, } \\
\text { TA1535, TA1537) }\end{array}$ & $\begin{array}{l}\text { Gene } \\
\text { mutation }\end{array}$ & - & - & NR & EGDE & Herbold et al. 1998 \\
\hline $\begin{array}{l}\text { S. typhimurium } \\
\text { (TA1535, TA1537) }\end{array}$ & $\begin{array}{l}\text { Gene } \\
\text { mutation }\end{array}$ & - & - & NR & DMSO & Herbold et al. 1998 \\
\hline
\end{tabular}

aZeiger et al. (1987) incorrectly show the tested strain as TA97; the data shown are identical to those shown for TA1537 in the original report (NTP 1986).

$-=$ negative result; $+/-=$ mixed results; $+=$ positive result; $-(\mathrm{c})$; positive only at cytotoxic concentrations; DMSO = dimethylsulfoxide; DNA = deoxyribonucleic acid; EGDE = ethylene glycol dimethylether; $\mathrm{MDI}=$ methylenediphenyl diisocyanate; NR = not reported; NT = not tested; TDI = toluene diisocyanate 
Experiments conducted by Seel et al. (1999) also included using two different S9 microsome quantities: 10 and 30\%. The authors observed that the mutagenic responses were slightly diminished in the tests with higher S9 content, and postulated that the higher protein content in the 30\% S9 mix provided alternative substrates for TDI reaction, yielding relatively lower amounts of the mutagenic TDA degradation products.

TDI has also been tested in mammalian cell systems for mutagenicity (McGregor et al. 1991), chromosomal aberrations, and sister chromatid exchanges (Gulati et al. 1989), as well as unscheduled DNA synthesis (Shaddock et al. 1990), as shown in Table 3-7. All of the tests used DMSO as the test material solvent.

Only commercial-grade TDI has been tested for in vivo genotoxicity (see Table 3-8); data on the individual isomers are not available. In workers exposed occupationally to TDI $\left(0.007-0.016 \mathrm{mg} / \mathrm{m}^{3}\right)$ during plastic production, significantly increased numbers of sister chromatid exchanges, micronuclei, and structural chromosomal aberrations were observed in peripheral blood lymphocytes, when compared with unexposed persons from the same geographic area (Bilban et al. 2004). The study did not adjust for the statistically significant differences in average age and smoking index (number of cigarettes smoked per day per years of smoking) between the exposed and unexposed groups; the exposed group was older and had a higher smoking index. In a controlled exposure experiment, Marczynski et al. (2005) compared the frequency of DNA strand breaks in lymphocytes before and after exposure of 5 workers with prior diisocyanate exposure and airway symptoms and 10 subjects without prior exposure but with asthma or bronchial hyperresponsiveness. The subjects were exposed to industrial-grade TDI (80:20 mixture of 2,4- and 2,6-TDI) in the following sequence: 30 minutes at $5 \mathrm{ppb}, 30$ minutes at $10 \mathrm{ppb}, 90$-minute break, 30 minutes at $20 \mathrm{ppb}, 90$-minute break, and ending with 30 minutes at $30 \mathrm{ppb}$. Blood was sampled for use in the comet assay before as well as 30 minutes and 19 hours after the end of exposure. Blood was also collected at the same time points from a group of 10 healthy subjects who were not subjected to any exposure. Mean values of the olive tail moment before and after exposure did not differ significantly, nor were there significant differences between the groups. In workers exposed to isocyanates, primarily TDI and MDI (mean TDI levels ranged from $<1$ to $60 \mu \mathrm{g} / \mathrm{m}^{3}$ ), and several tertiary amines, no significant increases in chromosomal aberrations, sister chromatid exchanges, or micronuclei frequency in peripheral lymphocytes were observed, as compared to a referent group (Holmen et al. 1988). Exposing S. typhimurium T98 or E. coli WP2 uvrA to urinary samples from the exposed workers did not result in increases in mutagenic activity. 
Table 3-8. Genotoxicity of TDI and MDI In Vivo

\begin{tabular}{|c|c|c|c|c|c|}
\hline Species (test system) & End point & Results & Purity or grade & $\begin{array}{l}\text { Route of } \\
\text { exposure }\end{array}$ & Reference \\
\hline \multicolumn{6}{|l|}{$2,6-T D I$} \\
\hline \multicolumn{6}{|l|}{ No data } \\
\hline \multicolumn{6}{|l|}{ 2,4-TDI } \\
\hline \multicolumn{6}{|l|}{ No data } \\
\hline \multicolumn{6}{|c|}{ Commercial-grade 2,4- and 2,6-TDI (80:20 mixture) } \\
\hline \multicolumn{6}{|l|}{ Humans } \\
\hline $\begin{array}{l}\text { Peripheral blood } \\
\text { lymphocytes }\end{array}$ & Micronuclei & + & NA & Inhalation & Bilban 2004 \\
\hline $\begin{array}{l}\text { Peripheral blood } \\
\text { lymphocytes }\end{array}$ & $\begin{array}{l}\text { Structural } \\
\text { chromosomal } \\
\text { aberrations }\end{array}$ & + & NA & Inhalation & Bilban 2004 \\
\hline $\begin{array}{l}\text { Peripheral blood } \\
\text { lymphocytes }\end{array}$ & $\begin{array}{l}\text { Sister chromatid } \\
\text { exchange }\end{array}$ & + & NA & Inhalation & Bilban 2004 \\
\hline $\begin{array}{l}\text { Peripheral blood } \\
\text { lymphocytes }\end{array}$ & DNA strand breaks & - & $\begin{array}{l}\text { Industrial } \\
\text { grade }\end{array}$ & Inhalation & $\begin{array}{l}\text { Marczynski et al. } \\
2005\end{array}$ \\
\hline \multicolumn{6}{|l|}{ Non-human mammals } \\
\hline Mouse bone marrow & Micronuclei & - & $\begin{array}{l}\text { Production } \\
\text { grade }\end{array}$ & Inhalation & Loeser et al. 1983 \\
\hline Mouse bone marrow & $\begin{array}{l}\text { Micronucleated } \\
\text { PCEs }\end{array}$ & - & NR & Inhalation & Lindberg et al. 2011 \\
\hline Mouse bone marrow & $\begin{array}{l}\text { Chromosomal } \\
\text { aberrations }\end{array}$ & + & $95 \%$ & Inhalation & Ji et al. 2008 \\
\hline Mouse bone marrow & $\begin{array}{l}\text { Sister chromatid } \\
\text { exchange }\end{array}$ & + & $95 \%$ & Inhalation & Ji et al. 2008 \\
\hline $\begin{array}{l}\text { Mouse peripheral } \\
\text { blood }\end{array}$ & $\begin{array}{l}\text { Micronucleated } \\
\text { PCEs }\end{array}$ & - & NR & Inhalation & Lindberg et al. 2011 \\
\hline Rat bone marrow & Micronuclei & - & $\begin{array}{l}\text { Production } \\
\text { grade }\end{array}$ & inhalation & Loeser et al. 1983 \\
\hline \multicolumn{6}{|l|}{ Non-mammalian systems } \\
\hline $\begin{array}{l}\text { Drosophila } \\
\text { melanogaster post- } \\
\text { meiotic and meiotic } \\
\text { germ cells }\end{array}$ & $\begin{array}{l}\text { Sex-linked recessive } \\
\text { lethal mutation }\end{array}$ & + & $99 \%$ & $\begin{array}{l}\text { Feeding } \\
\text { (ethanol } \\
\text { vehicle) }\end{array}$ & $\begin{array}{l}\text { Foureman et al. } \\
1994\end{array}$ \\
\hline $\begin{array}{l}\text { D. melanogaster post- } \\
\text { meiotic and meiotic } \\
\text { germ cells }\end{array}$ & Translocation & + & $99 \%$ & $\begin{array}{l}\text { Feeding } \\
\text { (ethanol } \\
\text { vehicle) }\end{array}$ & $\begin{array}{l}\text { Foureman et al. } \\
1994\end{array}$ \\
\hline
\end{tabular}


Table 3-8. Genotoxicity of TDI and MDI In Vivo

\begin{tabular}{|c|c|c|c|c|c|}
\hline Species (test system) & End point & Results & Purity or grade & $\begin{array}{l}\text { Route of } \\
\text { exposure }\end{array}$ & Reference \\
\hline \multicolumn{6}{|l|}{ 4,4'-MDI (monomer) } \\
\hline $\begin{array}{l}\text { Peripheral blood } \\
\text { lymphocytes }\end{array}$ & DNA strand breaks & - & $\begin{array}{l}\text { Industrial } \\
\text { grade: } 60 \% \\
\text { methylene- } \\
\text { diphenyl } \\
\text { diisocyanate, } \\
30 \% \text { triiso- } \\
\text { cyanates, } 10 \% \\
\text { diisocyanates }\end{array}$ & Inhalation & $\begin{array}{l}\text { Marczynski et al. } \\
2005\end{array}$ \\
\hline Mouse bone marrow & $\begin{array}{l}\text { Micronucleated } \\
\text { PCEs }\end{array}$ & - & $98 \%$ & Inhalation & Lindberg et al. 2011 \\
\hline $\begin{array}{l}\text { Mouse peripheral } \\
\text { blood }\end{array}$ & $\begin{array}{l}\text { Micronucleated } \\
\text { PCEs }\end{array}$ & - & $98 \%$ & Inhalation & Lindberg et al. 2011 \\
\hline Rat bone marrow & $\begin{array}{l}\text { Micronucleated } \\
\text { PCEs }\end{array}$ & + & & Inhalation & $\begin{array}{l}\text { Zhong and Siegel } \\
2000\end{array}$ \\
\hline Rat bone marrow & Micronuclei & - & $99 \%$ & Inhalation & Pauluhn et al. 2001 \\
\hline $\begin{array}{l}\text { Rat epidermis and } \\
\text { liver }\end{array}$ & $\begin{array}{l}\text { DNA adduct } \\
\text { formation }\end{array}$ & - & NR & Dermal & Vock and Lutz 1997 \\
\hline Rat epidermis & $\begin{array}{l}\text { DNA adduct } \\
\text { formation }\end{array}$ & - & NR & Dermal & Vock et al. 1995 \\
\hline
\end{tabular}

- = negative result; + = positive result; $(+/-)=$ mixed results; DNA = deoxyribonucleic acid; MDI = methylenediphenyl diisocyanate; NA = not applicable; NR = not reported; NT = not tested; PCE = polychromated erythrocyte;

TDI = toluene diisocyanate 
Lindberg et al. (2011) observed no increase in the frequency of micronucleated polychromatic erythrocytes (PCEs) in mouse bone marrow or peripheral blood after five daily 1-hour periods of exposure to TDI vapor (63\% 2,4-TDI and 37\% 2,6-TDI) at concentrations up to $2.4 \mathrm{mg} / \mathrm{m}^{3}$ (0.34 ppm). Similarly, Loeser et al. (1983) did not observe an increase in micronucleated erythrocytes in bone marrow of rats or mice exposed for 4 weeks to vapor concentrations of $0,0.05$, or $0.15 \mathrm{ppm}, 6$ hours/day for 5 days/week. Ji et al. (2008) reported a significant increase in the frequencies of chromosomal aberrations and sister chromatid exchanges in bone marrow of mice exposed for 4 hours/day on 14 consecutive days to TDI vapor (composition not specified, but reported as $95 \%$ pure) at a concentration characterized as one-fourth of the $\mathrm{LC}_{50}$ (no other exposure details were provided). However, given the lack of study details, especially the absence of information on exposure concentration, the results reported by Ji et al. (2008) cannot be evaluated in the context of the other available data.

In in vivo tests of sex-linked recessive lethal mutation and translocation using male Drosophila exposed by feeding, commercial-grade TDI (mixture of 2,4- and 2,6- isomers of unknown composition, administered in ethanol) yielded positive results (Foureman et al. 1994).

MDI. Studies of the in vitro genotoxicity of MDI are shown in Table 3-7. As was seen with experiments on TDI, stability testing of MDI in DMSO showed diminished levels of free MDI as a function of time in the solvent (Herbold et al. 1998). However, in contrast to TDI, the rate of MDI degradation in both DMSO and EGDE was much slower. In fact, MDI was stable in EGDE; even in the presence of $12.78 \mathrm{mM}$ water, $<1 \%$ of the tested mass of MDI (tested as 4,4'-MDI, monomeric MDI isomers, and polymeric MDI) had degraded after 4 hours (Herbold et al. 1998). Consistent with its greater stability in EGDE, MDI was uniformly negative in mutagenicity testing using this solvent (Herbold et al. 1998), while positive results (in TA98 and TA100 for monomeric and polymeric MDI and 4,4'-MDI and in TA1538 for 2,4-MDI) were observed when DMSO was used as the solvent (Anderson et al. 1980; Herbold et al. 1998; Shimizu et al. 1985).

Only 4,4'-MDI has been tested for genotoxicity in mammalian cells; Vock et al. (1998) observed doublestrand DNA breaks in human lung epithelial cells (A549) at 4,4'-MDI concentrations (in EGDE) that were cytotoxic. The authors noted that cytotoxicity in the test system was exacerbated both by the slight toxicity of the EGDE solvent and by the lack of nutrients and growth factors in the test solution (phosphate-buffered saline was used instead of growth medium to minimize reaction between MDI and 
medium constituents like proteins). The study authors concluded that the observed DNA damage was a function of cytotoxicity rather than direct genotoxicity.

Likewise, 4,4'-MDI is the only isomer or composition that has been tested for genotoxicity in in vivo systems (Table 3-8). Marczynski et al. (2005) assessed the potential of MDI to induce DNA strand breaks. MDI workers $(n=25)$ and controls $(n=10)$ were exposed to 4,4'-MDI in the same sequences as the TDI study: 30-minute exposure to $5 \mathrm{ppb}, 30$-minute exposure to $10 \mathrm{ppb}, 90$-minute break, 30-minute exposure to $20 \mathrm{ppb}$, 90-minute break, and 30-minute exposure to $30 \mathrm{ppb}$. 4,4'-MDI exposure did not significantly increase DNA strand breaks, as assessed using olive tail moment comet assay. Lindberg et al. (2011) observed no increase in the frequency of micronucleated PCEs in mouse bone marrow or peripheral blood after five daily 1-hour periods of exposure to 4,4'-MDI aerosol at concentrations up to $23.3 \mathrm{mg} / \mathrm{m}^{3}$. Zhong and Siegel (2000) reported a concentration-dependent increase in the frequency of micronucleated PCEs in the bone marrow of male Brown-Norway rats 7 days following exposure to 4,4'-MDI. The rats were exposed for 3 weeks, 1 hour/week to concentrations of 7 and $113 \mathrm{mg} / \mathrm{m}^{3}$ 4,4'-MDI aerosol. Pauluhn et al. (2001) also exposed male Brown-Norway rats for 1 hour/week for 3 weeks at concentrations up to $118 \mathrm{mg} / \mathrm{m}^{3}$ of 4,4'-MDI aerosol. Pauluhn et al. (2001) sacrificed the rats on post-exposure days 1,2, and 7; no increase in micronucleated PCEs was seen at any time point. Vock and colleagues (Vock and Lutz 1997; Vock et al. 1995) observed minimal to no induction of isocyanateDNA adducts (assessed by ${ }^{32} \mathrm{P}$ postlabelling) in the skin liver, kidney, lung, and bladder of female Wistar rats exposed to 6.9-9 $\mathrm{mg} 4,4$ '-MDI in acetone via topical application.

\subsection{TOXICOKINETICS}

Both TDI and MDI combine readily with biological macromolecules including hemoglobin, albumin, and others. As a consequence of their reactivity, these compounds or their reaction products are often found at higher concentrations at the site of entry into the body early in exposure, and may continue to be distributed from the site of entry long after exposure has terminated.

Many studies in humans and laboratory animals use levels of diamines (TDA or methylenediphenyl diamine [MDA]) as a biomarker to evaluate TDI and MDI toxicokinetic properties. Most studies are not measuring free TDA or MDA levels that are the result of TDI or MDI metabolism. Rather, the studies are treating the plasma and urine samples with acids or bases to hydrolyze the diisocyanate-protein or diamine-protein conjugates and acetylated diamines, resulting in the formation of free diamine (Sennbro et al. 2004; Sepai et al. 1995). 
TDI is absorbed after human exposure, but available data are not adequate to permit estimation of the rate or extent of absorption. In rats, absorption of inhaled 2,4-TDI was estimated to be between 61 and $90 \%$ (Timchalk et al. 1994). One study in rats exposed to monomeric 4,4'-MDI as an aerosol estimated that $32 \%$ of an inhaled dose of $0.078 \mathrm{mg}$ was systemically available (Gledhill et al. 2005). Limited data are available on the oral absorption of TDI or MDI. Following gavage administration of 2,4-TDI, 12-20\% of the dose was absorbed (Timchalk et al. 1994); no data on the oral absorption of MDI are available. There is evidence that both TDI and MDI are absorbed across the skin to some extent, but the available data do not provide clear estimates of the rate or extent of absorption.

Once absorbed into the body, TDI is bound to macromolecules, forming adducts with hemoglobin, albumin, glutathione, and other macromolecules. The binding of TDI to glutathione appears to be reversible (Day et al. 1997), and may represent a mechanism by which TDI is transported between tissues. After inhalation (Kennedy et al. 1994; Timchalk et al. 1994) and gavage administration (Timchalk et al. 1994) exposure of rats to radiolabeled TDI, radioactivity was detected in a number of tissues, albeit at low levels. Systemic distribution of low levels of radioactivity has also been observed after inhalation (Gledhill et al. 2005) and dermal exposure (Vock et al. 1997) of rats to radiolabeled MDI.

The metabolic fate of TDI depends on the exposure route. After oral exposure, TDI is hydrolyzed in the gastrointestinal tract to TDA, and subsequently either absorbed and metabolized further or reacted with unhydrolyzed TDI to form polyurea polymers that pass unabsorbed through the gastrointestinal tract. However, after inhalation exposure, the primary fate of TDI appears to be conjugation reactions; little to no TDI is hydrolyzed to TDA. Little information on the metabolism of MDI was located; the single available study (Gledhill et al. 2005) indicated that after inhalation exposure of rats to MDI aerosol, the primary metabolites in the urine and bile were $\mathrm{N}$-acetylated and $\mathrm{N}$-acetylated hydroxylated products of MDI, and the primary product in feces is believed to be mixed molecular weight polyureas resulting from spontaneous reaction of MDI.

In humans exposed experimentally, TDA levels in hydrolyzed urine exhibits a biphasic pattern, with an initial rapid phase followed by a slower phase. The primary route of TDI elimination after inhalation or oral exposure of rats is via the feces, which may include material absorbed and excreted via the bile. Data on the elimination of MDI are limited. Like TDI, MDI is excreted primarily in the feces of rats after inhalation exposure, and there is evidence for biliary excretion of MDI. No studies of MDI elimination after oral exposure were located in the available literature. 


\subsubsection{Absorption}

\subsubsection{Inhalation Exposure}

TDI. Two studies reporting urinary concentrations of diisocyanate-derived amines in volunteers exposed to mixtures of TDI in exposure chambers showed absorption of both the 2,4- and 2,6-TDI isomers (Brorson et al. 1991; Skarping et al. 1991). These studies show that at least 20\%, and possibly more, of an inhaled dose of TDI is absorbed, based on analysis of TDA levels in hydrolyzed urine. Brorson et al. (1991) exposed each of two men to a mixture of 70\% 2,6-TDI with 30\% 2,4-TDI in an exposure chamber at concentrations of 25,50 , and $70 \mu \mathrm{g} / \mathrm{m}^{3}$ for 4-hour periods. Hydrolyzed plasma samples collected immediately after exposure showed detectable levels of 2,4-TDA after exposure to the highest concentration and detectable levels of 2,6-TDA after exposure to 50 and $70 \mu \mathrm{g} / \mathrm{m}^{3}$. Analysis of 24-hour hydrolyzed urine samples showed excretion of 2,4-TDA estimated to represent $14-19 \%$ of the inhaled 2,4-TDI dose and levels of 2,6-TDA estimated to represent 17-23\% of the inhaled 2,6-TDI dose. In another experiment, Skarping et al. (1991) exposed five men to a mixture of 52\% 2,6-TDI and 48\% 2,4-TDI at a concentration of 36 to $43 \mu \mathrm{g} / \mathrm{m}^{3}$ for 7.5 hours, and measured TDA levels in hydrolyzed urine samples. Urinary levels of 2,4-TDA was estimated to represent $8-14 \%$ of the inhaled dose of 2,4-TDI and urinary levels of 2,6-TDA was estimated to represent $14-18 \%$ of the inhaled 2,6-TDI dose. As these urinary excretion levels reflected only the first 24-28 hours of excretion and fecal levels of TDI were not measured, the total absorption of 2,4- and 2,6-TDI may have been higher than estimated.

The results of a study in male F344 rats exposed to ${ }^{14} \mathrm{C}$ ring-labeled 2,4-TDI vapor (2 ppm) via inhalation for 4 hours suggest that approximately $61-90 \%$ of the radioactivity was absorbed; the remaining radioactivity was likely rapidly cleared from the respiratory tract and swallowed (Timchalk et al. 1994).

Using guinea pigs, Kennedy et al. (1989) showed a linear relationship between ${ }^{14} \mathrm{C}$ TDI exposure concentrations multiplied by exposure duration and radioactivity levels in blood samples taken immediately after 1 -hour exposure to concentrations ranging from 0.0005 to $0.146 \mathrm{ppm}$, suggesting that absorption via the lung is not saturable in this concentration range. Blood samples taken during exposure via arterial cannula showed steady, essentially linear uptake during the 60-minute exposure period (Kennedy et al. 1989).

MDI. A single study examined the toxicokinetics of inhaled MDI in rats (Gledhill et al. 2005). The male Wistar rats were exposed, head only, to ${ }^{14} \mathrm{C}-4,4$ '-MDI (monomeric, as a condensation aerosol) at a 
concentration of $2 \mathrm{mg} / \mathrm{m}^{3}$ for 6 hours. A separate group of bile-cannulated rats was similarly exposed. Using data on urinary, biliary, and fecal excretion as well as radioactivity in the carcass measured 168 hours after exposure, the authors estimated that approximately $32 \%$ of the inhaled dose (calculated to be equivalent to $0.078 \mathrm{mg}$ MDI per animal) was systemically available.

\subsubsection{Oral Exposure}

TDI. The absorption of TDI after oral exposure has only been examined in one gavage administration study. Timchalk et al. (1994) administered a single gavage dose of ${ }^{14} \mathrm{C}$ ring-labeled 2,4-TDI (60 mg/kg) to male F344 rats and analyzed excreta collected over the next 48 hours for radioactivity. Based on the measured radioactivity in the urine and carcass, at least $12 \%$ of the oral dose was absorbed; the investigators suggested that another $8 \%$ may have been eliminated through biliary excretion into the feces (Timchalk et al. 1994). It was also suggested that the radioactivity was absorbed as ${ }^{14} \mathrm{C}-2,4-\mathrm{TDA}$ rather than as the parent compound. TDI absorption is likely to differ between ingestion and gavage administration due to differences in the $\mathrm{pH}$ of the oral cavity and stomach. Installation of TDI directly into the acidic stomach is likely to favor the formation of TDA, ureas, and polyureas. Comparatively, the neutral $\mathrm{pH}$ of the oral cavity would likely favor the binding of TDI to macromolecules and the formation of urea and polyureas.

MDI. No data on the absorption of MDI after oral exposure were located in the available literature.

\subsubsection{Dermal Exposure}

TDI. The limited available data demonstrate that TDI is absorbed across the skin, but the data are not adequate to estimate the rate and extent of absorption. Hoffman et al. (2010) detected $<1 \%$ of a dermallyapplied dose of $350 \mathrm{mg} / \mathrm{kg}$ body weight $\left(12 \mathrm{mg} / \mathrm{cm}^{2}\right){ }^{14} \mathrm{C}-2,4-\mathrm{TDI}$ in the urine, plasma, and carcasses of male rats exposed for $0.5,1$, or 8 hours; no detectable radioactivity was found in the feces. However, the animals were sacrificed immediately after exposure. Yeh et al. (2008) demonstrated dermal absorption of 2,4- and 2,6-TDI in male rats by measuring TDA levels in hydrolyzed urine for 6 days after a 5-hour dermal exposure to commercial-grade TDI at concentrations of $0.2,1$, and $5 \%$. The maximum concentration in urine, as well as the area under the urinary concentration versus time curve both showed dose-related increases, providing evidence for dermal absorption.

MDI. Henriks-Eckerman et al. (2015) suggested that a comparison between urinary acetylated MDA levels at the end of the workshift to levels after a day off from work provides evidence of dermal 
absorption of MDI since the workers wore respiratory protection. However, the investigators also noted that respiratory protection only reduced the inhalable amount by $60 \%$.

When male rats were exposed to a topical dose of 15 or $165 \mathrm{mg} / \mathrm{kg}{ }^{14} \mathrm{C}-4,4$ '-MDI and sacrificed at the end of the 8-hour exposure, or 24 or 120 hours after the commencement of exposure, $<1 \%$ of the applied radioactivity was detected in the urine, feces, tissues, gut and its contents, and carcass (Hoffman et al. 2010). At both doses, the estimated amount of 4,4'-MDI absorbed was higher in rats sacrificed at later time points; for example, absorbed amounts were estimated to be $0.21,0.66$, and $0.88 \%$ of the applied dose of $165 \mathrm{mg} / \mathrm{kg}$ in rats sacrificed at 8, 24, and 120 hours after the beginning of exposure, respectively. However, in female rats exposed to topical doses of $\sim 30 \mathrm{mg} / \mathrm{kg}{ }^{14} \mathrm{C}-4,4^{\prime}-\mathrm{MDI}$ for 48 hours, 29-30\% of the applied radioactivity was recovered in the feces during the first 48 hours after treatment, indicating significant dermal uptake (Vock and Lutz 1997). It is not clear whether the greater absorption suggested by the study by Vock and Lutz (1997) reflects a gender difference or an impact of longer exposure, or whether the rats in that study had unintended oral exposure via grooming. Hoffman et al. (2010) took measures to prevent oral exposure, while Vock and Lutz (1997) did not.

\subsubsection{Distribution}

\subsubsection{Inhalation Exposure}

TDI. Immediately after inhalation exposure to $2 \mathrm{ppm}{ }^{14} \mathrm{C}$ ring-labeled TDI for 4 hours, radioactivity levels were highest in the carcass, skin, gastrointestinal contents, and gastrointestinal tracts of male F344 rats (Timchalk et al. 1994). When examined 48 hours later, the highest percentage of recovered dose was found in the gastrointestinal contents $(\sim 17 \%)$, followed by the carcass $(10 \%)$ and skin $(6 \%)$. Table 3-9 shows the distribution of radioactivity immediately after exposure and 48 hours after exposure. Kennedy et al. (1994) measured radioactivity in tissues immediately after 4-hour exposure of rats to concentrations of $0.026,0.143$, and $0.821 \mathrm{ppm}{ }^{14} \mathrm{C}-2,4$-TDI. The highest specific activities ( $\mu \mathrm{gEq} / \mathrm{g}$ ) were located in the airways (trachea and lung) followed by the gastrointestinal tract (esophagus and stomach) and systemic circulation (blood, liver, kidney, spleen, and heart). When expressed as percent of dose /total tissue, the highest level was in the blood, followed by the liver or stomach, kidney or lung, and trachea. In guinea pigs exposed to ${ }^{14} \mathrm{C}-2,4-\mathrm{TDI}$ concentrations ranging from 0.00005 to $0.146 \mathrm{ppm}$ for 1,4 , or 5 hours, the highest levels of radioactivity were detected in the trachea and lung, followed by the kidney, heart, spleen, and liver (Kennedy et al. 1989). 


\section{Table 3-9. Tissue Distribution of ${ }^{14} \mathrm{C}$ in Male F344 Rats Exposed to ${ }^{14} \mathrm{C}$ Ring-} Labelled 2,4-Toluene Diisocyanate Via Gavage or Inhalation

\begin{tabular}{|c|c|c|c|c|}
\hline \multirow[b]{2}{*}{ Tissue } & \multicolumn{2}{|c|}{$\begin{array}{l}\text { Percent of administered dose after } \\
\text { oral exposure }(60 \mathrm{mg} / \mathrm{kg})\end{array}$} & \multicolumn{2}{|c|}{$\begin{array}{l}\text { Percent of recovered dose after inhalation } \\
\text { exposure ( } 2 \mathrm{ppm}, 4 \text { hours) }\end{array}$} \\
\hline & $\begin{array}{l}2 \text { hours } \\
\text { postdosing }\end{array}$ & $\begin{array}{l}48 \text { hours } \\
\text { postdosing }\end{array}$ & $\begin{array}{l}\text { Immediately after } \\
\text { exposure }\end{array}$ & $\begin{array}{l}48 \text { hours } \\
\text { postexposure }\end{array}$ \\
\hline Blood & NA & $0.05 \pm 0.02$ & NA & $0.23 \pm 0.15$ \\
\hline Gastrointestinal contents & $65.82 \pm 8.35$ & $2.56 \pm 0.84$ & $9.76 \pm 2.31$ & $16.63 \pm 9.18$ \\
\hline Carcass & $5.50 \pm 3.62$ & $0.77 \pm 0.20$ & $71.54 \pm 2.99$ & $10.02 \pm 2.69$ \\
\hline Gastrointestinal tract & $10.10 \pm 3.09$ & $0.10 \pm 0.05$ & $3.75 \pm 1.56$ & $0.76 \pm 0.37$ \\
\hline Skin & $1.12 \pm 0.53$ & $0.15 \pm 0.02$ & $9.86 \pm 3.12$ & $5.59 \pm 1.61$ \\
\hline Lung & $0.99 \pm 0.52$ & $<0.01$ & $2.50 \pm 1.13$ & $0.28 \pm 0.12$ \\
\hline Liver & $0.50 \pm 0.15$ & $0.11 \pm 0.00$ & $1.68 \pm 0.13$ & $0.37 \pm 0.01$ \\
\hline Kidney & $0.08 \pm 0.02$ & $0.02 \pm 0.00$ & $0.69 \pm 0.08$ & $0.25 \pm 0.04$ \\
\hline Fat & $<0.01$ & $<0.01$ & $0.02 \pm 0.00$ & $<0.01$ \\
\hline Total & $83.18 \pm 7.19$ & $3.77 \pm 0.87$ & - & $34.14 \pm 11.53$ \\
\hline
\end{tabular}

Source: Timchalk et al. 1994 
Kennedy et al. (1994) quantified the distribution of radioactivity in blood components after a 4-hour inhalation exposure of rats to ${ }^{14} \mathrm{C}-2,4$-TDI. Radioactivity was primarily recovered from the plasma (74$87 \%$ ), but radioactivity was also detected in the cell pellet. The plasma was fractionated by molecular weight, showing that the vast majority of the radioactivity (97-100\%) was associated with high molecular weight $(>10 \mathrm{kDa})$ components; electrophoresis was then used to demonstrate that the majority of the radioactivity was associated with a $70 \mathrm{kDa}$ protein, which the authors suggested was likely albumin. Analysis of stomach contents by fractionation and electrophoresis showed that a higher proportion of the radioactivity in the stomach $(28 \%)$ was in the low molecular weight fraction $(<10 \mathrm{kDa})$ compared with the fraction in plasma. High performance liquid chromatography (HPLC) analysis of the low molecular weight fraction showed a TDA peak in addition to other products, demonstrating that TDA is not the primary reaction product after inhalation exposure. The authors postulated that the inhaled TDI reacted with macromolecules in the airway prior to being transported to the stomach, where proteolysis occurred, yielding the low molecular weight adducts.

Day et al. (1996) analyzed hemoglobin adducts of TDI in guinea pigs exposed to 1 ppm 2,4-TDI for 3 hours/day on 5 consecutive days, and identified several TDI-derived adducts that demonstrated that the isocyanate moiety was capable being transported from the lung into the blood and across the erythrocyte membrane to form a hemoglobin adduct.

MDI. Systemic distribution of radioactivity was measured in male Wistar rats exposed head-only for 6 hours to an aerosol of ${ }^{14} \mathrm{C}-4,4$ '-MDI $\left(2 \mathrm{mg} / \mathrm{m}^{3}\right)$ (Gledhill et al. 2005). The results are shown in Table 3-10. As the table indicates, the largest percentages of received radioactivity were recovered from the respiratory and gastrointestinal tracts, but radioactivity was detected in all of the tissues examined (Gledhill et al. 2005). The authors suggested that the radioactivity in the gastrointestinal tract and its contents likely resulted from oral intake during grooming after the exposure period and/or mucociliary clearance of material from the respiratory tract (Gledhill et al. 2005).

\subsubsection{Oral Exposure}

TDI. In male F344 rats given a single gavage dose of $60 \mathrm{mg} / \mathrm{kg}{ }^{14} \mathrm{C}$ ring-labeled TDI, the highest proportion of administered dose was recovered from the gastrointestinal tract and contents when sampled 2 or 48 hours postdosing (Timchalk et al. 1994). Radioactivity levels in the skin, lung, liver, and kidney reflected $1.1,1.0,0.5$, and $0.08 \%$ of the administered dose, respectively, at 2 hours postdosing; lower concentrations were seen at 48 hours postdosing (Timchalk et al. 1994). 


\section{Table 3-10. Tissue Distribution of ${ }^{14} \mathrm{C}$ in Male Wistar Rats Exposed to ${ }^{14} \mathrm{C}$ Ring- Labelled 4,4'-Methylenediphenyl Diisocyanate Aerosol Via Inhalation}

\begin{tabular}{llll}
\hline \multicolumn{4}{l}{ Percent of received radioactivity } \\
\hline Tissue & 0 hours postexposure & 24 hours postexposure & 168 hours postexposure \\
\hline Adrenals & $0.025 \pm 0.01$ & $0.021 \pm 0.005$ & $0.025 \pm 0.004$ \\
Brain & $0.051 \pm 0.018$ & $0.031 \pm 0.007$ & $<0.016 \pm<0.006$ \\
Gastrointestinal & $4.173 \pm 0.801$ & $0.992 \pm 0.406$ & $<0.141 \pm<0.007$ \\
Gonads & $0.356 \pm 0.022$ & $0.201 \pm 0.032$ & $0.054 \pm 0.021$ \\
Heart & $0.375 \pm 0.068$ & $0.157 \pm 0.041$ & $0.053 \pm 0.013$ \\
Kidneys & $0.524 \pm 0.089$ & $0.363 \pm 0.03$ & $0.103 \pm 0.014$ \\
Liver & $3.379 \pm 0.756$ & $2.004 \pm 0.408$ & $0.424 \pm 0.058$ \\
Lungs & $12.771 \pm 2.521$ & $5.558 \pm 0.944$ & $3.558 \pm 0.503$ \\
Nasal tissue (olfactory) & $0.115 \pm 0.018$ & $0.047 \pm 0.017$ & $0.029 \pm 0.032$ \\
Nasal tissue (respiratory) & $1.44 \pm 1.873$ & $0.182 \pm 0.247$ & $0.058 \pm 0.01$ \\
Esophagus & $0.074 \pm 0.02$ & $0.014 \pm 0.005$ & $<0.039 \pm<0.048$ \\
Pancreas & $0.046 \pm 0.008$ & $0.031 \pm 0.005$ & $0.021 \pm 0.009$ \\
Spleen & $0.102 \pm 0.021$ & $0.071 \pm 0.012$ & $0.043 \pm 0.009$ \\
Stomach & $0.335 \pm 0.22$ & $0.234 \pm 0.185$ & $0.039 \pm 0.026$ \\
Thyroid & $0.024 \pm 0.021$ & $0.004 \pm 0.001$ & $0.004 \pm 0.003$ \\
Trachea & $0.167 \pm 0.168$ & $0.095 \pm 0.103$ & $0.012 \pm 0.002$ \\
Residual carcass & $37.106 \pm 9.752$ & $18.539 \pm 4.058$ & $5.001 \pm 1.187$ \\
Total & 61.063 & 54.901 & 5.159 \\
Stomach contents & $<0.921 \pm<1.564$ & $0.351 \pm 0.358$ & $<0.103 \pm<0.039$ \\
Gastrointestinal contents & $31.787 \pm 5.133$ & $13.177 \pm 5.487$ & $0.617 \pm 0.13$ \\
\hline & & & \\
\hline & & & \\
\end{tabular}

Source: Gledhill et al. 2005 
MDI. No data on the distribution of MDI after oral exposure were located in the available literature.

\subsubsection{Dermal Exposure}

TDI. The carcasses of male rats exposed to $330 \mathrm{mg} / \mathrm{kg}{ }^{14} \mathrm{C}-2,4-\mathrm{TDI}$ for $0.5,1,0$, or 8.0 hours via topical application contained $0.25,0.44$, and $0.52 \%$ of the applied radioactivity, respectively (Hoffman et al. 2010).

MDI. No radioactivity was detected in the tissues of male rats exposed for 8 hours to a topical dose of 15 or $165 \mathrm{mg} / \mathrm{kg}{ }^{14} \mathrm{C}-4,4^{\prime}$-MDI and sacrificed 8, 24, or 120 hours after the commencement of exposure (Hoffman et al. 2010). Vock and Lutz (1997) detected small amounts of radioactivity ( $\leq 1 \%$ of applied radioactivity in total) in the lung, liver, kidney, and muscle of female rats exposed to topical doses of 11$15 \mathrm{mg} / \mathrm{kg}{ }^{14} \mathrm{C}-4,4^{\prime}-\mathrm{MDI}$ for 24 hours or to $29-30 \mathrm{mg} / \mathrm{kg}$ for 48 hours. Of the applied radioactivity, 9$12 \%$ was recovered in the epidermis (Vock and Lutz 1997).

\subsubsection{Metabolism}

TDI reacts readily with sulfhydryl, amine, and hydroxyl groups, forming adducts with hemoglobin, glutathione, albumin, and other macromolecules. After gavage exposure, TDI is hydrolyzed in the gastrointestinal tract to TDA, which may be absorbed and metabolized further (acetylated, conjugated, or metabolized to aminophenolic or aminobenzoic acid compounds) (Timchalk et al. 1994). In the gut, TDA may also react with unhydrolyzed TDI to form polyurea polymers that pass unabsorbed through the gastrointestinal tract. In contrast, after inhalation exposure, little TDI, if any, is hydrolyzed to TDA; conjugation reactions are believed to represent be the primary fate of inhaled TDI. These route-specific differences in the fate of TDI were observed when rat urine was analyzed after gavage and inhalation exposure; after gavage exposure to TDI, $35 \%$ of the detected metabolites were free or acetylated TDA (the balance reflected acid-labile conjugates of TDI or TDA), while only $10 \%$ of the metabolites detected after inhalation exposure were acetylated TDA (Timchalk et al. 1994). The acidic pH of the stomach favors the hydrolysis of TDI to form TDA. At neutral $\mathrm{pH}$ levels, TDI is more likely to form polyurea polymers (as discussed in Sielken et al. 2012); thus, TDA formation may not occur following inhalation, ingestion, or dermal exposure to TDI.

Figure 3-4 shows the proposed metabolic scheme for 2,4-TDI in the rat. 
Figure 3-4. Proposed Metabolic Scheme for 2,4-Toluene Diisocyanate in the Rat

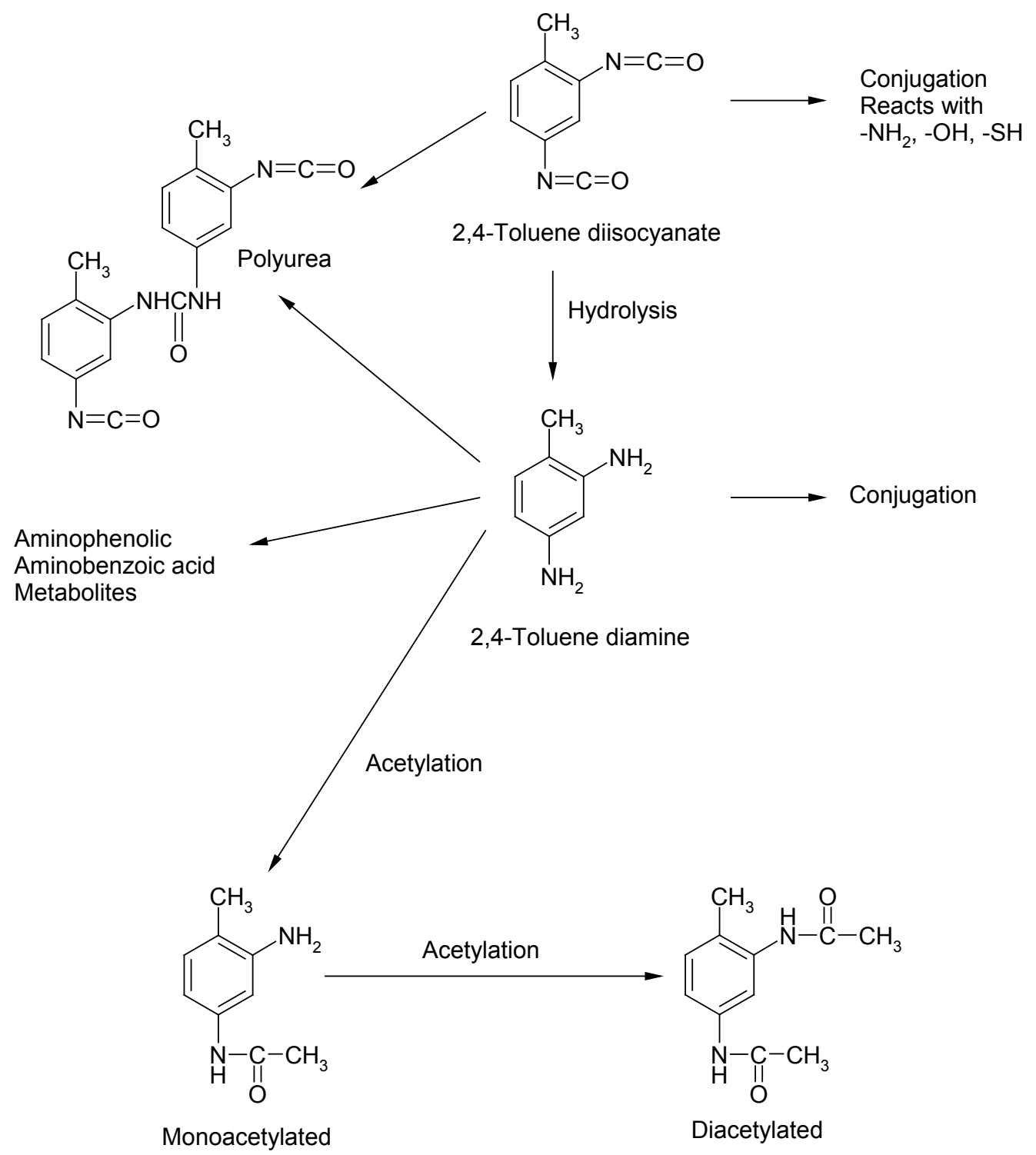

Source: Timchalk et al. 1994 
A single study evaluating the metabolism of MDI was located. In male rats exposed via inhalation to MDI aerosol, five metabolites were identified in the urine, feces, and bile (Gledhill et al. 2005).

Table 3-11 shows the percentage of administered dose represented by each metabolite. Four metabolites were identified as $\mathrm{N}$-acetylated and $\mathrm{N}$-acetylated hydroxylated products of MDI, while the fifth could not be identified. The primary product detected in feces was proposed to be mixed molecular weight polyureas resulting from spontaneous reaction of MDI. No free MDA was detected in excreta or bile (Gledhill et al. 2005).

\subsubsection{Inhalation Exposure}

TDI. When rats were exposed by inhalation to $2 \mathrm{ppm} 2,4-\mathrm{TDI}$ for 4 hours, no free TDA was detected in the urine (Timchalk et al. 1994). A total of $0.26 \mu \mathrm{g}$ equivalents of 2,4-TDA were detected in the hydrolyzed urine as mono- and diacetylated products, while $2.53 \mu \mathrm{g}$ equivalents were detected as acidlabile conjugates of 2,4-TDI or TDA. Another inhalation study (Kennedy et al. 1994) showed that 95\% of the TDI in plasma was conjugated to macromolecules, which the investigators suggested demonstrated that macromolecules successfully competed with hydrolysis to form the diamine.

In one study, TDI was shown to induce a decrease in CYP2B1 expression. Exposure of male SpragueDawley rats to commercial-grade TDI (80:20 mix of 2,4- and 2,6-TDI) at a concentration of $1 \mathrm{ppm}$ for 8 hours resulted in decreased CYP2B1 mRNA (33\%) and protein (40\%) levels in the lung when compared with control rats (Pons et al. 2000). TDI exposure did not alter expression of other CYPs investigated (1A1, 2E1, or 3A1) or glutathione S-transferase (GST).

MDI. A total of five metabolites of 4,4'-MDI monomer were observed in the urine, feces, and bile of male rats exposed to $2 \mathrm{mg} / \mathrm{m}^{3}$ radiolabeled MDI aerosol for 6 hours; four were identified by liquid chromatography-mass spectrometry (LC-MS) and LC-MS ${ }^{3}$ analysis as N-acetylated and N-acetylated hydroxylated products of MDI, while the fifth could not be identified (Gledhill et al. 2005). The primary product detected in feces was proposed to be mixed molecular weight polyureas resulting from spontaneous reaction of MDI. Free MDA was not detected in excreta or bile. After acid hydrolysis of the 6-, 12-, and 24-hour urine samples, MDA was detected at concentrations of 483, 120, and $131 \mathrm{ng} / \mathrm{mL}$, respectively. Analysis of the acid-hydrolyzed urine also revealed deacetylated products of the metabolites N,N'-diacetyl-4,4'-diaminobenzhydrol and N,N'-diacetyl 4,4'-diaminobenzophenone (Gledhill et al. 2005). 
Table 3-11. Metabolites of Methylenediphenyl Diisocyanate (MDI) in Male F344 Rats Exposed to ${ }^{14} \mathrm{C}$ Ring-Labelled 4,4'-MDI Monomer Via Inhalation

\begin{tabular}{llllll}
\hline & \multicolumn{2}{l}{$\begin{array}{l}\text { Percentage of administered } \\
\text { dose in intact rats }\end{array}$} & \multicolumn{2}{l}{$\begin{array}{l}\text { Percentage of administered } \\
\text { dose in bile-cannulated rats }\end{array}$} \\
\hline Metabolite & Urine & Feces & Urine & Bile & Feces \\
\hline N,N'-Diacetyl-4,4'-diaminobenzhydrol & 1 & ND & 6 & 1 & ND \\
N,N'-Diacetyl-4,4'-diaminophenyl- & 0.5 & ND & 4 & 4 & ND \\
methane & & & & & \\
N-Acetyl-4, 4'-diaminophenylmethane & 0.3 & ND & ND & ND & ND \\
N,N'-Diacetyl 4,4'-diaminobenzophenone & 0.4 & ND & ND & ND & ND \\
Metabolite V; not identified & 0.2 & ND & $<1$ & ND & ND \\
$\begin{array}{l}\text { Proposed as mixed molecular weight } \\
\text { polyureas derived from MDI }\end{array}$ & ND & 56 & ND & 9 & 24 \\
Total & 2.4 & 56 & 10 & 14 & 24 \\
\hline
\end{tabular}

$\mathrm{ND}=$ not detected

Source: Gledhill et al. 2005 


\subsubsection{Oral Exposure}

TDI. After rats were given a single gavage dose of $60 \mathrm{mg} / \mathrm{kg}$ 2,4-TDI, 2,4-TDA was detected (by HPLC) in the urine collected during the first 12 hours postdosing (Timchalk et al. 1994). In the urine, $2.08 \mu \mathrm{g}$ equivalents of free 2,4-TDA were detected, while monoacetylated, and diacetylated 2,4-TDA were measured to be 5.12 and $8.17 \mu$ g equivalents of 2,4-TDA. Approximately $44.51 \mu \mathrm{g}$ equivalents existed in the urine as acid-labile conjugates of 2,4-TDA and/or 2,4-TDI (Timchalk et al. 1994). The relevance of these gavage data in which the TDI is instilled into the acidic stomach to human ingestion is questionable. At neutral $\mathrm{pH}$ levels, such as found in the mouth, TDI is more likely to react with other TDI molecules to form polyurea polymers than to hydrolyze to TDA (as discussed in Sielken et al. 2012).

MDI. No data on the metabolism of MDI after oral exposure were located in the available literature.

\subsubsection{Dermal Exposure}

TDI. No data on the metabolism of TDI after dermal exposure of humans or animals were located in the available literature.

MDI. No data on the metabolism of MDI after dermal exposure of humans or animals were located in the available literature.

\subsubsection{Elimination and Excretion}

\subsubsection{Inhalation Exposure}

TDI. Budnik et al. (2011) evaluated urinary excretion of diamines following specific inhalation challenge exposure to known concentrations ranging from 0.5 to $30 \mathrm{ppb}$ of 2,4 -TDI $(\mathrm{n}=18)$ or 2,6 -TDI $(\mathrm{n}=18)$. The subjects were workers with prior exposure to these compounds who were being evaluated for occupational asthma. Levels of TDA in the spot urine samples collected over the following 24 hours were subjected to acid hydrolysis prior to analysis by gas chromatography (GC)/MS. In subjects exposed to 2,4- and 2,6-TDI, creatinine-corrected urinary levels of the corresponding diamines peaked at 4.1 and 4.8 hours, respectively. The half-life for TDA in urine was estimated to be 6 hours. Subjects exposed to higher concentrations of either isomer of TDI (mean exposure 1,569 ppb) did not exhibit correspondingly higher urinary peak levels of TDA when compared with the low exposure group (496 ppb). 
The plasma elimination rate for both 2,4- and 2,6-TDI was estimated to average 21 days in workers chronically exposed to airborne concentrations between 0.4 and $4 \mu \mathrm{g} / \mathrm{m}^{3}$ TDI (mixture of 2,4- and 2,6-TDI with varying composition) (Lind et al. 1996).

TDA levels in hydrolyzed urine in humans experimentally exposed for 4-7.5 hours to mixtures of 2,4- and 2,6-TDI exhibited a biphasic pattern, with an initial rapid phase followed by a slower phase (Brorson et al. 1991; Skarping et al. 1991). The half-time for urinary excretion in the initial rapid phase was estimated to be between 1.6 and 2.5 hours for 2,6-TDI and between 1.9 and 5 hours for 2,4-TDI (Brorson et al. 1991; Skarping et al. 1991). The half-time for the slower phase was reportedly about 5 hours for both isomers (Skarping et al. 1991).

In guinea pigs, 2,3-TDI is cleared slowly from the blood. Kennedy et al. (1989) observed a gradual decline in blood radioactivity over the course of 72 hours following exposure of guinea pigs to concentrations of ${ }^{14} \mathrm{C}-2,4-\mathrm{TDI}$ ranging from 0.004 to $0.336 \mathrm{ppm}$. Radioactivity remaining in the blood at 72 hours postexposure persisted at that level for a second week, suggesting that the molecule to which the radioactivity was bound was saturated, and that the adduct did not have a rapid turnover rate (Kennedy et al. 1989).

The primary excretory pathway for 2,4-TDI in rats exposed via inhalation was fecal (Timchalk et al. 1994). Forty-eight hours after a 4-hour exposure to $2 \mathrm{ppm}{ }^{14} \mathrm{C}$ ring-labeled 2,4-TDI, male F344 rats excreted $47 \%$ of the recovered radioactivity in the feces and $15 \%$ in the urine. No radioactivity was detected in exhaled $\mathrm{CO}_{2}$ or volatile organics (Timchalk et al. 1994). Detection of significant amounts of radioactivity in the gastrointestinal contents both immediately after exposure (10\% of recovered dose) and 48 hours later (17\% of recovered dose) (Timchalk et al. 1994) suggests biliary excretion of 2,4-TDI.

MDI. In addition to evaluating urinary excretion of diamines in workers undergoing specific inhalation challenge with TDI, Budnik et al. (2011) measured levels of 4,4'-MDA in acid hydrolyzed urine following specific inhalation challenge exposure to 4,4'-MDI ( $0.5-30 \mathrm{ppb} ; \mathrm{n}=36$ subjects). The peak level of 4,4'-MDA in urine occurred at 14 hours after exposure. Urinary excretion of 4,4'-MDA was slower and more prolonged than that of the TDAs, and excretion was not complete during the 24-hour study period. In addition, the excretion time course was longer in those subjects exposed to higher concentrations of 4,4'-MDI (mean exposure 1,569 ppb) compared with those exposed to lower concentrations (mean exposure $496 \mathrm{ppb}$ ). 
Male rats exposed (head only) to aerosols of ${ }^{14} \mathrm{C}-4,4^{\prime}-\mathrm{MDI}$ monomer for 6 hours at $2 \mathrm{mg} / \mathrm{m}^{3}$ excreted the majority of the received radioactivity in the feces $(80 \%)$, with about $5 \%$ excreted in urine during the 168-hour follow-up time (Gledhill et al. 2005). In bile duct-cannulated rats exposed similarly, biliary excretion was estimated to be $14 \%$ of the dose and urinary excretion was $12 \%$.

\subsubsection{Oral Exposure}

TDI. After gavage exposure to a $60 \mathrm{mg} / \mathrm{kg}{ }^{14} \mathrm{C}$ ring-labeled 2,4-TDI, $81 \%$ of the administered dose was recovered in the feces and 8\% was recovered in the urine of male F344 rats; total radioactivity recovered represented $94 \%$ of the administered dose (Timchalk et al. 1994). Quantifiable levels of radioactivity were not detected in exhaled $\mathrm{CO}_{2}$ or volatile organics.

MDI. No data on the elimination of MDI after oral exposure were located in the available literature.

\subsubsection{Dermal Exposure}

TDI. Hoffman et al. (2010) detected $<1 \%$ of a dermally-applied dose of $330 \mathrm{mg} / \mathrm{kg}{ }^{14} \mathrm{C}$-TDI in the urine of rats after exposure durations up to 8 hours; no radioactivity was detected in the feces. Yeh et al. (2008) evaluated the kinetics of urinary excretion of 2,4- and 2,6-TDI in male rats by measuring urinary TDA for 6 days after topical application of commercial-grade TDI (80:20 mixture of 2,4- and 2.6-TDI) at concentrations of $0.2,1$, and 5\%. 2,4- and 2,6-TDA were measured in acid-hydrolyzed urine samples collected at 12-hour intervals. The results are shown in Table 3-12. For both compounds and regardless of applied concentration, the maximum concentration in urine was reached during the first 12-hour interval. At the highest exposure level, urinary excretion was not complete at the end of the 6-day collection period, but was essentially complete at the lower concentrations. The half-life for urinary elimination of 2,4- and 2.6-TDA ranged between 18.4 and 26.6 hours. The data readily fit a first-order kinetic linear model $(\mathrm{p}<0.05)$, but the pattern at the highest exposure demonstrated a non-linear saturation at 60 hours after Cmax was reached (Yeh et al. 2008).

MDI. Hoffman et al. (2010) detected only small amounts of radioactivity in the feces of male rats exposed via dermal application of 15 or $165 \mathrm{mg} / \mathrm{kg}{ }^{14} \mathrm{C}-4,4$ '-MDI for 8 hours and sacrificed 8 , 24, or 120 hours after treatment. In contrast, approximately $29-30 \%$ of the applied radioactivity was recovered in the feces during a 48-hour exposure of female rats to topical doses of $\sim 30 \mathrm{mg} / \mathrm{kg}{ }^{14} \mathrm{C}-4,4$ '-MDI (Vock 
Table 3-12. Kinetics of Urinary Toluene Diamine (TDA) Excretion in Rats Exposed to Toluene Diisocyanate Via Topical Application

\begin{tabular}{lllllll}
\hline & $2,4-T D A$ & \multicolumn{5}{c}{$2,6-$ TDA } \\
\hline Applied dose & $0.2 \%$ & $1 \%$ & $5 \%$ & $0.2 \%$ & $1 \%$ & $5 \%$ \\
\hline Tmax (hours) & 12 & 12 & 12 & 12 & 12 & 12 \\
Cmax $(\mu \mathrm{g} / \mathrm{mL})$ & $0.062 \pm$ & $0.238 \pm$ & $6.116 \pm$ & $0.056 \pm$ & $0.268 \pm$ & $3.777 \pm$ \\
& 0.009 & 0.060 & 0.429 & 0.004 & 0.060 & 0.384 \\
AUC $\left(\mu g^{*}\right.$ hour $\left./ \mathrm{mL}\right)$ & $2.186 \pm$ & $8.395 \pm$ & $158.599 \pm$ & $2.046 \pm$ & $10.558 \pm$ & $133.994 \pm$ \\
& 0.376 & 0.919 & 5.517 & 0.263 & 0.538 & 20.35 \\
Accumulative amount $(\mu \mathrm{g})$ & $2.682 \pm$ & $12.940 \pm$ & $83.843 \pm$ & $2.622 \pm$ & $14.978 \pm$ & $69.810 \pm$ \\
& 0.631 & 4.224 & 29.542 & 0.779 & 2.628 & 11.541 \\
$\mathrm{k}(1 /$ hour) & $0.0376 \pm$ & $0.0341 \pm$ & $0.0325 \pm$ & $0.0329 \pm$ & $0.0339 \pm$ & $0.0264 \pm$ \\
& 0.002 & 0.003 & 0.003 & 0.0020 & 0.0027 & 0.004 \\
$\mathrm{t} 1 / 2$ (hours) & $18.4 \pm 0.8$ & $20.4 \pm 01.5$ & $21.5 \pm 2.2$ & $21.1 \pm 1.3$ & $20.5 \pm 1.6$ & $26.6 \pm 3.7$ \\
\hline
\end{tabular}

Source: Yeh et al. 2008 
and Lutz 1997). Hoffman et al. (2010) took measures to prevent oral exposure of the rats via grooming, while Vock and Lutz (1997) did not. In both studies, recovery of radioactivity in the urine was $<1 \%$ of the applied dose (Hoffman et al. 2010; Vock and Lutz 1997).

\subsubsection{Physiologically Based Pharmacokinetic (PBPK)/Pharmacodynamic (PD) Models}

Physiologically based pharmacokinetic (PBPK) models use mathematical descriptions of the uptake and disposition of chemical substances to quantitatively describe the relationships among critical biological processes (Krishnan et al. 1994). PBPK models are also called biologically based tissue dosimetry models. PBPK models are increasingly used in risk assessments, primarily to predict the concentration of potentially toxic moieties of a chemical that will be delivered to any given target tissue following various combinations of route, dose level, and test species (Clewell and Andersen 1985). Physiologically based pharmacodynamic (PBPD) models use mathematical descriptions of the dose-response function to quantitatively describe the relationship between target tissue dose and toxic end points.

PBPK/PD models refine our understanding of complex quantitative dose behaviors by helping to delineate and characterize the relationships between: (1) the external/exposure concentration and target tissue dose of the toxic moiety, and (2) the target tissue dose and observed responses (Andersen and Krishnan 1994; Andersen et al. 1987). These models are biologically and mechanistically based and can be used to extrapolate the pharmacokinetic behavior of chemical substances from high to low dose, from route to route, between species, and between subpopulations within a species. The biological basis of PBPK models results in more meaningful extrapolations than those generated with the more conventional use of uncertainty factors.

The PBPK model for a chemical substance is developed in four interconnected steps: (1) model representation, (2) model parameterization, (3) model simulation, and (4) model validation (Krishnan and Andersen 1994). In the early 1990s, validated PBPK models were developed for a number of toxicologically important chemical substances, both volatile and nonvolatile (Krishnan and Andersen 1994; Leung 1993). PBPK models for a particular substance require estimates of the chemical substancespecific physicochemical parameters, and species-specific physiological and biological parameters. The numerical estimates of these model parameters are incorporated within a set of differential and algebraic equations that describe the pharmacokinetic processes. Solving these differential and algebraic equations provides the predictions of tissue dose. Computers then provide process simulations based on these solutions. 
The structure and mathematical expressions used in PBPK models significantly simplify the true complexities of biological systems. However, if the uptake and disposition of the chemical substance(s) are adequately described, this simplification is desirable because data are often unavailable for many biological processes. A simplified scheme reduces the magnitude of cumulative uncertainty. The adequacy of the model is, therefore, of great importance, and model validation is essential to the use of PBPK models in risk assessment.

PBPK models improve the pharmacokinetic extrapolations used in risk assessments that identify the maximal (i.e., the safe) levels for human exposure to chemical substances (Andersen and Krishnan 1994). PBPK models provide a scientifically sound means to predict the target tissue dose of chemicals in humans who are exposed to environmental levels (for example, levels that might occur at hazardous waste sites) based on the results of studies where doses were higher or were administered in different species. Figure 3-5 shows a conceptualized representation of a PBPK model.

No physiologically based pharmacokinetics models for TDI or MDI were located in the available literature.

\subsection{MECHANISMS OF ACTION}

\subsubsection{Pharmacokinetic Mechanisms}

The metabolic fate of TDI is route-dependent. After oral exposure, TDI is hydrolyzed in the gastrointestinal tract to TDA, which may be absorbed and metabolized further (acetylated, conjugated, or metabolized to aminophenolic or aminobenzoic acid compounds) (Timchalk et al. 1994). In the gut, TDA may also react with unhydrolyzed TDI to form polyurea polymers that pass unabsorbed through the gastrointestinal tract. In contrast, after inhalation exposure, little TDI, if any, is hydrolyzed to TDA; conjugation reactions are believed to represent be the primary fate of inhaled TDI. As a consequence of these route differences, exposure to TDI via the gastrointestinal tract will likely result in higher tissue concentrations of TDA and its downstream products than would occur after inhalation exposure. 


\section{Figure 3-5. Conceptual Representation of a Physiologically Based Pharmacokinetic (PBPK) Model for a Hypothetical Chemical Substance}

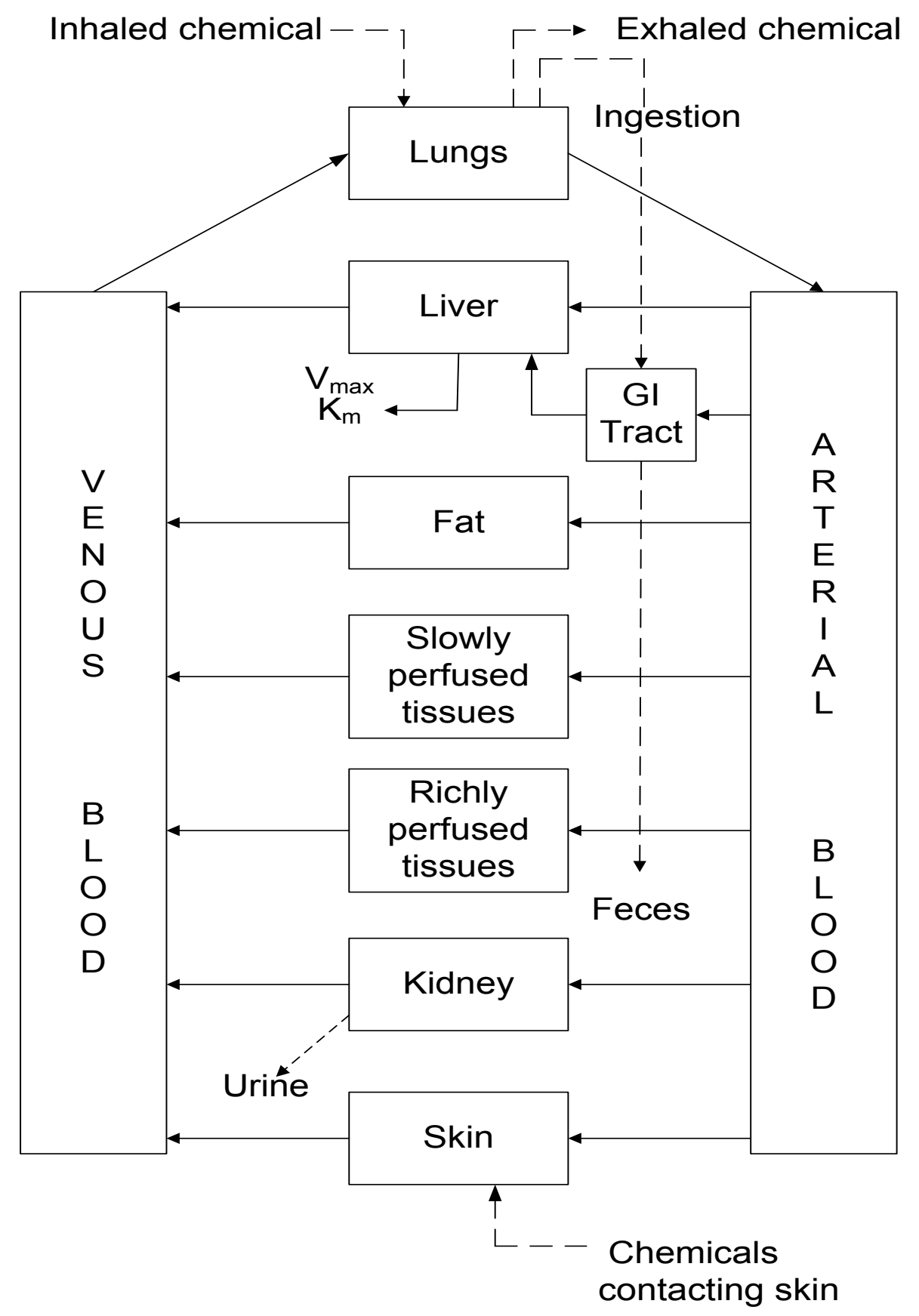

Note: This is a conceptual representation of a physiologically based pharmacokinetic (PBPK) model for a hypothetical chemical substance. The chemical substance is shown to be absorbed via the skin, by inhalation, or by ingestion, metabolized in the liver, and excreted in the urine or by exhalation. 


\subsubsection{Mechanisms of Toxicity}

The respiratory tract is the primary target of TDI and MDI toxicity resulting in declines in lung function and occupational asthma; chronic airway inflammation likely plays a key role in both effects. The mechanisms of diisocyanate-induced occupational asthma have been more extensively investigated than those involved in reduced lung function. The pathogenesis of TDI/MDI asthma has not been fully elucidated; it appears to be multifaceted and involves a number immunological and non-immunological mechanisms. TDI/MDI occupational asthma has many similar features to allergic asthma, including persistent airway inflammation and subsequent airway hyperresponsiveness; however, there are several features present in TDI/MDI asthma not seen in allergic asthma including airway neutrophilia, increases in interleukin (IL)-8 levels, low prevalence of diisocyanate-specific IgE antibodies, and lack of association with atopy (Furusho et al. 2006). It is believed that diisocyanates bind to airway cell proteins and are taken up by epithelial cells resulting in cytokine and chemokine production and cellular recruitment, which leads to airway inflammation (Kim et al. 2010). Wisnewski et al. (2013) speculated that albumin is the primary protein target of diisocyanate reactivity; the diisocyanate-albumin conjugate can trigger innate and adaptive cellular responses associated with airway inflammation and asthma. Glutathione serves as a carbamoylating intermediate through which diisocyanate is transported from the airways to the blood where there are higher levels of albumin. This shuttle mechanism could explain the rapid accumulation of diisocyanate-albumin conjugates in the peripheral blood in animals exposed to diisocyanates (Wisnewski et al. 2013).

The immunological mechanisms appear to involve hypersensitivity response, although other types of immune response are likely involved. There is suggestive evidence that all types of hypersensitivity are involved. An immediate response to a diisocyanate challenge is likely indicative of Type 1 hypersensitivity, which is mediated by IgE. Specific IgE antibodies to TDI-HSA (Baur and Fruhmann 1981; Cvitanovic e t al. 1989; Park and Nahm 1996; Park et al. 1999; Pezzini et al. 1984; Sharifi et al. 2013) or MDI-HSA (Hur et al. 2008; Pezzini et al. 1984; Tse et al. 1985) have been found. However, only a small percentage of TDI and MDI workers with occupational asthma have elevated levels of IgE, suggesting that other mechanisms are likely involved. The delayed response to a TDI or MDI challenge is suggestive of one or more subtype of Type IV hypersensitivity. This type of response is typically driven by leukotrienes, chemokines, and cytokines synthesized by activated mast cells and CD4+ Th2 cells. A study of CD4 knockout mice sensitized to TDI showed a significant reduction in airway hyperresponsiveness to a TDI challenge as compared to wild-type controls. A marked reduction of pulmonary inflammation by neutrophils, lymphocytes, eosinophils, and macrophage infiltration and 
decreases in Th2 cytokines-IL-4, IL-5, and IL-13-were also observed in the CD4 knockout mice (Matheson et al. 2005). The role of CD4+ Th2 subtype of Type IV hypersensitivity in diisocyanateinduced asthma is supported by the findings of increased IL-4 and IL-6 levels in the bronchoalveolar lavage (BAL) fluid of rats sensitized to TDI (Zheng et al. 2001a, 2001b). Increases in the production of IL-1 $\beta$, IL-1 $\alpha$, and tumor necrosis factor (TNF)- $\alpha$ expression were observed in the lungs of mice with TDI-induced asthma; increases in IL-1 $\beta$ and TNF- $\alpha$ expression were also observed in the lung biopsy samples from workers with TDI-induced asthma (Johnson et al. 2005). Studies in TDI-sensitized mice in which IL-1 $\beta$ or IL-1 $\alpha$ was suppressed showed that they have unique and overlapping roles (Johnson et al. 2005). A central role for TNF- $\alpha$ in the propagation of airway inflammation and hyperresponsiveness is supported by a study of TNF- $\alpha$ deficient mice that found a reduction in TDI-induced inflammation, airway hyperresponsiveness, and migration of airway dendritic cells to the draining lymph nodes (Matheson et al. 2002). The increases in IFN- $\gamma$ and TNF- $\alpha$ observed in TDI sensitized mice also support a Th1 response mechanism (Świerczyńska-Machura et al. 2014). There is also some evidence to support mechanisms for the other two subtypes of Type IV hypersensitivity. A significant reduction in the Th1 cytokine, interferon- $\gamma$ (INF- $\gamma$ ), was observed in CD4 knockout mice (Matheson et al. 2005). In contrast, Zheng et al. (2001a) did not find significant differences in Th1 cytokines (IL-2 or IFN- $\gamma$ ) levels in TDIsensitized rats, as compared to controls. The Matheson et al. (2005) study also provides some evidence of the CD8+ subtype of Type IV hypersensitivity; reductions in airway hyperresponsiveness and pulmonary inflammation were observed in CD8 knockout mice sensitized to TDI as compared to TDI-sensitized wild-type mice.

In addition to immune hypersensitivity mechanism, there is evidence to suggest that other immune and non-immune mechanisms are involved in TDI/MDI-induced inflammation and airway hyperresponsiveness. In vitro studies in bronchial epithelial cells have showed enhanced production of IL-8 in the presence of TDI-HSA conjugate (Lee et al. 2003; Ogawa et al. 2006). The IL-8 attracts and activates neutrophils, and increased neutrophil counts have been observed in the BAL fluid of sensitized workers exhibiting a delayed response to a TDI challenge (Fabbri et al. 1987). A marked infiltration of eosinophils, as well as neutrophils, was observed in the central and peripheral airways of TDI-sensitized rats (Zheng et al. 2001a); in sensitized mice, increased leukocyte levels were observed in the BAL fluid with the eosinophils having the greatest increase (Zheng et al. 2004). De Vooght et al. (2013) showed that granulocytes played a key role in TDI-induced airway hyperresponsiveness. Ogawa et al. (2006) showed that TDI-HSA increased cytokine and chemokine production through the epidermal growth factor (EGFR) and p38 mitogen-activated protein kinase (MAPK) pathways. Results from studies conducted by 
Pham et al. (2014) suggest that TDI can bind to tissue transglutaminase and that this conjugate can induce specific IgG antibody production, which can increase airway inflammation.

Intercellular adhesion molecule-1 (ICAM-1) plays a key regulatory role in TDI-induced inflammation by mediating the adhesion of blood leukocytes to the vascular epithelium (Furusho et al. 2006). In ICAM-1 knockout mice sensitized and challenged with TDI, there is a reduction in neutrophil, lymphocyte, eosinophil, and macrophage airway infiltration, a blocking of airway hyperresponsiveness, and marked decreases in TNF- $\alpha$, IL-4, IL-5, and IFN- $\gamma$ levels in the BAL fluid. Another mediator of airway inflammation that is overexpressed in response to TDI-HSA conjugates is vascular endothelial growth factor (VEGF) (Zhao et al. 2009). Overexpression of VEGF can result in increased vascular permeability and Th2 cell sensitization. Incubating bronchial cells with TDI-HSA resulted in increased cell permeability; however, neutralizing VEGF partially inhibited this increase in cell permeability (Zhao et al. 2009). Kim et al. (2011) found higher VEGF levels in workers with TDI-induced asthma, as compared to asymptomatic TDI-exposed workers.

Several investigators have shown that oxidative stress plays an essential role in diisocyanate-induced inflammation. Studies of workers with TDI- or MDI-induced asthma have shown increased transferrin levels and decreased ferritin levels (Hur et al. 2009; Kim et al. 2010). Ferritin is used for detoxification during oxidative stress-induced inflammation. Kim et al. (2010) found that TDI suppressed the synthesis of ferritin light chain in human airway epithelial cells. Several other antioxidant proteins were also found to be downregulated by TDI, including heme oxygenase-1, thioredoxins-1, glutathione peroxidase, peroxiredoxin-1, and catalase. Heme oxygenase-1/ferritin light chain expression was likely suppressed through the MAPK-Nrf2 signaling pathway (Kim et al. 2010). Studies in epithelial cells have also shown that TDI exposure induces the generation of reactive oxygen species (Hur et al. 2009).

\subsubsection{Animal-to-Human Extrapolations}

Kennedy et al. (1994) compared the quantities of TDI-derived components (as radioactivity) in the blood of guinea pigs, rats, and humans exposed by inhalation to ${ }^{14} \mathrm{C}-2,4-\mathrm{TDI}$ in several studies, and observed a linear relationship between the log-transformed microgram equivalents of the tolyl group per $\mathrm{mL}$ of blood and the log-transformed exposure concentration $\mathrm{x}$ time metric (ppm-hours). This observation suggests limited interspecies differences in the absorption of inhaled TDI into the blood stream. No data on interspecies differences in the pharmacokinetic behavior of MDI were located in the available literature. 


\subsection{TOXICITIES MEDIATED THROUGH THE NEUROENDOCRINE AXIS}

Recently, attention has focused on the potential hazardous effects of certain chemicals on the endocrine system because of the ability of these chemicals to mimic or block endogenous hormones. Chemicals with this type of activity are most commonly referred to as endocrine disruptors. However, appropriate terminology to describe such effects remains controversial. The terminology endocrine disruptors, initially used by Thomas and Colborn (1992), was also used in 1996 when Congress mandated the EPA to develop a screening program for "...certain substances [which] may have an effect produced by a naturally occurring estrogen, or other such endocrine effect[s]...”. To meet this mandate, EPA convened a panel called the Endocrine Disruptors Screening and Testing Advisory Committee (EDSTAC), and in 1998, the EDSTAC completed its deliberations and made recommendations to EPA concerning endocrine disruptors. In 1999, the National Academy of Sciences released a report that referred to these same types of chemicals as hormonally active agents. The terminology endocrine modulators has also been used to convey the fact that effects caused by such chemicals may not necessarily be adverse. Many scientists agree that chemicals with the ability to disrupt or modulate the endocrine system are a potential threat to the health of humans, aquatic animals, and wildlife. However, others think that endocrine-active chemicals do not pose a significant health risk, particularly in view of the fact that hormone mimics exist in the natural environment. Examples of natural hormone mimics are the isoflavinoid phytoestrogens (Adlercreutz 1995; Livingston 1978; Mayr et al. 1992). These chemicals are derived from plants and are similar in structure and action to endogenous estrogen. Although the public health significance and descriptive terminology of substances capable of affecting the endocrine system remains controversial, scientists agree that these chemicals may affect the synthesis, secretion, transport, binding, action, or elimination of natural hormones in the body responsible for maintaining homeostasis, reproduction, development, and/or behavior (EPA 1997). Stated differently, such compounds may cause toxicities that are mediated through the neuroendocrine axis. As a result, these chemicals may play a role in altering, for example, metabolic, sexual, immune, and neurobehavioral function. Such chemicals are also thought to be involved in inducing breast, testicular, and prostate cancers, as well as endometriosis (Berger 1994; Giwercman et al. 1993; Hoel et al. 1992).

No studies were located regarding endocrine disruption in humans and/or animals after exposure to TDI or MDI. No in vitro studies were located regarding endocrine disruption of TDI or MDI. 


\subsection{CHILDREN'S SUSCEPTIBILITY}

This section discusses potential health effects from exposures during the period from conception to maturity at 18 years of age in humans, when most biological systems will have fully developed. Potential effects on offspring resulting from exposures of parental germ cells are considered, as well as any indirect effects on the fetus and neonate resulting from maternal exposure during gestation and lactation. Relevant animal and in vitro models are also discussed.

Children are not small adults. They differ from adults in their exposures and may differ in their susceptibility to hazardous chemicals. Children's unique physiology and behavior can influence the extent of their exposure. Exposures of children are discussed in Section 6.6, Exposures of Children.

Children sometimes differ from adults in their susceptibility to adverse health effects from exposure to hazardous chemicals, but whether there is a difference depends on the chemical(s) (Guzelian et al. 1992; NRC 1993). Children may be more or less susceptible than adults to exposure-related health effects, and the relationship may change with developmental age (Guzelian et al. 1992; NRC 1993). Vulnerability often depends on developmental stage. There are critical periods of structural and functional development during both prenatal and postnatal life that are most sensitive to disruption from exposure to hazardous substances. Damage from exposure in one stage may not be evident until a later stage of development. There are often differences in pharmacokinetics and metabolism between children and adults. For example, absorption may be different in neonates because of the immaturity of their gastrointestinal tract and their larger skin surface area in proportion to body weight (Morselli et al. 1980; NRC 1993); the gastrointestinal absorption of lead is greatest in infants and young children (Ziegler et al. 1978). Distribution of xenobiotics may be different; for example, infants have a larger proportion of their bodies as extracellular water, and their brains and livers are proportionately larger (Altman and Dittmer 1974; Fomon 1966; Fomon et al. 1982; Owen and Brozek 1966; Widdowson and Dickerson 1964). Past literature has often described the fetus/infant as having an immature (developing) blood-brain barrier that is leaky and poorly intact (Costa et al. 2004). However, current evidence suggests that the blood-brain barrier is anatomically and physically intact at this stage of development, and the restrictive intracellular junctions that exist at the blood-CNS interface are fully formed, intact, and functionally effective (Saunders et al. 2008, 2012).

However, during development of the brain, there are differences between fetuses/infants and adults that are toxicologically important. These differences mainly involve variations in physiological transport 
systems that form during development (Ek et al. 2012). These transport mechanisms (influx and efflux) play an important role in the movement of amino acids and other vital substances across the blood-brain barrier in the developing brain; these transport mechanisms are far more active in the developing brain than in the adult. Because many drugs or potential toxins may be transported into the brain using these same transport mechanisms - the developing brain may be rendered more vulnerable than the adult. Thus, concern regarding possible involvement of the blood-brain barrier with enhanced susceptibility of the developing brain to toxins is valid. It is important to note however, that this potential selective vulnerability of the developing brain is associated with essential normal physiological mechanisms; and not because of an absence or deficiency of anatomical/physical barrier mechanisms.

The presence of these unique transport systems in the developing brain of the fetus/infant is intriguing; whether these mechanisms provide protection for the developing brain or render it more vulnerable to toxic injury is an important toxicological question. Chemical exposure should be assessed on a case-bycase basis. Research continues into the function and structure of the blood-brain barrier in early life (Kearns et al. 2003; Saunders et al. 2012; Scheuplein et al. 2002).

Many xenobiotic metabolizing enzymes have distinctive developmental patterns. At various stages of growth and development, levels of particular enzymes may be higher or lower than those of adults, and sometimes unique enzymes may exist at particular developmental stages (Komori et al. 1990; Leeder and Kearns 1997; NRC 1993; Vieira et al. 1996). Whether differences in xenobiotic metabolism make the child more or less susceptible also depends on whether the relevant enzymes are involved in activation of the parent compound to its toxic form or in detoxification. There may also be differences in excretion, particularly in newborns given their low glomerular filtration rate and not having developed efficient tubular secretion and resorption capacities (Altman and Dittmer 1974; NRC 1993; West et al. 1948). Children and adults may differ in their capacity to repair damage from chemical insults. Children also have a longer remaining lifetime in which to express damage from chemicals; this potential is particularly relevant to cancer.

Certain characteristics of the developing human may increase exposure or susceptibility, whereas others may decrease susceptibility to the same chemical. For example, although infants breathe more air per kilogram of body weight than adults breathe, this difference might be somewhat counterbalanced by their alveoli being less developed, which results in a disproportionately smaller surface area for alveolar absorption (NRC 1993). 
Limited data for TDI and MDI on children's susceptibility were identified. In the absence of data, it is assumed that the respiratory tract would be the most sensitive target of toxicity for both compounds. Two studies have examined the developmental toxicity and both reported skeletal effects. Exposure to TDI on GDs 6-15 resulted in poorly ossified cervical vertebrae at a concentration also resulting in markedly reduced maternal weight gain and respiratory symptoms (Tyl et al. 1999a). An increase in the occurrence of asymmetric sternebrae was observed in rats; maternal toxicity was limited to a decrease in food consumption (Buchsmann et al. 1996).

\subsection{BIOMARKERS OF EXPOSURE AND EFFECT}

Biomarkers are broadly defined as indicators signaling events in biologic systems or samples. They have been classified as markers of exposure, markers of effect, and markers of susceptibility (NAS/NRC 1989).

A biomarker of exposure is a xenobiotic substance or its metabolite(s) or the product of an interaction between a xenobiotic agent and some target molecule(s) or cell(s) that is measured within a compartment of an organism (NAS/NRC 1989). The preferred biomarkers of exposure are generally the substance itself, substance-specific metabolites in readily obtainable body fluid(s), or excreta. However, several factors can confound the use and interpretation of biomarkers of exposure. The body burden of a substance may be the result of exposures from more than one source. The substance being measured may be a metabolite of another xenobiotic substance (e.g., high urinary levels of phenol can result from exposure to several different aromatic compounds). Depending on the properties of the substance (e.g., biologic half-life) and environmental conditions (e.g., duration and route of exposure), the substance and all of its metabolites may have left the body by the time samples can be taken. It may be difficult to identify individuals exposed to hazardous substances that are commonly found in body tissues and fluids (e.g., essential mineral nutrients such as copper, zinc, and selenium). Biomarkers of exposure to TDI and MDI are discussed in Section 3.8.1.

Biomarkers of effect are defined as any measurable biochemical, physiologic, or other alteration within an organism that, depending on magnitude, can be recognized as an established or potential health impairment or disease (NAS/NRC 1989). This definition encompasses biochemical or cellular signals of tissue dysfunction (e.g., increased liver enzyme activity or pathologic changes in female genital epithelial cells), as well as physiologic signs of dysfunction such as increased blood pressure or decreased lung capacity. Note that these markers are not often substance specific. They also may not be directly 
adverse, but can indicate potential health impairment (e.g., DNA adducts). Biomarkers of effects caused by TDI and MDI are discussed in Section 3.8.2.

A biomarker of susceptibility is an indicator of an inherent or acquired limitation of an organism's ability to respond to the challenge of exposure to a specific xenobiotic substance. It can be an intrinsic genetic or other characteristic or a preexisting disease that results in an increase in absorbed dose, a decrease in the biologically effective dose, or a target tissue response. If biomarkers of susceptibility exist, they are discussed in Section 3.10, Populations That Are Unusually Susceptible.

\subsubsection{Biomarkers Used to Identify or Quantify Exposure to TDI and MDI}

A number of potential urinary and plasma biomarkers of exposure to TDI and MDI have been investigated. TDA, likely released by hydrolysis of protein adducts, has been measured in plasma and in acid- or alkaline-hydrolyzed urine as a biomarker of exposure to 2,4- and 2,6-TDI (Austin et al. 2007; Brorson et al. 1991; Geens et al. 2012; Sennbro et al. 2004; Sepai et al. 1995; Skarping et al. 1991; Tinnerberg et al. 1997, 2014). Both Geens et al. (2012) and Sennbro et al. (2004) observed strong correlations (coefficients ranging from 0.75 to 0.88 ) between personal air concentrations of 2,4- and 2,6-TDI and plasma and urinary levels of 2,4-, 2,6-, and total TDA in occupationally exposed persons. Similarly, the diamine metabolite of MDI (MDA) has been studied as a biomarker of exposure (Sabbioni et al. 2007; Schutze et al. 1995; Sennbro et al. 2003, 2006; Sepai et al. 1995). Sennbro et al. (2006) reported statistically significant, but not strong, correlation coefficients of $0.51-0.65$ for the association between personal air measurements of MDI and plasma or urinary levels of MDA (samples collected the same day as the air measurements; urinary samples were hydrolyzed). The authors noted that there was significant interindividual variation. Tinnerberg et al. (2014) also found correlations between TDA levels in hydrolyzed urine (creatinine adjusted or specific gravity adjusted) and TDA levels in hydrolyzed plasma; strong correlations were also found for MDA levels in hydrolyzed urine and hydrolyzed plasma. It was noted that GSTM1 polymorphisms modified the association between urine and plasma TDA levels.

To facilitate the distinction between background levels of exposure and occupational exposure, Sennbro et al. (2005) measured plasma and hydrolyzed urinary 2,4- and 2,6-TDA and MDA in workers with and without occupational exposure to isocyanates. Upper reference limits on the background biomarker levels were calculated using the receiver operator characteristic curve method; the results are shown in Table 3-13. TDA was detected infrequently in unexposed persons (detection frequencies ranging from 
2 to $15 \%$ ), while MDA was detected in nearly all (97\%) urinary and plasma samples (Sennbro et al. 2005).

Diamines may be present in the plasma and urine as a result of exposure to the corresponding diisocyanate or exposure to the diamine itself; thus, this biomarker is not specific to isocyanate exposure. Sabbioni et al. (2010, 2012) and Kumar et al. (2009) developed methods for measuring TDI and MDI adducts of albumin that are specific to isocyanates. Sabbioni et al. (2012) detected 2,4- and 2,6-TDI adducts with the lysine of albumin in blood samples taken from 10 workers 26 days after they were accidentally exposed to TDI (details of the exposure were not provided). Three lysine adducts were detected: $\mathrm{N}^{\varepsilon}-\left[\left(\{3\right.\right.$-amino-4-methylphenyl $\}$ amino)carbonyl]-lysine (3A4MP-Lys); $\mathrm{N}^{\varepsilon}-[(\{5$-amino2-methylphenyl $\}$ amino)carbonyl]-lysine (5A2MP-Lys); and $\mathrm{N}^{\varepsilon}$-[( \{3-amino-2-methylphenyl $\}$ amino)carbonyl]-lysine (3A2MP-Lys). The adducts were detected at concentrations ranging from 29 to $269 \mathrm{fmol} / \mathrm{mg}$. Repeat analysis of selected samples showed coefficients of variation ranging from 2.1 to $6.6 \%$ for the three adducts. Half-lives of the albumin adduct levels were estimated to be 21.7 days for 3A4MP-Lys, 40.3 days for 5A2MP-Lys, and 19.6 days for 3A2MP-Lys.

Sabbioni et al. $(2010,2016)$ likewise detected albumin adducts of MDI in workers exposed to MDI; the adducts were identified as $\mathrm{N}^{6}-[(\{4-[4-$ aminobenzyl $]$ phenyl $\}$ amino)carbonyl $]$ lysine (MDI-Lys) and $\mathrm{N}^{6}$-[(\{4-[4-acetylaminobenzyl]phenyl $\}$ amino)carbonyl]lysine (AcMDI-Lys). The level of MDI-Lys was correlated with MDA in acid- and alkaline-hydrolyzed urine, but not with measurements of hemoglobin adducts of MDA. The authors (Sabbioni et al. 2010) noted that measurement of hemoglobin adducts only would have underestimated the number of exposed workers; only $27 \%$ of workers exhibited hemoglobin adducts of MDI, while albumin adducts were observed in $64 \%$ of workers.

In summary, recent exposure to diisocyanates may be reflected in TDA or MDA levels in acid- or alkaline-hydrolyzed urine or plasma, but these biomarkers may also be present in urine and plasma as a result of exposure to the diamines themselves (TDA and MDA). Background levels of TDA and MDA in urine and plasma should be considered in the interpretation of measured values from subjects with 


\section{Table 3-13. Upper Reference Limits for Biomarkers of Exposure to Toluene Diisocyanate and Methylenediphenyl Diisocyanate}

\begin{tabular}{lllllrc}
\hline & $\begin{array}{l}\text { Median } \\
(\mu \mathrm{g} / \mathrm{L})\end{array}$ & $\begin{array}{l}\mathrm{R}^{\text {Range }}(\mu \mathrm{g} / \mathrm{L}) \\
\text { Biomarker }\end{array}$ & $\begin{array}{l}\text { Frequency of Upper } \\
\text { detection } \\
(\%)\end{array}$ & $\begin{array}{l}\text { reference } \\
\text { limit }(\mu \mathrm{g} / \mathrm{L})\end{array}$ & $\begin{array}{l}\text { Sensitivity } \\
(\%)\end{array}$ & $\begin{array}{l}\text { Specificity } \\
(\%)\end{array}$ \\
\hline Urinary 2,4-TDA & $<0.1$ & $<0.1-0.4$ & 7 & 0.4 & 94 & 100 \\
Plasma 2,4-TDA & $<0.1$ & $<0.1-0.1$ & 2 & 0.1 & 100 & 100 \\
Urinary 2,6-TDA & $<0.1$ & $<0.1-0.2$ & 15 & 0.2 & 97 & 100 \\
Plasma 2,6-TDA & $<0.1$ & $<0.1-0.1$ & 2 & 0.2 & 99 & 100 \\
Urinary MDA & 0.2 & $<0.05-3.0$ & 97 & 0.5 & 100 & 97 \\
Plasma MDA & 0.2 & $<0.05-0.4$ & 97 & 0.4 & 88 & 100 \\
\hline
\end{tabular}

aTDA and MDA measured in 120 unexposed workers from five workplaces in Sweden.

MDA = methylenediphenyl amine $;$ TDA = toluene diamine

Source: Sennbro et al. 2005 
unknown exposure. Finally, serum levels of albumin adducts of TDI or MDI are specific to diisocyanate exposure and, due to their longer half-life, may be useful in assessing exposure over the preceding weeks. These biomarkers have been shown to be useful for identifying exposure to TDI or MDI; however, no biomarkers have been identified that allow for quantification of exposure.

\subsubsection{Biomarkers Used to Characterize Effects Caused by TDI and MDI}

One of the prominent health effects associated with inhalation exposure to TDI or MDI is the induction of occupational asthma. Several tests have been developed to diagnosis occupational asthma; these include measurement of peak expiratory flow rate, nonspecific bronchial provocation testing, specific immunological testing, skin-prick testing, specific inhalational challenge testing, and nasal lavage testing (Jolly et al. 2015; Ott et al. 2007). With the exception of the specific immunological and specific inhalational challenge tests, these tests are not specific to TDI or MDI exposure. Although specific inhalational challenge testing is considered one of the better tests for diagnosing sensitizer-induced occupational asthma (Jolly et al. 2015; Ott et al. 2007; Vandenplas et al. 2014), the American College of Occupational and Environmental Medicine notes that it is a highly technical test and has the potential for inducing severe adverse effects, including fatalities (Jolly et al. 2015). Several investigators have evaluated the usefulness of specific immunological tests, TDI-/MDI-specific IgE and IgG levels, for diagnosing TDI-/MDI-induced occupational asthma. As discussed in Section 3.2.1.2, a number of occupational exposure studies have reported IgG- or IgE-specific antibodies to TDI-HSA in workers with TDI-induced asthma (Baur and Fruhmann 1981; Cvitanovic et al. 1989; Park and Nahm 1996; Park et al. 1999; Pezzini et al. 1984; Sharifi et al. 2013) or MDI-HSA in MDI workers (Hur et al. 2008; Pezzini et al. 1984; Tse et al. 1985; Zeiss et al. 1980). However, specific IgG or IgE antibodies were typically observed in a small percentage of TDI workers (16-57\%). In a small study of MDI workers (Budnik et al. 2013), MDI-specific IgE antibodies were detected in four of seven workers with confirmed MDIinduced asthma, none of the four workers with hypersensitivity pneumonitis, and none of the six asymptomatic workers. In contrast, IgG antibody levels were detected in four of seven workers with asthma, four of four subjects with hypersensitivity pneumonitis, and one of six asymptomatic workers. In a review conducted by Wisnewski (2007), isocyanate-specific serum IgE has been found in up to $50 \%$ of workers. It is noted that isocyanate-specific IgE levels have a half-life of approximately 2 days and levels can drop below the detection limit following brief periods with no exposure (Wisnewski 2007). Palikhe et al. (2011) also noted that the prevalence of $\operatorname{IgG}$ antibodies was not a reliable biomarker because the prevalence was too low. This is less of an issue for $\mathrm{IgG}$, which has a half-life of approximately 30 days. The American College of Occupational and Environmental Medicine concluded that there is insufficient 
evidence to assess the usefulness of IgE testing for low molecular weight antigens (Jolly et al. 2015); it is noted that this recommendation is not specific to isocyanates.

Several studies have examined other biomarkers that could be used for early diagnosis of TDI-induced asthma. Significantly lower matrix metalloproteinase-9 (MMP-9) level and higher VEGF levels were found in workers with TDI-induced asthma, as compared to asymptomatic workers (Kim et al. 2011; Palikhe et al. 2011). The sensitivity and specificity of the MMP-9 were 79.7 and $80.0 \%$, respectively (Kim et al. 2011). Combining several variables (MMP-9, VEGF, and interleukin-8) increased the sensitivity to $82.6 \%$, but decreased the specificity to $75.8 \%$. Kim et al. (2012) found that the levels of vitamin D-binding protein (VDBP) were significantly higher in workers with isocyanate-induced occupational asthma, as compared to asymptomatic workers from the same working environment, or in unexposed healthy subjects; the sensitivity and specificity was 69 and 81\%, respectively. Ye et al. (2006) examined the usefulness of three cytokeratins (CK8, CK18, and CK19) for identifying TDI-induced asthma. Significantly higher IgG antibody levels of CK8, CK18, and CK19 were found in the workers with TDI-induced asthma as compared to asymptomatic workers, subjects with allergic asthma, and healthy subjects. The sensitivity and specificity for C8, CK18, and CK19 antibodies were 18.2 and $95.2 \%, 26.2$ and $93.5 \%$, and 26.2 and $93.5 \%$, respectively.

\subsection{INTERACTIONS WITH OTHER CHEMICALS}

No studies were identified examining the influence of other chemical on the toxicity or toxicokinetics of TDI or MDI.

\subsection{POPULATIONS THAT ARE UNUSUALLY SUSCEPTIBLE}

A susceptible population will exhibit a different or enhanced response to TDI or MDI than will most persons exposed to the same level of TDI or MDI in the environment. Factors involved with increased susceptibility may include genetic makeup, age, health and nutritional status, and exposure to other toxic substances (e.g., cigarette smoke). These parameters result in reduced detoxification or excretion of TDI and MDI, or compromised function of organs affected by TDI and MDI. Populations who are at greater risk due to their unusually high exposure to TDI and MDI are discussed in Section 6.7, Populations with Potentially High Exposures.

There are data to suggest that there is a genetic susceptibility factor that may predispose certain individuals to develop occupational asthma as a result of exposure to TDI or MDI. Several investigators 
have examined possible associations between genetic polymorphisms and diisocyanate-induced asthma. Vucesoy et al. (2012) demonstrated that genetic variants of antioxidant defense genes are associated with increased susceptibility to diisocyanate (TDI, MDI, or HDI)-induced asthma in a study of diisocyanate workers with confirmed occupational asthma, workers reporting respiratory symptoms who did not react to diisocyanate challenge, and asymptomatic HDI workers. Significant associations between diisocyanate-induced asthma and three types of variant genotypes (manganese superoxide dismutase [SOD2] rs4880, microsomal epoxide hydrolase [EPHX1] 2740171, and a glutathione S-transferase [GSTP1] rs1695) were noted. Blindow et al. (2015) also found greater responses to specific inhalation challenges among symptomatic isocyanate workers with GST1 deletions and a higher risk of developing IgE-mediated reactions in workers with GSTM1 deletions. In a study of 84 workers with TDI-induced occupational asthma, higher bronchial hyperresponsiveness was observed in TDI workers with asthma with polymorphisms of catenin alpha 3, alpha-T-catenin (CTNNA3) (Kim et al. 2009). Similar results were observed in a second study of diisocyanate workers; increased risks of CTNNA3 polymorphisms were found among workers with occupational asthma, but not among workers without asthma (Bernstein et al. 2013).

Several studies have examined the frequency of human leukocyte antigen class II (HLA) haplotypes among with TDI-induced asthma. Higher frequencies of haplotypes DRB1*15-DPB1*05 (Kim et al. 2006) and DRB1*1501-DQB1*0602-DPB1*0501 (Choi et al. 2009) and the allele DQB1*0503 and the allelic combination of DQB $1 * 0201 / 0301$ (Bignon et al. 1994) were found among workers with TDIinduced asthma. Similarly, Yucesoy et al. (2014) found increases in the susceptibility to diisocyanateinduced asthma among diisocyanate workers with single nucleotide polymorphisms in HLA-E HLADPB1, HLA-DOA, or HLA-DQA2 genes. Both Kim et al. (2006) and Beghe et al. (2004) found an alteration in the distribution of HLA class I antigens in subjects with TDI-induced asthma. Ye et al. (2010) found no differences in the allelic, genotypic, or haplotypic frequencies of beta 2-adrenergic receptor gene (ADRB2) polymorphisms among TDI workers with occupational asthma, asymptomatic workers, or controls with no TDI exposure. However, significant associations between two ADRB2 polymorphisms (Arg16Gly and Arg173Arg single nucleotide polymorphisms) and the prevalence of specific IgE antibodies to TDI-HSA were found among TDI workers and a significantly higher TDI-HSA specific IgE sensitization was found in workers with the ADRB2 ht1/ht1 homozygote. Broberg et al. (2008) found that an increased risk of eye symptoms was associated with the CYP1A1*2A variant and an increased risk of wheezing was associated with CYP1A1*2B. Studies by Yucesoy et al. $(2015,2016)$ identified several gene and single nucleotide polymorphisms that may be associated with susceptibility to diisocyanate-induced asthma. Single nucleotide polymorphisms mapping to several genes including 
TNFa, TGB1, PTGS1, PTGS2, HERC2, CDH17, and ODZ3 have been found to contribute to diisocyanate-induced asthma susceptibility.

Studies examining clinical features of subjects with suspected occupational asthma found no differences in the incidence of atopy among workers who reacted to a TDI challenge and workers not reacting to the TDI challenge (Mapp et al. 1988; Moscato et al. 1991; Paggiaro et al. 1984). Significantly fewer subjects reacting to TDI were found to be current smokers; although a higher percentage of ex-smokers were found among the TDI reactors (Moscato et al. 1991; Paggiaro et al. 1984). One study found a higher number of workers with positive skin tests to common allergens among the reactors (Paggiaro et al. 1984).

\subsection{METHODS FOR REDUCING TOXIC EFFECTS}

This section will describe clinical practice and research concerning methods for reducing toxic effects of exposure to TDI and MDI. Because some of the treatments discussed may be experimental and unproven, this section should not be used as a guide for treatment of exposures to TDI and MDI. When specific exposures have occurred, poison control centers, board certified medical toxicologists, board-certified occupational medicine physicians and/or other medical specialists with expertise and experience treating patients overexposed to TDI and MDI can be consulted for medical advice. The following texts provide specific information about treatment following exposures to TDI and MDI:

Blanc PD. 2018. Section II: Specific poisons and drugs: Diagnosis and treatment: Isocyanates. In: Poisoning \& drug overdose. 7th ed. McGraw-Hill Education.

https://accessmedicine.mhmedical.com/book.aspx?bookid=2284. May 30, 2018.

Leikin JB, Paloucek FP. 2008. Methylene diisocyanate and toluene diisocyanate. In: Poisoning and toxicology handbook. 4th ed. Boca Raton, FL: CRC Press, 824; 857-858.

Vena J, McKay C. 2007. Isocyanates and related compounds. In: Haddad and Winchester's clinical management of poisoning and drug overdose. 4th ed. Philadelphia, PA: Saunders Elsevier, 1317-1322.

Additional relevant information can be found in the front section of this profile under QUICK REFERENCE FOR HEALTH CARE PROVIDERS.

\subsubsection{Reducing Peak Absorption Following Exposure}

No studies were identified that examined reducing peak absorption of TDI or MDI following exposure. 


\subsubsection{Reducing Body Burden}

No studies were identified that examined reducing body burden of TDI or MDI following exposure.

\subsubsection{Interfering with the Mechanism of Action for Toxic Effects}

Several studies have examined the effectiveness of asthma medication or corticosteroid medication inhibiting the asthmatic reaction and nonspecific airway reactivity associated with TDI exposure in sensitized individuals. An acute treatment course with ketotifen, atropine, slow-release verapamil, or cromolyn did not prevent dual and/or late asthmatic reactions in TDI-sensitized individuals receiving an inhalation challenge with TDI (Mapp et al. 1987; Paggiaro et al. 1987; Tossin et al. 1989). Ketotifen, verapamil, and cromolyn also did not alter bronchial responsiveness to methacholine (Mapp et al. 1987; Tossin et al. 1989). In contrast, administration of beclomethasone or prednisone prevented the asthmatic reaction and airway hyperresponsiveness following a TDI inhalation challenge (Boschetto et al. 1987; Mapp et al. 1987). Slow-release theophylline partially inhibited the immediate and late asthmatic reaction to TDI but did not alter airway hyperresponsiveness (Mapp et al. 1987). In subjects receiving a 5-month treatment with beclomethasone, there was an improvement in the response to TDI inhalation challenge 1 month post-treatment; however, a similar improvement was found in untreated controls (Maestrelli et al. 1993). However, beclomethasone treatment did improve airway hyperresponsiveness to methacholine, a finding not observed in the untreated controls.

\subsection{ADEQUACY OF THE DATABASE}

Section 104(I)(5) of CERCLA, as amended, directs the Administrator of ATSDR (in consultation with the Administrator of EPA and agencies and programs of the Public Health Service) to assess whether adequate information on the health effects of TDI and MDI is available. Where adequate information is not available, ATSDR, in conjunction with the National Toxicology Program (NTP), is required to assure the initiation of a program of research designed to determine the adverse health effects (and techniques for developing methods to determine such health effects) of TDI and MDI.

The following categories of possible data needs have been identified by a joint team of scientists from ATSDR, NTP, and EPA. They are defined as substance-specific informational needs that if met would reduce the uncertainties of human health risk assessment. This definition should not be interpreted to mean that all data needs discussed in this section must be filled. In the future, the identified data needs will be evaluated and prioritized, and a substance-specific research agenda will be proposed. 


\subsubsection{Existing Information on Health Effects of TDI and MDI}

The existing data on health effects of inhalation, oral, and dermal exposure of humans and animals to TDI and MDI are summarized in Figure 3-6 and 3-7, respectively. The purpose of these figures is to illustrate the existing information concerning the health effects of TDI and MDI. Each dot in the figure indicates that one or more studies provide information associated with that particular effect. The dot does not necessarily imply anything about the quality of the study or studies, nor should missing information in this figure be interpreted as a "data need". A data need, as defined in ATSDR's Decision Guide for Identifying Substance-Specific Data Needs Related to Toxicological Profiles (ATSDR 1989), is substance-specific information necessary to conduct comprehensive public health assessments. Generally, ATSDR defines a data gap more broadly as any substance-specific information missing from the scientific literature.

\subsubsection{Identification of Data Needs}

Acute-Duration Exposure. Although several case reports of single exposures to TDI (Axford et al. 1976; Le Quesne et al. 1976; Schmidt-Nowara et al. 1973; Singer and Scott 1987; Vandenplas et al. 1992; Yoshizawa et al. 1989) and MDI (Chang and Karol 1984; Suojalehto et al. 2011) have reported respiratory effects following an acute exposure, they did not include monitoring data. Several acute exposure experimental studies have examined lung function following a single exposure to TDI (Chester et al. 1979; Vandenplas et al. 1999). Animal studies have examined the toxicity of TDI (Aoyama et al. 1994; Arts et al. 2008; Buckley et al. 1984; Gagnaire et al. 1996; Gordon et al. 1985; Johnson et al. 2007; Marek et al. 1999; Sangha and Alarie 1979; Wong et al. 1985; Zissu 1995) and MDI (Marek et al. 1999); the observed effects on the respiratory system include histological damage to the nasal cavity and lungs and increased airway responsiveness. In general, these studies did not examine end points outside of the target tissues, the respiratory tract. The database for TDI was considered adequate for derivation of an acute-duration inhalation MRL; however, a repeated exposure study examining lung function in humans would provide support for this MRL. The database was not considered adequate for derivation of an acute-duration inhalation MRL for MDI and studies are needed that provide concentration-response data. Acute-duration data on the toxicity of TDI following oral exposure are limited to single and 14-day exposure studies that found increases in mortality and decreases in body weight gain (NTP 1986); other 
3. HEALTH EFFECTS

Figure 3-6. Existing Information on Health Effects of Toluene Diisocyanate

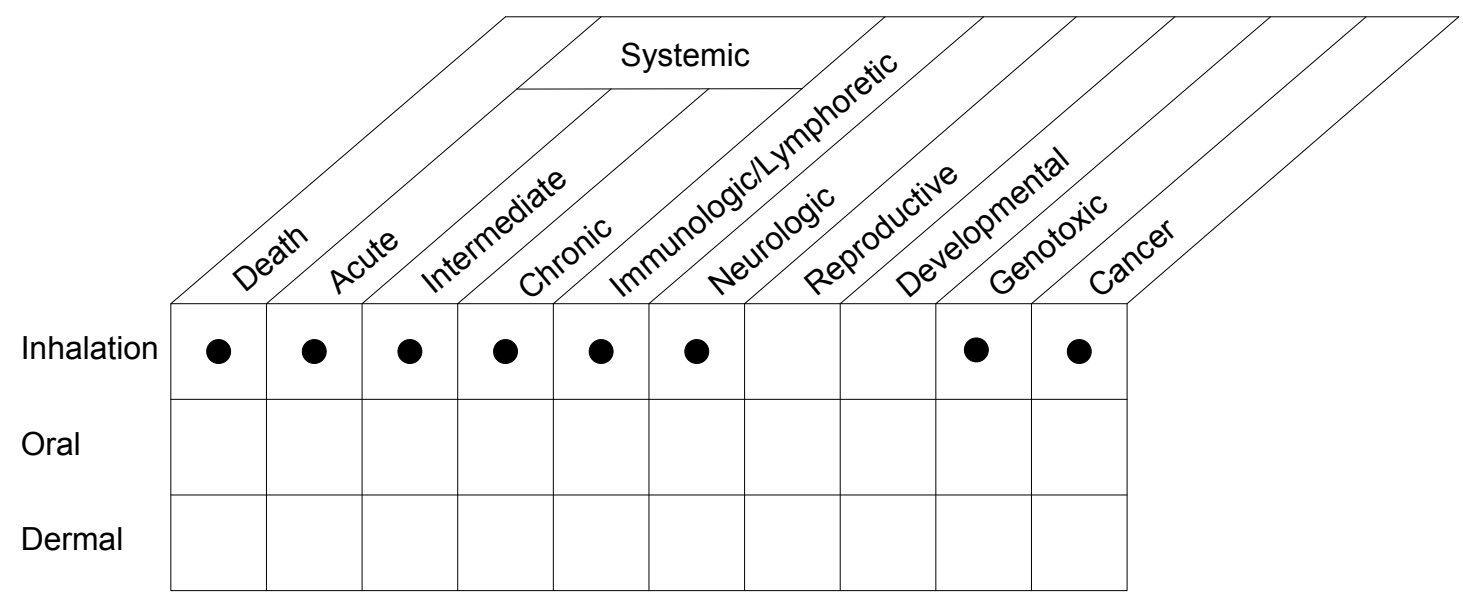

Human

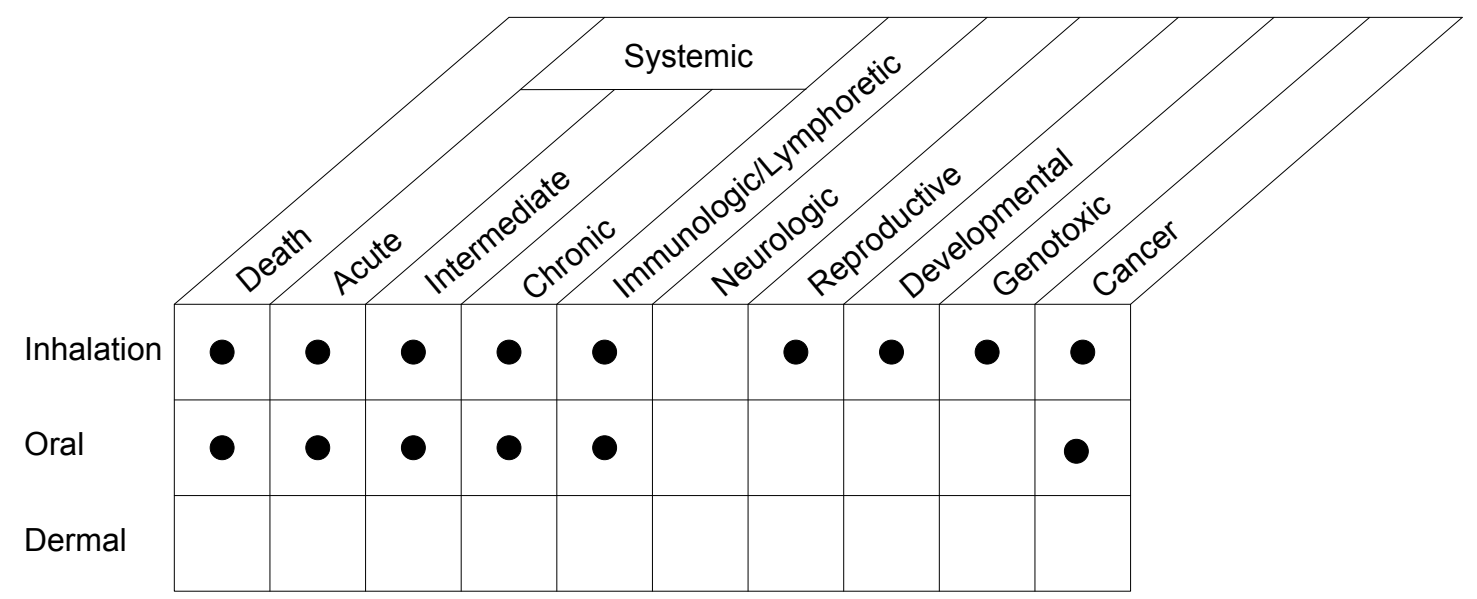

Animal

Existing Studies 
Figure 3-7. Existing Information on Health Effects of Methylenediphenyl Diisocyanate

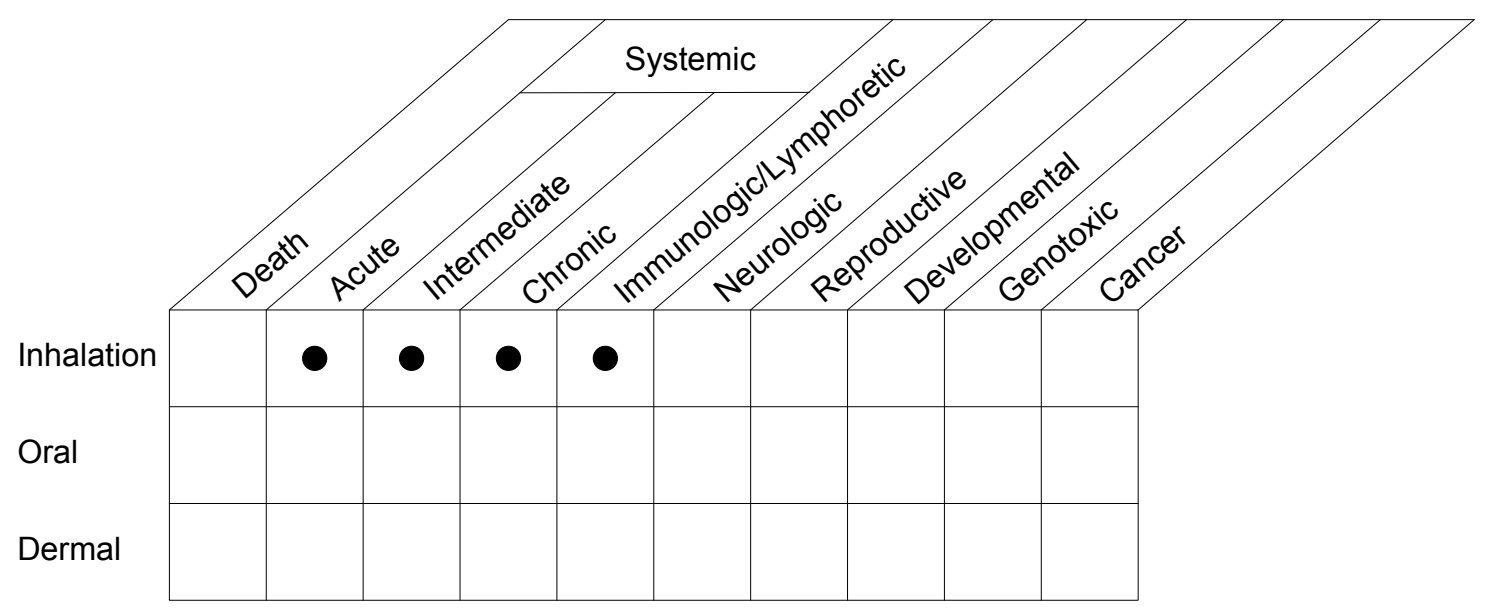

Human

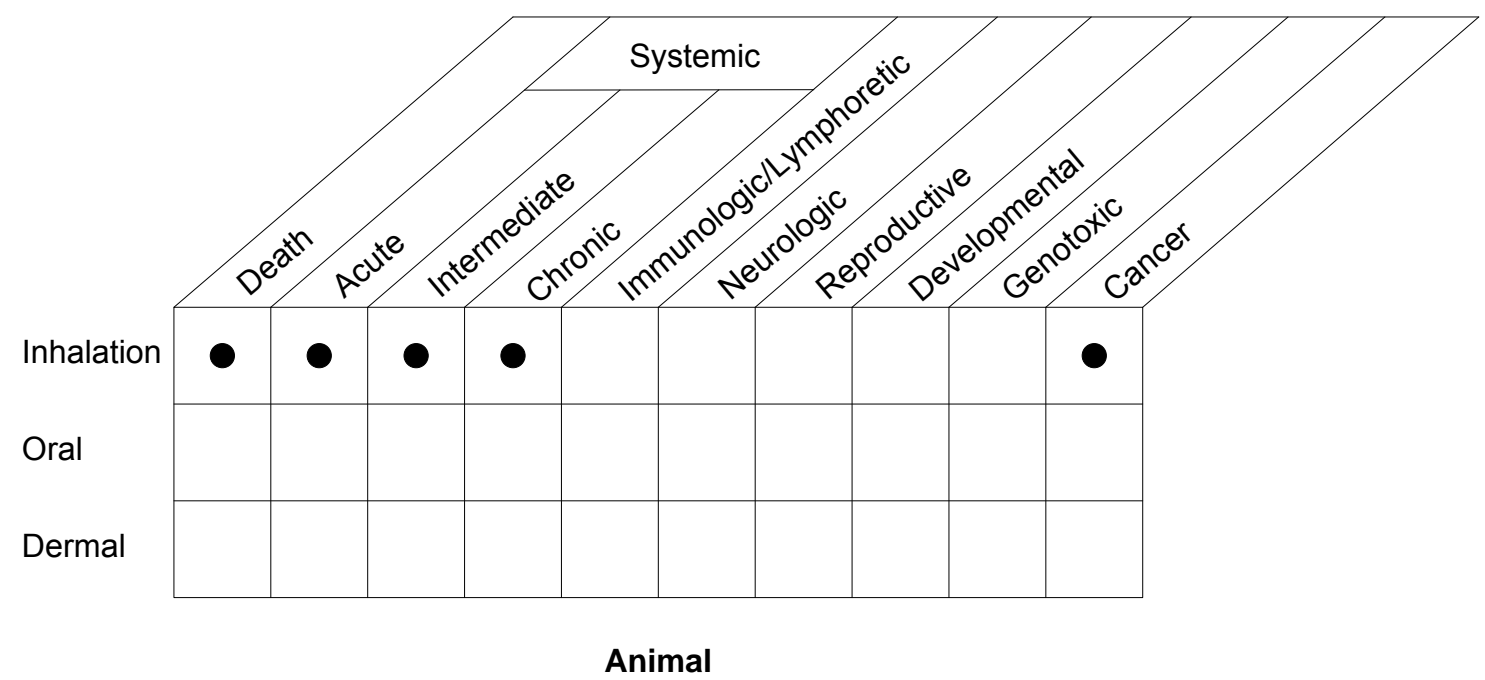

Existing Studies 
end points were not examined. No studies examined the acute-duration oral toxicity of MDI. Studies that examine the dermal toxicity of TDI and MDI are needed, particularly since ocular and dermal irritation has been reported in workers exposed to airborne TDI and MDI.

Intermediate-Duration Exposure. Occupational exposure studies typically involve chronicduration exposure; however, there is suggestive evidence that effects can occur after several months of exposure (Clark et al. 1998). Three studies have examined the toxicity of TDI to the respiratory tract of animals following intermediate-duration exposure (Matheson et al. 2005; Wong et al. 1985; Zissu 1995). The studies reported histological damage in the nasal cavity and lungs and an increase in airway hyperresponsiveness. One study examined the intermediate-duration toxicity of MDI in animals (Marek et al. 1999), but the study was limited to the examination of airway hyperresponsiveness and did not include a histological examination of the respiratory tract. Although the database was considered inadequate for the derivation of intermediate-duration inhalation MRLs, the chronic-duration inhalation MRLs could be used for intermediate duration.

Chronic-Duration Exposure and Cancer. The chronic toxicity of TDI and MDI has been extensively investigated in occupational studies of production facilities and polyurethane manufacturing facilities and in workers applying polyurethane varnishes (Bodner et al. 2001; Burge 1982; Clark et al. 1998, 2003; Diem et al. 1982; Jang et al. 2000; Liss et al. 1988; Mapp et al. 1998; Moscato et al. 1991; Musk et al. 1982; Ott et al. 2000; Paggiaro et al. 1986, 1993; Sulotto et al. 1990; Zammit-Tabona et al. 1983). These studies provide strong evidence that the respiratory tract is the most sensitive target of TDI or MDI toxicity. Longitudinal studies of TDI workers provide sufficient monitoring data to allow for the derivation of a chronic-duration inhalation MRL (Clark et al. 1998; Diem et al. 1982). Monitoring data in the MDI studies were not considered adequate. The chronic toxicity of TDI and MDI has also been investigated in two animal studies (Loeser 1983; Reuzel et al. 1994); these studies also identify the respiratory tract as the most sensitive target. A chronic-duration rat study (Reuzel et al. 1994) was used to derive a chronic-duration inhalation MRL for MDI. Data on the chronic toxicity of orally administered TDI was investigated by NTP (1986). No long-term studies on the dermal toxicity of TDI or MDI were located.

There are limited human data on the carcinogenicity of TDI or MDI. Three studies of polyurethane foam manufacturing workers provide some suggestive evidence of an increased lung cancer risk, but the association with diisocyanates was not established (Mikoczy et al. 2004; Schnorr et al. 1996; Sorahan and Nichols 2002). No significant increases in lung cancer were observed in animals following TDI (Loeser 
1983) or MDI (Reuzel et al. 1994) exposure. Increases in tumor incidence were observed in a chronicduration gavage study of TDI (NTP 1986). The relevance of the findings in this gavage study to humans exposed to TDI via ingestion has been questioned due to likely toxicokinetic differences between ingestion and gavage administration of this very reactive compound. Additional studies are needed to address these concerns.

Genotoxicity. Both TDI and MDI have been tested for genotoxicity in prokaryotic and mammalian systems in vitro. TDI is not stable in most in vitro test systems; TDA is formed rapidly in the vehicles used in available genotoxicity tests, and it has been suggested that TDA is responsible for positive mutagenicity tests of TDI (Seel et al. 1999). Mixed results have been found in in vivo tests for genotoxic end points. However, the interpretation of the results of some of the studies is limited by methodological problems or poor reporting. Additional in vivo studies would facilitate assessing the interpretation of the genotoxicity data.

MDI also degrades to MDA in in vitro test systems using DMSO or EGDE, but at a much slower rate than TDI does. When MDI was tested for genotoxicity in EGDE (in which MDI is more stable), the results were negative, while positive results were seen when DMSO was used as the solvent (Herbold et al. 1998). There is little information on genotoxicity of MDI in humans or non-human mammalian systems tested in vivo.

Reproductive Toxicity. The available data on the reproductive toxicity of TDI consists of a 2-generation study in rats exposed via inhalation (Tyl et al. 1999b) in which no effects on reproductive parameters were observed. No data on the reproductive toxicity of MDI in humans or animals exposed by any route were located in the available literature.

Developmental Toxicity. A single developmental toxicity study of TDI in rats exposed via inhalation (Tyl et al. 1999a) showed poorly ossified cervical centra at an exposure concentration that also resulted in maternal toxicity; no other exposure-related effects were seen in the offspring. Similarly, there is one study of MDI developmental toxicity in rats exposed via inhalation (Buchsmann et al. 1996); an increased incidence of litters with asymmetric sternebrae was the only treatment-related effect. There are no data on the developmental toxicity of TDI or MDI via oral or dermal exposure routes.

Immunotoxicity. Available literature did not include human or animal studies evaluating immunological effects after exposure to TDI or MDI. Occupational asthma observed in TDI (Mapp et al. 
1988; Moller et al. 1986; Moscato et al. 1991; Padoan et al. 2003; Paggiaro et al. 1984, 1986; Saetta et al. 1995) and MDI (Bonauto et al. 2005; Burge 1982; Chang and Karol 1983; Hur et al. 2008; Liss et al. 1988; Suojalehto et al. 2011; Woellner et al. 1997; Zammit-Tabona et al. 1983) workers may be the result of immunotoxicity; however, additional research is needed to identify the mechanism of toxicity.

Neurotoxicity. The database for diisocyanates (including both TDI and MDI) does not include any information on neurological effects of chronic-duration exposure. Human and/or animal studies are warranted given the suggestive evidence for long-term impairment after acute exposure (Le Quesne et al. 1976; Singer and Scott 1987). In addition, no information on potential neurotoxicity of MDI was located; animal and/or mechanistic studies are needed to evaluate this end point.

Epidemiological and Human Dosimetry Studies. Numerous studies have examined the toxicity of TDI (Bodner et al. 2001; Clark et al. 1998, 2003; Diem et al. 1982; Mapp et al. 1998; Moscato et al. 1991; Ott et al. 2000; Paggiaro et al. 1986, 1993) and MDI (Burge 1982; Jang et al. 2000; Liss et al. 1988; Musk et al. 1982; Sulotto et al. 1990; Zammit-Tabona et al. 1983) in occupationally exposed subjects; additionally, two studies have examined possible adverse health outcomes in residents living near TDI sources (Nuorteva et al. 1987; Wilder et al. 2011). These studies provide strong evidence that the respiratory tract is the most sensitive target resulting in occupational asthma, respiratory symptoms, and impaired lung function. However, many studies are lacking reliable monitoring data, particularly in studies examining workers exposed to MDI. Several occupational exposure studies have also assessed the potential association between inhalation exposure to diisocyanates and cancer (Mikoczy et al. 2004; Schnorr et al. 1996; Sorahan and Nichols 2002) and found suggestive evidence between work in the polyurethane foam manufacturing industry and lung cancer in female workers, but an association with diisocyanate exposure was not established. Significant limitations of all three studies included the lack of control for confounding factors, such as smoking and alcohol consumption, and coexposure to mixtures of compounds including those other than diisocyanates. Continued epidemiological research focused on improving exposure estimates (for example, using biomarkers of exposure) and control for confounding is recommended.

\section{Biomarkers of Exposure and Effect.}

Exposure. Biomarkers of exposure to TDI and MDI include the diamine hydrolysis products (TDA and MDA) as well as hemoglobin and albumin adducts of the isocyanates. Improvements in the standardization of methods used to pretreat biological samples (e.g., acid- and alkaline-hydrolysis) prior 
to analysis could help to refine the predictive relationship between levels of metabolites or adducts in the samples and exposure.

Effect. Given the continued decline in lung function and the delay in recovery when TDI- or MDIsensitized workers remain in jobs involving TDI/MDI exposure (Banks et al. 1990; Mapp et al. 1988; Padoan et al. 2003; Paggiaro et al. 1984; Park and Nahm 1997), biomarkers that would allow for early detection of sensitization are needed. Investigators have identified several potential biomarkers of effect including MMP-9 (Kim et al. 2011), VEGF (Kim et al. 2011), cytokeratins (Ye et al. 2006), which may be useful for early detection of occupational asthma. Additional studies in sensitized workers are needed to evaluate the usefulness of these biomarkers and others for early detection of TDI and/or MDI sensitization.

Absorption, Distribution, Metabolism, and Excretion. Human and animal data suggest that TDI and MDI are absorbed to some extent via all exposure routes. Both TDI and MDI combine readily with biological macromolecules including hemoglobin, albumin, and others. As a consequence of their reactivity, these compounds or their reaction products are often found at higher concentrations at the site of entry into the body early in exposure, and may continue to be distributed from the site of entry long after exposure has terminated. Once in the body, conjugated TDI and MDI are distributed to a large number of tissues, albeit at low levels.

The metabolic fate of TDI depends on the exposure route. After oral exposure, TDI is hydrolyzed in the gastrointestinal tract to TDA, and subsequently either absorbed and metabolized further or reacted with unhydrolyzed TDI to form polyurea polymers that pass unabsorbed through the gastrointestinal tract. However, after inhalation exposure, the primary fate of TDI appears to be conjugation reactions; little TDI, if any, is hydrolyzed to TDA. In humans exposed experimentally, urinary excretion of the TDI metabolite TDA exhibits a biphasic pattern, with an initial rapid phase followed by a slower phase. The primary route of TDI elimination after inhalation or oral exposure of rats is via the feces, which may include material absorbed and excreted via the bile.

Few data on the metabolism and elimination of MDI were identified in the available literature. Like TDI, MDI is excreted primarily in the feces of rats after inhalation exposure, and there is evidence for biliary excretion of MDI. As there are no data on the pharmacokinetic behavior of MDI after oral exposure in humans or animals, research on the route-dependence of MDI metabolism would be particularly beneficial. 
PBPK models of TDI and MDI pharmacokinetics have not yet been developed.

Comparative Toxicokinetics. There are few data on species differences in the toxicokinetics of TDI, and no data on this issue for MDI. Research to assess species differences in MDI toxicokinetics would provide important information regarding the extrapolation from animal toxicity information to human effects.

Methods for Reducing Toxic Effects. Several investigators have examined the effectiveness of asthma medication or corticosteroids for treating occupational asthma induced by TDI (Boschetto et al. 1987; Maestrelli et al. 1993; Mapp et al. 1987; Paggiaro et al. 1987; Tossin et al. 1989). Although some beneficial effects were observed when asthmatic subjects were challenged with TDI during the treatment course (Boschetto et al. 1987; Mapp et al. 1987), long-term benefits have not been found (Maestrelli et al. 1993). Since a large number of subjects with occupational asthma do not recover even after exposure cessation, additional research is needed on the treatment of TDI- or MDI-induced occupational asthma. In addition, studies are needed to assess the treatment of other TDI- or MDI-related health effects such as decreased lung function.

Children's Susceptibility. Data needs relating to both prenatal and childhood exposures, and developmental effects expressed either prenatally or during childhood, are discussed in detail in the Developmental Toxicity subsection above.

No information on children's susceptibility to TDI or MDI toxicity was identified and it is not known if children would be more susceptible to the irritating properties of TDI or MDI. Although TDI/MDI exposure primarily occurs in the workplace, communities living near TDI or MDI sources or the commercial use of products containing uncured TDI or MDI can result in exposure to children. Two studies have examined communities living near a TDI source (Nuorteva et al. 1987; Wilder et al. 2011), one of these studies included children (Nuorteva et al. 1987); however, the data were not analyzed by age group. Given the potential for exposure, studies are needed to address this data gap.

Child health data needs relating to exposure are discussed in Section 6.8.1, Identification of Data Needs: Exposures of Children. 


\subsubsection{Ongoing Studies}

The following ongoing studies pertaining to TDI and MDI have been identified in the National Institutes of Health (NIH) Research Portfolio Online Reporting Tools (RePORTER 2016) database.

Adam Wisnewski at L2 Diagnostics, LLC is developing two immunoassays that can be used to biomonitor MDI exposure in the workplace. The two biomarkers being investigated are MDI-specific IgG antibodies and MDI albumin conjugates 


\section{CHEMICAL AND PHYSICAL INFORMATION}

\subsection{CHEMICAL IDENTITY}

Information regarding the chemical identity of TDI and MDI is provided in Table 4-1.

TDI and MDI have widespread commercial use due to their reactivity and versatility. TDI and MDI and their related polyisocyanates make up $>90 \%$ of the commercial market (EPA 2011a). Commercial-grade TDI is made up of an 80:20 mixture of isomers 2,4- and 2,6-TDI and represents $>95 \%$ of TDI industrial use (NIOSH 1989).

Commercial-grade MDI consists of several isomers, including 4,4'-, 2,4'-, and 2,2'-MDI, as well as oligomers and polymeric compounds. The principal commercial product of MDI is made up of a mixture of all of these components, with a typical composition in the range of 40-50\% 4,4'-MDI, 2.5-4.0\% 2,4'-MDI, and $0.1-0.2 \%$ 2,2'-MDI; the remainder is oligomers. 4,4'-MDI is the most commercially common isomer and is referred to as pure MDI (IARC 1999a).

\subsection{PHYSICAL AND CHEMICAL PROPERTIES}

Information regarding the physical and chemical properties of TDI and MDI is provided in Table 4-2. 


\section{Table 4-1. Chemical Identity of Toluene Diisocyanate and Methylenediphenyl Diisocyanate $^{a}$}

\begin{tabular}{|c|c|c|}
\hline Characteristic & Methylenediphenyl diisocyanate & Toluene diisocyanate \\
\hline Chemical name & Benzene, 1,1'-methylenebis(4-isocyanato-) & $\begin{array}{l}\text { Benzene, 1,3-diisocyanato- } \\
\text { methyl- }\end{array}$ \\
\hline Synonyms(s) & $\begin{array}{l}\text { 4,4'-Methylenedi(phenyl isocyanate); } \\
\text { 4,4'-methylenebis(phenyl isocyanate); } \\
\text { 4,4'-methylenediphenyl diisocyanate; } \\
\text { bis(4-isocyanatophenyl)methane; isocyanic } \\
\text { acid, methylenedi-p-phenylene ester; MDI }\end{array}$ & $\begin{array}{l}\text { Diisocyanatotoluene; isocyanic } \\
\text { acid, methylphenylene ester; } \\
\text { methylphenylene isocyanate; } \\
\text { TDI }\end{array}$ \\
\hline Registered trade name(s) & $\begin{array}{l}\text { Caradate 30; Desmodur 44; Hylene M; } \\
\text { Isonate M; Nacconate }\end{array}$ & $\begin{array}{l}\text { TDI 80/20; Mondur TD; Hylene } \\
\text { T; Rubinate TDI; Niax TDI }\end{array}$ \\
\hline Chemical formula & $\mathrm{C}_{15} \mathrm{H}_{10} \mathrm{~N}_{2} \mathrm{O}_{2}$ & $\mathrm{C}_{9} \mathrm{H}_{6} \mathrm{~N}_{2} \mathrm{O}_{2}$ \\
\hline Chemical structure & $\mathrm{O}=\mathrm{C}=\mathrm{N}$ & $*-\mathrm{CH}_{3}$ \\
\hline \multicolumn{3}{|l|}{ Identification numbers: } \\
\hline CAS registry & $\begin{array}{l}\text { 101-68-8 } \\
9016-87-9 \text { (polymeric MDI) }\end{array}$ & $\begin{array}{l}26471-62-5 \text { (mixture of } 2,4-T D I \\
\text { and 2,6-TDI) }\end{array}$ \\
\hline NIOSH RTECS & NQ9350000点 & NQ9490000e \\
\hline EPA hazardous waste & No data & U223 \\
\hline OHM/TADS & No data & No data \\
\hline $\begin{array}{l}\text { DOT/UN/NA/IMCO } \\
\text { shipping }\end{array}$ & $\begin{array}{l}\text { UN } 2489^{\mathrm{c}} \\
\text { IMO } 6.1^{\mathrm{d}}\end{array}$ & $\begin{array}{l}\text { UN } 2078 \\
\text { IMO } 6.1\end{array}$ \\
\hline HSDB & 2630 & 6003 \\
\hline $\mathrm{NCl}$ & C50668 & No data \\
\hline
\end{tabular}




\section{Table 4-1. Chemical Identity of Toluene Diisocyanate and Methylenediphenyl Diisocyanate $^{a}$}

\begin{tabular}{|c|c|c|}
\hline Characteristic & 2,4-Toluene diisocyanate & 2,6-Toluene diisocyanate \\
\hline Chemical name & Benzene, 2,4-diisocyanato-1-methyl & $\begin{array}{l}\text { Benzene, 1,3-diisocyanato- } \\
\text { 2-methyl }\end{array}$ \\
\hline Synonyms(s) & $\begin{array}{l}\text { 2,4-Diisocyanatotoluene; isocyanic acid, } \\
\text { 4-methyl-m-phenylene ester; 4-methyl- } \\
\text { phenylene diisocyanate; toluene- } \\
\text { 2,4-diisocyanate; } 2,4 \text {-TDI }\end{array}$ & $\begin{array}{l}\text { 2,6-Diisocyanatotoluene; } \\
\text { 2,6-diisocyanto-1-methylbenzene; } \\
\text { 2-methyl-phenylene diisocyanate; } \\
\text { toluene-2,6-diisocyanate; } 2,6 \text {-TDI }\end{array}$ \\
\hline Registered trade name(s) & Hylene T; Mondur TDS & Hylene T; Mondur TDS \\
\hline Chemical formula & $\mathrm{C}_{9} \mathrm{H}_{6} \mathrm{~N}_{2} \mathrm{O}_{2}$ & $\mathrm{C}_{9} \mathrm{H}_{6} \mathrm{~N}_{2} \mathrm{O}_{2}$ \\
\hline Chemical structure & ${ }^{*} v_{0}$ & $C \leqslant 0$ \\
\hline \multicolumn{3}{|l|}{ Identification numbers: } \\
\hline CAS registry & $584-84-9$ & $91-08-7$ \\
\hline NIOSH RTECS & CZ6300000f & CZ6310000g \\
\hline EPA hazardous waste & U223 & U223 \\
\hline OHM/TADS & No data & No data \\
\hline $\begin{array}{l}\text { DOT/UN/NA/IMCO } \\
\text { shipping }\end{array}$ & $\begin{array}{l}\text { UN } 2206 / 2207 / 2478 / 3080^{d} \\
\text { IMO } 6.1\end{array}$ & $\begin{array}{l}\text { UN } 2207^{d} \\
\text { IMO } 6.1\end{array}$ \\
\hline HSDB & 874 & 5272 \\
\hline $\mathrm{NCl}$ & C50533 & No data \\
\hline
\end{tabular}

aAll information obtained from HSDB (2012), unless otherwise noted.

bRTECS 2009a

${ }^{\mathrm{c} C h e m S p i d e r} 2013$

dLewis 2004

eNIOSH 1989

fRTECS $2009 \mathrm{~b}$

gRTECS 2009c

CAS $=$ Chemical Abstracts Services $;$ DOT/UN/NA/IMCO $=$ Department of Transportation/United Nations/North America/Intergovernmental Maritime Dangerous Goods Code; EPA = Environmental Protection Agency; HSDB = Hazardous Substances Data Bank; NCI = National Cancer Institute; NIOSH = National Institute for Occupational Safety and Health; OHM/TADS = Oil and Hazardous Materials/Technical Assistance Data System; RTECS=Registry of Toxic Effects of Chemical Substances 


\section{Table 4-2. Physical and Chemical Properties of Toluene Diisocyanate and Methylenediphenyl Diisocyanate ${ }^{a}$}

\begin{tabular}{|c|c|c|}
\hline Property & Methylenediphenyl diisocyanate & Toluene diisocyanate \\
\hline Molecular weight & 250.252 & 174.16 \\
\hline Color & Light-yellow & Clear, colorless to pale yellow \\
\hline Physical state & Solid/crystals & Liquid \\
\hline Melting point & $37^{\circ} \mathrm{C}$ & $11-14^{\circ} \mathrm{C}$ \\
\hline Boiling point & $196^{\circ} \mathrm{C}($ at $5 \mathrm{~mm} \mathrm{Hg})$ & $250^{\circ} \mathrm{C}$ \\
\hline $\begin{array}{l}\text { Density: } \\
\text { at } 25^{\circ} \mathrm{C} \\
\text { at } 70^{\circ} \mathrm{C}\end{array}$ & $\begin{array}{l}\text { No data } \\
1.197 \mathrm{~g} / \mathrm{cm}^{3}\end{array}$ & $\begin{array}{l}1.22 \mathrm{~g} / \mathrm{mL} \\
\text { No data }\end{array}$ \\
\hline Odor & Odorless & Pungent \\
\hline \multicolumn{3}{|l|}{ Odor threshold: } \\
\hline Water & Not applicable ${ }^{b}$ & Not applicable ${ }^{b}$ \\
\hline Air & No data & $360-920 \mu \mathrm{g} / \mathrm{m}^{3}$ \\
\hline \multicolumn{3}{|l|}{ Solubility: } \\
\hline Water at $25^{\circ} \mathrm{C}$ & Not applicable ${ }^{b}$ & Not applicable ${ }^{b}$ \\
\hline Organic solvents & $\begin{array}{l}\text { Soluble in acetone, benzene, } \\
\text { kerosene, and nitrobenzene }\end{array}$ & $\begin{array}{l}\text { Miscible with alcohol, ether, } \\
\text { acetone, carbon tetrachloride, } \\
\text { benzene, and kerosene }\end{array}$ \\
\hline \multicolumn{3}{|l|}{ Partition coefficients: } \\
\hline Log $K_{\text {ow }}$ & Not applicable ${ }^{b}$ & Not applicable ${ }^{b}$ \\
\hline $\log K_{o c}$ & Not applicable ${ }^{b}$ & Not applicable ${ }^{b}$ \\
\hline Vapor pressure at $25^{\circ} \mathrm{C}$ & $5.1 \times 10^{-6} \mathrm{~mm} \mathrm{Hg}$ & $2.30 \times 10^{-2} \mathrm{~mm} \mathrm{Hg}$ \\
\hline Henry's law constant at $25^{\circ} \mathrm{C}$ & Not applicable ${ }^{b}$ & Not applicable ${ }^{b}$ \\
\hline Autoignition temperature & No data & No data \\
\hline Flashpoint & $202^{\circ} \mathrm{C}$ (open cup) & $132^{\circ} \mathrm{C}$ (closed cup) \\
\hline Flammability limits & Flammable & $0.9-9.5$ volume $\%$ \\
\hline Conversion factors & $1 \mathrm{ppm}=10.24 \mathrm{mg} / \mathrm{m}^{3}$ & No data \\
\hline Explosive limits & No data & Explosive (vapor) \\
\hline
\end{tabular}




\section{Table 4-2. Physical and Chemical Properties of Toluene Diisocyanate and Methylenediphenyl Diisocyanate ${ }^{a}$}

\begin{tabular}{|c|c|c|}
\hline Property & 2,4-Toluene diisocyanate & 2,6-Toluene diisocyanate \\
\hline Molecular weight & 174.16 & 174.16 \\
\hline Color & Colorless to pale yellow & Colorless to pale yellow \\
\hline Physical state & Liquid & Liquid \\
\hline Melting point & $20.5^{\circ} \mathrm{C}$ & $18.3^{\circ} \mathrm{C}$ \\
\hline Boiling point & $251^{\circ} \mathrm{C}$ & $129-133^{\circ} \mathrm{C}$ (at $\left.18 \mathrm{~mm} \mathrm{Hg}\right)$ \\
\hline $\begin{array}{l}\text { Density: } \\
\text { at } 20^{\circ} \mathrm{C} / 4^{\circ} \mathrm{C} \\
\text { at } 25^{\circ} \mathrm{C}\end{array}$ & $\begin{array}{l}1.2244 \\
\text { No data }\end{array}$ & $\begin{array}{l}\text { No data } \\
1.22\end{array}$ \\
\hline Odor & Sharp, pungent & Pungent \\
\hline \multicolumn{3}{|l|}{ Odor threshold: } \\
\hline Water & Not applicable ${ }^{b}$ & Not applicable ${ }^{b}$ \\
\hline Air & $0.4-2.14 \mathrm{ppm}$ & No data \\
\hline \multicolumn{3}{|l|}{ Solubility: } \\
\hline Water at $25^{\circ} \mathrm{C}$ & Not applicable ${ }^{b}$ & Not applicable ${ }^{b}$ \\
\hline Organic solvents & $\begin{array}{l}\text { Miscible with alcohol } \\
\text { (decomposition), ether, acetone, } \\
\text { benzene, carbon tetrachloride, } \\
\text { chlorobenzene, diglycol } \\
\text { monomethyl ether, kerosene, and } \\
\text { olive oil }\end{array}$ & Soluble in acetone and benzene \\
\hline \multicolumn{3}{|l|}{ Partition coefficients: } \\
\hline Log Kow & Not applicable ${ }^{b}$ & Not applicable ${ }^{b}$ \\
\hline Log $K_{o c}$ & Not applicable ${ }^{b}$ & Not applicable ${ }^{b}$ \\
\hline Vapor pressure at $25^{\circ} \mathrm{C}$ & $8.0 \times 10^{-3} \mathrm{~mm} \mathrm{Hg}\left(20^{\circ} \mathrm{C}\right)$ & $2.09 \times 10^{-2} \mathrm{~mm} \mathrm{Hg}$ \\
\hline Henry's law constant at $25^{\circ} \mathrm{C}$ & Not applicable ${ }^{b}$ & Not applicable ${ }^{b}$ \\
\hline Autoignition temperature & $620^{\circ} \mathrm{C}$ & No data \\
\hline Flashpoint & $132^{\circ} \mathrm{C}$ (open cup) ${ }^{\mathrm{C}}$ & No data \\
\hline Flammability limits & $0.9-9.5$ volume $\%$ & Flammable \\
\hline Conversion factors & No data & $1 \mathrm{mg} / \mathrm{m}^{3}=0.14 \mathrm{ppm}$ \\
\hline Explosive limits & Explosive (vapor) & No data \\
\hline
\end{tabular}

aAll information obtained from HSDB (2012), unless otherwise noted.

bDiisocyanates hydrolyze rapidly in water; therefore, these end points are not applicable.

'Lewis 2004 
4. CHEMICAL AND PHYSICAL INFORMATION

This page is intentionally blank. 


\section{PRODUCTION, IMPORT/EXPORT, USE, AND DISPOSAL}

\subsection{PRODUCTION}

TDI is manufactured via the dinitration of toluene with mixed acid to produce a mixture of 2,4- and 2,6-dinitro isomers in a 80:20 ratio. Catalytic reduction of these isomers under hydrogen pressure forms the corresponding diamines, which are then treated with phosgene to yield TDI, made up of an 80:20 mixture of isomers 2,4- and 2,6-TDI (HSDB 2012).

MDI is produced through a two-step process starting with the condensation reaction between aniline and formaldehyde in the presence of hydrochloric acid to yield MDA, followed by the phosgenation to MDI. The production of polymeric MDI also proceeds via this reaction, with the percent distribution of homologues and isomers being dependent on the ratio of aniline to formaldehyde, the acid concentration, and the reaction conditions (HSDB 2012).

The worldwide production of polyurethanes was around 15.9 million tons in 2007, which corresponds to a total consumption of 1.9 million tons of TDI (Geens et al. 2012). The worldwide production volume of MDI in 2008 was approximately 1.4 million tons (Gries and Leng 2013). Also in 2008, the demand for pure MDI and polymeric MDI was 192.1 and 1,418 million pounds, respectively, in the United States (EPA 2011a). The demand for TDI in 2008 in the United States was 425.2 million pounds (EPA 2011b). 2,4-TDI, 2,6-TDI, and 4,4'-MDI are listed by the EPA as High Production Volume (HPV) chemicals. Chemicals listed under the HPV Challenge Program were produced or imported into the United States in quantities $>1$ million pounds in 1990 and/or 1994 (HSDB 2012). The aggregated national production volumes reported for 2,4-TDI, 2,6-TDI, and 4,4'-MDI under the EPA's 2010 Inventory Update Rule were $10-<50,<500,000$, and 100-<500 million pounds (EPA 2010). TDI (mixed isomers) had a reported aggregated national production volume of $\geq 1$ billion pounds (EPA 2010).

TDI (mixed isomers), 2,4-TDI, and 2,6-TDI are chemicals that manufacturing and processing facilities would be required to report under Section 313 of the Emergency Planning and Community Right-toKnow Act (Title III of the Superfund Amendments and Reauthorization Act of 1986 [SARA]) (EPA 1998a). Tables 5-1, 5-2, and 5-3 list the production year, number of facilities, the state where each facility is located, and the range (in pounds) for each domestic manufacturer that reported the production or formulation of TDI (mixed isomers), 2,4-TDI, and 2,6-TDI, respectively in 2016 (TRI16 2017). The TRI category diisocyanates contains data for MDI and 20 other diisocyanates (not including TDI); however, since there is no way to parse out the data for MDI separately, it was not included. 


\section{Table 5-1. Facilities that Produce, Process, or Use Toluene Diisocyanate (Mixed Isomers)}

\begin{tabular}{|c|c|c|c|c|}
\hline State $^{a}$ & $\begin{array}{l}\text { Number of } \\
\text { facilities }\end{array}$ & $\begin{array}{l}\text { Minimum } \\
\text { amount on site } \\
\text { in pounds }{ }^{b}\end{array}$ & $\begin{array}{l}\text { Maximum } \\
\text { amount on site } \\
\text { in pounds }\end{array}$ & Activities and uses $^{\mathrm{c}}$ \\
\hline$\overline{A R}$ & 1 & 100,000 & 999,999 & 6 \\
\hline$A Z$ & 1 & No data & No data & No data \\
\hline CA & 11 & 100 & $9,999,999$ & $6,7,8,11$ \\
\hline DE & 2 & 10,000 & 99,999 & 6,7 \\
\hline $\mathrm{FL}$ & 3 & 10,000 & 999,999 & 6,7 \\
\hline GA & 6 & 10,000 & 999,999 & 6 \\
\hline IA & 2 & 10,000 & 999,999 & 6,7 \\
\hline IL & 3 & 1,000 & 999,999 & $6,7,12$ \\
\hline IN & 6 & 1,000 & $9,999,999$ & 6,7 \\
\hline KS & 2 & 1,000 & $9,999,999$ & 6 \\
\hline KY & 2 & 100,000 & $49,999,999$ & 6,9 \\
\hline LA & 3 & 100,000 & $9,999,999$ & $1,4,6,12$ \\
\hline MA & 4 & 10,000 & $9,999,999$ & 6,7 \\
\hline MD & 2 & 100,000 & 999,999 & 6,7 \\
\hline ME & 2 & 10,000 & 99,999 & 6 \\
\hline MI & 5 & 10,000 & $9,999,999$ & $6,7,9,10,11$ \\
\hline MN & 1 & 1,000 & 9,999 & $6,7,8$ \\
\hline MO & 5 & 100,000 & 999,999 & 6 \\
\hline MS & 6 & 100,000 & $9,999,999$ & 6,7 \\
\hline $\mathrm{NC}$ & 11 & 10,000 & $9,999,999$ & 6,7 \\
\hline $\mathrm{NH}$ & 1 & 1,000 & 9,999 & 6 \\
\hline NJ & 7 & 10,000 & 999,999 & 6,7 \\
\hline NM & 2 & 100,000 & 999,999 & 6,7 \\
\hline $\mathrm{OH}$ & 8 & 1,000 & 999,999 & $6,7,8,9,12$ \\
\hline OR & 1 & 100,000 & 999,999 & 6 \\
\hline PA & 7 & 1,000 & 999,999 & 6,7 \\
\hline PR & 1 & No data & No data & No data \\
\hline SC & 2 & 10,000 & 99,999 & 6 \\
\hline TN & 4 & 1,000 & 999,999 & $6,7,9$ \\
\hline $\mathrm{TX}$ & 14 & 1,000 & $9,999,999$ & $1,3,6,7,12$ \\
\hline VA & 4 & 100,000 & $9,999,999$ & $6,7,9,12$ \\
\hline WA & 2 & 10,000 & 999,999 & 6,7 \\
\hline
\end{tabular}


Table 5-1. Facilities that Produce, Process, or Use Toluene Diisocyanate (Mixed Isomers)

\begin{tabular}{lllll}
\hline & $\begin{array}{l}\text { Minimum } \\
\text { facilities of }\end{array}$ & $\begin{array}{l}\text { amount on site } \\
\text { in pounds }\end{array}$ & $\begin{array}{l}\text { Maximum } \\
\text { amount on site } \\
\text { in pounds }\end{array}$ & ${\text { Activities and } \text { uses }^{\text {c }}}^{\text {in ptate }}$ \\
\hline WI & 2 & 100,000 & 999,999 & 6,7 \\
WV & 1 & $1,000,000$ & $9,999,999$ & $6,7,9$ \\
\hline
\end{tabular}

apost office state abbreviations used.

${ }^{b}$ Amounts on site reported by facilities in each state.

cActivities/Uses:
1. Produce
6. Impurity
2. Import
7. Reactant
11. Chemical Processing Aid
3. Onsite use/processing
8. Formulation Component
12. Manufacturing Aid
4. Sale/Distribution
9. Article Component
13. Ancillary/Other Uses
5. Byproduct
10. Repackaging
14. Process Impurity

Source: TRI16 2017 (Data are from 2016) 
5. PRODUCTION, IMPORT/EXPORT, USE, AND DISPOSAL

Table 5-2. Facilities that Produce, Process, or Use 2,4-Toluene Diisocyanate

\begin{tabular}{|c|c|c|c|c|}
\hline State $^{a}$ & $\begin{array}{l}\text { Number of } \\
\text { facilities }\end{array}$ & $\begin{array}{l}\text { Minimum } \\
\text { amount on site } \\
\text { in pounds }\end{array}$ & $\begin{array}{l}\text { Maximum } \\
\text { amount on site } \\
\text { in pounds }\end{array}$ & Activities and uses $^{c}$ \\
\hline$\overline{\mathrm{AL}}$ & 1 & 10,000 & 99,999 & 7 \\
\hline AR & 2 & 100,000 & 999,999 & 9,12 \\
\hline $\mathrm{CO}$ & 1 & $1,000,000$ & $9,999,999$ & 6,8 \\
\hline CT & 1 & 1,000 & 9,999 & 6 \\
\hline GA & 2 & 100,000 & 999,999 & 10 \\
\hline IA & 1 & 1,000 & 9,999 & 10 \\
\hline IL & 1 & No data & No data & No data \\
\hline IN & 2 & 1,000 & 999,999 & 6 \\
\hline KS & 1 & No data & No data & No data \\
\hline KY & 1 & 10,000 & 99,999 & 6 \\
\hline MA & 1 & 10,000 & 99,999 & 6 \\
\hline$M D$ & 1 & 1,000 & 9,999 & 6,7 \\
\hline MI & 5 & 10,000 & 999,999 & $6,7,11$ \\
\hline MN & 1 & 10,000 & 99,999 & 12 \\
\hline MO & 2 & 10,000 & 99,999 & $6,7,12$ \\
\hline MS & 4 & 0 & $9,999,999$ & $6,7,12$ \\
\hline $\mathrm{NC}$ & 1 & 100,000 & 999,999 & 6 \\
\hline NE & 1 & 100,000 & 999,999 & 6 \\
\hline $\mathrm{NJ}$ & 3 & 10,000 & 99,999 & 6 \\
\hline NY & 1 & 10,000 & 99,999 & 6,7 \\
\hline $\mathrm{OH}$ & 5 & 1,000 & 99,999 & $6,7,8,12$ \\
\hline PA & 4 & 1,000 & 999,999 & $6,7,8$ \\
\hline $\mathrm{RI}$ & 1 & No data & No data & No data \\
\hline $\mathrm{TN}$ & 2 & 1,000 & 999,999 & $6,10,11$ \\
\hline $\mathrm{TX}$ & 3 & 1,000 & $9,999,999$ & 9,12 \\
\hline UT & 1 & 10,000 & 99,999 & 12 \\
\hline VA & 1 & 10,000 & 99,999 & 8 \\
\hline WI & 2 & 0 & 99 & 12 \\
\hline WV & 1 & 100,000 & 999,999 & $2,3,7$ \\
\hline
\end{tabular}

apost office state abbreviations used.

${ }^{b}$ Amounts on site reported by facilities in each state.

${ }^{\mathrm{c} A c t i v i t i e s / \text { Uses: }}$
1. Produce
6. Impurity
2. Import
7. Reactant
11. Chemical Processing Aid
3. Onsite use/processing
8. Formulation Component
12. Manufacturing Aid
4. Sale/Distribution
9. Article Component
13. Ancillary/Other Uses
5. Byproduct
10. Repackaging
14. Process Impurity

Source: TRI16 2017 (Data are from 2016) 
5. PRODUCTION, IMPORT/EXPORT, USE, AND DISPOSAL

Table 5-3. Facilities that Produce, Process, or Use 2,6-Toluene Diisocyanate

\begin{tabular}{|c|c|c|c|c|}
\hline State $^{a}$ & $\begin{array}{l}\text { Number of } \\
\text { facilities }\end{array}$ & $\begin{array}{l}\text { Minimum } \\
\text { amount on site } \\
\text { in pounds }{ }^{b}\end{array}$ & $\begin{array}{l}\text { Maximum } \\
\text { amount on site } \\
\text { in pounds }\end{array}$ & Activities and uses $^{c}$ \\
\hline$\overline{A R}$ & 1 & 10,000 & 99,999 & 12 \\
\hline $\mathrm{CO}$ & 1 & 100,000 & 999,999 & 6,8 \\
\hline GA & 1 & 10,000 & 99,999 & 10 \\
\hline IL & 1 & No data & No data & No data \\
\hline IN & 1 & 10,000 & 99,999 & 6 \\
\hline KS & 1 & No data & No data & No data \\
\hline MA & 1 & 1,000 & 9,999 & 6 \\
\hline MD & 1 & 1,000 & 9,999 & 6,7 \\
\hline MI & 4 & 10,000 & 999,999 & $6,7,8$ \\
\hline MO & 2 & 1,000 & 99,999 & 6,7 \\
\hline MS & 2 & 10,000 & $9,999,999$ & 6,7 \\
\hline NE & 1 & 10,000 & 99,999 & 6 \\
\hline $\mathrm{OH}$ & 5 & 100 & 99,999 & $6,7,8,12$ \\
\hline PA & 1 & 10,000 & 99,999 & $6,7,1$ \\
\hline TN & 2 & 1,000 & 999,999 & $6,7,10,11$ \\
\hline $\mathrm{TX}$ & 1 & No data & No data & No data \\
\hline WI & 2 & 0 & 99 & 12 \\
\hline WV & 1 & 10,000 & 99,999 & $2,3,6,7$ \\
\hline
\end{tabular}

apost office state abbreviations used.

${ }^{b}$ Amounts on site reported by facilities in each state.

cActivities/Uses:
1. Produce
6. Impurity
2. Import
7. Reactant
11. Chemical Processing Aid
3. Onsite use/processing
8. Formulation Component
12. Manufacturing Aid
4. Sale/Distribution
9. Article Component
13. Ancillary/Other Uses
5. Byproduct
10. Repackaging
14. Process Impurity

Source: TRI16 2017 (Data are from 2016) 
Table 5-4. Facilities that Produce, Process, or Use Diisocyanates

\begin{tabular}{|c|c|c|c|c|}
\hline State $^{a}$ & $\begin{array}{l}\text { Number of } \\
\text { facilities }\end{array}$ & $\begin{array}{l}\text { Minimum } \\
\text { amount on site } \\
\text { in pounds }{ }^{b}\end{array}$ & $\begin{array}{l}\text { Maximum } \\
\text { amount on site } \\
\text { in pounds }\end{array}$ & Activities and uses ${ }^{c}$ \\
\hline$\overline{\mathrm{AL}}$ & 32 & 1,000 & $9,999,999$ & $1,3,4,6,7,8,10,11,12$ \\
\hline AR & 13 & 0 & 999,999 & $2,4,6,7$ \\
\hline$A Z$ & 12 & 1,000 & 999,999 & 6,10 \\
\hline CA & 63 & 100 & $9,999,999$ & $2,4,6,7,8,9,10,11$ \\
\hline $\mathrm{CO}$ & 8 & 10,000 & $9,999,999$ & $6,7,8$ \\
\hline CT & 13 & 1,000 & 999,999 & $6,7,8,9,10,11$ \\
\hline $\mathrm{DE}$ & 4 & 10,000 & 99,999 & 6,7 \\
\hline $\mathrm{FL}$ & 28 & 100 & $9,999,999$ & $6,7,8,9,14$ \\
\hline GA & 54 & 1,000 & $9,999,999$ & $2,3,4,6,7,8,9,10$ \\
\hline IA & 20 & 1,000 & 999,999 & $6,7,8,11,12$ \\
\hline ID & 3 & 10,000 & 999,999 & 8,12 \\
\hline IL & 49 & 0 & $9,999,999$ & $2,3,6,7,8,9,11,12$ \\
\hline IN & 84 & 100 & $9,999,999$ & $1,2,3,5,6,7,8,9,10,11,12,14$ \\
\hline KS & 15 & 10,000 & 999,999 & $6,7,8,11,12$ \\
\hline KY & 25 & 10,000 & $9,999,999$ & $1,4,6,7,8,9,10,11$ \\
\hline LA & 14 & 0 & $49,999,999$ & $1,2,3,4,6,7,9,12$ \\
\hline MA & 23 & 1,000 & $9,999,999$ & $6,7,8,9,11$ \\
\hline MD & 5 & 1,000 & 999,999 & $6,7,9,11$ \\
\hline ME & 3 & 10,000 & $9,999,999$ & $1,5,6,8$ \\
\hline MI & 90 & 100 & $9,999,999$ & $1,2,3,5,6,7,8,9,10,11,12,14$ \\
\hline $\mathrm{MN}$ & 40 & 1,000 & 999,999 & $2,3,4,6,7,8,9,11,12$ \\
\hline MO & 55 & 100 & $9,999,999$ & $2,3,6,7,8,9,10,11,12$ \\
\hline MS & 22 & 1,000 & 999,999 & $6,7,8,10,11,12$ \\
\hline MT & 2 & No data & No data & No data \\
\hline NC & 54 & 1,000 & $49,999,999$ & $6,7,8,9,10,11,12$ \\
\hline ND & 2 & 10,000 & $9,999,999$ & 7 \\
\hline NE & 10 & 1,000 & $9,999,999$ & $6,8,9,10,12$ \\
\hline $\mathrm{NH}$ & 5 & 1,000 & 999,999 & $2,3,6,7,8,9$ \\
\hline NJ & 17 & 100 & 999,999 & $6,7,8,11$ \\
\hline NM & 2 & 100,000 & 999,999 & 6 \\
\hline NV & 7 & 10,000 & 999,999 & $6,7,12$ \\
\hline NY & 23 & 1,000 & $9,999,999$ & $2,3,6,7,8,9$ \\
\hline $\mathrm{OH}$ & 89 & 100 & $499,999,999$ & $1,5,6,7,8,9,10,11,12$ \\
\hline OK & 15 & 1,000 & 999,999 & $6,7,8,11$ \\
\hline OR & 23 & 0 & $9,999,999$ & $1,2,3,4,6,7,8,9,10,12,13$ \\
\hline PA & 64 & 0 & $9,999,999$ & $2,3,6,7,8,9,10,11,12$ \\
\hline PR & 2 & 1,000 & 9,999 & 12 \\
\hline $\mathrm{RI}$ & 7 & 1,000 & 999,999 & $6,7,8,9$ \\
\hline SC & 32 & 0 & $9,999,999$ & $1,3,5,6,7,8,9,10,11,12$ \\
\hline SD & 2 & No data & No data & No data \\
\hline
\end{tabular}


5. PRODUCTION, IMPORT/EXPORT, USE, AND DISPOSAL

\section{Table 5-4. Facilities that Produce, Process, or Use Diisocyanates}

\begin{tabular}{|c|c|c|c|c|}
\hline State $^{a}$ & $\begin{array}{l}\text { Number of } \\
\text { facilities }\end{array}$ & $\begin{array}{l}\text { Minimum } \\
\text { amount on site } \\
\text { in pounds }^{b}\end{array}$ & $\begin{array}{l}\text { Maximum } \\
\text { amount on site } \\
\text { in pounds }\end{array}$ & 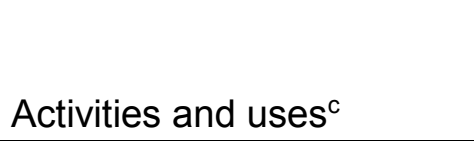 \\
\hline$\overline{\mathrm{TN}}$ & 58 & 100 & $9,999,999$ & $2,3,6,7,8,9,11,12$ \\
\hline $\mathrm{TX}$ & 85 & 100 & $499,999,999$ & $1,2,3,4,6,7,8,9,10,11,12$ \\
\hline UT & 14 & 1,000 & $9,999,999$ & $2,3,6,7,8,9,10,12$ \\
\hline VA & 20 & 1,000 & 999,999 & $6,7,8,9,10,11,12$ \\
\hline VT & 1 & No data & No data & No data \\
\hline WA & 11 & 1,000 & $9,999,999$ & $6,7,11,12$ \\
\hline WI & 71 & 1,000 & $9,999,999$ & $2,3,6,7,8,9,10,11,12$ \\
\hline WV & 13 & 1,000 & $9,999,999$ & $2,3,6,7,8,9,11$ \\
\hline
\end{tabular}

apost office state abbreviations used.

${ }^{b}$ Amounts on site reported by facilities in each state.

cActivities/Uses:
1. Produce
6. Impurity
2. Import
7. Reactant
11. Chemical Processing Aid
3. Onsite use/processing
8. Formulation Component
12. Manufacturing Aid
4. Sale/Distribution
9. Article Component
13. Ancillary/Other Uses
5. Byproduct
10. Repackaging
14. Process Impurity

Source: TRI16 2017 (Data are from 2016) 
Manufacturers are required to report Toxics Release Inventory (TRI) data to satisfy EPA requirements. The TRI data should be used with caution since only certain types of facilities are required to report (EPA 2005). This is not an exhaustive list.

\subsection{IMPORT/EXPORT}

U.S. imports of mixed isomers of TDI were $984,000 \mathrm{~kg}$ (2.1 million pounds) in 1989, and decreased to $1,000 \mathrm{~kg}$ (2,200 pounds) in 1996 but increased again to 15 million $\mathrm{kg}$ (32 million pounds) in 2006; 2008 imports were reported as 500,000 kg (1.1 million pounds) (NTP 2011). U.S. imports of unmixed isomers of TDI were reported as $426,000 \mathrm{~kg}(939,000$ pounds) in 1989 , and reached a low of 9,000 $\mathrm{kg}$ (19,800 pounds) in 1998. U.S. imports of unmixed isomers peaked at 1.3 million $\mathrm{kg}$ ( 2.8 million pounds) in 2004; 2008 imports were 130,000 kg (286,000 pounds). U.S. exports of mixed isomers of TDI were 62 million $\mathrm{kg}$ (125 million pounds) in 1989, rising to 277 million $\mathrm{kg}$ (609 million pounds) in 2003. U.S. exports of unmixed isomers of TDI peaked in 1994 at 46 million $\mathrm{kg}$ (101 million pounds), falling to a low of 3.9 million $\mathrm{kg}$ (8.6 million pounds) in 2008 (NTP 2011).

It was reported that 5\% of the total U.S. production volume of MDI was exported in 2000 (HSDB 2012). No export data could be located for MDI in the available literature.

\subsection{USE}

TDI and MDI have widespread commercial use due to their reactivity and versatility. TDI and MDI and their related polyisocyanates make up $>90 \%$ of the commercial market (EPA 2011a). Commercial-grade TDI is made up of an 80:20 mixture of isomers 2,4- and 2,6-TDI and represents $>95 \%$ of TDI industrial use (NIOSH 1989). Technical MDI products vary in composition and consist of several MDI isomers and oligomeric derivatives with increasing number of aromatic rings (Bobeldijk et al. 2008).

Diisocyanates, such as MDI and TDI, are generally supplied as raw materials to formulators who use their reactivity to combine them with other chemicals to create various polyurethanes with a wide diversity of applications (EPA 2011a, 2011b).

TDI is a widely used industrial intermediate in the manufacture of polyurethane products (Bilban 2004). In the presence of amines, TDI reacts rapidly with polyols to form polyurethane foam for the furniture, bedding, and automotive industries (Austin 2007). 
MDI, polymeric MDI, and TDI are used predominantly in the production of flexible and rigid polyurethane foams. Rigid foams are mainly used for insulation, while flexible foams are used for cushioning. A smaller amount of the total production volume of MDI, polymeric MDI, and TDI is used in the non-foam polyurethane sector, including coatings, adhesives, binders, and sealants (EPA 2011a, 2011b).

Prior to reaching the consumer market, the majority of polyurethane products made with TDI and MDI undergo a curing process (process by which TDI and MDI react with other product components to form polyurethane). However, polyurethane products such as spray foams, coatings, sealants, and adhesives may be sold and used containing uncured TDI and MDI (EPA 2011a, 2011b). In general, polyurethane products sold to the consumer have low concentrations of uncured TDI and MDI and are generally accompanied by product safety information.

\subsection{DISPOSAL}

TDI is designated with an EPA hazardous waste number U223, and therefore, generators of waste containing this contaminant must conform with EPA regulations in storage, transport, treatment, and disposal (HSDB 2012).

TDI and MDI wastes from distillation equipment are preferably sent to special waste incinerators for burning. Hydrolysis reaction products of TDI and MDI contained in waste waters can be biodegraded by treatment with activated sludge. Recommended methods of TDI and MDI disposal include incineration, and alkaline hydrolysis. Disposal to landfills is not recommended (HSDB 2012).

A study was conducted to assess the effectiveness of using wet sand in the event of a spill to detoxify TDI in situ. A 30-L container holding $5 \mathrm{~kg}$ of TDI was covered with a mixture of $30 \mathrm{~kg}$ of sand and $5 \mathrm{~kg}$ of water at ambient temperature. After 24 hours, it was observed that only 5.5\% of the TDI remained unreacted. The reaction degradation product, TDA, was not present above the detection limit (10 ppb) (Duff 1983).

Another study described a procedure to decontaminate diisocyanates by which liquid TDI or MDI was added to a decontamination solution containing water (90\%), concentrated ammonia solution (8\%), and liquid detergent (2\%) to effect safe disposal (Duff 1983). 
The EPA proposed "low part per million concentration level" criteria of $10 \mathrm{ppm}$ for TDI, which would allow a pronouncement that the spilled TDI residues treated in situ could be considered nonhazardous, if the criteria are achieved (Duff 1983). 


\section{POTENTIAL FOR HUMAN EXPOSURE}

\subsection{OVERVIEW}

TDI has been identified in 4 of the 1,854 hazardous waste sites that have been proposed for inclusion on the EPA National Priorities List (NPL) (ATSDR 2017). Diisocyanates were not found at the sites most likely due to their rapid hydrolysis in the environment. The frequency of these sites can be seen in Figure 6-1.

TDI and MDI are extremely reactive compounds that are widely used in the production of polyurethane materials. There are no natural sources of diisocyanates. Almost all of the potential exposures to these compounds are associated with the production, handling, use, and disposal of diisocyanates and diisocyanate-containing products and material. Exposure of the general population to diisocyanates could potentially result from industrial exposures, as well as from the use of consumer products containing uncured TDI and MDI (EPA 2011a, 2011b).

The dominant process affecting the overall environmental fate, transport, and bioaccumulation potential of diisocyanates is hydrolysis (EPA 2011a, 2011b). Diisocyanates react with water forming the respective amines, which in turn may react with more diisocyanates to produce inert, insoluble polyureas (WHO 2000). Hydrolysis half-lives of MDI and TDI have been measured to be on the order of a few minutes to a few hours (HSDB 2012).

\subsection{RELEASES TO THE ENVIRONMENT}

The Toxics Release Inventory (TRI) data should be used with caution because only certain types of facilities are required to report (EPA 2005). This is not an exhaustive list. Manufacturing and processing facilities are required to report information to the TRI only if they employ 10 or more full-time employees; if their facility is included in Standard Industrial Classification (SIC) Codes 10 (except 1011, 1081, and 1094), 12 (except 1241), 20-39, 4911 (limited to facilities that combust coal and/or oil for the purpose of generating electricity for distribution in commerce), 4931 (limited to facilities that combust coal and/or oil for the purpose of generating electricity for distribution in commerce), 4939 (limited to facilities that combust coal and/or oil for the purpose of generating electricity for distribution in commerce), 4953 (limited to facilities regulated under RCRA Subtitle C, 42 U.S.C. section 6921 et seq.), 
Figure 6-1. Frequency of NPL Sites with 1,3-Toluene Diisocyanate Contamination

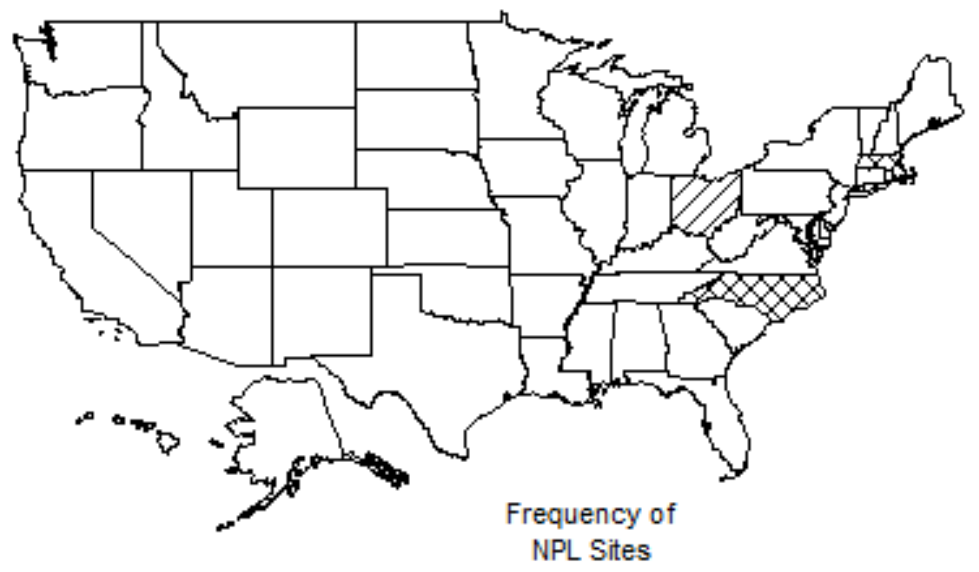

Source: ATSDR 2017

$\mathrm{X}_{1} \square 2$ 
5169, 5171, and 7389 (limited S.C. section 6921 et seq.), 5169, 5171, and 7389 (limited to facilities primarily engaged in solvents recovery services on a contract or fee basis); and if their facility produces, imports, or processes $\geq 25,000$ pounds of any TRI chemical or otherwise uses $>10,000$ pounds of a TRI chemical in a calendar year (EPA 2005).

TDI can enter the environment through industrial releases, such as through vent stacks of facilities handling this compound or as an accidental spillage to land or surface waters during transit (Duff 1983).

EPA's National Emission Inventory (NEI) database contains comprehensive and detailed estimates regarding sources that emit criteria air pollutants and their precursors, and hazardous air pollutants (HAPs) for the 50 United States, Washington DC, Puerto Rico, and the U.S. Virgin Islands. The NEI database includes point and non-point source emissions, on-road sources, non-road sources, and event sources such as emissions from wildfires. According to data from the 2014 NEI, 26,0381 pounds of MDI were released and 764,987 pounds of TDI were released (EPA 2014f).

\subsubsection{Air}

Estimated releases of $19,050,737$, and 381 pounds ( $~ 8.64,0.33$, and 0.17 metric tons) of TDI (mixed isomers), 2,4-TDI, and 2,6-TDI to the atmosphere from 134, 53, and 29 domestic manufacturing and processing facilities in 2016 (TRI16 2017) are summarized in Tables 6-1, 6-2, and 6-3. Table 6-4 summarizes releases of 207,137 pounds ( $\sim 93.96$ metric tons) of the diisocyanates category, which consists of MDI and 19 other substances, to the atmosphere from 1,304 domestic manufacturing and processing facilities in 2016 (TRI16 2017).

There is no information on releases of MDI to the atmosphere from manufacturing and processing facilities because these releases are not required to be reported (EPA 1998a).

During processing in a polyurethane foam plant, TDI emissions are removed from the workplace air by ventilation systems. However, any residual TDI leaving the plant vent stack is then dispersed into the atmosphere (Duff 1983).

Researchers studying six flexible foam manufacturing plants in Germany found that discharge concentrations of TDI emitted in factory exhaust gases ranged from 3 to $8 \mathrm{mg} / \mathrm{m}^{3}$. Concentrations 
Table 6-1. Releases to the Environment from Facilities that Produce, Process, or Use Toluene Diisocyanate (Mixed Isomers) ${ }^{a}$

\begin{tabular}{|c|c|c|c|c|c|c|c|c|c|}
\hline \multirow[b]{3}{*}{ State $^{c}$} & \multirow[b]{3}{*}{$\mathrm{RF}^{\mathrm{d}}$} & \multicolumn{8}{|c|}{ Reported amounts released in pounds per yearb } \\
\hline & & \multirow[b]{2}{*}{ Air } & \multirow[b]{2}{*}{ Water $^{f}$} & \multirow[b]{2}{*}{$\mathrm{UI}^{\mathrm{g}}$} & \multirow[b]{2}{*}{ Land $^{\mathrm{h}}$} & \multirow[b]{2}{*}{ Other ${ }^{\mathrm{i}}$} & \multicolumn{3}{|c|}{ Total release } \\
\hline & & & & & & & On-sitej & Off-site ${ }^{k}$ & $\begin{array}{l}\text { On- and } \\
{ }^{k} \text { off-site }\end{array}$ \\
\hline$\overline{\mathrm{AR}}$ & 1 & 373 & 0 & 0 & 0 & 0 & 373 & 0 & 373 \\
\hline$A Z$ & 1 & No data & No data & No data & No data & No data & No data & No data & No data \\
\hline CA & 11 & 1,993 & 0 & 0 & 70 & 32 & 1,993 & 102 & 2,095 \\
\hline DE & 2 & 4 & 0 & 0 & 0 & 0 & 4 & 0 & 4 \\
\hline $\mathrm{FL}$ & 3 & 1,230 & 0 & 0 & 0 & 9,563 & 1,230 & 9,563 & 10,793 \\
\hline GA & 6 & 623 & 0 & 0 & 0 & 209 & 623 & 209 & 832 \\
\hline IA & 2 & 382 & 0 & 0 & 0 & 0 & 382 & 0 & 382 \\
\hline IL & 3 & 234 & 0 & 0 & 3 & 0 & 234 & 3 & 237 \\
\hline IN & 6 & 960 & 0 & 0 & 0 & 0 & 960 & 0 & 960 \\
\hline KS & 2 & 295 & 0 & 0 & 0 & 0 & 295 & 0 & 295 \\
\hline KY & 2 & 2,555 & 0 & 0 & 7 & 0 & 2,561 & 0 & 2,561 \\
\hline LA & 3 & 37 & 0 & 0 & 77 & 0 & 37 & 77 & 114 \\
\hline MA & 4 & 167 & 0 & 0 & 0 & 0 & 167 & 0 & 167 \\
\hline MD & 2 & 294 & 0 & 0 & 0 & 0 & 294 & 0 & 294 \\
\hline ME & 2 & 5 & 0 & 0 & 0 & 574 & 5 & 574 & 579 \\
\hline MI & 5 & 48 & 0 & 0 & 11 & 0 & 59 & 0 & 59 \\
\hline MN & 1 & 325 & 0 & 0 & 0 & 0 & 325 & 0 & 325 \\
\hline MO & 5 & 121 & 0 & 0 & 0 & 0 & 121 & 0 & 121 \\
\hline MS & 6 & 2,070 & 0 & 0 & 0 & 0 & 2,070 & 0 & 2,070 \\
\hline $\mathrm{NC}$ & 11 & 894 & 0 & 0 & 0 & 0 & 894 & 0 & 894 \\
\hline $\mathrm{NH}$ & 1 & 1 & 0 & 0 & 0 & 352 & 1 & 352 & 353 \\
\hline NJ & 7 & 625 & 0 & 0 & 0 & 9,129 & 625 & 9,129 & 9,754 \\
\hline NM & 2 & 214 & 0 & 0 & 0 & 2,195 & 214 & 2,195 & 2,409 \\
\hline $\mathrm{OH}$ & 8 & 468 & 0 & 0 & 14,195 & 0 & 14,363 & 300 & 14,663 \\
\hline OR & 1 & 122 & 0 & 0 & 0 & 0 & 122 & 0 & 122 \\
\hline PA & 7 & 1,547 & 0 & 0 & 0 & 430 & 1,547 & 430 & 1,977 \\
\hline PR & 1 & No data & No data & No data & No data & No data & No data & No data & No data \\
\hline SC & 2 & No data & No data & No data & No data & No data & No data & No data & No data \\
\hline $\mathrm{TN}$ & 4 & 676 & 0 & 0 & 0 & 0 & 676 & 0 & 676 \\
\hline $\mathrm{TX}$ & 14 & 916 & 0 & 892 & 223 & 52 & 916 & 1,167 & 2,084 \\
\hline VA & 4 & 610 & 0 & 0 & 0 & 0 & 610 & 0 & 610 \\
\hline WA & 2 & 276 & 0 & 0 & 0 & 0 & 276 & 0 & 276 \\
\hline WI & 2 & 500 & 0 & 0 & 0 & 0 & 500 & 0 & 500 \\
\hline
\end{tabular}




\section{Table 6-1. Releases to the Environment from Facilities that Produce, Process, or Use Toluene Diisocyanate (Mixed Isomers) ${ }^{\mathrm{a}}$}

\begin{tabular}{|c|c|c|c|c|c|c|c|c|}
\hline \multirow[b]{3}{*}{ State $^{c}$} & \multirow[b]{3}{*}{$\mathrm{RF}^{\mathrm{d}}$} & \multicolumn{7}{|c|}{ Reported amounts released in pounds per year ${ }^{b}$} \\
\hline & & \multirow[b]{2}{*}{ Aire } & \multirow[b]{2}{*}{ Water $^{f}$} & \multirow[b]{2}{*}{$U I^{g}$} & \multirow[b]{2}{*}{ Land $^{\text {h }}$} & \multirow[b]{2}{*}{ Other ${ }^{i}$} & \multicolumn{2}{|c|}{ Total release } \\
\hline & & & & & & & On-site & $\begin{array}{l}\text { On- and } \\
\text { Off-site }^{k} \text { off-site }\end{array}$ \\
\hline$\overline{W V}$ & 1 & 486 & 0 & 0 & 0 & 0 & 486 & 486 \\
\hline Total & 134 & 19,050 & 0 & 892 & 14,586 & 22,536 & 32,963 & $24,101 \quad 57,064$ \\
\hline
\end{tabular}

aThe TRI data should be used with caution since only certain types of facilities are required to report. This is not an exhaustive list. Data are rounded to nearest whole number.

${ }^{\mathrm{b}}$ Data in TRI are maximum amounts released by each facility.

cPost office state abbreviations are used.

dNumber of reporting facilities.

eThe sum of fugitive and point source releases are included in releases to air by a given facility.

fSurface water discharges, waste water treatment-(metals only), and publicly owned treatment works (POTWs) (metal and metal compounds).

gClass I wells, Class II-V wells, and underground injection.

${ }^{h}$ Resource Conservation and Recovery Act (RCRA) subtitle C landfills; other onsite landfills, land treatment, surface impoundments, other land disposal, other landfills.

iStorage only, solidification/stabilization (metals only), other off-site management, transfers to waste broker for disposal, unknown.

iThe sum of all releases of the chemical to air, land, water, and underground injection wells.

kTotal amount of chemical transferred off-site, including to POTWs.

$\mathrm{RF}=$ reporting facilities; $\mathrm{UI}=$ underground injection

Source: TRI16 2017 (Data are from 2016) 
Table 6-2. Releases to the Environment from Facilities that Produce, Process, or Use 2,4-Toluene Diisocyanate ${ }^{a}$

\begin{tabular}{|c|c|c|c|c|c|c|c|c|c|}
\hline \multirow[b]{3}{*}{ State $^{c}$} & \multirow[b]{3}{*}{$\mathrm{RF}^{\mathrm{d}}$} & \multicolumn{8}{|c|}{ Reported amounts released in pounds per yearb } \\
\hline & & \multirow[b]{2}{*}{ Air ${ }^{\mathrm{e}}$} & \multirow[b]{2}{*}{ Water $^{f}$} & \multirow[b]{2}{*}{$\mathrm{Ul}^{\mathrm{g}}$} & \multirow[b]{2}{*}{ Land $^{\mathrm{h}}$} & \multirow[b]{2}{*}{ Other ${ }^{i}$} & \multicolumn{3}{|c|}{ Total release } \\
\hline & & & & & & & On-site & Off-site ${ }^{k}$ & On- and off-site \\
\hline$\overline{\mathrm{AL}}$ & 1 & 5 & 0 & 0 & 0 & 0 & 5 & 0 & 5 \\
\hline AR & 2 & 1 & 0 & 0 & 2 & 0 & 1 & 2 & 3 \\
\hline $\mathrm{CO}$ & 1 & 5 & 0 & 0 & 0 & 0 & 5 & 0 & 5 \\
\hline CT & 1 & 1 & 0 & 0 & 0 & 0 & 1 & 0 & 1 \\
\hline GA & 2 & 255 & 250 & 0 & 0 & 0 & 505 & 0 & 505 \\
\hline IA & 1 & No data & No data & No data & No data & No data & No data & No data & No data \\
\hline IL & 1 & No data & No data & No data & No data & No data & No data & No data & No data \\
\hline IN & 2 & 47 & 0 & 0 & 0 & 0 & 47 & 0 & 47 \\
\hline KS & 1 & No data & No data & No data & No data & No data & No data & No data & No data \\
\hline KY & 1 & 10 & 0 & 0 & 0 & 0 & 10 & 0 & 10 \\
\hline MA & 1 & 0 & 0 & 0 & 0 & 545 & 0 & 545 & 545 \\
\hline MD & 1 & 10 & 0 & 0 & 0 & 0 & 10 & 0 & 10 \\
\hline MI & 5 & 28 & 0 & 0 & 0 & 0 & 28 & 0 & 28 \\
\hline MN & 1 & 0 & 0 & 0 & 1,020 & 0 & 0 & 1,020 & 1,020 \\
\hline MO & 2 & 59 & 0 & 0 & 0 & 0 & 59 & 0 & 59 \\
\hline MS & 4 & 173 & 0 & 0 & 0 & 0 & 173 & 0 & 173 \\
\hline $\mathrm{NC}$ & 1 & No data & No data & No data & No data & No data & No data & No data & No data \\
\hline NE & 1 & 22 & 0 & 0 & 0 & 0 & 22 & 0 & 22 \\
\hline NJ & 3 & 10 & 0 & 0 & 0 & 0 & 10 & 0 & 10 \\
\hline NY & 1 & 10 & 0 & 0 & 0 & 0 & 10 & 0 & 10 \\
\hline $\mathrm{OH}$ & 5 & 28 & 0 & 0 & 4,745 & 0 & 4,773 & 0 & 4,773 \\
\hline PA & 4 & 1 & 0 & 0 & 0 & 540 & 1 & 540 & 541 \\
\hline RI & 1 & No data & No data & No data & No data & No data & No data & No data & No data \\
\hline TN & 2 & 23 & 0 & 0 & 0 & 250 & 23 & 250 & 273 \\
\hline TX & 3 & 22 & 0 & 0 & 0 & 0 & 22 & 0 & 22 \\
\hline UT & 1 & No data & No data & No data & No data & No data & No data & No data & No data \\
\hline VA & 1 & 21 & 0 & 0 & 0 & 0 & 21 & 0 & 21 \\
\hline WI & 2 & 1 & 0 & 0 & 0 & 0 & 1 & 0 & 1 \\
\hline
\end{tabular}




\section{Table 6-2. Releases to the Environment from Facilities that Produce, Process, or Use 2,4-Toluene Diisocyanate ${ }^{a}$}

\begin{tabular}{|c|c|c|c|c|c|c|c|c|c|}
\hline \multirow[b]{3}{*}{ State $^{c}$} & \multirow[b]{3}{*}{$\mathrm{RF}^{\mathrm{d}}$} & \multicolumn{8}{|c|}{ Reported amounts released in pounds per year ${ }^{b}$} \\
\hline & & \multirow[b]{2}{*}{ Aire } & \multirow[b]{2}{*}{ Water $^{f}$} & \multirow[b]{2}{*}{$U I^{g}$} & \multirow[b]{2}{*}{ Land $^{\text {h }}$} & \multirow[b]{2}{*}{ Other ${ }^{i}$} & \multicolumn{3}{|c|}{ Total release } \\
\hline & & & & & & & On-site & Off-site & On- and off-site \\
\hline$\overline{\mathrm{WV}}$ & 1 & 2 & 0 & 0 & 0 & 0 & 2 & 0 & 2 \\
\hline $\begin{array}{l}\text { Total } \\
\end{array}$ & 53 & 737 & 250 & 0 & 5,767 & 1,335 & 5,732 & 2,357 & 8,088 \\
\hline
\end{tabular}

aThe TRI data should be used with caution since only certain types of facilities are required to report. This is not an exhaustive list. Data are rounded to nearest whole number.

bData in TRI are maximum amounts released by each facility.

cPost office state abbreviations are used.

${ }^{\mathrm{d} N u m b e r}$ of reporting facilities.

eThe sum of fugitive and point source releases are included in releases to air by a given facility.

fSurface water discharges, waste water treatment-(metals only), and publicly owned treatment works (POTWs) (metal and metal compounds).

gClass I wells, Class II-V wells, and underground injection.

${ }^{\text {h}}$ Resource Conservation and Recovery Act (RCRA) subtitle $C$ landfills; other onsite landfills, land treatment, surface impoundments, other land disposal, other landfills.

iStorage only, solidification/stabilization (metals only), other off-site management, transfers to waste broker for disposal, unknown

iThe sum of all releases of the chemical to air, land, water, and underground injection wells.

kTotal amount of chemical transferred off-site, including to POTWs.

$\mathrm{RF}=$ reporting facilities; $\mathrm{UI}=$ underground injection

Source: TRI16 2017 (Data are from 2016) 
Table 6-3. Releases to the Environment from Facilities that Produce, Process, or Use 2,6-Toluene Diisocyanate ${ }^{a}$

\begin{tabular}{|c|c|c|c|c|c|c|c|c|c|}
\hline \multirow[b]{3}{*}{ State $^{c}$} & \multirow[b]{3}{*}{$\mathrm{RF}^{\mathrm{d}}$} & \multicolumn{8}{|c|}{ Reported amounts released in pounds per yearb } \\
\hline & & \multirow[b]{2}{*}{ Air } & \multirow[b]{2}{*}{ Water $^{f}$} & \multirow[b]{2}{*}{$U^{g}$} & \multirow[b]{2}{*}{ Land $^{\text {h }}$} & \multirow[b]{2}{*}{ Other $^{i}$} & \multicolumn{3}{|c|}{ Total release } \\
\hline & & & & & & & On-site & Off-site ${ }^{k}$ & On- and off-site \\
\hline$\overline{\mathrm{AR}}$ & 1 & No data & No data & \multicolumn{4}{|c|}{ No data No data No data No data } & No data & No data \\
\hline $\mathrm{CO}$ & 1 & 1 & 0 & 0 & 0 & 0 & 1 & 0 & 1 \\
\hline GA & 1 & 255 & 5 & 0 & 0 & 0 & 260 & 0 & 260 \\
\hline IL & 1 & No data & No data & \multicolumn{4}{|c|}{ No data No data No data No data } & No data & No data \\
\hline IN & 1 & 11 & 0 & 0 & 0 & 0 & 11 & 0 & 11 \\
\hline KS & 1 & No data & No data & \multicolumn{4}{|c|}{ No data No data No data No data } & No data & No data \\
\hline MA & 1 & 1 & 0 & 0 & 0 & 2,365 & 1 & 2,365 & 2,366 \\
\hline MD & 1 & 10 & 0 & 0 & 0 & 0 & 10 & 0 & 10 \\
\hline MI & 4 & 8 & 0 & 0 & 0 & 0 & 8 & 0 & 8 \\
\hline MO & 2 & 2 & 0 & 0 & 0 & 0 & 2 & 0 & 2 \\
\hline MS & 2 & 27 & 0 & 0 & 0 & 0 & 27 & 0 & 27 \\
\hline NE & 1 & 11 & 0 & 0 & 0 & 0 & 11 & 0 & 11 \\
\hline $\mathrm{OH}$ & 5 & 3 & 0 & 0 & 1,726 & 0 & 1,729 & 0 & 1,730 \\
\hline PA & 1 & No data & No data & \multicolumn{4}{|c|}{ No data No data No data No data } & No data & No data \\
\hline TN & 2 & 47 & 0 & 0 & 0 & 250 & 47 & 250 & 297 \\
\hline $\mathrm{TX}$ & 1 & No data & No data & \multicolumn{4}{|c|}{ No data No data No data No data } & No data & No data \\
\hline WI & 2 & 3 & 0 & 0 & 0 & 0 & 3 & 0 & 3 \\
\hline WV & 1 & 2 & 0 & 0 & 0 & 0 & 2 & 0 & 2 \\
\hline Total & 29 & 381 & 5 & 0 & 1,726 & 2,615 & 2,112 & 2,615 & 4,727 \\
\hline
\end{tabular}

aThe TRI data should be used with caution since only certain types of facilities are required to report. This is not an exhaustive list. Data are rounded to nearest whole number.

${ }^{b}$ Data in TRI are maximum amounts released by each facility.

cPost office state abbreviations are used.

${ }^{\mathrm{d}}$ Number of reporting facilities.

eThe sum of fugitive and point source releases are included in releases to air by a given facility.

fSurface water discharges, waste water treatment-(metals only), and publicly owned treatment works (POTWs) (metal and metal compounds).

gClass I wells, Class II-V wells, and underground injection.

hesource Conservation and Recovery Act (RCRA) subtitle C landfills; other onsite landfills, land treatment, surface impoundments, other land disposal, other landfills.

iStorage only, solidification/stabilization (metals only), other off-site management, transfers to waste broker for disposal, unknown

iThe sum of all releases of the chemical to air, land, water, and underground injection wells.

kTotal amount of chemical transferred off-site, including to POTWs.

$\mathrm{RF}=$ reporting facilities; $\mathrm{UI}=$ underground injection

Source: TRI16 2017 (Data are from 2016) 
Table 6-4. Releases to the Environment from Facilities that Produce, Process, or Use Diisocyanates ${ }^{a}$

\begin{tabular}{|c|c|c|c|c|c|c|c|c|c|}
\hline \multirow[b]{3}{*}{ State $^{c}$} & \multirow[b]{3}{*}{$\mathrm{RF}^{\mathrm{d}}$} & \multicolumn{8}{|c|}{ Reported amounts released in pounds per year ${ }^{b}$} \\
\hline & & \multirow[b]{2}{*}{ Air } & \multirow[b]{2}{*}{ Water } & \multirow[b]{2}{*}{$\mathrm{Ul}^{\mathrm{g}}$} & \multirow[b]{2}{*}{ Land $^{\text {h }}$} & \multirow[b]{2}{*}{ Other ${ }^{\mathrm{i}}$} & \multicolumn{3}{|c|}{ Total release } \\
\hline & & & & & & & On-site & Off-site ${ }^{k}$ & $\begin{array}{l}\text { On- and } \\
\text { off-site }\end{array}$ \\
\hline$\overline{\mathrm{AL}}$ & 32 & 301 & 5 & 0 & 251 & 2,921 & 306 & 3,172 & 3,478 \\
\hline AR & 13 & 1,554 & 0 & 0 & 18,609 & 0 & 1,554 & 18,609 & 20,163 \\
\hline$A Z$ & 12 & 7 & 0 & 0 & 0 & 0 & 7 & 0 & 7 \\
\hline $\mathrm{CA}$ & 63 & 399 & 0 & 0 & 5,036 & 6,526 & 400 & 11,561 & 11,961 \\
\hline $\mathrm{CO}$ & 8 & 7 & 0 & 0 & 0 & 3,672 & 7 & 3,672 & 3,679 \\
\hline $\mathrm{CT}$ & 13 & 659 & 0 & 0 & 0 & 180 & 659 & 180 & 839 \\
\hline DE & 4 & 4 & 0 & 0 & 0 & 2,015 & 4 & 2,015 & 2,019 \\
\hline $\mathrm{FL}$ & 28 & 44 & 0 & 0 & 26,109 & 43,418 & 44 & 69,527 & 69,570 \\
\hline GA & 54 & 15,813 & 0 & 0 & 26,578 & 0 & 15,813 & 26,578 & 42,391 \\
\hline IA & 20 & 11,548 & 0 & 0 & 750 & 2,291 & 11,548 & 3,041 & 14,589 \\
\hline ID & 3 & 4 & 0 & 0 & 45,081 & 0 & 45,085 & 0 & 45,085 \\
\hline IL & 49 & 13,788 & 0 & 0 & 172 & 1,118 & 13,836 & 1,242 & 15,079 \\
\hline IN & 84 & 4,666 & 0 & 0 & 50,317 & 1,285 & 4,786 & 51,482 & 56,267 \\
\hline KS & 15 & 491 & 0 & 0 & 250 & 0 & 491 & 250 & 741 \\
\hline KY & 25 & 12,781 & 0 & 0 & 99,504 & 0 & 12,781 & 99,504 & 112,285 \\
\hline LA & 14 & 2,142 & 0 & 0 & 13,200 & 17,998 & 2,142 & 31,198 & 33,340 \\
\hline MA & 23 & 411 & 0 & 0 & 4 & 15,799 & 411 & 15,803 & 16,214 \\
\hline MD & 5 & 1,300 & 0 & 0 & 0 & 28,549 & 1,300 & 28,549 & 29,849 \\
\hline ME & 3 & 2,223 & 0 & 0 & 0 & 3,675 & 2,223 & 3,675 & 5,898 \\
\hline MI & 90 & 28,009 & 0 & 0 & 790,863 & 58,974 & 28,044 & 849,802 & 877,846 \\
\hline MN & 40 & 2,430 & 0 & 0 & 77,725 & 23,754 & 2,430 & 101,479 & 103,910 \\
\hline MO & 55 & 58,809 & 0 & 0 & 12,306 & 20,397 & 58,819 & 32,693 & 91,512 \\
\hline MS & 22 & 2,583 & 0 & 0 & 5,736 & 0 & 2,583 & 5,736 & 8,319 \\
\hline MT & 2 & No data & No data & No data & No data & No data & No data & No data & No data \\
\hline $\mathrm{NC}$ & 54 & 1,166 & 0 & 0 & 12,125 & 18,204 & 1,166 & 30,329 & 31,495 \\
\hline ND & 2 & 44 & 0 & 0 & 0 & 0 & 44 & 0 & 44 \\
\hline NE & 10 & 896 & 0 & 0 & 673 & 0 & 896 & 673 & 1,569 \\
\hline $\mathrm{NH}$ & 5 & 3 & 0 & 0 & 0 & 1,500 & 3 & 1,500 & 1,503 \\
\hline NJ & 17 & 1,390 & 0 & 0 & 5 & 0 & 1,395 & 0 & 1,395 \\
\hline NM & 2 & 2 & 0 & 0 & 0 & 2,512 & 2 & 2,512 & 2,514 \\
\hline NV & 7 & 59 & 0 & 0 & 16,324 & 40 & 14,847 & 1,576 & 16,423 \\
\hline NY & 23 & 1,224 & 0 & 0 & 403 & 2,365 & 1,224 & 2,768 & 3,992 \\
\hline $\mathrm{OH}$ & 89 & 7,483 & 0 & 0 & 68,334 & 126,119 & 13,683 & 188,253 & 201,936 \\
\hline OK & 15 & 3,841 & 0 & 0 & 0 & 594 & 3,841 & 594 & 4,435 \\
\hline OR & 23 & 3,293 & 0 & 0 & 0 & 566 & 3,293 & 566 & 3,859 \\
\hline PA & 64 & 6,188 & 0 & 0 & 146,145 & 12,487 & 6,188 & 158,632 & 164,819 \\
\hline PR & 2 & No data & No data & No data & No data & No data & No data & No data & No data \\
\hline
\end{tabular}




\section{Table 6-4. Releases to the Environment from Facilities that Produce, Process, or Use Diisocyanates ${ }^{a}$}

\begin{tabular}{|c|c|c|c|c|c|c|c|c|c|}
\hline \multirow[b]{3}{*}{ State $^{c}$} & \multirow[b]{3}{*}{$\mathrm{RF}^{\mathrm{d}}$} & \multicolumn{8}{|c|}{ Reported amounts released in pounds per year ${ }^{b}$} \\
\hline & & \multirow[b]{2}{*}{ Air } & \multirow[b]{2}{*}{ Water $^{f}$} & \multirow[b]{2}{*}{$U^{g}$} & \multirow[b]{2}{*}{ Land $^{\mathrm{h}}$} & \multirow[b]{2}{*}{ Other ${ }^{\mathrm{i}}$} & \multicolumn{3}{|c|}{ Total release } \\
\hline & & & & & & & On-site & Off-site ${ }^{k}$ & $\begin{array}{l}\text { On- and } \\
\text { off-site }\end{array}$ \\
\hline$\overline{\mathrm{RI}}$ & 7 & 0 & 0 & 0 & 0 & 5,512 & 0 & 5,512 & 5,512 \\
\hline SC & 32 & 2,097 & 0 & 0 & 5,013 & 0 & 2,097 & 5,013 & 7,110 \\
\hline SD & 2 & No data & No data & No data & No data & No data & No data & No data & No data \\
\hline $\mathrm{TN}$ & 58 & 1,687 & 0 & 0 & 102,845 & 622 & 1,687 & 103,467 & 105,154 \\
\hline $\mathrm{TX}$ & 85 & 6,936 & 38 & 0 & 130,388 & 5,839 & 87,152 & 56,049 & 143,201 \\
\hline UT & 14 & 1,154 & 0 & 0 & 0 & 723 & 1,154 & 723 & 1,877 \\
\hline VA & 20 & 564 & 0 & 0 & 2 & 5,609 & 564 & 5,611 & 6,175 \\
\hline VT & 1 & No data & No data & No data & No data & No data & No data & No data & No data \\
\hline WA & 11 & 272 & 0 & 0 & 0 & 250 & 272 & 250 & 522 \\
\hline WI & 71 & 2,234 & 0 & 0 & 10,263 & 121,093 & 2,234 & 131,356 & 133,590 \\
\hline WV & 13 & 6,634 & 0 & 0 & 44,014 & 1,500 & 6,634 & 45,514 & 52,147 \\
\hline Total & 1,304 & 207,137 & 43 & 0 & $1,709,025$ & 538,106 & 353,646 & $2,100,666$ & $2,454,312$ \\
\hline
\end{tabular}

aThe TRI data should be used with caution since only certain types of facilities are required to report. This is not an exhaustive list. Data are rounded to nearest whole number.

${ }^{b}$ Data in TRI are maximum amounts released by each facility.

cPost office state abbreviations are used.

dNumber of reporting facilities.

eThe sum of fugitive and point source releases are included in releases to air by a given facility.

fSurface water discharges, waste water treatment-(metals only), and publicly owned treatment works (POTWs) (metal and metal compounds).

gClass I wells, Class II-V wells, and underground injection.

${ }^{\text {h} R e s o u r c e ~ C o n s e r v a t i o n ~ a n d ~ R e c o v e r y ~ A c t ~(R C R A) ~ s u b t i t l e ~ C ~ l a n d f i l l s ; ~ o t h e r ~ o n s i t e ~ l a n d f i l l s, ~ l a n d ~ t r e a t m e n t, ~ s u r f a c e ~}$ impoundments, other land disposal, other landfills.

iStorage only, solidification/stabilization (metals only), other off-site management, transfers to waste broker for disposal, unknown

iThe sum of all releases of the chemical to air, land, water, and underground injection wells.

kTotal amount of chemical transferred off-site, including to POTWs.

$\mathrm{RF}=$ reporting facilities; $\mathrm{UI}=$ underground injection

Source: TRI16 2017 (Data are from 2016) 
released were dependent on the foam density produced at a given time. The study reported that only $0.005 \%$ of all of the TDI processed within the facilities was lost to the atmosphere (Duff 1983).

It has been reported that 2,6-TDI dominates TDI emissions to air from newly manufactured polyurethane foams, despite the 80:20 ratio of 2,4-TDI to 2,6-TDI in the original TDI formulation used. This is due to the lower reactivity of 2,6-TDI (Kelly et al. 1999). This information mainly relates to releases to indoor air.

Due to the diversity of applications and wide variety of MDI formulations, typical emission levels of MDI are difficult to quantify. Emissions may be comprised of MDI vapor, MDI aerosol, or a reacting mix of aerosol and vapor, which is predominantly converted to polyurethane. Emission levels are generally much lower than those of TDI flexible foam processes. A survey conducted in the United Kingdom of polyurethane production facilities (comprising $50 \%$ of total U.K. rigid foam manufacture) producing insulation board by spray and liquid laydown techniques and rigid foam slabstock produced by both continuous and discontinuous processes found typical emission levels to be $\leq 0.2 \mathrm{mg} / \mathrm{m}^{3}$ (Gilbert 1988). The American Chemistry Council Center for the Polyurethane Industry has developed an emissions calculator to estimate emissions from typical process applications and activities, which may be downloaded at https://polyurethane.americanchemistry.com. Tury et al. (2003) estimated that typical environmental loadings are less than 1 gram per metric ton of MDI used and about 25 grams per metric ton of TDI used.

Developments in polyurethane processing to control emissions of TDI and MDI include increasing the use of reaction injection moulding closed-circuit technology and advancement in the carbon absorption of emissions (Gilbert 1988).

During the application of MDI in foam or film coating of surfaces by spray gun techniques, the measured environmental contamination during application showed levels of total MDI as high as $5 \mathrm{mg} / \mathrm{m}^{3}$. More than $95 \%$ of air samples contained MDI particulates of respirable size, and counts were from 2 to 8 million parts/feet ${ }^{3}$ (ACGIH 2001).

Available information on the releases of TDI and MDI to the air in occupational settings and indoor air, along with exposure levels, are discussed in Section 6.5. 
6. POTENTIAL FOR HUMAN EXPOSURE

\subsubsection{Water}

Estimated releases of 0,250 , and 5 pounds ( $~ 0,0.11$, and 0.002 metric tons) of TDI (mixed isomers), 2,4-TDI, and 2,6-TDI to surface water from 134, 53, and 29 domestic manufacturing and processing facilities in 2016 (TRI16 2017) are summarized in Tables 6-1, 6-2, and 6-3. Table 6-4 summarizes releases of 43 pounds ( $\sim 0.02$ metric tons) of the diisocyanates category, which consists of MDI and 19 other substances, to surface water from 1,304 domestic manufacturing and processing facilities in 2016 (TRI16 2017).

Because of their reactivity with water, TDI and MDI are not likely to be found in waste water streams or in other aquatic environments, except possibly near point sources after immediate release.

\subsubsection{Soil}

Estimated releases of $14,586,5,767$, and 1,726 pounds ( $\sim 6.62,2.62$, and 0.78 metric tons) of TDI (mixed isomers), 2,4-TDI, and 2,6-TDI to soils from 134, 53, and 29 domestic manufacturing and processing facilities in 2016 (TRI16 2017) are summarized in Tables 6-1, 6-2, and 6-3. Table 6-4 summarizes releases of $1,709,025$ pounds ( $\sim 775.2$ metric tons) of the diisocyanates category, which consists of MDI and 19 other substances, to soils from 1,304 domestic manufacturing and processing facilities in 2016 (TRI16 2017). Estimated releases of 892, 0 , and 0 pounds $(\sim 0.4,0$, and 0 metric tons) of TDI (mixed isomers), 2,4-TDI, and 2,6-TDI via underground injection from 134, 53, and 29 domestic manufacturing and processing facilities in 2016 (TRI16 2017) are summarized in Tables 6-1, 6-2, and 6-3. There were no releases of the diisocyanates category, which consists of MDI and 19 other substances, via underground injection (TRI16 2017). These releases are summarized in Tables 6-4.

\subsection{ENVIRONMENTAL FATE}

Diisocyanates are extremely reactive compounds (Geens et al. 2012), especially with water. The dominant process affecting the overall environmental fate, transport, and bioaccumulation potential of diisocyanates is hydrolysis (EPA 2011b).

\subsubsection{Transport and Partitioning}

Based on their vapor pressures (see Table 4-2), MDI is expected to exist in both the vapor and particulate phases in the ambient atmosphere, while TDI isomers are expected to exist solely as a vapor (Bidleman 
1988; Eisenreich et al. 1981). Based on a study of the atmospheric hydrolysis of TDI (Dyson and Hermann 1971), it is likely that wet deposition of particulate-phase MDI from the atmosphere is not an important removal process because of its reactivity with water. TDI and MDI may be stable enough to be transported some distances under conditions of low humidity (EPA 2011a, 2011b); however, no studies were found on long distance transport in the available literature.

If released to water or moist soil/sediment, TDI and MDI will rapidly undergo hydrolysis (EPA 2011a, $2011 \mathrm{~b}$ ), and therefore, the potential to volatilize to air and leaching or adsorption to soil and sediments will be negligible. The rapid hydrolysis of these compounds also suggests that they will not bioconcentrate in aquatic organisms or bioaccumulate in the food chain. This is supported by a study using three artificial ponds to determine the fate and biological effects from a simulated accidental pollution event with MDI on an aquatic ecosystem. MDI did not accumulate in fish after 119 days postMDI addition due to its rapid reaction on the sediment surface with water to form polyurea and carbon dioxide (Heimbach et al. 1996). Also, during another study by the International Isocyanate Institute (1981), no accumulation of TDI or its respective amine hydrolysis product was found in the whole bodies of carp after 8 weeks of exposure in a model river system with an initial TDI concentration of $0.1 \mathrm{ppm}$. No bioconcentration factors (BCFs) for TDI or MDI were found in the available literature.

Volatilization from dry soil surfaces is not expected to be an important fate process for TDI, TDI isomers, or MDI based on their vapor pressures (see Table 4-2).

\subsubsection{Transformation and Degradation}

TDI and MDI are extremely reactive compounds and are well known to react with water (Yakabe et al. 1999). Hydrolysis is the dominant environmental process for TDI and MDI (EPA 2011a, 2011b), forming the respective amines, which in turn may react with more diisocyanates to produce inert, insoluble polyureas (WHO 2000).

\subsubsection{Air}

Kelly et al. (1994) reported that TDI and MDI have half-lives of $<1$ day due to reaction with OH radicals in the atmosphere. The International Isocyanate Institute (1987) also measured the rate constant for the reaction of TDI with $\mathrm{OH}$ radicals in the atmosphere to be $7.4 \times 10^{-12} \mathrm{~cm}^{3} /$ molecule-second, which corresponds to a half-life of 26 hours. These experimental half-lives are in good agreement with estimated half-lives for the reaction with photochemically produced hydroxyl radicals of 20 and 11 hours 
based on vapor phase reaction rate constants of $7.07 \times 10^{-12}$ and $1.2 \times 10^{-11} \mathrm{~cm}^{3} / \mathrm{molecule}$-second at $25^{\circ} \mathrm{C}$, for TDI and MDI respectively, determined using a structure estimation method (HSDB 2012). Aromatic isocyanates, such as TDI and MDI, do not absorb light in the ultraviolet region (wavelengths $>290 \mathrm{~nm}$ ) (Lyman et al. 1990), and therefore, direct photolysis by sunlight is not expected to be an important degradation process in the atmosphere.

In an experiment using an environmental chamber to assess the impact of photolysis, reaction with free radicals, and adsorption onto particulate matter as atmospheric removal processes of TDI, the loss rate of TDI in irradiated clean air was first order, with a half-life of 3.3 hours. It was shown that free radicals were responsible for removal, not photolysis. The removal rate was not altered by the addition of an urban surrogate hydrocarbon mixture to simulate urban air, demonstrating that adsorption onto particulate matter had minimal effect (Duff 1985).

Gas-phase TDI was originally thought to react with water vapor in the atmosphere to form TDA. One study measured a maximum reduction of $50 \%$ for TDI concentrations of 0.4 and 0.034 ppm after 8 seconds and showed that the disappearance of TDI in air depends almost solely on the water vapor concentration. The percent reduction of TDI increased 3.2\% per unit increase in absolute humidity (g water/kg dry air) and a 50\% reduction was obtained at $15 \mathrm{~g}$ water $/ \mathrm{kg}$ dry air (Dyson and Hermann 1971). A study conducted by Holdren et al. (1984) contradicts early findings of TDI reaction with water vapor, indicating that TDI loss was likely due to gas-surface or heterogeneous reactions in reaction chambers with large surface to volume ratios. In this study, gas-phase reactions between TDI and water vapor were observed in a room-sized environmental chamber. It was found that the loss rate of TDI was independent of humidity, measured over a relative humidity range of $7-70 \%$, and that no TDA or other hydrolysis product could be detected. Loss was stated to be caused by the adsorption of TDI to the chamber walls. These studies, however, did not investigate the condensed phase atmospheric hydrolysis of TDI, such as reactions with rain drops, fog, or clouds. The average hydrolysis half-lives of TDI and MDI are on the order of a few minutes to a few hours (HSDB 2012), which suggests that the heterogeneous condensed phase atmospheric hydrolysis of these compounds may be rapid.

\subsubsection{Water}

Diisocyanates that are released to water hydrolyze rapidly, forming amines that can react with residual diisocyanates, ultimately producing inert insoluble polyureas (WHO 2000). Polyureas have been reported to be the main degradation products resulting from environmental contact of TDI and MDI with water, 
with smaller amounts of soluble diamines being formed (Yakabe et al. 1999). Hydrolysis half-lives of MDI and TDI have been measured to be on the order of a few minutes to a few hours (HSDB 2012). The hydrolysis half-lives of polyureas are on the order of millennia (Sendijarevic et al. 2004).

TDI added to a model river system and a seawater system at initial concentrations of $50 \mathrm{ppm}$ was monitored over the course of 30 days. In the freshwater system, the concentration of TDI declined rapidly ranging from not detected to $0.1 \mathrm{ppm}$ after 1 day. Low levels of diamine degradation products were detectable only during early sampling periods. In the seawater system, the concentration of TDI also declined rapidly to $0.1 \mathrm{ppm}$ after 1 day (Duff 1983). The concentration of MDI added to a model marine system and a model river to simulate spill situations fell to a maximum of $5 \%$ of the initial value within 1 day (Gilbert 1988).

Yakabe et al. (1999) examined the kinetics of the hydrolysis of TDI and MDI in well-stirred and unstirred environments, with unstirred reactions representing conditions of an environmental spill. The reported half-life was 30 seconds for $28 \mathrm{mg} / \mathrm{L}$ of TDI in a well-stirred water system, while with less efficient stirring, the half-life for TDI was in the region of 3-5 minutes. At a loading of 1,000 $\mathrm{mg} / \mathrm{L}$, the half-lives of 2,4- and 2,6-TDI were about 0.7 and 1.7 hours, respectively, demonstrating that reaction rate was a function of the concentration of TDI. After 30 minutes in well-stirred water, the extent of TDI reacted varied from $85 \%$ at $10 \mathrm{mg} / \mathrm{L}$ to $20 \%$ at $10,000 \mathrm{mg} / \mathrm{L}$. The observed half-life of about 20 hours for polymeric MDI was much slower than TDI, due to its greater viscosity. Because of the viscosity and difficulty mixing with water, the reaction rate was affected by surface area contact with water and not on concentration. The well-stirred, homogeneous environments showed that TDI and MDI are expected to be rapidly degraded in water and never attain any significant concentrations. However, the complete reaction of both TDI and MDI may take several weeks under poorly mixed conditions, typical of an environmental spill, due to the formation of insoluble, solid polyurea crusts. These predictions are consistent with field observations. For example, when 14 tons of TDI were accidentally spilled onto marshy woodland in 1975, the material was covered with wet sand and monitored for 6 years. The TDI was converted to polyureas within 6 weeks, while no TDA was detected in soil $(<3 \mathrm{mg} / \mathrm{kg})$ or water $(<50 \mu \mathrm{g} / \mathrm{L})$ at any point and no adverse environmental effects were reported. In another accidental spill involving 20 tons of TDI into a fast-moving stream, the TDI reacted to form polyureas that were distributed for 2-3 km downstream, while TDA was detected at $5 \mathrm{mg} / \mathrm{L}$ downstream after 2 days, but fell below the detection limit after 2 weeks. In 1991, about 50 tons of prepolymeric MDI was spilled into a river and a majority was reported to have formed solid polyureas when it was scooped out after 2 days. The EPA testing of the river ceased after 3 days and the material in the river was declared nonhazardous. 
During a study using three artificial ponds to determine the fate and biological effects from a simulated accidental pollution event with MDI on an aquatic ecosystem, MDI was not detected in water after 119 days post-MDI addition due to its rapid reaction on the sediment surface with water to form polyurea and carbon dioxide (Heimbach et al. 1996).

TDI and MDI are expected to be hydrolyzed much more quickly than they would undergo biodegradation in water, although the resulting diamines should be subject to biodegradation (HSDB 2012). TDI, MDI, and prepolymeric MDI, at concentrations of $50 \mathrm{ppm}$ each, were reported to be completely biodegraded within 15 days at $25^{\circ} \mathrm{C}$ in a freshwater model river system with bottom sludge, and in a saltwater system, TDI could not be detected after 4 days, while MDI disappeared after 1 day (International Isocyanate Institute 1980, 1983, 1987). However, hydrolysis was not taken into account during these experiments, and it should be the predominant degradation process, not biodegradation.

\subsubsection{Sediment and Soil}

No studies of the transformation and degradation of TDI and MDI in dry soil could be located in the available literature. When monomeric MDI, and under many circumstances TDI, are handled as a liquid, they will solidify on contact with soil (Gilbert 1988). TDI and MDI will hydrolyze in moist soil and sediment due to their rapid reaction with water to form diamines and polyureas (HSDB 2012; WHO 2000) and hydrolysis is expected to occur much more rapidly than biodegradation (HSDB 2012). Therefore, reaction with water is expected to be the only significant fate process in moist soil and sediment.

In a laboratory experiment involving TDI in undisturbed moist sand, 5.5 and $3.5 \%$ of unreacted TDI remained after 24 hours and 8 days, respectively, indicating that TDI is converted to polyureas at a decreasing rate. The diamine hydrolysis product was not found above the detection limit (0.01 ppm). These results suggest the encapsulation of unreacted TDI within a rapidly forming water-insoluble polyurea crust (Gilbert 1988).

Ten days after a spill of 13 tons of TDI onto swampy, wet forest soil, the TDI solidified and the area was covered with sand. The concentration of TDI and degradation product, TDA, combined declined from the parts per thousand to the parts per million range in the soil between 10 days and 12 weeks after the spill. 
After 6 years, soil samples showed only TDI-derived polyureas (Brochhagen and Grieveson 1984; HSDB 2012).

\subsection{LEVELS MONITORED OR ESTIMATED IN THE ENVIRONMENT}

Reliable evaluation of the potential for human exposure to TDI and MDI depends in part on the reliability of supporting analytical data from environmental samples and biological specimens. Concentrations of TDI and MDI in unpolluted atmospheres and in pristine surface waters are often so low as to be near the limits of current analytical methods. In reviewing data on TDI and MDI levels monitored or estimated in the environment, it should also be noted that the amount of chemical identified analytically is not necessarily equivalent to the amount that is bioavailable. The analytical methods available for monitoring TDI and MDI in a variety of environmental media are detailed in Chapter 7.

\subsubsection{Air}

Most monitored TDI and MDI concentrations in air are found in occupational settings (see Section 6.5). Limited data were located in the available literature on measured concentration of TDI and MDI in the ambient atmosphere, likely due to their relatively short half-lives ( $<1$ day) (Kelly et al. 1994) from reaction with hydroxyl radicals.

Detectable concentrations may be found near point sources of TDI and MDI, such as near waste streams from manufacturing and processing facilities and hazardous waste sites. In an exposure assessment to TDI from a polyurethane foam manufacturing plant in North Carolina conducted in 1997, concentrations of TDI in ambient air were as high as 29 ppbv at a monitoring station approximately 100 feet outside the facilities fence line (MMWR 1998). Stack exhaust streams from a polyurethane foam manufacturing plant had reported concentrations of $100-17,700 \mu \mathrm{g} / \mathrm{m}^{3}$ of TDI (HSDB 2012). In a study conducted by the North Carolina Department of Health and Human services from 2007 to 2010, TDI was detected in only one air sample at a concentration of $0.001 \mathrm{ppbv}$ near polyurethane foam plants in North Carolina (NCDHHS 2017). Levels of MDI and TDI were monitored at six schools in the United States in order to assess outdoor air quality in representative schools (EPA 2017). MDI and TDI were not detected in the outdoor air near these schools.

A monitoring study conducted from 1984 to 1999 analyzed 4,551 area and 3,583 personal air samples in which airborne MDI concentrations were measured in a wide variety of manufacturing processes that use either polymeric MDI (PMDI) or monomeric (pure) MDI (Booth et al. 2009). Nearly 50\% of the area 
samples were below the level of quantification. Detectable levels ranged from $8.5 \times 10^{-5}$ to $9.5 \mathrm{mg} / \mathrm{m}^{3}$, with an arithmetic mean (standard deviation) of $0.057(0.32) \mathrm{mg} / \mathrm{m}^{3}$ (Booth et al 2009).

Both MDI and TDI are included in EPA's National Air Toxics Assessment (NATA), which is an ongoing comprehensive evaluation of air toxics in the United States. Emissions inventory statistics are collected from data reported by large individual facilities (point sources) and estimated for area and mobile sources using various emissions inventory models. Ambient air levels are estimated using the air dispersion model, AERMOD. Nationwide estimated average concentrations of MDI and TDI from point sources were $7.3 \times 10^{-5}$ and $1.4 \times 10^{-5} \mathrm{mg} / \mathrm{m}^{3}$, respectively, for the 2011 assessment (EPA 2015).

\subsubsection{Water}

No information on the concentration of TDI or MDI in natural water was located in the available literature. Significant concentrations are not likely to be found in the aquatic environment due to the rapid hydrolysis of these compounds; however, small amounts may be detected near point sources such as industrial waste streams and hazardous waste sites immediately after release.

\subsubsection{Sediment and Soil}

No information on the concentration of TDI or MDI in soil or sediment was located in the available literature. Significant concentrations are not likely to be found in moist soil or sediment due to the rapid hydrolysis of these compounds; however, small amounts may be detected near point sources such as industrial waste streams and hazardous waste sites.

\subsubsection{Other Environmental Media}

Commercial TDI has been detected in a urethane foam fabric coating in concentrations of $<200 \mathrm{mg} / \mathrm{kg}$ (HSDB 2012). Application of a water sealant to a concrete slab resulted in measured TDI emission rates of 319,000 or $257,000 \mu \mathrm{g} / \mathrm{m}^{2} /$ hour in 30 -minute tests at $21^{\circ} \mathrm{C}$ and $360,000 \mu \mathrm{g} / \mathrm{m}^{2} /$ hour in a 1 -hour test at $27^{\circ} \mathrm{C}$ (Kelly et al. 1999). These emission rates corresponded to 35, 38, and $179 \mu \mathrm{g}$ of total TDI emitted, respectively; 75.2, 97.8, and 79.2\% of the TDI emitted was 2,6-TDI. MDI emissions were detected at $60 \mathrm{ppt}$ for aluminum and wood substrates cured with polyurethane glue in the first 8 hours of sampling, but was below the detection limit (20 ppt) thereafter (Parekh and Karoly 2001). No data on the concentrations of TDI or MDI in other environmental media, including food, were found in the available 
literature. Due to the rapid hydrolysis of these compounds, TDI and MDI will not bioaccumulate in the food chain and are therefore not expected to be found in significant concentration in fish and foods.

\subsection{GENERAL POPULATION AND OCCUPATIONAL EXPOSURE}

Exposure of the general population to TDI from its use in polyurethane products in household materials was once thought to be negligible. An increase in the number of uncured diisocyanate-containing products used by consumers has been noted by researchers. These researchers also noted that exposure of the general population to TDI and MDI could potentially result from industrial exposures, as well as from the use of consumer products containing uncured TDI and MDI (EPA 2011a). In a study of the emission rates from polyurethane household product and materials, TDI emissions were not detectable from carpet padding, mattress and sheet foam, furniture cushion foam, spray varnishes, brush-on varnishes, general purpose water sealers, mastic construction adhesive, or high-performance caulk (Kelly et al. 1999). The only product with a large, detectable TDI emission rate was a concrete sealant. Total TDI emitted from these samples were 35 and $38 \mu \mathrm{g}$ over 30 minutes at $21^{\circ} \mathrm{C}$ and $179 \mu \mathrm{g}$ over 1 hour at $27^{\circ} \mathrm{C}$, where $75-$ $98 \%$ of the TDI released was the 2,6-isomer (Kelly et al. 1999). The predominant possible sources of exposure to MDI to the general population comes from its use in the construction and installation of foams, glue and putty, dyes, varnishes, and furniture (EPA 2011a).

Due to the concern about the presence of TDI and MDI in an uncured form in products used by or around consumers, the EPA created Action Plans to address the use of MDI, TDI, and related compounds that may result in consumer and general population exposures. The Action Plans are intended to describe courses of action to pursue to mitigate concerns over exposure (EPA 2011a, 2011b). It should be noted that these Action Plans are focused on concerns for unreacted uncured TDI and MDI products, as the completely cured products are considered inert and nontoxic.

Exposure to TDI and MDI is mainly an occupational problem due to their manufacturing and processing in many different industries. Diisocyanates are used in the production of polyurethane foam during foaming, casting, spraying, and other processes. Exposure may also occur after production when the polymer is processed. Thermal degradation of polyurethane foam during processes such as heat cutting of foam blocks, flame lamination with textiles, and welding, cutting, or grinding of polyurethane-coated metal, can also release diisocyanates into the air (Dahlin et al. 2008). MDI emission levels due to thermal degradation from the use of polyurethane core binder materials in foundry molds was reported to be $<0.02-1.0 \mathrm{mg} / \mathrm{kg}$ (Renman et al. 1986). 
Workers may be predominantly exposed to TDI and MDI by inhalation of aerosol and vapor (TDI only). Another route is through dermal exposure (Tinnerberg et al. 1997). Most occupational diisocyanate exposure studies have focused on TDI because of its widespread industrial use in the manufacture of polyurethane foam (Tinnerberg et al. 1997). A common way of assessing workplace exposure is through air monitoring. The average air concentration of TDI measured in a TDI flexible foam plant was $29.8 \mu \mathrm{g} / \mathrm{m}^{3}$, while the highest exposure peak was approximately $3 \mathrm{mg} \mathrm{TDI} / \mathrm{m}^{3}$ (Tinnerberg et al. 1997). Mean TDI levels ranged from 0.7 to $180 \mu \mathrm{g} / \mathrm{m}^{3}$ for workplace air in U.S. factories manufacturing TDI between 1973 and 1978 (IARC 1985). Mean TDI levels ranged from not detected to $540 \mu \mathrm{g} / \mathrm{m}^{3}$ for personal and workplace air in U.S. factories producing polyurethane foam between 1972 and 1981 (IARC 1985). A monitoring study conducted from 1984 to 1999 analyzed 3,583 personal air samples in which airborne MDI concentrations were measured in a wide variety of manufacturing processes that use either PMDI or monomeric (pure) MDI (Booth et al. 2009). Nearly $75 \%$ of the personal samples were below the level of quantification, and detectable levels ranged from $2 \times 10^{-5}$ to $3.9 \mathrm{mg} / \mathrm{m}^{3}$ (Booth et al 2009). The highest airborne levels tended to occur when MDI was heated or sprayed, and control measures such as appropriate ventilation and protective equipment were recommended to reduce occupational exposures.

Diem et al. (1982) performed a 5-year (April 1973 to October 1978) longitudinal study of 277 workers in a new TDI manufacturing plant in Louisiana in which over 2,000 personal air samples were measured for TDI concentrations. The 8-hour TWAs ranged from 0.1 to $25 \mathrm{ppb}$. Different jobs in the facility fell into low, moderate, and high TWA exposure categories. The average time periods spent above $20 \mathrm{ppb}$ were 1.3, 8.6, and 28.2 minutes per 8-hour shift for workers in the low, moderate, and high exposure categories, respectively.

In a study conducted in 2000 involving a plastic production plant using TDI, the concentration of TDI detected in the air ranged from 0.007 to $0.016 \mathrm{mg} / \mathrm{m}^{3}$ (Bilban 2004). Ambient air concentrations that included 60 personal breathing zone samples collected from workers in a petrochemical industrial complex in Korea contained mean TDI and MDI concentrations of 0.0174 and $0.0013 \mathrm{mg} / \mathrm{m}^{3}$, respectively (Jang et al. 2000). Tarlo et al. 1997 reported an air sampling study of 223 companies in Ontario, Canada that had potential diisocyanate exposure to workers during 1984-1988. The highest exposure levels of MDI in 123 companies were $<0.005 \mathrm{ppm}$ in 95 companies and $\geq 0.005 \mathrm{ppm}$ in 38 companies. The highest exposure levels of TDI in 78 companies were $<0.005 \mathrm{ppm}$ in 58 companies and $\geq 0.005$ ppm in 20 companies (Tarlo et al. 1997). 
At a facility that manufactures refrigerated tractor trailers in the United States, MDI was detected in the personal breathing zone of workers in the polyurethane foaming area at levels ranging from not detected to $9.1 \mu \mathrm{g} / \mathrm{m}^{3}$, with a mean concentration of $1.5 \mu \mathrm{g} / \mathrm{m}^{3}$ (Lushniak et al. 1998). Workplace air sampled during spraying operations had MDI concentrations of 21.4, 5.9, and $2.1 \mathrm{mg} / \mathrm{m}^{3}$ at distances of 2, 6, and $10 \mathrm{~m}$ away from production machinery, respectively (D’Eril et al. 1995).

A study determining the workplace air exposure concentrations of MDI to sprayers, helpers, and personnel produced during the spray application of polyurethane foam during typical indoor and outdoor construction operations was conducted by Bilan et al. (1989). In outdoor locations (three rooftops), sprayers were exposed to MDI air concentrations ranging from 0.003 to $0.05 \mathrm{ppm}$, helpers were exposed to $0.013-0.038 \mathrm{ppm}$, area personnel 5-40 feet away were exposed to $0.003-0.006 \mathrm{ppm}$, and area personnel 45 feet away were in an area with no detectable MDI. In five indoor locations ranging from 750 to 3,375 square feet, sprayers were exposed to MDI air concentrations ranging from 0.008 to $0.129 \mathrm{ppm}$, helpers were exposed to $0.001-0.018 \mathrm{ppm}$, area personnel $6-<25$ feet away were exposed to $0.007-0.093 \mathrm{ppm}$, and area personnel 25-100 feet away were in an area with no detectable MDI to $0.002 \mathrm{ppm}$. This study determined that the dominant factor in worker exposure to MDI was the distance from the spray operation and the time spent near the spray operation (Bilan et al. 1989). In another study measuring the exposure of sprayers and helpers to MDI during applications of polyurethane foam to dwellings and office buildings, MDI was measured in the personal air samples of sprayers at concentrations of $0.018-0.077$ and $0.017-0.400 \mathrm{mg} / \mathrm{m}^{3}$ during outdoor and indoor applications, respectively (Crespo and Galan 1999). Helpers were exposed to MDI concentrations of 0.034-0.045 and $0.025-0.308 \mathrm{mg} / \mathrm{m}^{3}$ during outdoor and indoor applications, respectively. Maximum airborne MDI concentrations measured 15,45 , and $>45$ minutes after spray foam application inside five single-family homes were $0.019 \mathrm{mg} / \mathrm{m}^{3}, 0.003 \mathrm{mg} / \mathrm{m}^{3}$, and below the limit of quantification (LOQ) (0.036 $\mu \mathrm{g} / \mathrm{sample}$ ), respectively (Lesage et al. 2007). Measured MDI concentrations sampled 1-3, 3-6, and 6-12 m away from application in this study were $0.147-1.55,0.005-1.12$, and $<\mathrm{LOQ}-0.822 \mathrm{mg} / \mathrm{m}^{3}$, respectively (Lesage et al. 2007). During the application of MDI in foam or film coating of surfaces by spray gun techniques, $>95 \%$ of air samples contained MDI particulates of respirable size, and counts were from 2 to 8 million parts/feet ${ }^{3}$.

In general, MDI levels decreased rapidly and were undetectable 1 hour postapplication. Many of the airborne MDI samples collected in the breathing zone of the applicators during spraying exceeded the OSHA permissible exposure limit (PEL) of $0.2 \mathrm{mg} / \mathrm{m}^{3}$, and thus, there are recommendations that workers use an air-purifying respirator equipped with a combination organic vapor cartridge and prefilter during 
application. Additionally, in order to decrease dermal exposure, personal protective equipment such as gloves, coveralls, and goggles are recommended. Additional industry recommendations when spray polyurethane foam (SPF) insulation is being applied to buildings are to vacate the structure and ventilate the area following installation. Building occupants should not return until after the manufacturer's recommended re-occupancy time (typically 24 hours) has elapsed.

Air monitoring methods may not fully characterize exposure patterns to workers, as they do not take into account possible dermal absorption (Austin 2007). In a study of 19 workers at an iron foundry, the average personal air concentration of MDI was $0.55 \mu \mathrm{g} / \mathrm{m}^{3}$ and dermal exposure to MDI ranged from 0.006 to $0.34 \mu \mathrm{g}$, indicating that dermal exposure can be a significant exposure pathway (Liljelind et al. 2010). Therefore, biological markers of isocyanates in urine and plasma may be valuable indicators in the work environment (Austin 2007). TDI in biological samples are hydrolyzed to form TDA for analysis (Tinnerberg et al. 1997). Austin (2007) conducted a study that showed how urinary TDA was a useful indication of the contribution of skin exposure to total TDI exposure in a polyurethane foam plant using 80:20 mixture of 2,4- and 2,6-TDI. This was done by comparing urinary TDA levels in two groups: 13 workers who had physical contact with uncured polyurethane foam (handlers) and 13 workers in the same plant environment who had no physical contact with uncured foam (non-handlers) on the day of sampling. Both groups were exposed to the same TDI air concentrations, ranging from $<3.5$ to $8.4 \mu \mathrm{g} / \mathrm{m}^{3}$. In hydrolyzed post-shift urine samples, 10 handlers were found to have urinary TDA above detection limits with a mean level of $2.21 \mu \mathrm{mol} / \mathrm{mol}$ creatinine, compared to only 2 non-handlers (mean $0.11 \mu \mathrm{mol} / \mathrm{mol}$ creatinine).

Hydrolyzed post-shift urine samples collected from 15 workers in a polyurethane foam plant had TDA concentrations of $0.6-4.0 \mu \mathrm{g} / \mathrm{L}$, while all urine samples from 12 people with no known history of TDI exposure had urinary TDA concentrations of below the detection limit of $0.1 \mu \mathrm{g} / \mathrm{L}$ (Carbonnelle et al. 1996).

In a study of four exposed workers and one volunteer working 8-hour shifts in a TDI flexible foam plant using an 80:20 mixture of 2,4- and 2,6-TDI, plasma concentrations were 1-38 and 7-24 $\mu \mathrm{g} / \mathrm{L}$ for 2,4- and 2,6-TDA, respectively. Over a 3-day period, the individual plasma levels among the workers varied between 7 and $73 \%$. An increase in plasma TDA for each workday was observed for the volunteer, and reached a maximum concentration 24 hours after the last exposure. The half-life in plasma was estimated to be about 10 days (Tinnerberg et al. 1997). In the urine samples of the workers, TDA concentrations varied greatly with time and exposure, reaching a maximum shortly after exposure. Measured 
concentrations of TDA in urine ranged from not detected to about $2.0 \mu \mathrm{g} / \mathrm{mmol}$ creatinine (Tinnerberg et al. 1997). Lind et al. (1996) performed a study monitoring 2,4- and 2,6-TDA in plasma from 11 workers at two separate flexible foam polyurethane production plants after their occupational exposure to 2,4- and 2,6-TDI. The TDI concentration and relative percent concentrations of 2,4- and 2,6-TDI were 0.4$4 \mu \mathrm{g} / \mathrm{m}^{3}$ and $60 / 40-5 / 95 \%$ in plant 1 , respectively, and $10-120 \mu \mathrm{g} / \mathrm{m}^{3}$ and $65 / 35-30 / 70 \%$ in plant 2 , respectively. The lower exposure levels in plant 1 compared to plant 2 was reflected in the plasma TDA concentrations. Plasma 2,4- and 2,6-TDA concentrations were $0.4-1.3$ and $1.8-5.6 \mathrm{ng} / \mathrm{mL}$, respectively, in plant 1 and 2-23 and 7.0-23 ng/mL, respectively, in plant 2 before a summer holiday.

In a study comparing the exposure to TDI in air and the concentration of TDA in urine of nine workers from two production lines in a polyurethane foam production plant using an 80:20 mixture of 2,4- and 2,6-TDI, it was reported that exposure to TDI in personal air during a shift resulted in an increase in TDA in the urine of the workers (Geens et al. 2012). Sampled over 4 days, personal air TDI concentrations ranged from 4.2 to $141.9 \mu \mathrm{g} / \mathrm{m}^{3}$ and hydrolyzed pre- and post-shift urine TDA concentrations were 1.0 19.5 and 4.4-142.6 $\mu \mathrm{g} / \mathrm{L}$, respectively (Geens et al. 2012). Kaaria et al. (2001a) performed another study on the determination of airborne TDI and urinary 2,4- and 2-6-TDA during the production of flexible foam in two separate plants in which samples were collected during one work shift on 2 consecutive days. Plant 1, which applied high-pressure molding, had TDI air concentrations ranging from not detected (LOD $0.2 \mu \mathrm{g} / \mathrm{m}^{3}$ ) to $230 \mu \mathrm{g} / \mathrm{m}$, while Plant 2, which applied low-pressure molding, had concentrations ranging from not detected to $41 \mu \mathrm{g} / \mathrm{m}^{3}$. The proportions of 2,4-and 2,6-TDI in the total exposure varied during different stages of the production process, but 2,6-TDI constituted about 75\% of all TDI detected. In urine samples collected from 17 workers, total TDA (2,4- and 2,6-TDA) was detected at concentrations of 0.11-39 nmol $/ \mathrm{mmol}$ creatinine in Plant 1 and $<0.05-7.1 \mathrm{nmol} / \mathrm{mmol}$ creatinine in Plant 2. The higher urinary TDA concentrations in Plant 1 compared to Plant 2 parallels the higher TDI concentrations in Plant 1. Kaaria et al. (2001b) observed similar results in the study of exposure to airborne MDI during the molding of rigid polyurethane foam in a refrigerator and freezer manufacturing plant. MDI was below the limit of detection $\left(3 \mu \mathrm{g} / \mathrm{m}^{3}\right)$ in $64 \%$ of air samples collected from the workers' breathing zone, with detectable samples containing 0.03-3.3 $\mu \mathrm{g} / \mathrm{m}^{3}$ MDI. However, detectable amounts of urinary MDA were found in $97 \%$ of urine samples ranging from 0.12 to $0.20 \mathrm{nmol} / \mathrm{mmol}$ creatinine, showing that monitoring of MDA in urine may be a useful method of assessing MDI exposure in workplaces that have low MDI concentrations in air.

During a study assessing MDI exposure by monitoring a specific MDI hemoglobin adduct, 5-isopropyl3-[4-(4-aminobenzyl)phenyl]hydantoin (ABP-Val-Hyd), in human blood, blood samples from 25 workers 
from an MDI plant had ABP-Val-Hyd marker concentrations ranging from 0.15 to $16.2 \mathrm{pmol} / \mathrm{g}$, while 40 people from the general population with no known exposure had no detectable amounts of ABP-ValHyd (limit of detection of $0.062 \mathrm{pmol} / \mathrm{g}$ ) (Gries and Leng 2013).

The National Occupational Exposure Survey (NOES) conducted by NIOSH in 1983 estimated that 53,321 workers employed at 2,896 facilities were potentially exposed to MDI in the United States (RTECS 2009a). The 1983 NOES also estimated that 10,921 and 2,872 workers employed at 838 and 415 facilities were potentially exposed to 2,4- and 2,6-TDI in the United States, respectively (RTECS $2009 b, 2009$ c). The NOES database does not contain information on the frequency, concentration, or duration of exposure; the survey provides only estimates of workers potentially exposed to chemicals in the workplace.

\subsection{EXPOSURES OF CHILDREN}

This section focuses on exposures from conception to maturity at 18 years in humans. Differences from adults in susceptibility to hazardous substances are discussed in Section 3.7, Children's Susceptibility.

Children are not small adults. A child's exposure may differ from an adult's exposure in many ways. Children drink more fluids, eat more food, breathe more air per kilogram of body weight, and have a larger skin surface in proportion to their body volume than adults. A child's diet often differs from that of adults. The developing human's source of nutrition changes with age: from placental nourishment to breast milk or formula to the diet of older children who eat more of certain types of foods than adults. A child's behavior and lifestyle also influence exposure. Children crawl on the floor, put things in their mouths, sometimes eat inappropriate things (such as dirt or paint chips), and may spend more time outdoors. Children also are generally closer to the ground and have not yet developed the adult capacity to judge and take actions to avoid hazards (NRC 1993).

Exposure to TDI and MDI is mainly an occupational problem due to their manufacturing and processing in many different industries. There is limited data pertaining to the use and exposure of consumer and commercial products containing uncured TDI and MDI. Because of this, exposure levels to children have not been well characterized (EPA 2011a, 2011b). 


\subsection{POPULATIONS WITH POTENTIALLY HIGH EXPOSURES}

Exposure to TDI and MDI is mainly an occupational problem. Workers involved in the production of MDI and TDI, as well as those involved in the production of polyurethane foams, have the potential for high exposure, mostly via inhalation (Dahlin et al. 2008). However, the general population could be exposed to higher than background levels through the use of uncured polyurethane consumer products such as adhesives, sealants, paints, craft materials, and insulating foams.

Diisocyanates, such as MDI and TDI, are generally supplied as raw materials to formulators who use their reactivity to combine them with other chemicals to create various polyurethanes with a wide diversity of applications. This diversity of applications leads to worker exposures in a broad range of production facilities, from small businesses to automated production lines. Diisocyanates are commonly available in unreacted, uncured forms as part of product mixtures that require an end-use reaction to form a final product. Since some of these applications can occur beyond the confines of a controlled production facility, workers and formulators need to be careful to prevent exposures (EPA 2011a).

\subsection{ADEQUACY OF THE DATABASE}

Section 104(i)(5) of CERCLA, as amended, directs the Administrator of ATSDR (in consultation with the Administrator of EPA and agencies and programs of the Public Health Service) to assess whether adequate information on the health effects of TDI and MDI is available. Where adequate information is not available, ATSDR, in conjunction with NTP, is required to assure the initiation of a program of research designed to determine the health effects (and techniques for developing methods to determine such health effects) of TDI and MDI.

The following categories of possible data needs have been identified by a joint team of scientists from ATSDR, NTP, and EPA. They are defined as substance-specific informational needs that if met would reduce the uncertainties of human health assessment. This definition should not be interpreted to mean that all data needs discussed in this section must be filled. In the future, the identified data needs will be evaluated and prioritized, and a substance-specific research agenda will be proposed.

\subsubsection{Identification of Data Needs}

Physical and Chemical Properties. The physical-chemical properties of TDI and MDI are provided in Chapter 4. Important properties such as melting point, boiling point, and vapor pressure are available. 
Other properties such as water solubility and octanol/water partition coefficient are not applicable due to the rapid rate of hydrolysis. No data needs are identified.

Production, Import/Export, Use, Release, and Disposal. According to the Emergency Planning and Community Right-to-Know Act of 1986, 42 U.S.C. Section 11023, industries are required to submit substance release and off-site transfer information to the EPA. This database is updated yearly and should provide a list of industrial production facilities and emissions.

Production, use, and import/export data are available (EPA 2011a; NTP 2011). Continuous updated information regarding these quantities is necessary.

Environmental Fate. The environmental fate and transport of TDI and MDI is well understood. Hydrolysis is the dominant process affecting the overall environmental fate, transport, and bioaccumulation potential. Additional research on the heterogeneous condensed phase atmospheric hydrolysis of TDI and MDI would be helpful in determining the significance of atmospheric hydrolysis for these compounds.

Bioavailability from Environmental Media. The rapid hydrolysis of TDI and MDI suggests that these compounds will not be biologically available in the environment. No data needs are identified.

Food Chain Bioaccumulation. The rapid hydrolysis of TDI and MDI suggests that these compounds will not bioconcentrate in aquatic organisms or bioaccumulate in the food chain. No data needs are identified.

Exposure Levels in Environmental Media. Reliable monitoring data for the levels of TDI and MDI in contaminated media at hazardous waste sites are needed so that the information obtained on levels of TDI and MDI in the environment can be used in combination with the known body burden of TDI and MDI to assess the potential risk of adverse health effects in populations living in the vicinity of hazardous waste sites.

Exposure Levels in Humans. In order to evaluate the possible correlation between the air levels of diisocyanates and the urine and plasma levels of the amine metabolites, more studies monitoring the concentration in workplace air and concentration in biological samples of workers exposed to diisocyanates are needed (Tinnerberg et al. 1997). 
There is limited exposure data pertaining to the use and exposure of consumer and commercial products containing uncured TDI and MDI (EPA 2011a, 2011b). Additional studies on the personal air and dermal exposure characterizing the concentration of TDI and MDI during application of these products is needed to assess the exposure to the general population.

This information is necessary for assessing the need to conduct health studies on these populations.

Exposures of Children. There are limited data pertaining to the use and exposure of consumer and commercial products containing uncured TDI and MDI. Because of this, exposure levels to children have not been well characterized (EPA 2011a, 2011b). Additional studies on the personal air and dermal exposure characterizing the concentration of TDI and MDI during application of these products is needed to assess the exposure to children.

Child health data needs relating to susceptibility are discussed in Section 3.12.2, Identification of Data Needs: Children's Susceptibility.

Exposure Registries. The information amassed in the National Exposure Registry facilitates the epidemiological research needed to assess adverse health outcomes that may be related to exposure to these substances; however, no exposure registries for TDI and MDI were located. TDI and MDI are not currently compounds for which a sub-registry has been established in the National Exposure Registry. TDI and MDI will be considered in the future when chemical selection is made for sub-registries to be established.

\subsubsection{Ongoing Studies}

No ongoing environmental fate studies for TDI or MDI were identified using the NIH RePORTER (2014) or the Defense Technical Information Center (DTIC) online database. 
6. POTENTIAL FOR HUMAN EXPOSURE

This page is intentionally blank. 


\section{ANALYTICAL METHODS}

The purpose of this chapter is to describe the analytical methods that are available for detecting, measuring, and/or monitoring TDI and MDI, their metabolites, and other biomarkers of exposure and effect to TDI and MDI. The intent is not to provide an exhaustive list of analytical methods. Rather, the intention is to identify well-established methods that are used as the standard methods of analysis. Many of the analytical methods used for environmental samples are the methods approved by federal agencies and organizations such as EPA and the National Institute for Occupational Safety and Health (NIOSH). Other methods presented in this chapter are those that are approved by groups such as the Association of Official Analytical Chemists (AOAC) and the American Public Health Association (APHA). Additionally, analytical methods are included that modify previously used methods to obtain lower detection limits and/or to improve accuracy and precision.

\subsection{BIOLOGICAL MATERIALS}

Some of the methods used for determining TDI and MDI in biological media are reported in Table 7-1.

Since diisocyanates react much more rapidly with the sulfhydryl, amino, and hydroxyl groups present on proteins than with water in physiological situations, they are primarily eliminated from the body as protein adducts. TDI and MDI can be effectively assayed in urine by first carrying out a strong acid extraction of the urine samples, which releases the corresponding free amine (i.e., TDA or MDA) (Rosenberg and Savolainen 1986b). The urine hydrolysate is then extracted with toluene and a perfluoroalkyl anhydride, commonly heptafluorobutyric anhydride or pentafluoropropionic anhydride, is added to produce perfluoroacylated amide derivatives that are analyzed by gas chromatography (GC)/mass spectrometry (MS) (Dalene et al. 1997; Rosenberg and Savolainen 1986b). Instead of using GC/MS, these amide derivatives may also be evaporated from the toluene solution and then dissolved in a mobile phase consisting of $0.1 \mathrm{M}$ ammonium acetate in 55/20/25\% acetonitrile/methanol/water for analysis by liquid chromatography (LC)/MS (Skarping et al. 1994).

Alkaline hydrolysis of diisocyanates protein adducts to amines has also been used for quantification in urine. A method involving strongly alkaline conditions to hydrolyze TDI protein adducts to toluene diamines followed by extraction with toluene and analysis using reverse phase high performance liquid chromatography (HPLC) and electrochemical detection has been described (Carbonelle et al. 1996). 


\section{Table 7-1. Analytical Methods for Determining TDI and MDI in Biological Materials}

\begin{tabular}{|c|c|c|c|c|c|}
\hline Sample matrix & Preparation method & $\begin{array}{l}\text { Analytical } \\
\text { method }\end{array}$ & $\begin{array}{l}\text { Sample } \\
\text { detection } \\
\text { limit }\end{array}$ & $\begin{array}{l}\text { Percent } \\
\text { recovery }\end{array}$ & Reference \\
\hline $\begin{array}{l}\text { Human urine } \\
\text { (diisocyanate- } \\
\text { derived amines) }\end{array}$ & $\begin{array}{l}\text { Heat with sulfuric acid; } \\
\text { adjust } \mathrm{pH} \text { to } \sim 9.2 ; \text { cleanup } \\
\text { on SPE silica cartridge; } \\
\text { solvent extraction with } \\
\text { toluene; derivatization with } \\
\text { heptafluorobutyric anhydride }\end{array}$ & GC/MS & $\begin{array}{l}0.2 \text { pmol per } \\
\text { injection }\end{array}$ & No data & $\begin{array}{l}\text { Rosenberg } \\
\text { and } \\
\text { Savolainen } \\
\text { 1986a }\end{array}$ \\
\hline $\begin{array}{l}\text { Human urine } \\
(2,6-T D A)\end{array}$ & $\begin{array}{l}\text { Heat with sulfuric acid; } \\
\text { solvent extraction with } \\
\text { toluene; derivatization with } \\
\text { heptafluorobutyric anhydride }\end{array}$ & GC/MS & $\begin{array}{l}2 \mathrm{pg} \text { for a } \\
1 \mu \mathrm{L} \text { sample }\end{array}$ & $\begin{array}{l}96 \%(3 \% \\
\text { RSD) }\end{array}$ & $\begin{array}{l}\text { Rosenberg } \\
\text { and } \\
\text { Savolainen } \\
\text { 1986b }\end{array}$ \\
\hline $\begin{array}{l}\text { Human urine } \\
\left(4,4^{\prime}-M D A\right)\end{array}$ & $\begin{array}{l}\text { Acidic hydrolysis with } \\
\text { sulfuric acid; extraction with } \\
\text { toluene; derivatization with } \\
\text { pentafluoropropionic } \\
\text { anhydride; evaporation; } \\
\text { dissolution in } 0.1 \mathrm{M} \\
\text { ammonium acetate in } \\
55 / 20 / 25 \% \mathrm{ACN} / \text { methanol/ } \\
\text { water }\end{array}$ & LC/PSP-MS & $0.1 \mathrm{pg} / \mu \mathrm{L}$ & No data & $\begin{array}{l}\text { Skarping et } \\
\text { al. } 1994\end{array}$ \\
\hline $\begin{array}{l}\text { Human urine } \\
\text { (TDAs) }\end{array}$ & $\begin{array}{l}\text { Alkaline hydrolysis with } \\
\text { sodium hydroxide; } \\
\text { extraction with toluene; } \\
\text { purification with a cation- } \\
\text { exchange column containing } \\
\text { methanol and phosphoric } \\
\text { acid solution }\end{array}$ & RP-HPLC/ED & $\begin{array}{l}0.1 \mu \mathrm{g} / \mathrm{L} \\
(2,6-\mathrm{TDA}) \\
0.15 \mu \mathrm{g} / \mathrm{L} \\
(2,4-\mathrm{TDA})\end{array}$ & $\begin{array}{l}87.6 \% \\
(7.9 \% \text { RSD) } \\
(2,6-\text { TDA }) \\
88.3 \% \\
\text { (5.3\% RSD) } \\
(2,4-\text { TDA) }\end{array}$ & $\begin{array}{l}\text { Carbonnelle } \\
\text { et al. } 1996\end{array}$ \\
\hline $\begin{array}{l}\text { Human urine, } \\
\text { plasma } \\
\text { (TDA, MDA) }\end{array}$ & $\begin{array}{l}\text { Acidic hydrolysis with } \\
\text { sulfuric acid; extraction with } \\
\text { toluene; derivatization with } \\
\text { pentafluoropropionic } \\
\text { anhydride }\end{array}$ & GC/MS & No data & No data & $\begin{array}{l}\text { Dalene et al. } \\
1997\end{array}$ \\
\hline $\begin{array}{l}\text { Human blood } \\
\text { (MDI adduct ABP- } \\
\text { Val-Hyd) }\end{array}$ & $\begin{array}{l}\text { Blood sample centrifuged } \\
\text { and washed with } 2.5 \mathrm{~mL} \text { of } \\
0.9 \% \text { sodium chloride } \\
\text { solution; hydrolysis with } \\
\mathrm{HCl} \text {; derivatization with } \\
\text { heptafluorobutyric anhydride }\end{array}$ & GC/MS-NCI & $\begin{array}{l}0.02 \text { ng } \\
\text { ABP-Val- } \\
\text { Hyd/g globin }\end{array}$ & $\begin{array}{l}99.8 \%(3.0- \\
9.3 \% \text { RSD) }\end{array}$ & $\begin{array}{l}\text { Gries and } \\
\text { Leng } 2013\end{array}$ \\
\hline
\end{tabular}

ABP-Val-Hyd = 5-isopropyl-3-[4-(4-aminobenzyl)phenyl]hydantoin; $A C N=$ acetonitrile; $E D=$ electrochemical detection; $\mathrm{GC}=$ gas chromatography; $\mathrm{HCl}=$ hydrochloric acid; $\mathrm{LC}=$ liquid chromatography; $\mathrm{MDA}=$ methylene dianiline; $\mathrm{MDI}=$ methylenediphenyl diisocyanate; $\mathrm{MS}=$ mass spectrometry; $\mathrm{NA}=$ not applicable; $\mathrm{NCl}=$ negative chemical ionization; PSP = plasma spray; RP-HPLC = reverse phase high performance liquid chromatography; $\mathrm{RSD}=$ relative standard deviation; $\mathrm{SPE}=$ solid-phase extraction; TDA $=$ toluene diamine; TDI $=$ toluene diisocyanate 
Amine hydrolysis products may also be detected in plasma. Similar to urinalysis, sample preparation involves heating the plasma with sulfuric acid to hydrolyze the amines diisocyanate-protein adducts, which are extracted with toluene and then pentafluoropropionic anhydride is added to produce perfluoroacylated amide derivatives that are analyzed by GC/MS (Dalene et al. 1997).

Gries and Leng (2013) have described a method for detecting the MDI-hemoglobin adduct ABP-Val-Hyd in human blood as a marker for MDI exposure. In this technique, a blood sample is centrifuged to separate the erythrocytes from the plasma, which are then washed with $2.5 \mathrm{~mL}$ of $0.9 \%$ sodium chloride solution. A globin residue is produced, which is hydrolyzed using $2 \mathrm{~mL}$ of $2 \mathrm{M}$ hydrochloric acid and derivatization was done by adding heptafluorobutyric anhydride to produce a perfluoroacylated amide. Analysis is performed by GC and high-resolution MS with negative chemical ionization.

\subsection{ENVIRONMENTAL SAMPLES}

Methods of analysis are available for the determination of TDI and MDI in air. These include HPLC, GC, and spectrophotometry. The use of a bubbler that collects air through an impinger containing an absorbent solution is the most common sampling procedure (Rosenberg and Savolainen 1986b). A critical review of sampling and analysis methods for TDI and MDI in air is presented in Levine et al. (1995). A summary of analytical methods is shown in Table 7-2.

Analysis of aromatic diisocyanates was historically performed using Marcali or Ranta colorimetric methods, with the Marcali method being the method of choice. However, these methods are limited by their lack of specificity. The Marcali method uses an acidified aqueous bubbler solution to collect diisocyanates in air and convert them into their respective diamines. The diamines then couple with N-1-naphthyl ethylenediamine to produce a colored complex. The intensity of the color measured at two different wavelengths is a measure of the amount of diisocyanates in the bubble. The inability to distinguish the diisocyanates from the produced diamines is the major limitation of this method (OSHA 1980).

The first sensitive and diisocyanate-specific method of analysis is employed by OSHA as Method 18 (OSHA 1980). Diisocyanates in air are trapped in a bubbler solution consisting of a nitro reagent (0.0002 M p-nitrobenzyl-N-n-propylamine) in toluene. This amine reacts with the diisocyanates to 


\section{Table 7-2. Analytical Methods for Determining TDI and MDI in Environmental Samples}

\begin{tabular}{|c|c|c|c|c|c|}
\hline $\begin{array}{l}\text { Sample } \\
\text { matrix }\end{array}$ & Preparation method & $\begin{array}{l}\text { Analytical } \\
\text { method }\end{array}$ & $\begin{array}{l}\text { Sample } \\
\text { detection limit }\end{array}$ & $\begin{array}{l}\text { Percent } \\
\text { recovery }\end{array}$ & Reference \\
\hline $\begin{array}{l}\text { Air } \\
\text { (diisocyanates) }\end{array}$ & $\begin{array}{l}\text { Air drawn through a } \\
\text { glass tube with a glass } \\
\text { fiber filter and } 0.1 \mathrm{mg} \text { of } \\
\text { 1-2PP adsorbent; } \\
\text { extraction with } 90: 10 \\
\text { (v/v) ACN/DMSO }\end{array}$ & $\begin{array}{l}\text { HPLC/UV } \\
\text { (Method } \\
42 \text { ) }\end{array}$ & $\begin{array}{l}1.6 \mu \mathrm{g} / \mathrm{m}^{3} \\
(2,6-\mathrm{TDI}) ; \\
1.3 \mu \mathrm{g} / \mathrm{m}^{3} \\
(2,4-\mathrm{TDI}) ; \text { for a } \\
15-\mathrm{L} \text { sample }\end{array}$ & $\begin{array}{l}86.4 \% \\
(1.6 \% \\
\text { RSD) } \\
(2,6-T D I) ; \\
80.3 \% \\
(2.4 \% \\
\text { RSD) } \\
(2,4-T D I)\end{array}$ & OSHA 1989a \\
\hline $\begin{array}{l}\text { Air } \\
\text { (MDI) }\end{array}$ & $\begin{array}{l}\text { Air drawn through a } \\
\text { glass tube with a glass } \\
\text { fiber filter and } 1.0 \mathrm{mg} \text { of } \\
\text { 1-2PP adsorbent; } \\
\text { extraction with } 90: 10 \\
\text { (v/v) ACN/DMSO }\end{array}$ & $\begin{array}{l}\text { HPLC/UV } \\
\text { (Method } \\
47 \text { ) }\end{array}$ & $\begin{array}{l}0.8 \mu \mathrm{g} / \mathrm{m}^{3} \\
\text { for a } 15-\mathrm{L} \text { sample }\end{array}$ & $\begin{array}{l}94.8 \% \\
(4.5 \% \\
\text { RSD) }\end{array}$ & OSHA 1989b \\
\hline $\begin{array}{l}\text { Air } \\
\text { (diisocyanates) }\end{array}$ & $\begin{array}{l}\text { Air drawn into a } \\
\text { bubbler containing nitro } \\
\text { reagent in toluene }\end{array}$ & $\begin{array}{l}\text { HPLC } \\
\text { (Method } \\
18 \text { ) }\end{array}$ & $\begin{array}{l}0.15 \mathrm{ppb} \\
\left(1 \mu \mathrm{g} / \mathrm{m}^{3}\right) \\
(2,4-\mathrm{TDI}) \\
0.10 \mathrm{ppb} \\
\left(1 \mu \mathrm{g} / \mathrm{m}^{3}\right) \text { (MDI); } \\
\text { for a } 20-\mathrm{L} \text { sample }\end{array}$ & $\begin{array}{l}100 \% \\
(2,4-T D I \\
\text { and MDI) }\end{array}$ & OSHA 1980 \\
\hline $\begin{array}{l}\text { Air } \\
\text { (total } \\
\text { diisocyanates) }\end{array}$ & $\begin{array}{l}\text { Air collected on } \\
\text { fiberglass filters } \\
\text { impregnated with nitro } \\
\text { reagent (4-nitro- } \\
\text { N-propylbenzylamine); } \\
\text { SPE with } 4: 6: 1 \\
\text { methanol/water/0.2M } \\
\text { hydrochloric acid }\end{array}$ & DPP & $\begin{array}{l}8 \mu \mathrm{g} / \mathrm{m}^{3} \text { for a } 50-\mathrm{L} \\
\text { sample }\end{array}$ & $\begin{array}{l}98 \% \\
(1.9 \% \\
\text { RSD) }\end{array}$ & Corbini et al. 1991 \\
\hline $\begin{array}{l}\text { Air } \\
\text { (total } \\
\text { diisocyanates) }\end{array}$ & $\begin{array}{l}\text { Air drawn through a } \\
\text { glass tube with a glass } \\
\text { fiber filter and } 0.13- \\
1.1 \text { mg of MAP } \\
\text { adsorbent; acetylation } \\
\text { with acetic anhydride; } \\
\text { extraction with } 65: 35 \\
\text { (v/v) ACN/ } \\
\text { triethylammonium } \\
\text { phosphate/formate }\end{array}$ & $\begin{array}{l}\text { RP- } \\
\text { HPLC/UV/ } \\
\text { FD } \\
\text { (Method } \\
5525 \text { ) }\end{array}$ & $\begin{array}{l}17 \mathrm{ng} / \mathrm{sample} \text {; for } \\
\text { a } 15-\mathrm{L} \text { sample }\end{array}$ & $\begin{array}{l}97-99 \% \\
(1.0-3.5 \% \\
\text { RSD) }\end{array}$ & NIOSH 2003 \\
\hline $\begin{array}{l}\text { Air } \\
(2,4-\text { TDI) }\end{array}$ & $\begin{array}{l}\text { Air drawn through a } \\
\text { tube with } 200 \text { mg of } \\
\text { Tenax-TA adsorbent; } \\
\text { thermal desorption }\end{array}$ & $\begin{array}{l}\text { capGC/ } \\
\text { FID-ITD }\end{array}$ & $\begin{array}{l}<0.001 \mu \mathrm{g} / \mathrm{sample} \\
\text { for a } 1-\mathrm{L} \text { sample }\end{array}$ & $\begin{array}{l}99.5 \% \\
(3.4-7 \% \\
\text { RSD) }\end{array}$ & $\begin{array}{l}\text { Bianchi and Joyner } \\
1997\end{array}$ \\
\hline
\end{tabular}




\section{Table 7-2. Analytical Methods for Determining TDI and MDI in Environmental Samples}

\begin{tabular}{|c|c|c|c|c|c|}
\hline $\begin{array}{l}\text { Sample } \\
\text { matrix }\end{array}$ & Preparation method & $\begin{array}{l}\text { Analytical } \\
\text { method }\end{array}$ & $\begin{array}{l}\text { Sample } \\
\text { detection limit }\end{array}$ & $\begin{array}{l}\text { Percent } \\
\text { recovery }\end{array}$ & Reference \\
\hline $\begin{array}{l}\text { Air } \\
(2,4-T D I)\end{array}$ & $\begin{array}{l}\text { Air drawn into traps } \\
\text { containing silica gel } \\
\text { coated with phosphoric } \\
\text { acid; elution with } \\
\text { sodium hydroxide and } \\
\text { methanol; separation } \\
\text { with } 60: 40 \text { (v/v) } \\
\text { phosphate buffer/ } \\
\text { methanol }\end{array}$ & HPLC/UV & $\begin{array}{l}0.2 \mu \mathrm{g} / \mathrm{m}^{3} \text { for } \mathrm{a} \\
20-\mathrm{L} \text { sample }\end{array}$ & $\begin{array}{l}100 \% \\
(<3 \% \\
\text { RSD })\end{array}$ & Colli et al. 1993 \\
\hline $\begin{array}{l}\text { Air } \\
\text { (TDI) }\end{array}$ & $\begin{array}{l}\text { Air collected into a } \\
\text { glass tube; } \\
\text { simultaneous } \\
\text { absorption and } \\
\text { derivatization with } \\
\text { p-aminophenol }\end{array}$ & $\begin{array}{l}\mathrm{HPLC} / \\
\mathrm{ECHD}\end{array}$ & $94 \mathrm{pg} / \mathrm{sample}$ & $\begin{array}{l}75-80 \% \\
(<2 \% \\
\text { RSD) }\end{array}$ & $\begin{array}{l}\text { Meyer and Tallman } \\
1983\end{array}$ \\
\hline $\begin{array}{l}\text { Air } \\
\text { (TDI vapor and } \\
\text { aerosols) }\end{array}$ & $\begin{array}{l}\text { Air collected onto a } \\
\text { denuder coated with } \\
\text { dimethylpolysiloxane } \\
\text { (adsorbent) and } \\
\text { dibutylamine } \\
\text { (derivatization reagent) } \\
\text { in series with a glass } \\
\text { fiber filter; extraction } \\
\text { with ACN }\end{array}$ & $\begin{array}{l}\text { LC-ESI/ } \\
\text { MS-MS }\end{array}$ & $\begin{array}{l}1.9 \mathrm{ng} / \mathrm{m}^{3} \\
(2,4-\mathrm{TDI}) ; \\
1.5 \mathrm{ng} / \mathrm{m}^{3} \\
(2,6-\mathrm{TDI})\end{array}$ & $\begin{array}{l}99.4 \% \\
(2,4-T D I) ; \\
99.7 \% \\
(2,6-T D I)\end{array}$ & Nordqvist et al. 2005 \\
\hline $\begin{array}{l}\text { Air (MDI vapor } \\
\text { and aerosols) }\end{array}$ & $\begin{array}{l}\text { Air collected onto a } \\
\text { denuder coated with } \\
\mathrm{N}-4 \text {-nitrobenzyl- } \\
\mathrm{N}-1 \text {-propylamine in } \\
\text { series with a glass fiber } \\
\text { filter; extraction with } \\
\text { ACN }\end{array}$ & HPLC/UV & $\begin{array}{l}0.7 \mu \mathrm{g} / \mathrm{m}^{3} \text { (vapor } \\
\text { phase); } \\
3.3 \mu \mathrm{g} / \mathrm{m}^{3} \\
\text { (condensed } \\
\text { phase) }\end{array}$ & No data & $\begin{array}{l}\text { Rando and Poovey } \\
1994\end{array}$ \\
\hline $\begin{array}{l}\text { Air } \\
\text { (diisocyanates) }\end{array}$ & $\begin{array}{l}\text { Air drawn through a } \\
\text { glass tube with a glass } \\
\text { fiber filter and di- } \\
\text { n-butylamine in } \\
\text { toluene; extraction with } \\
\text { ACN }\end{array}$ & LC/MS & $5-10 \mathrm{ng} / \mathrm{mL}$ & $\begin{array}{l}92 \% \\
(2,6-T D I) ; \\
96 \% \\
(2,4-T D I) ; \\
86 \% \text { (MDI) }\end{array}$ & Bobeldijk et al. 2008 \\
\hline $\begin{array}{l}\text { Occupational } \\
\text { air } \\
\text { (TDI) }\end{array}$ & $\begin{array}{l}\text { Air collected on a } \\
15 \text {-mg } 1-2 \mathrm{MPP} \text { - } \\
\text { impregnated glass fiber } \\
\text { filter; extraction with } \\
1 \mathrm{~mL} \mathrm{ACN} \mathrm{with} 0.5 \% \\
\text { acetic anhydride }\end{array}$ & $\begin{array}{l}\text { RP-HPLC/ } \\
\text { UV }\end{array}$ & $\begin{array}{l}0.1 \mathrm{ng} \text { per } \\
\text { injection }\end{array}$ & No data & $\begin{array}{l}\text { Rosenberg and } \\
\text { Savolainen } 1986 b\end{array}$ \\
\hline
\end{tabular}




\section{Table 7-2. Analytical Methods for Determining TDI and MDI in Environmental Samples}

\begin{tabular}{|c|c|c|c|c|c|}
\hline $\begin{array}{l}\text { Sample } \\
\text { matrix }\end{array}$ & Preparation method & $\begin{array}{l}\text { Analytical } \\
\text { method }\end{array}$ & $\begin{array}{l}\text { Sample } \\
\text { detection limit }\end{array}$ & $\begin{array}{l}\text { Percent } \\
\text { recovery }\end{array}$ & Reference \\
\hline $\begin{array}{l}\text { Occupational } \\
\text { air } \\
\text { (diisocyanates) }\end{array}$ & $\begin{array}{l}\text { Air collected using } \\
\text { midget impinge flasks } \\
\text { and derivatized with di- } \\
\text { n-butylamine in toluene } \\
\text { followed by a glass } \\
\text { fiber filter; evaporation; } \\
\text { dissolution in ACN }\end{array}$ & LC/MS & $\begin{array}{l}0.002 \mu \mathrm{g} / \mathrm{m}^{3}(\mathrm{TDI} \\
\text { and } \mathrm{MDI})\end{array}$ & $\begin{array}{l}\sim 95 \% \\
\text { (<4\% RSD } \\
\text { for TDI); } \\
(12 \% \text { RSD } \\
\text { for MDI) }\end{array}$ & Karlsson et al. 2000 \\
\hline $\begin{array}{l}\text { Occupational } \\
\text { air } \\
\text { (diisocyanates) }\end{array}$ & $\begin{array}{l}\text { Air collected with an } \\
\text { impinger and } \\
\text { derivatized with } \\
\text { 1-2MPP in toluene; } \\
\text { acetylation; } \\
\text { evaporation; dissolution } \\
\text { in ACN/methanol buffer }\end{array}$ & $\begin{array}{l}\text { HPLC/ } \\
\text { ECHD/UV } \\
\text { (Method } \\
5521 \text { ) }\end{array}$ & $\begin{array}{l}0.2 \mu \mathrm{g} / \mathrm{sample} \\
(2,4-\text { and } 2,6-\mathrm{TDI}) \\
0.09 \mu \mathrm{g} / \mathrm{sample} \\
(\mathrm{MDI})\end{array}$ & No data & NIOSH 1994 \\
\hline $\begin{array}{l}\text { Occupational } \\
\text { air } \\
\text { (diisocyanates) }\end{array}$ & $\begin{array}{l}\text { Air collected using an } \\
\text { impinger and } \\
\text { derivatized with } \\
\text { tryptamine in DMSO; } \\
\text { dissolution in ACN/ } \\
\text { sodium acetate buffer }\end{array}$ & $\begin{array}{l}\text { HPLC/FD/ } \\
\text { ECHD } \\
\text { (Method } \\
5522 \text { ) }\end{array}$ & $\begin{array}{l}0.1 \mu \mathrm{g} / \mathrm{sample} \\
(2,4-\mathrm{TDI}) ; \\
0.2 \mu \mathrm{g} / \mathrm{sample} \\
(2,6-\mathrm{TDI}) ; \\
0.3 \mu \mathrm{g} / \mathrm{sample} \\
(\mathrm{MDI})\end{array}$ & $\begin{array}{l}90.5 \% \\
(2,4-T D I) ; \\
102.8 \% \\
(2,6-T D I) ; \\
96.4 \% \\
\text { (MDI) }\end{array}$ & NIOSH 1996 \\
\hline $\begin{array}{l}\text { Occupational } \\
\text { air } \\
\text { (MDI) }\end{array}$ & $\begin{array}{l}\text { Air drawn into traps } \\
\text { containing silica gel } \\
\text { coated with phosphoric } \\
\text { acid; elution with } \\
\text { sodium hydroxide and } \\
\text { methanol }\end{array}$ & GC/NPD & $\begin{array}{l}0.7 \mu \mathrm{g} / \mathrm{m}^{3} \text { for } a \\
20-\mathrm{L} \text { sample }\end{array}$ & $\begin{array}{l}100 \% \\
(<5 \% \\
\text { RSD) }\end{array}$ & D’Eril et al. 1995 \\
\hline $\begin{array}{l}\text { Occupational } \\
\text { vapor } \\
(2,4-\text { TDI })\end{array}$ & $\begin{array}{l}\text { Air drawn through a } \\
\text { glass tube with a } \\
\text { 1-2PP/methylene } \\
\text { chloride adsorbent; } \\
\text { extraction with } \\
\text { methanol/water }\end{array}$ & $\begin{array}{l}\text { RP-HPLC/ } \\
\text { UV }\end{array}$ & $\begin{array}{l}1 \mathrm{ppb} \text { for a } 15-\mathrm{L} \\
\text { sample }\end{array}$ & $\begin{array}{l}106.3 \% \\
\text { (10\% } \\
\text { RSD) }\end{array}$ & $\begin{array}{l}\text { Chang and Burg } \\
1982\end{array}$ \\
\hline $\begin{array}{l}\text { Chemical } \\
\text { products (TDI } \\
\text { and MDI) }\end{array}$ & $\begin{array}{l}\text { Derivatized with } \\
9 \text {-(methyl } \\
\text { aminomethyl)- } \\
\text { anthracene }(1 \% \mathrm{v} / \mathrm{v}) \text { in } \\
\text { dichloromethane }\end{array}$ & HPLC/UV & $\begin{array}{l}50 \mathrm{ppb} \text { (MDI) } \\
5 \mathrm{ppb} \text { (TDI) }\end{array}$ & $\begin{array}{l}92-97 \% \\
(<5 \% \\
\text { RSD) }\end{array}$ & Rastogi 1989 \\
\hline
\end{tabular}

1-2MPP = 1-(2-methoxyphenyl)piperazine; 1-2PP = 1-(2-pyridyl)piperazine; $A C N=$ acetonitrile; capGC = capillary gas chromatography; DMSO = dimethyl sulfoxide; DPP = differential-pulse polarography; $\mathrm{ECHD}=$ electrochemical detector; ED = electron capture detector; $E S I$ = electrospray interface; FD = fluorescence detector; FID = flame ionization detector; GC = gas chromatography; HPLC = high performance liquid chromatography; ITD = ion-trap detector; LC = liquid chromatography; MAP = 1-(9-anthracenylmethyl)piperazine; $\mathrm{MDI}$ = methylenediphenyl diisocyanate; MS = mass spectrometry; NPD = nitrogen-phosphorus detector; RP-HPLC = reverse-phase high performance liquid chromatography; RSD = relative standard deviation; SPE = solid-phase extraction; TDI = toluene diisocyanate; UV = ultraviolet absorbance detection 
produce ultraviolet (UV)-absorbing urea derivatives that can be easily analyzed by HPLC (OSHA 1980). Another nitro reagent method describes the analysis of diisocyanate monomers by collecting air onto fiberglass filters impregnated with 4-nitro-N-propylbenzylamine, followed by solid-phase extraction and determination of total diisocyanate concentration by differential-pulse polarography (Corbini et al. 1991).

A modified Marcali technique was described that allowed for the ability to isolate specific diisocyanates. Colli et al. (1993) reported this method for the determination of 2,4-TDI concentrations in air. In this procedure, air is collected in traps containing silica gel coated with phosphoric acid to form 2,4-TDA, followed by elution with methanol and sodium hydroxide and analysis using HPLC and UV detection. A similar method was described for the determination of MDI in workplace air, particularly spraying operations, which employs analysis by GC and a nitrogen-phosphorus detector (D’Eril et al. 1995).

Other sampling techniques collect air onto a solid sorbent media by using an impinger and a reagentimpregnated glass-fiber filter. These methods employ the use of a derivatizing agent, such as 1-(2-methoxyphenyl)piperazine, to form stable derivatives of the diisocyanates for HPLC and electrochemical detection (Rosenberg and Savolainen 1986b). Three NIOSH methods (Methods 5521, 5522, and 5525) have been used to analyze diisocyanates and employ the use of HPLC with UV, or UV and fluorescence detection (NIOSH 1994, 1996, 2003). Derivatizing agents in these methods include 1-(2-methoxyphenyl)piperazine, 1-(9-anthracenylmethyl)piperazine, and tryptamine. Several methods use 1-(2-pyridyl)piperazine as a derivatizing agent to form stable urea derivatives for detection by HPLC with UV (Chang and Burg 1982; OSHA 1989a, 1989b). Karlsson et al. (2000) described a method using a di-n-butylamine derivatizing agent followed by LC/MS analysis. This method was validated by Bobeldijk et al. (2008).

A method employing a chemosorptive denuder in series with a glass fiber filter in order to sample personal exposure to TDI vapor and aerosols was described (Nordqvist et al. 2005). This method used a dimethylpolysiloxane denuder coating with dibutylamine as a derivatizing agent. Analysis is performed using LC with an electrospray interface with MS. The advantages of this method include a wide sampling concentration range and accurate vapor-particulate-phase distribution measurements (Nordqvist et al. 2005). Rando and Poovey (1994) described a similar method using a denuder in series with a glass fiber 
filter coated with nitro reagent, N-4-nitrobenzyl-N-1-propylamine, for collection and derivatization of MDI vapor and aerosol followed by HPLC analysis and UV detection.

Bianchi and Joyner (1997) describe a method for detecting TDI in air that collects samples directly onto an adsorbent tube packed with Tenax-TA followed by thermal desorption and then uses capillary GC with simultaneous flame ionization and ion-trap detection.

A method for determining TDI and MDI in various types of chemical products, such as adhesives, insulating foam, sealing waxes, surface coatings, etc., has been described (Rastogi 1989). This method involves the reaction of the chemical product with 9-(methyl aminomethyl)-anthracene to form urea derivatives from the diisocyanates present, followed by HPLC and UV detection.

Analytical methods for the detection of diisocyanates in other media were not located. Diisocyanates hydrolyze rapidly in water, so it is therefore unlikely that significant amounts would be found in other environmental media, such as water, soil, sediment, or food.

\subsection{ADEQUACY OF THE DATABASE}

Section 104(i)(5) of CERCLA, as amended, directs the Administrator of ATSDR (in consultation with the Administrator of EPA and agencies and programs of the Public Health Service) to assess whether adequate information on the health effects of TDI and MDI is available. Where adequate information is not available, ATSDR, in conjunction with NTP, is required to assure the initiation of a program of research designed to determine the health effects (and techniques for developing methods to determine such health effects) of TDI and MDI.

The following categories of possible data needs have been identified by a joint team of scientists from ATSDR, NTP, and EPA. They are defined as substance-specific informational needs that if met would reduce the uncertainties of human health assessment. This definition should not be interpreted to mean that all data needs discussed in this section must be filled. In the future, the identified data needs will be evaluated and prioritized, and a substance-specific research agenda will be proposed. 


\subsubsection{Identification of Data Needs}

\section{Methods for Determining Biomarkers of Exposure and Effect.}

Exposure. TDI-protein adducts in biological samples are hydrolyzed to form TDA. (Tinnerberg et al. 1997). Methods of measuring this biomarker of exposure are available (Austin 2007; Carbonelle et al. 1996).

Effect. Respiratory exposure to diisocyanates can lead to occupationally induced asthma. Workers diagnosed with diisocyanate-induced asthma manifest characteristic physiological responses after specific bronchoprovocation, which correlate to changes in their airways (Bernstein 1996).

\section{Methods for Determining Parent Compounds and Degradation Products in Environmental}

Media. Analytical methods for measuring diisocyanates in air are available (Levine et al. 1995; NIOSH 1994, 1996, 2003). Diisocyanates hydrolyze rapidly in water and it is unlikely that significant amounts would be found in environmental media, such as water, soil, and sediment.

\subsubsection{Ongoing Studies}

L2 Diagnostics, LLC (A. Wisnewski, Principal Investigator) are developing innovative biomonitoring approaches to exposure surveillance for MDI. Specifically, they aim to develop blood tests that measure two different MDI exposure biomarkers. The first biomarker is MDI-specific antibodies (IgG), produced by the immune system in response to exposure. The second biomarker is the chemical (MDI) itself conjugated to albumin, the major "protein adduct" in vivo (NIH RePORTER 2014). 
7. ANALYTICAL METHODS

This page is intentionally blank. 


\section{REGULATIONS, ADVISORIES, AND GUIDELINES}

MRLs are substance-specific estimates that are intended to serve as screening levels. They are used by ATSDR health assessors and other responders to identify contaminants and potential health effects that may be of concern at hazardous waste sites.

ATSDR has derived an acute-duration inhalation MRL of $1 \times 10^{-5} \mathrm{ppm}$ for TDI. The MRL is based on LOAEL of $0.005 \mathrm{ppm}$ for decreases in lung function in healthy volunteers exposed to TDI for 6 hours (Vandenplas et al. 1999). The LOAEL was adjusted to continuous 24-hour exposure (from 6 hours/day) and divided by a total uncertainty factor of 100 (10 for the use of a LOAEL and 10 for human variability). Since there is uncertainty that the MRL would be protective for continuous exposure for 14 days, it is suggested that measured air concentrations should not exceed the MRL of $1 \times 10^{-5} \mathrm{ppm}$ during a 24-hour period.

ATSDR has derived a chronic-duration inhalation MRL of $3 \times 10^{-6} \mathrm{ppm}$ for TDI. The MRL is based on the mean daily exposure level of $0.0012 \mathrm{ppm}$, which resulted in decreases in lung function in workers at flexible foam producing facilities (Clark et al. 1998). The adverse effect level of $0.0012 \mathrm{ppm}$ was adjusted for intermittent exposure ( 8 hours/day, 5 days/week) and divided by a total uncertainty factor of 100 (10 for the use of a LOAEL and 10 for human variability).

EPA (IRIS 2003) has derived a chronic-duration reference concentration (RfC) of $7 \times 10^{-5} \mathrm{mg} / \mathrm{m}^{3}$ $\left(1 \times 10^{-5} \mathrm{ppm}\right)$ based on a NOAEL of $0.0009 \mathrm{ppm}$ and a LOAEL of $0.0019 \mathrm{ppm}$ for decreases in lung function in workers at a TDI manufacturing facility (Diem et al. 1982). The NOAEL was adjusted for intermittent exposure ([10 $\mathrm{m}^{3} /$ day $] /\left[20 \mathrm{~m}^{3} /\right.$ day $], 5$ days/week $)$ and divided by a total uncertainty factor of 30 (3 to account for both extrapolation from a subchronic study and the lack of developmental toxicity data in a second species and 10 for intrahuman variability).

ATSDR has derived a chronic-duration inhalation MRL of $0.001 \mathrm{mg} / \mathrm{m}^{3}$ for polymeric MDI. The MRL is based on a $\mathrm{BMCL}_{10}$ of $0.48 \mathrm{mg} / \mathrm{m}^{3}$ for basal cell hyperplasia in the nasal cavity observed in rats exposed to polymeric MDI for 2 years (Reuzel et al. 1994). The BMCL 10 was adjusted for intermittent exposure (6 hours/day, 5 days/week) and multiplied by a regional deposited dose ratio for extrathoracic effect $\left(\mathrm{RDDR}_{\mathrm{ET}}\right)$ of 0.453 to calculate the human equivalent concentration $\left(\mathrm{BMCL}_{\mathrm{HEC}}\right)$. The $\mathrm{BMCL}_{\mathrm{HEC}}$ of $0.039 \mathrm{mg} / \mathrm{m}^{3}$ was divided by a total uncertainty factor of 30 (3 to extrapolate from animals to humans 
with dosimetric adjustments and 10 for human variability); EPA notes that "the two UFs of 3 each coalesce to a 10 , yielding a total UF of $100 . "$

EPA (IRIS 2002) has derived a chronic-duration RfC of $0.0006 \mathrm{mg} / \mathrm{m}^{3}$ based on a BMCL $\mathrm{BDJ}_{\text {of }}$ $0.14 \mathrm{mg} / \mathrm{m}^{3}$ for basal cell hyperplasia in rats exposed to polymeric MDI for 2 years (Reuzel et al. 1994). The BMCL $L_{H E C}$ was calculated by multiplying the BMCL $L_{A D J}$ of $0.14 \mathrm{mg} / \mathrm{m}^{3}$ by a RDDR ${ }_{\mathrm{ET}}$ of 0.453. The BMCL $\mathrm{HEC}_{\mathrm{HEC}}$ of $0.06 \mathrm{mg} / \mathrm{m}^{3}$ was divided by a total uncertainty factor of 100 (10 for intraindividual variation, 3 for the lack of reproductive data, and 3 for "interspecies variation inasmuch as dosimetric adjustments had been made").

The international and national regulations, advisories, and guidelines regarding TDI and MDI in air, water, and other media are summarized in Table 8-1. 
Table 8-1. Regulations, Advisories, and Guidelines Applicable to TDI and MDI

\begin{tabular}{|c|c|c|c|}
\hline Agency & Description & Information & Reference \\
\hline \multicolumn{4}{|c|}{ International } \\
\hline \multicolumn{4}{|l|}{$\overline{\text { Guidelines: }}$} \\
\hline \multirow[t]{3}{*}{ IARC } & Carcinogenicity classification & & \\
\hline & TDI & Group 2Ba & IARC 1999b \\
\hline & 4,4'-MDI & Group $3^{b}$ & IARC 1999a \\
\hline \multirow[t]{2}{*}{ WHO } & Air quality guidelines & Not listed & WHO 2010 \\
\hline & Drinking water quality guidelines & Not listed & WHO 2017 \\
\hline \multicolumn{4}{|l|}{ National } \\
\hline \multicolumn{4}{|c|}{$\overline{\text { Regulations and guidelines: }}$} \\
\hline \multicolumn{4}{|l|}{ a. Air } \\
\hline \multirow[t]{5}{*}{ ACGIH } & TLV-TWA $A^{c, d, e}$ & & \\
\hline & $2,4-\mathrm{TDI}$ or $2,6-\mathrm{TDI}$ (or as a mixture) & $0.001 \mathrm{ppm}^{\mathrm{f}}$ & ACGIH 2016a \\
\hline & Monomeric 4,4'-MDI & 0.005 ppm & ACGIH 2001 \\
\hline & STEL & & \\
\hline & $2,4-\mathrm{TDI}$ or $2,6-\mathrm{TDI}$ (or as a mixture) & $0.005 \mathrm{ppm}^{\mathrm{f}}$ & ACGIH 2016a \\
\hline \multirow[t]{18}{*}{ DOE } & PAC-19 & & DOE $2016 b$ \\
\hline & TDI, mixed isomers & 0.020 ppm & \\
\hline & 2,4-TDI & $0.020 \mathrm{ppm}$ & \\
\hline & 2,6-TDI & 0.020 ppm & \\
\hline & Monomeric 4,4'-MDI & $0.45 \mathrm{mg} / \mathrm{m}^{3}$ & \\
\hline & Polymeric 4,4'-MDI & $29 \mathrm{mg} / \mathrm{m}^{3}$ & \\
\hline & PAC-2g & & \\
\hline & TDI, mixed isomers & $0.083 \mathrm{ppm}$ & \\
\hline & 2,4-TDI & $0.083 \mathrm{ppm}$ & \\
\hline & 2,6-TDI & 0.083 ppm & \\
\hline & Monomeric 4,4'-MDI & $5 \mathrm{mg} / \mathrm{m}^{3}$ & \\
\hline & Polymeric 4,4'-MDI & $40 \mathrm{mg} / \mathrm{m}^{3}$ & \\
\hline & PAC-39 & & \\
\hline & TDI, mixed isomers & $0.51 \mathrm{ppm}$ & \\
\hline & 2,4-TDI & $0.51 \mathrm{ppm}$ & \\
\hline & 2,6-TDI & $0.51 \mathrm{ppm}$ & \\
\hline & Monomeric 4,4'-MDI & $55 \mathrm{mg} / \mathrm{m}^{3}$ & \\
\hline & Polymeric 4,4'-MDI & $240 \mathrm{mg} / \mathrm{m}^{3}$ & \\
\hline
\end{tabular}


Table 8-1. Regulations, Advisories, and Guidelines Applicable to TDI and MDI

\begin{tabular}{|c|c|c|c|}
\hline Agency & Description & Information & Reference \\
\hline \multirow[t]{41}{*}{ EPA } & 2,4-TDI & & EPA 2016a \\
\hline & AEGL-1h & & \\
\hline & 10 minutes & $0.020 \mathrm{ppm}$ & \\
\hline & 30 minutes & $0.020 \mathrm{ppm}$ & \\
\hline & 60 minutes & 0.020 ppm & \\
\hline & 4 hours & $0.010 \mathrm{ppm}$ & \\
\hline & 8 hours & $0.010 \mathrm{ppm}$ & \\
\hline & AEGL-2h & & \\
\hline & 10 minutes & $0.24 \mathrm{ppm}$ & \\
\hline & 30 minutes & $0.17 \mathrm{ppm}$ & \\
\hline & 60 minutes & $0.083 \mathrm{ppm}$ & \\
\hline & 4 hours & $0.021 \mathrm{ppm}$ & \\
\hline & 8 hours & $0.021 \mathrm{ppm}$ & \\
\hline & AEGL-3n & & \\
\hline & 10 minutes & $0.65 \mathrm{ppm}$ & \\
\hline & 30 minutes & $0.65 \mathrm{ppm}$ & \\
\hline & 60 minutes & $0.51 \mathrm{ppm}$ & \\
\hline & 4 hours & $0.32 \mathrm{ppm}$ & \\
\hline & 8 hours & $0.16 \mathrm{ppm}$ & \\
\hline & 2,6-TDI & & \\
\hline & AEGL-1h & & \\
\hline & 10 minutes & $0.020 \mathrm{ppm}$ & \\
\hline & 30 minutes & $0.020 \mathrm{ppm}$ & \\
\hline & 60 minutes & $0.020 \mathrm{ppm}$ & \\
\hline & 4 hours & $0.010 \mathrm{ppm}$ & \\
\hline & 8 hours & $0.010 \mathrm{ppm}$ & \\
\hline & AEGL-2h & & \\
\hline & 10 minutes & $0.24 \mathrm{ppm}$ & \\
\hline & 30 minutes & $0.17 \mathrm{ppm}$ & \\
\hline & 60 minutes & $0.083 \mathrm{ppm}$ & \\
\hline & 4 hours & $0.021 \mathrm{ppm}$ & \\
\hline & 8 hours & $0.021 \mathrm{ppm}$ & \\
\hline & AEGL-3 h & & \\
\hline & 10 minutes & $0.65 \mathrm{ppm}$ & \\
\hline & 30 minutes & $0.65 \mathrm{ppm}$ & \\
\hline & 60 minutes & $0.51 \mathrm{ppm}$ & \\
\hline & 4 hours & $0.32 \mathrm{ppm}$ & \\
\hline & 8 hours & $0.16 \mathrm{ppm}$ & \\
\hline & Hazardous air pollutant & & EPA 2016c 42 USC \\
\hline & 2,4-TDI & Yes & 7412 \\
\hline & Monomeric 4,4'-MDI & Yes & \\
\hline
\end{tabular}


Table 8-1. Regulations, Advisories, and Guidelines Applicable to TDI and MDI

\begin{tabular}{|c|c|c|c|}
\hline Agency & Description & Information & Reference \\
\hline & NAAQS & Not listed & EPA 2018b \\
\hline \multirow[t]{8}{*}{$\mathrm{NIOSH}$} & REL & & NIOSH 2016a, \\
\hline & 2,4-TDI & $\begin{array}{l}\text { Potential occupational } \\
\text { carcinogens }\end{array}$ & \\
\hline & Monomeric 4,4'-MDI & $0.05 \mathrm{mg} / \mathrm{m}^{3}$ & \\
\hline & Ceiling limit (10-minute) & & \\
\hline & Monomeric 4,4'-MDI & $0.2 \mathrm{mg} / \mathrm{m}^{3}$ & \\
\hline & IDLH & & \\
\hline & 2,4-TDI & $2.5 \mathrm{ppm}$ & \\
\hline & Monomeric 4,4'-MDI & $75 \mathrm{mg} / \mathrm{m}^{3}$ & \\
\hline \multirow[t]{4}{*}{ OSHA } & $\begin{array}{l}\text { Ceiling limit (15-minute TWA) for } \\
\text { general industry }\end{array}$ & & $\begin{array}{l}\text { OSHA 2017b } 29 \\
\text { CFR 1910.1000, }\end{array}$ \\
\hline & $2,4-T D I$ & $0.02 \mathrm{ppm}$ & Table Z-2 \\
\hline & Monomeric 4,4'-MDI & $0.02 \mathrm{ppm}$ & \\
\hline & Highly hazardous chemicals & Not listed & $\begin{array}{l}\text { OSHA 2017a } \\
29 \text { CFR 1910.119, } \\
\text { Appendix A }\end{array}$ \\
\hline \multicolumn{4}{|l|}{ b. Water } \\
\hline \multirow[t]{7}{*}{ EPA } & $\begin{array}{l}\text { Designated as hazardous substances } \\
\text { in accordance with } \\
\text { Section } 311(b)(2)(A) \text { of the Clean } \\
\text { Water Act }\end{array}$ & Not listed & $\begin{array}{l}\text { EPA 2017b } \\
40 \text { CFR } 116.4\end{array}$ \\
\hline & $\begin{array}{l}\text { Drinking water contaminant candidate } \\
\text { list }\end{array}$ & & $\begin{array}{l}\text { EPA 2016b } \\
81 \text { FR } 81099\end{array}$ \\
\hline & TDI & Yes & \\
\hline & $\begin{array}{l}\text { Drinking water standards and health } \\
\text { advisories }\end{array}$ & Not listed & EPA 2012 \\
\hline & $\begin{array}{l}\text { National primary drinking water } \\
\text { standards }\end{array}$ & Not listed & EPA 2009b \\
\hline & $\begin{array}{l}\text { National recommended water quality } \\
\text { criteria: human health for the } \\
\text { consumption of (at } 10^{-4} \text { risk) }\end{array}$ & Not listed & EPA 2018c \\
\hline & $\begin{array}{l}\text { Reportable quantities of hazardous } \\
\text { substances designated pursuant to } \\
\text { Section } 311 \text { of the Clean Water Act }\end{array}$ & Not listed & $\begin{array}{l}\text { EPA 2017d } \\
40 \text { CFR } 117.3\end{array}$ \\
\hline \multicolumn{4}{|l|}{ c. Food } \\
\hline \multirow[t]{2}{*}{ FDA } & Bottled water & Not listed & $\begin{array}{l}\text { FDA } 2017 \\
21 \text { CFR } 165.110\end{array}$ \\
\hline & EAFUSi & Not listed & FDA 2013 \\
\hline \multicolumn{4}{|l|}{ d. Other } \\
\hline \multirow[t]{2}{*}{ ACGIH } & Carcinogenicity classification & & ACGIH 2016a \\
\hline & $2,4-T D I$ or 2,6 -TDI (or as a mixture) & $A 3^{j}$ & \\
\hline
\end{tabular}


Table 8-1. Regulations, Advisories, and Guidelines Applicable to TDI and MDI

\begin{tabular}{|c|c|c|c|}
\hline Agency & Description & Information & Reference \\
\hline \multirow[t]{29}{*}{ EPA } & Carcinogenicity classification & & IRIS 2002, 2003 \\
\hline & TDI (toluene 2,4- (2,6-) diisocyanate) & No data & \\
\hline & $\begin{array}{l}\text { MDI (monomeric MD) and polymeric } \\
\text { MDI) }\end{array}$ & Group $D^{k}$ & \\
\hline & $\mathrm{RfC}$ & & \\
\hline & 2,4-/2,6-TDI & $7 \times 10^{-5} \mathrm{mg} / \mathrm{m}^{3}$ & \\
\hline & $\begin{array}{l}\text { MDI (monomeric MDI and polymeric } \\
\mathrm{MDI} \text { ) }\end{array}$ & $6 \times 10^{-4} \mathrm{mg} / \mathrm{m}^{3}$ & \\
\hline & $\mathrm{RfD}$ & & \\
\hline & $\begin{array}{l}\text { 2,4-/2,4-TDI (toluene 2,4- (2,6-) } \\
\text { diisocyanate) }\end{array}$ & Not listed & \\
\hline & $\begin{array}{l}\text { MDI (monomeric MDI and polymeric } \\
\mathrm{MDI} \text { ) }\end{array}$ & Not listed & \\
\hline & $\begin{array}{l}\text { Identification and listing of hazardous } \\
\text { waste }\end{array}$ & & $\begin{array}{l}\text { EPA 2017c } \\
40 \text { CFR 261, }\end{array}$ \\
\hline & TDI (toluene 2,4- (2,6-) diisocyanate) & U223 & Appendix VIII \\
\hline & Master Testing List & & EPA 1996 \\
\hline & Monomeric 4,4'-MDI & Yes & \\
\hline & $\begin{array}{l}\text { Polymethylene polyphenyl } \\
\text { isocyanate }\end{array}$ & Yes & \\
\hline & Polymeric 4,4'-MDI & Yes & \\
\hline & $\begin{array}{l}\text { RCRA waste minimization PBT priority } \\
\text { chemical list }\end{array}$ & Not listed & $\begin{array}{l}\text { EPA 1998b } \\
63 \text { FR } 60332\end{array}$ \\
\hline & $\begin{array}{l}\text { Standards for owners and operators of } \\
\text { hazardous waste TSD facilities; } \\
\text { groundwater monitoring list }\end{array}$ & Not listed & $\begin{array}{l}\text { EPA } 2017 \text { e } 40 \text { CFR } \\
264 \text {, Appendix IX }\end{array}$ \\
\hline & $\begin{array}{l}\text { Superfund, emergency planning, and } \\
\text { community right-to-know }\end{array}$ & & \\
\hline & $\begin{array}{l}\text { Designated CERCLA hazardous } \\
\text { substance and reportable quantity }\end{array}$ & & $\begin{array}{l}\text { EPA } 2017 f \\
40 \text { CFR } 302.4\end{array}$ \\
\hline & $\begin{array}{l}\text { TDI (toluene 2,4- (2,6-) } \\
\text { diisocyanate)! }\end{array}$ & 100 pounds & \\
\hline & 2,4-TDI & 100 pounds & \\
\hline & 2,6-TDI & 100 pounds & \\
\hline & Monomeric 4,4'-MDIm & 5,000 pounds & \\
\hline & $\begin{array}{l}\text { Effective date of toxic chemical } \\
\text { release reporting }\end{array}$ & & $\begin{array}{l}\text { EPA } 2017 \mathrm{~g} \\
40 \text { CFR } 372.65\end{array}$ \\
\hline & $\begin{array}{l}\text { TDI (toluene 2,4- (2,6-) } \\
\text { diisocyanate) }\end{array}$ & 01/01/1990 & \\
\hline & 2,4-TDI & $01 / 01 / 1987$ & \\
\hline & 2,6-TDI & $01 / 01 / 1987$ & \\
\hline & Monomeric 4,4'-MDI & $01 / 01 / 1987$ & \\
\hline & $\begin{array}{l}\text { Diisocyanates category (including } \\
\text { MDI and polymeric MDI) }\end{array}$ & 01/01/1995 & \\
\hline
\end{tabular}


Table 8-1. Regulations, Advisories, and Guidelines Applicable to TDI and MDI

\begin{tabular}{|c|c|c|c|}
\hline Agency & Description & Information & Reference \\
\hline & $\begin{array}{l}\text { Extremely hazardous substances } \\
\text { and its threshold planning quantity }\end{array}$ & & $\begin{array}{l}\text { EPA 2017h } \\
40 \text { CFR 355, }\end{array}$ \\
\hline & 2,4-TDI & 500 pounds & Appendix A \\
\hline & 2,6-TDI & 100 pounds & \\
\hline & $\begin{array}{l}\text { TSCA chemical lists and reporting } \\
\text { periods }\end{array}$ & & $\begin{array}{l}\text { EPA } 2017 \mathrm{i} \\
40 \text { CFR } 712.30\end{array}$ \\
\hline & Monomeric 4,4'-MDI & & \\
\hline & Effective date & $10 / 29 / 1990$ & \\
\hline & Reporting date & $12 / 27 / 1990$ & \\
\hline & Polymeric 4,4'-DMDI & & \\
\hline & Effective date & $10 / 29 / 1990$ & \\
\hline & Reporting date & $12 / 27 / 1990$ & \\
\hline & $\begin{array}{l}\text { TSCA health and safety data } \\
\text { reporting }\end{array}$ & & $\begin{array}{l}\text { EPA } 2017 \mathrm{j} \\
40 \text { CFR } 716.120\end{array}$ \\
\hline & $\begin{array}{l}\text { TDI (2,4 and 2,6 mixed isomers); } \\
\text { 2,4-TDI; monomeric 4,4'-MDI; } \\
\text { polymeric 4,4'-MDI }\end{array}$ & & \\
\hline & Effective date & 06/01/1987 & \\
\hline & Reporting date & 06/01/1997 & \\
\hline & 2,6-TDI & & \\
\hline & Effective date & $06 / 01 / 1987$ & \\
\hline & Reporting date & 12/19/1995 & \\
\hline \multirow[t]{2}{*}{ NTP } & Carcinogenicity classification & & NTP 2016 \\
\hline & TDI & $\begin{array}{l}\text { Reasonably anticipated } \\
\text { to be a human } \\
\text { carcinogen }\end{array}$ & \\
\hline
\end{tabular}

aGroup 2B: possibly carcinogenic to humans.

bGroup 3: not classifiable as to its carcinogenicity to humans.

'Skin notation: refers to potential significant contribution to the overall exposure by the cutaneous route (ACGIH 2016b).

${ }^{d}$ Dermal sensitization notation: refers to potential for agent to produce dermal sensitization (ACGIH 2016b).

eRespiratory sensitization notation: refers to potential for agent to produce respiratory sensitization (ACGIH $2016 \mathrm{~b})$.

IInhalable fraction and vapor: material exerts sufficient vapor pressure such that it may be present in both particle and vapor phases, with each contributing a significant portion of the dose at the TLV-TWA concentration (ACGIH 2016b).

gDefinitions of PAC terminology are available from DOE (2016a).

${ }^{\mathrm{h}} \mathrm{AEGL}-1$ is the airborne concentration of a substance above which it is predicted that the general population, including susceptible individuals, could experience notable discomfort, irritation, or certain asymptomatic nonsensory effects. However, the effects are not disabling and are transient and reversible upon cessation of exposure. AEGL2 is the airborne concentration of a substance above which it is predicted that the general population, including susceptible individuals, could experience irreversible or other serious, long-lasting adverse health effects or an impaired ability to escape. AEGL-3 is the airborne concentration of a substance above which it is predicted that the general population, including susceptible individuals, could experience life-threatening health effects or death (EPA 2018a).

iThe EAFUS list of substances contains ingredients added directly to food that FDA has either approved as food additives or listed or affirmed as GRAS.

jA3: confirmed animal carcinogen with unknown relevance to humans.

kGroup D: not classifiable as to human carcinogenicity. 
Table 8-1. Regulations, Advisories, and Guidelines Applicable to TDI and MDI

\begin{tabular}{llll}
\hline Agency Description & Information & Reference \\
\hline
\end{tabular}

'Designated CERCLA hazardous substance and reportable quantity pursuant to Section 112 of the Clean Air Act and Section 3001 of RCRA.

mDesignated CERCLA hazardous substance and reportable quantity pursuant to Section 112 of the Clean Air Act.

ACGIH = American Conference of Governmental Industrial Hygienists; AEGL = acute exposure guideline levels; CERCLA = Comprehensive Environmental Response, Compensation, and Liability Act; CFR = Code of Federal Regulations; $\mathrm{DOE}=$ Department of Energy; EAFUS = Everything Added to Food in the United States; EPA = Environmental Protection Agency; FDA = Food and Drug Administration; FR = Federal Register; GRAS = generally recognized as safe; IARC = International Agency for Research on Cancer; IDLH = immediately dangerous to life or health; IRIS = Integrated Risk Information System; MDI = methylenediphenyl diisocyanate; NAAQS = National Ambient Air Quality Standards; NIOSH = National Institute for Occupational Safety and Health; NTP = National Toxicology Program; OSHA = Occupational Safety and Health Administration; PAC = protective action criteria; $\mathrm{PBT}=$ persistent, bioaccumulative, and toxic; RCRA = Resource Conservation and Recovery Act; $\mathrm{REL}$ = recommended exposure limit; $\mathrm{RfC}=$ inhalation reference concentration; $\mathrm{RfD}=$ oral reference dose; SIDS = Screening Information Data Set; STEL = short-term exposure limit; TDI = toluene diisocyanate; TLV = threshold limit values; TSCA = Toxic Substances Control Act; TSD = treatment, storage, and disposal; TWA = time-weighted average; USC = United States Code; $\mathrm{WHO}=$ World Health Organization 


\section{REFERENCES}

ACGIH. 2001. Methylene bisphenyl isocyanate. In: Documentation of the threshold limit values for chemical substances. Cincinnati, $\mathrm{OH}$ : American Conference of Governmental Industrial Hygienists.

ACGIH. 2016a. Toluene diisocyanate, 2,4- or 2,6- (or as a mixture). Cincinnati, OH: American Conference of Governmental Industrial Hygienists.

ACGIH. 2016b. Definitions and notations. In: TLVs and BEIs based on the documentation of the threshold limit values for chemical substances and physical agents and biological exposure indices. Cincinnati, OH: American Conference of Governmental Industrial Hygienists, 72-74, 77.

Adams WG. 1975. Long-term effects on the health of men engaged in the manufacture of tolylene diisocyanate. Br J Ind Med 32(1):72-78.

AIHA. 2013. Emergency response planning guidelines (ERPG). Fairfax, VA: American Industrial Hygiene Association. https://www.aiha.org/get-involved/AIHAGuidelineFoundation/

EmergencyResponsePlanningGuidelines/Pages/default.aspx. January 08, 2014.

Altman PL, Dittmer DS. 1974. 2nd ed. Bethesda, MD: Federation of American Societies of Experimental Biology.

Andersen M, Binderup ML, Kiel P, et al. 1980. Mutagenic action of isocyanates used in the production of polyurethanes. Scand J Work Environ Health 6(3):221-226.

Andersen ME, Krishnan K. 1994. Relating in vitro to in vivo exposures with physiologically based tissue dosimetry and tissue response models. In: Salem H, ed. Animal test alternatives: Refinement, reduction, and replacement. New York, NY: Marcel Dekker, Inc., 9-25.

Andersen ME, Clewell HJ, Gargas ML, et al. 1987. Physiologically based pharmacokinetics and the risk assessment process for methylene chloride. Toxicol Appl Pharmacol 87(2):185-205.

Anderson D, Styles JA. 1978. An evaluation of 6 short-term tests for detecting organic chemical carcinogens. Appendix II. The bacterial mutation test. Br J Cancer 37:924-930.

Aoyama K, Huang J, Ueda A, et al. 1994. Provocation of respiratory allergy in guinea pigs following inhalation of free toluene diisocyanate. Arch Environ Contam Toxicol 26(3):403-407.

Arts JH, de Jong WH, van Triel JJ, et al. 2008. The respiratory local lymph node assay as a tool to study respiratory sensitizers. Toxicol Sci 106(2):423-434.

ATSDR. 1989. Decision guide for identifying substance-specific data needs related to toxicological profiles; Notice. Agency for Toxic Substances and Disease Registry. Fed Regist 54(174):37618-37634.

* Not cited in text 


\section{REFERENCES}

ATSDR. 2017. 1,3-Toluene diisocyanate. Full SPL data. Substance priority list (SPL) resource page. Agency for Toxic Substances and Disease Registry, Centers for Disease Control and Prevention. http://www.atsdr.cdc.gov/SPL/resources/index.html. October 6, 2017.

Austin S. 2007. Biological monitoring of TDI-derived amines in polyurethane foam production. Occup Med (Lond) 57(6):444-448.

Axford AT, McKerrow CB, Jones AP, et al. 1976. Accidental exposure to isocyanate fumes in a group of firemen. Br J Ind Med 33(2):65-71.

Banks DE, Rando RJ. 1988. Recurrent asthma induced by toluene diisocyanate. Thorax 43(8):660-662.

Banks DE, Barkman HW, Jr., Butcher BT, et al. 1986. Absence of hyperresponsiveness to methacholine in a worker with methylene diphenyl diisocyanate (MDI)-induced asthma. Chest 89(3):389-393.

Banks DE, Rando RJ, Barkman HW, Jr. 1990. Persistence of toluene diisocyanate-induced asthma despite negligible workplace exposures. Chest 97(1):121-125.

Banks DE, Sastre J, Butcher BT, et al. 1989. Role of inhalation challenge testing in the diagnosis of isocyanate-induced asthma. Chest 95(2):414-423.

Barnes DG, Dourson M. 1988. Reference dose (RfD): Description and use in health risk assessments. Regul Toxicol Pharmacol 8(4):471-486.

Bascom R, Kennedy TP, Levitz D, et al. 1985. Specific bronchoalveolar lavage IgG antibody in hypersensitivity pneumonitis from diphenylmethane diisocyanate. Am Rev Respir Dis 131(3):463-465.

Baur X. 1995. Hypersensitivity pneumonitis (extrinsic allergic alveolitis) induced by isocyanates. J Allergy Clin Immunol 95(5 Pt 1):1004-1010.

Baur X, Fruhmann G. 1981. Specific IgE antibodies in patients with isocyanate asthma. Chest 80(1 Suppl):73-76.

Baur X, Dewair M, Roemmelt H. 1984. Acute airway obstruction followed by hypersensitivity pneumonitis in an isocyanate (MDI) worker. J Occup Med 26(4):285-287.

Beghe B, Padoan M, Moss CT, et al. 2004. Lack of association of HLA class I genes and TNF $\alpha-308$ polymorphism in toluene diisocyanate-induced asthma. Allergy 59(1):61-64.

Berger GS, ed. 1994. Epidemiology of endometriosis. In: Endometriosis: Modern surgical management of endometriosis. New York, NY: Springer-Verlag, 3-7.

Bernstein DI, Kashon M, Lummus ZL, et al. 2013. CTNNA3 ( $\alpha$-Catenin) gene variants are associated with diisocyanate asthma: A replication study in a Caucasian worker population. Toxicol Sci 131(1):242-246.

Bernstein JA. 1996. Overview of diisocyanate occupational asthma. Toxicology 111(1-3):181-189.

Bianchi AP, Joyner TK. 1997. Determination of toluene-2,4-diisocyanate in environmental and workplace air by sampling onto Tenax-TA followed by thermal desorption and capillary gas chromatography using flame ionisation and ion-trap detection. J Chromatogr A 771(1-2):233-239. 


\section{REFERENCES}

Bidleman TF. 1988. Atmospheric processes. Wet and dry deposition of organic compounds are controlled by their vapor- particle partitioning. Environ Sci Technol 22(4):361-367.

Bignon JS, Aron Y, Ju LY, et al. 1994. HLA Class II alleles in isocyanate-induced asthma. Am J Respir Crit Care Med 149(1):71-75.

Bilan RA, Haflidson WO, McVittie DJ. 1989. Assessment of isocyanate exposure during the spray application of polyurethane foam. Am Ind Hyg Assoc J 50(6):303-306.

Bilban M. 2004. Mutagenic testing of workers exposed to toluene-diisocyanates during plastics production process. Am J Ind Med 45(5):468-474.

Blanc PD. 2018. Section II: Specific poisons and drugs: Diagnosis and treatment: Isocyanates. In: Poisoning \& drug overdose. 7th ed. McGraw-Hill Education.

https://accessmedicine.mhmedical.com/book.aspx?bookid=2284. May 30, 2018.

Blindow S, Preisser AM, Baur X, et al. 2015. Is the analysis of histamine and/or interleukin-4 release after isocyanate challenge useful in the identification of patients with IgE-mediated isocyanate asthma? J Immunol Methods 422:35-50. 10.1016/j.jim.2015.03.024.

Bobeldijk I, Karlsson D, Pronk A, et al. 2008. Validation of transferability of DBA derivatization and LC-MS/MS determination method for isocyanates via an interlaboratory comparison. Ann Occup Hyg 52(8):757-763.

Bodner KM, Burns CJ, Randolph NM, et al. 2001. A longitudinal study of respiratory health of toluene diisocyanate production workers. J Occup Environ Med 43(10):890-897.

Bonauto DK, Sumner AD, Curwick CC, et al. 2005. Work-related asthma in the spray-on truck bed lining industry. J Occup Environ Med 47(5):514-517.

Booth K, Cummings B, Karoly WJ, et al. 2009. Measurements of airborne methylene diphenyl diisocyanate (MDI) concentration in the U.S. workplace. J Occup Environ Hyg 6(4):228-238. 10.1080/15459620902724060.

Boschetto P, Fabbri LM, Zocca E, et al. 1987. Prednisone inhibits late asthmatic reactions and airway inflammation induced by toluene diisocyanate in sensitized subjects. J Allergy Clin Immunol 80(3 Pt 1):261-267.

Broberg K, Tinnerberg H, Axmon A, et al. 2008. Influence of genetic factors on toluene diisocyanaterelated symptoms: Evidence from a cross-sectional study. Environ Health 7:15.

Brochhagen FK, Grieveson BM. 1984. Environmental aspects of isocyanates in water and soil. Cell Polym 3:11-17.

Brorson T, Skarping G, Sango C. 1991. Biological monitoring of isocyanates and related amines. IV. 2,4- and 2,6-toluenediamine in hydrolysed plasma and urine after test-chamber exposure of humans to 2,4- and 2,6-toluene diisocyanate. Int Arch Occup Environ Health 63(4):253-259.

Buckley LA, Jiang XZ, James RA, et al. 1984. Respiratory tract lesions induced by sensory irritants at the RD50 concentration. Toxicol Appl Pharmacol 74(3):417-429. 
Budnik LT, Preisser AM, Permentier H, et al. 2013. Is specific IgE antibody analysis feasible for the diagnosis of methylenediphenyl diisocyanate-induced occupational asthma? Int Arch Occup Environ Health 86(4):417-430.

Burge PS. 1982. Non-specific bronchial hyper-reactivity in workers exposed to toluene di-isocyanate, diphenyl methane di-isocyanate and colophony. Eur J Respir Dis Suppl 123:91-96.

Buschmann J, Koch W, Fuhst R, et al. 1996. Embryotoxicity study of monomeric 4,4'methylenediphenyl diisocyanate (MDI) aerosol after inhalation exposure in Wistar rats. Fundam Appl Toxicol 32(1):96-101.

Butcher BT, Jones RN, O'Neil CE, et al. 1977. Longitudinal study of workers employed in the manufacture of toluene-diisocyanate. Am Rev Respir Dis 116(3):411-421.

Carbonnelle P, Boukortt S, Lison D, et al. 1996. Determination of toluenediamines in urine of workers occupationally exposed to isocyanates by high-performance liquid chromatography. Analyst 121(5):663669.

Chang KC, Karol MH. 1984. Diphenylmethane diisocyanate-induced asthma: Evaluation of the immunologic responses and application of an animal model of isocyanate sensitivity. Clin Allergy 14(4):329-340.

Chang SN, Burg WR. 1982. Determination of airborne 2,4-toluenediisocyanate vapors. J Chromatogr 246(1):113-120.

ChemSpider. 2013. Methylene diphenyl diisocyanate. ChemSpider. Royal Society of Chemistry. http://www.chemspider.com/Chemical-Structure.7289.html?rid=d6605a66-cfd2-4c9d-a2d63491d6d532db. December 30, 2013.

Chester EH, Martinez-Catinchi FL, Schwartz HJ, et al. 1979. Patterns of airway reactivity to asthma produced by exposure to toluene di-isocyanate. Chest 75(2 Suppl):229-231.

Choi J, Lee K, Kim C, et al. 2009. The HLA DRB1*1501-DQB1*0602-DPB1*0501 haplotype is a risk factor for toluene diisocyanate-induced occupational asthma. Int Arch Allergy Immunol 150(2):156-163. $10.1159 / 000218118$.

Clark RL, Bugler J, McDermott M, et al. 1998. An epidemiology study of lung function changes of toluene diisocyanate foam workers in the United Kingdom. Int Arch Occup Environ Health 71(3):169179.

Clark RL, Bugler J, Paddle GM, et al. 2003. A 17-year epidemiological study on changes in lung function in toluene diisocyanate foam workers. Int Arch Occup Environ Health 76(4):295-301.

Clewell HJ, Andersen ME. 1985. Risk assessment extrapolations and physiological modeling. Toxicol Ind Health 1(4):111-131.

Cocker J. 2011. Biological monitoring for isocyanates. Ann Occup Hyg 55(2):127-131. 


\section{REFERENCES}

Colli M, Zabarini L, Melzi D'Eril GV, et al. 1993. Evaluation of a modified Marcali technique with high-performance liquid chromatography-ultraviolet detection for the determination of 2,4-toluene diisocyanate in air. J Chromatogr 643(1-2):51-54.

Corbini G, Corti P, Dreassi E, et al. 1991. Determination of diisocyanate monomers in air by differential-pulse polarography. Analyst 116(7):731-734.

Costa LG, Aschner M, Vitalone A, et al. 2004. Developmental neuropathology of environmental agents. Annu Rev Pharmacol Toxicol 44:87-110.

Crespo J, Galan J. 1999. Exposure to MDI during the process of insulating buildings with sprayed polyurethane foam. Ann Occup Hyg 43(6):415-419.

Cvitanovic S, Zekan L, Marusic M. 1989. Occurrence and specificity of IgE antibodies to isocyanates in occupationally exposed workers. Int Arch Occup Environ Health 61(7):483-486.

Daftarian HS, Lushniak BD, Reh CM, et al. 2002. Evaluation of self-reported skin problems among workers exposed to toluene diisocyanate (TDI) at a foam manufacturing facility. J Occup Environ Med 44(12):1197-1202.

Dahlin J, Spanne M, Dalene M, et al. 2008. Size-separated sampling and analysis of isocyanates in workplace aerosols--Part II: Aging of aerosols from thermal degradation of polyurethane. Ann Occup Hyg 52(5):375-383.

Dalene M, Skarping G, Lind P. 1997. Workers exposed to thermal degradation products of TDI and MDI-based polyurethane: Biomonitoring of 2,4-TDA, 2,6-TDA, and 4,4'-MDA in hydrolyzed urine and plasma. Am Ind Hyg Assoc J 58(8):587-591.

*Dart RC. 2004. Miscellaneous chemical agents. In: Medical toxicology. 3rd ed. Philadelphia, PA: Lippincott Williams \& Wilkins, 1181-1187.

Day BW, Jin R, Basalyga DM, et al. 1997. Formation, solvolysis, and transcarbamoylation reactions of bis(S-glutathionyl) adducts of 2,4- and 2,6-diisocyanatotoluene. Chem Res Toxicol 10(4):424-431.

Day BW, Jin R, Karol MH. 1996. In vivo and in vitro reactions of toluene diisocyanate isomers with guinea pig hemoglobin. Chem Res Toxicol 9(3):568-573.

D'Eril GM, Cappuccia N, Colli M, et al. 1995. Gas chromatography of 4,4'-diphenylmethane diisocyanate in the workplace atmosphere. J Chromatogr A 718(1):141-146.

De Vooght V, Smulders S, Haenen S, et al. 2013. Neutrophil and eosinophil granulocytes as key players in a mouse model of chemical-induced asthma. Toxicol Sci 131(2):406-418. 10.1093/toxsci/kfs308.

Diem JE, Jones RN, Hendrick DJ, et al. 1982. Five-year longitudinal study of workers employed in a new toluene diisocyanate manufacturing plant. Am Rev Respir Dis 126(3):420-428.

Dieter MP, Boorman GA, Jameson CW, et al. 1990. The carcinogenic activity of commercial grade toluene diisocyanate in rats and mice in relation to the metabolism of the 2,4- and 2,6-TDI isomers. Toxicol Ind Health 6(6):599-621. 


\section{REFERENCES}

DOE. 2016a. Protective Action Criteria (PAC) with AEGLs, ERPGs, \& TEELs: Rev. 29 for Chemicals of Concern - May 2016. Oak Ridge, TN: U.S. Department of Energy. https://sp.eota.energy.gov/pac/. January 10, 2018.

DOE. 2016b. Table 3: Protective Action Criteria (PAC) Rev. 29 based on applicable 60-minute AEGLs, ERPGs, or TEELs. The chemicals are listed by CASRN. May 2016. Oak Ridge, TN: U.S. Department of Energy. https://sp.eota.energy.gov/pac/docs/Revision_29_Table3.pdf. January 10, 2018.

Duff PB. 1983. The fate of TDI in the environment. In: Polyurethane- new paths to progress marketing technology. Proceedings of the SPI $6^{\text {th }}$ International Tech/Market Conference, 408-412.

Duff PB. 1985. Fate of toluene diisocyanate in air. Phase II study. In: Proceedings of the SPI $6^{\text {th }}$ International Tech/Market Conference 29:9-14.

Dyson WL, Hermann ER. 1971. Reduction of atmospheric toluene diisocyanate by water vapor. Am Ind Hyg Assoc J 32(11):741-744.

Eisenreich SJ, Looney BB, Thornton JD. 1981. Airborne organic contaminants in the Great Lakes ecosystem. Environ Sci Technol 15(1):30-38.

Ek CJ, Dziegielewska KM, Habgood MD, et al. 2012. Barriers in the developing brain and neurotoxicology. Neurotoxicology 33(3):586-604.

EPA. 1988. Recommendations for the documentation of biological values for use in risk assessment. Cincinnati, OH: U.S. Environmental Protection Agency. PB88179874.

EPA. 1990. Interim methods for development of inhalation reference concentrations. Washington, DC: U.S. Environmental Protection Agency, Office of Health and Environmental Assessment, Office of Research and Development.

EPA. 1996. Master Testing List. Washington, DC: U.S. Environmental Protection Agency, Office of Pollution Prevention and Toxics. https://nepis.epa.gov/Exe/ZyPURL.cgi?Dockey=910156U5.TXT. February 22, 2018.

EPA. 1997. Special report on environmental endocrine disruption: An effects assessment and analysis. Washington, DC: U.S. Environmental Protection Agency, Office of Pollution Prevention and Toxics.

EPA. 1998a. Toxicological review of methylene diphenyl diisocyanate (MDI). Washington, DC: U.S. Environmental Protection Agency.

EPA. 1998b. RCRA waste minimization PBT priority chemical list. Fed Regist 63 FR 60332. U. S. Environmental Protection Agency. https://www.gpo.gov/fdsys/pkg/FR-1998-11-09/pdf/9829952.pdf\#page=1. February 26, 2018.

EPA. 2005. Toxic chemical release inventory reporting forms and instructions: Revised 2004 version. Section 313 of the Emergency Planning and Community Right-to-Know Act (Title III of the Superfund Amendments and Reauthorization Act of 1986). U.S. Environmental Protection Agency, Office of Environmental Information.

*EPA. 2009a. Drinking water contaminant candidate list. U.S. Environmental Protection Agency. Fed Regist 74 FR 51850:51850 -51862. http://www.gpo.gov/fdsys. January 08, 2014. 


\section{REFERENCES}

EPA. 2009b. National primary drinking water regulations. Washington, DC: U.S. Environmental Protection Agency, Office of Ground Water and Drinking Water. EPA816F090004. https://www.epa.gov/sites/production/files/2016-06/documents/npwdr_complete_table.pdf. September 7, 2017.

EPA. 2010. Benzene, 1,1'-methylenebis[4-isocyanato- (CAS: 101-68-8), benzene, 2,4-diisocyanato-1methyl- (CAS: 584-84-9), benzene, 1,3-diisocyanato-2-methyl- (CAS: 91-08-7). Inventory update reporting (IUR). Non-confidential 2006 IUR company/chemical records. U.S. Environmental Protection Agency. http://cfpub.epa.gov/iursearch/. May 29, 2014.

EPA. 2011a. Methylene diiphenyl diisocyanate (MDI) and related compounds. Action plan. U.S. Environmental Protection Agency. http://www.epa.gov/oppt/existingchemicals/pubs/actionplans/mdi.pdf. May 30, 2014.

EPA. 2011b. Toluene diisocyanate (TDI) and related compounds. Action plan. U.S. Environmental Protection Agency. http://www.epa.gov/oppt/existingchemicals/pubs/actionplans/tdi.pdf. May 30, 2014.

EPA. 2012. Drinking water standards and health advisories. Washington, DC: U.S. Environmental Protection Agency, Office of Water. EPA822S12001. https://www.epa.gov/sites/production/files/201509/documents/dwstandards2012.pdf. April 25, 2013.

EPA. 2015. Technical support document. EPA's 2011 National-scale air toxics assessment. 2011 NATA TSD. Research Triangle Park, NC: U.S. Environmental Protection Agency, Office of Air Quality, Planning, and Standards.

EPA. 2016a. Acute Exposure Guideline Levels (AEGLs) values. U.S. Environmental Protection Agency. https://www.epa.gov/sites/production/files/2016-03/documents/compiled_aegl_update_.pdf. September 8, 2017.

EPA. 2016b. Drinking water contaminant candidate list. Fed Regist 81 FR 81099. U.S. Environmental Protection Agency. https:/www.gpo.gov/fdsys/pkg/FR-2016-11-17/pdf/2016-27667.pdf\#page=1. February 26, 2018.

EPA. 2016c. Part A - Air quality and emission limitations. Hazardous air pollutants. United States Code 42 USC 7412. U.S. Environmental Protection Agency. https://www.gpo.gov/fdsys/pkg/USCODE2016-title42/pdf/USCODE-2016-title42-chap85-subchapI-partA-sec7412.pdf. February 21, 2018.

EPA. 2017a. Assessing outdoor air near schools. Roland-Story High School- Story City, IA. U.S. Environmental Protection Agency. https://www3.epa.gov/air/sat/RolandStorResults.html. August 03, 2017.

EPA. 2017b. Designation of hazardous substances. Code of Federal Regulations. 40 CFR 116.4. U.S. Environmental Protection Agency. https://www.gpo.gov/fdsys/pkg/CFR-2017-title40-vol24/pdf/CFR2017-title40-vol24-sec116-4.pdf. February 26, 2018.

EPA. 2017c. Identification and listing of hazardous waste. Hazardous constituents. Code of Federal Regulations. 40 CFR 261, Appendix VIII. U.S. Environmental Protection Agency. https:/www.gpo.gov/fdsys/pkg/CFR-2017-title40-vol28/pdf/CFR-2017-title40-vol28-part261.pdf. February 22, 2018. 


\section{REFERENCES}

EPA. 2017d. Reportable quantities of hazardous substances designated pursuant to section 311 of the Clean Water Act. Code of Federal Regulations. 40 CFR 117.3. U.S. Environmental Protection Agency. https://www.gpo.gov/fdsys/pkg/CFR-2017-title40-vol24/pdf/CFR-2017-title40-vol24-sec117-3.pdf. February 26, 2018.

EPA. 2017e. Standards for owners and operators of hazardous waste TSD facilities. Groundwater monitoring list. Code of Federal Regulations. 40 CFR 264, Appendix IX. U.S. Environmental Protection Agency. https://www.gpo.gov/fdsys/pkg/CFR-2017-title40-vol28/pdf/CFR-2017-title40vol28-part264-appIX.pdf. February 26, 2018.

EPA. 2017f. Superfund, emergency planning, and community right-to-know programs. Designation of hazardous substances. Code of Federal Regulations. 40 CFR 302.4. U.S. Environmental Protection Agency. https://www.gpo.gov/fdsys/pkg/CFR-2017-title40-vol30/pdf/CFR-2017-title40-vol30-sec3024.pdf. February 26, 2018.

EPA. $2017 \mathrm{~g}$. Superfund, emergency planning, and community right-to-know programs. Toxic chemical release reporting. Subpart D - Specific toxic chemical listings. Code of Federal Regulations. 40 CFR 372.65. U.S. Environmental Protection Agency. https://www.gpo.gov/fdsys/pkg/CFR-2017-title40vol30/pdf/CFR-2017-title40-vol30-sec372-65.pdf. February 26, 2018.

EPA. 2017h. Superfund, emergency planning, and community right-to-know programs. Extremely hazardous substances and their threshold planning quantities. Code of Federal Regulations. 40 CFR 355, Appendix A. U.S. Environmental Protection Agency. https://www.gpo.gov/fdsys/pkg/CFR-2017-title40vol30/pdf/CFR-2017-title40-vol30-part355-appA.pdf. February 26, 2018.

EPA. 2017i. Toxic Substances Control Act. Chemical lists and reporting periods. Code of Federal Regulations. 40 CFR 712.30. U.S. Environmental Protection Agency. https://www.gpo.gov/fdsys/pkg/CFR-2017-title40-vol33/pdf/CFR-2017-title40-vol33-sec712-30.pdf. February 26, 2018.

EPA. 2017j. Toxic Substances Control Act. Health and safety data reporting. Subpart B - Specific chemical listings. Substances and listed mixtures to which this subpart applies. Code of Federal Regulations. 40 CFR 716.120. U.S. Environmental Protection Agency. https://www.gpo.gov/fdsys/pkg/CFR-2017-title40-vol33/pdf/CFR-2017-title40-vol33-sec716-120.pdf. February 26, 2018.

EPA. 2018a. About Acute Exposure Guideline Levels (AEGLs). U.S. Environmental Protection Agency. https://www.epa.gov/aegl/about-acute-exposure-guideline-levels-aegls. February 26, 2018.

EPA. 2018b. National ambient air quality standards (NAAQS). U.S. Environmental Protection Agency. https://www.epa.gov/criteria-air-pollutants/naaqs-table. February 21, 2018.

EPA. 2018c. National recommended water quality criteria - Human health criteria table. U.S. Environmental Protection Agency. https://www.epa.gov/wqc/national-recommended-water-qualitycriteria-human-health-criteria-table. February 26, 2018.

Fabbri LM, Boschetto P, Zocca E, et al. 1987. Bronchoalveolar neutrophilia during late asthmatic reactions induced by toluene diisocyanate. Am Rev Respir Dis 136(1):36-42. 


\section{REFERENCES}

FDA. 2013. Everything added to food in the United States (EAFUS). Washington, DC: U.S. Food and Drug Administration. http://www.accessdata.fda.gov/scripts/fcn/fcnnavigation.cfm?rpt=eafuslisting. January 8, 2014.

FDA. 2017. Subpart B - Requirements for specific standardized beverages. Bottled water. U.S. Food and Drug Administration. Code of Federal Regulations. 21 CFR 165.110

Feron VJ, Kittel B, Kuper CF, et al. 2001. Chronic pulmonary effects of respirable methylene diphenyl diisocyanate (MDI) aerosol in rats: Combination of findings from two bioassays. Arch Toxicol 75(3):159-175.

Fomon SJ. 1966. Body composition of the infant: Part 1: The male reference infant. In: Faulkner F, ed. Human development. Philadelphia, PA: WB Saunders, 239-246.

Fomon SJ, Haschke F, Ziegler EE, et al. 1982. Body composition of reference children from birth to age 10 years. Am J Clin Nutr 35(Suppl 5):1169-1175.

Foureman P, Mason JM, Valencia R, et al. 1994. Chemical mutagenesis testing in Drosophila. X. Results of 70 coded chemicals tested for the National Toxicology Program. Environ Mol Mutagen 23(3):208-227.

Furusho S, Myou S, Fujimura M, et al. 2006. Role of intercellular adhesion molecule-1 in a murine model of toluene diisocyanate-induced asthma. Clin Exp Allergy 36(10):1294-1302.

Gagnaire F, Ban M, Micillino JC, et al. 1996. Bronchial responsiveness and inflammation in guinea pigs exposed to toluene diisocyanate: A study on single and repeated exposure. Toxicology 114(2):91-100.

Geens T, Dugardin S, Schockaert A, et al. 2012. Air exposure assessment of TDI and biological monitoring of TDA in urine in workers in polyurethane foam industry. Occup Environ Med 69(2):93-98.

Gilbert DS. 1988. Fate of TDI and MDI in air, soil, and water. J Cell Plast 24:178-192.

Giwercman A, Carlsen E, Keiding N, et al. 1993. Evidence for increasing incidence of abnormalities of the human testis: A review. Environ Health Perspect 101(2):65-71.

Gledhill A, Wake A, Hext P, et al. 2005. Absorption, distribution, metabolism and excretion of an inhalation dose of $\left[{ }^{14} \mathrm{C}\right]$ 4,4'-methylenediphenyl diisocyanate in the male rat. Xenobiotica 35(3):273-292.

Gordon T, Sheppard D, McDonald DM, et al. 1985. Airway hyperresponsiveness and inflammation induced by toluene diisocyanate in guinea pigs. Am Rev Respir Dis 132(5):1106-1112.

Gries W, Leng G. 2013. Analytical determination of specific 4,4'-methylene diphenyl diisocyanate hemoglobin adducts in human blood. Anal Bioanal Chem 405(23):7205-7213.

Gui W, Wisnewski AV, Neamtiu I, et al. 2014. Inception cohort study of workers exposed to toluene diisocyanate at a polyurethane foam factory: Initial one-year follow-up. Am J Ind Med 57(11):12071215. 10.1002/ajim.22385.

Gulati DK, Witt K, Anderson B, et al. 1989. Chromosome aberration and sister chromatid exchange tests in Chinese hamster ovary cells in vitro. III. Results with 27 chemicals. Environ Mol Mutagen 13(2):133-193. 
Guzelian PS, Henry CJ, Olin SS, eds. 1992. Similarities and differences between children and adults: Implications for risk assessment. Washington, DC: International Life Sciences and Press Institute Press.

Hagmar L, Stromberg U, Welinder H, et al. 1993a. Incidence of cancer and exposure to toluene diisocyanate and methylene diphenyldiisocyanate - A cohort based case-referent study in the polyurethane foam manufacturing industry. Br J Ind Med 50(11):1003-1007.

Hagmar L, Welinder H, Mikoczy Z. 1993b. Cancer incidence and mortality in the Swedish polyurethane foam manufacturing industry. Br J Ind Med 50(6):537-543.

Heimbach F, Jaeger K, Sporenberg W. 1996. Fate and biological effects of polymeric MDI (4,4'diphenylmethane diisocyanate and homologs) in small artificial ponds. Ecotoxicol Environ Saf 33(2):143-153.

Helaskoski E, Suolahto H, Kuuliala O, et al. 2015. Prick testing with chemicals in the diagnosis of occupational contact urticaria and respiratory diseases. Contact Dermatitis 72(1):20-32.

Henriks-Eckerman ML, Makela EA, Laitinen J, et al. 2015. Role of dermal exposure in systemic intake of methylenediphenyl diisocyanate (MDI) among construction and boat building workers. Toxicol Lett 232(3):595-600. 10.1016/j.toxlet.2014.12.012.

Herbold B, Haas P, Seel K, et al. 1998. Studies on the effect of the solvents dimethylsulfoxide and ethyleneglycoldimethylether on the mutagenicity of four types of diisocyanates in the Salmonella/microsome test. Mutat Res 412(2):167-175.

Hoel DG, Davis DL, Miller AB, et al. 1992. Trends in cancer mortality in 15 industrialized countries, 1969-1986. J Natl Cancer Inst 84(5):313-320.

Hoffmann HD, Leibold E, Ehnes C, et al. 2010. Dermal uptake and excretion of ${ }^{14} \mathrm{C}$-toluene diisocyanate (TDI) and ${ }^{14} \mathrm{C}$-methylene diphenyl diisocyanate (MDI) in male rats. Clinical signs and histopathology following dermal exposure of male rats to TDI. Toxicol Lett 199(3):364-371.

Holdren MW, Spicer CW, Riggin RM. 1984. Gas phase reaction of toluene diisocyanate with water vapor. Am Ind Hyg Assoc J 45(9):626-633.

Holmén A, Åkesson B, Hansén L, et al. 1988. Comparison among five mutagenicity assays in workers producing polyurethane foams. Int Arch Occup Environ Health 60(3):175-179.

HSDB. 2012. Toluene diisocyanates. Hazardous Substances Data Bank. National Library of Medicine. http://toxnet.nlm.nih.gov. September 10, 2014.

Huang J, Wang XP, Chen BM, et al. 1991b. Immunological effects of toluene diisocyanate exposure on painters. Arch Environ Contam Toxicol 21(4):607-611.

Huang J, Wang XP, Ueda A, et al. 1991a. Allergologic evaluation for workers exposed to toluene diisocyanate. Ind Health 29(3):85-92.

Hughes MA, Carson M, Collins MA, et al. 2014. Does diisocyanate exposure result in neurotoxicity? Clin Toxicol 52:242-257. 


\section{REFERENCES}

Hur GY, Kim SH, Park SM, et al. 2009. Tissue transglutaminase can be involved in airway inflammation of toluene diisocyanate-induced occupational asthma. J Clin Immunol 29(6):786-794.

Hur GY, Koh DH, Choi GS, et al. 2008. Clinical and immunologic findings of methylene diphenyl diisocyanate-induced occupational asthma in a car upholstery factory. Clin Exp Allergy 38(4):586-593.

IARC. 1985. Toluene diisocyanate. In: IARC monographs on the evaluation of carcinogenic risk of chemicals to humans. Vol 39. Some chemicals used in plastics and elastomers. In: Lyon, France: International Agency for Research on Cancer, 287-323.

IARC. 1999a. 4,4'-Methylenediphenyl diisocyanate and polymeric 4,4'- methylenediphenyl diisocyanate. IARC Monographs on the evaluation of carcinogenic risks to humans. Volume 71. Re-evaluation of some organic chemicals, hydrazine and hydrogen peroxide. Part 3A. Lyon, France: International Agency for Research on Cancer. http://monographs.iarc.fr/ENG/Monographs/vol71/mono71-47.pdf. February 21, 2018.

IARC. 1999b. Toluene diisocyanates. IARC Monographs on the evaluation of carcinogenic risks to humans. Volume 71. Re-evaluation of some organic chemicals, hydrazine and hydrogen peroxide. Part 2. Lyon, France: International Agency for Research on Cancer.

http://monographs.iarc.fr/ENG/Monographs/vol71/mono71-37.pdf. February 21, 2018.

*IARC. 2014. Agents classified by the IARC monographs. Volumes 1-109. Lyon, France: International Agency for Research on Cancer. http://monographs.iarc.fr/ENG/Classification/index.php. May 15, 2014.

International Isocyanate Institute. 1983. Biodegradability and toxicity bioassays of isocyanates and amines. Submitted to the U.S. Environmental Protection Agency under TSCA, Section 8d.

OTS0515179. EPA8687000652.

International Isocyanate Institute. 1987. Reactions of OH radicals with toluene diisocyanate, toluene diamine, and methylene dianiline under simulated atmosphere. Submitted to the U.S. Environmental Protection Agency under TSCA, Section 8d. OTS0515193. EPA8687000666.

International Isocyanate Institute. 1980. Biodegradation of toluene diisocyanate and diphenyl methane diisocyanate. Submitted to the U.S. Environmental Protection Agency under TSCA, Section 8d.

OTS0515172. EPA8687000646.

IRIS. 2002. Methylene diphenyl diisocyanate (monomeric MDI) and polymeric MDI (PMDI) (CASRN 101-68-8, 9016-87-9). Integrated Risk Information System. Chemical assessment summary.

Washington, DC: U.S. Environmental Protection Agency.

https://cfpub.epa.gov/ncea/iris/iris_documents/documents/subst/0529_summary.pdf. February 22, 2018.

IRIS. 2003. 2,4-/2,6-Toluene diisocyanate mixture (TDI) (CASRN 26471-62-5). Integrated Risk Information System. Chemical assessment summary. Washington, DC: U.S. Environmental Protection Agency. https://cfpub.epa.gov/ncea/iris/iris_documents/documents/subst/0503_summary.pdf. February $22,2018$.

Jang AS, Choi IS, Koh YI, et al. 2000. Increase in airway hyperresponsiveness among workers exposed to methylene diphenyldiisocyanate compared to workers exposed to toluene diisocyanate at a petrochemical plant in Korea. Am J Ind Med 37(6):663-667. 


\section{REFERENCES}

Ji Y, Ji C, Lang L, et al. 2008. The effects of TDI on mice marrow cells. IEEEXplore. Digital Library, 4570-4572.

Johnson VJ, Yucesoy B, Luster MI. 2005. Prevention of IL-1 signaling attenuates airway hyperresponsiveness and inflammation in a murine model of toluene diisocyanate-induced asthma. $\mathrm{J}$ Allergy Clin Immunol 116(4):851-858.

Johnson VJ, Yucesoy B, Reynolds JS, et al. 2007. Inhalation of toluene diisocyanate vapor induces allergic rhinitis in mice. J Immunol 179(3):1864-1871.

Jolly AT, Klees JE, Pacheco KA, et al. 2015. Work-related asthma. J Occup Environ Med 57(10):e121e129.

Jones RN, Rando RJ, Glindmeyer HW, et al. 1992. Abnormal lung function in polyurethane foam producers. Weak relationship to toluene diisocyanate exposures. Am Rev Respir Dis 146(4):871-877.

Kaaria K, Hirvonen A, Norppa H, et al. 2001a. Exposure to 2,4- and 2,6-toluene diisocyanate (TDI) during production of flexible foam: Determination of airborne TDI and urinary 2,4- and 2,6toluenediamine (TDA). Analyst 126(7):1025-1031.

Kaaria K, Hirvonen A, Norppa H, et al. 2001b. Exposure to 4,4'-methylenediphenyl diisocyanate (MDI) during molding of rigid polyurethane foam: Determination of airborne MDI and urinary 4,4'methylenedianiline (MDA). Analyst 126(4):476-479.

Karlsson D, Spanne M, Dalene M, et al. 2000. Airborne thermal degradation products of polyurethane coatings in car repair shops. J Environ Monit 2(5):462-469.

*Karol MH, Hauth BA, Riley EJ, et al. 1981. Dermal contact with toluene diisocyanate (TDI) produces respiratory tract hypersensitivity in guinea pigs. Toxicol Appl Pharmacol 58(2):221-230.

Kearns GL, Abdel-Rahman SM, Alander SW, et al. 2003. Developmental pharmacology--drug disposition, action, and therapy in infants and children. N Engl J Med 349(12):1157-1167.

Kelly TJ, Mukund R, Spicer CW, et al. 1994. Concentrations and transformations of hazardous air pollutants. Environ Sci Technol 28(8):378A-387A.

Kelly TJ, Myers JD, Holdren MW. 1999. Testing of household products and materials for emission of toluene diisocyanate. Indoor Air 9(2):117-124.

Kennedy AL, Stock MF, Alarie Y, et al. 1989. Uptake and distribution of ${ }^{14} \mathrm{C}$ during and following inhalation exposure to radioactive toluene diisocyanate. Toxicol Appl Pharmacol 100(2):280-292.

Kennedy AL, Wilson TR, Stock MF, et al. 1994. Distribution and reactivity of inhaled ${ }^{14} \mathrm{C}-$ labeled toluene diisocyanate (TDI) in rats. Arch Toxicol 68(7):434-443.

Kim JH, Kim JE, Choi GS, et al. 2011. Serum cytokines markers in toluene diisocyanate-induced asthma. Respir Med 105(7):1091-1094.

Kim SH, Cho BY, Park CS, et al. 2009. Alpha-T-catenin (CTNNA3) gene was identified as a risk variant for toluene diisocyanate-induced asthma by genome-wide association analysis. Clin Exp Allergy 39(2):203-212. 


\section{REFERENCES}

Kim SH, Choi GS, Nam YH, et al. 2012. Role of vitamin D-binding protein in isocyanate-induced occupational asthma. Exp Mol Med 44(5):319-329.

Kim SH, Choi GS, Ye YM, et al. 2010. Toluene diisocyanate (TDI) regulates haem oxygenase-1/ferritin expression: Implications for toluene diisocyanate-induced asthma. Clin Exp Immunol 160(3):489-497

Kim SH, Park HJ, Lee CM, et al. 2006. Epigallocatechin-3-gallate protects toluene diisocyanate-induced airway inflammation in a murine model of asthma. FEBS Lett 580(7):1883-1890.

Komori M, Nishio K, Kitada M, et al. 1990. Fetus-specific expression of a form of cytochrome P-450 in human livers. Biochemistry 29(18):4430-4433.

*Koschier FJ, Burden EJ, Brunkhorst CS, et al. 1983. Concentration-dependent elicitation of dermal sensitization in guinea pigs treated with 2,4-toluene diisocyanate. Toxicol Appl Pharmacol 67(3):401407.

Kouadio K, Zheng KC, Toure AA, et al. 2014. IL-4 and IL-5 secretions predominate in the airways of Wistar rats exposed to toluene diisocyanate vapor. J Prev Med Public Health/ Yebang Uihakhoe chi 47(1):57-63. 10.3961/jpmph.2014.47.1.57.

Krishnan K, Anderson ME, Clewell HJ, et al. 1994. Physiologically based pharmacokinetic modeling of chemical mixtures. In: Yang RSH, ed. Toxicology of chemical mixtures. Case studies, mechanisms, and novel approaches. San Diego, CA: Academic Press, 399-437.

Kumar A, Dongari N, Sabbioni G. 2009. New isocyanate-specific albumin adducts of 4,4'methylenediphenyl diisocyanate (MDI) in rats. Chem Res Toxicol 22(12):1975-1983.

Lee YM, Kim HA, Park HS, et al. 2003. Exposure to toluene diisocyanate (TDI) induces IL-8 production from bronchial epithelial cells: Effect of pro-inflammatory cytokines. J Korean Med Sci 18(6):809-812.

Leeder JS, Kearns GL. 1997. Pharmacogenetics in pediatrics: Implications for practice. Pediatr Clin North Am 44(1):55-77.

Leikin JB, Paloucek FP. 2008. Methylene diisocyanate and toluene diisocyanate. In: Poisoning and toxicology handbook. 4th ed. Boca Raton, FL: CRC Press, 824; 857-858.

Lemiere C, Cartier A, Dolovich J, et al. 1996. Outcome of specific bronchial responsiveness to occupational agents after removal from exposure. Am J Respir Crit Care Med 154(2):329-333.

Le Quesne PM, Axford AT, McKerrow CB, et al. 1976. Neurological complications after a single severe exposure to toluene di-isocyanate. Br J Ind Med 33(2):72-78.

Lesage J, Stanley J, Karoly WJ, et al. 2007. Airborne methylene diphenyl diisocyanate (MDI) concentrations associated with the application of polyurethane spray foam in residential construction. $\mathrm{J}$ Occup Environ Hyg 4(2):145-155.

Leung H. 1993. Physiologically-based pharmacokinetic modelling. In: Ballantyne B, Marrs T, Turner P, eds. General and applied toxicology. Vol. 1. New York, NY: Stockton Press, 153-164. 


\section{REFERENCES}

Levine SP, Hillig KJD, Dharmarajan V, et al. 1995. Critical review of methods of sampling, analysis, and monitoring for TDI and MDI. Am Ind Hyg Assoc J 56(6):581-589.

Lewis RJ. 2004. Toluene-2,4-diisocyanate. In: Sax's dangerous properties of industrial materials. Vol. 3. 11 ed. Hoboken, NJ: John Wiley \& Sons, 3484.

*Lim RH, Arredouani MS, Fedulov A, et al. 2007. Maternal allergic contact dermatitis causes increased asthma risk in offspring. Respir Res 8:56.

Lind P, Dalene M, Skarping G, et al. 1996. Toxicokinetics of 2,4- and 2,6-toluenediamine in hydrolysed urine and plasma after occupational exposure to 2,4- and 2,6-toluene diisocyanate. Occup Environ Med 53(2):94-99.

Lindberg HK, Korpi A, Santonen T, et al. 2011. Micronuclei, hemoglobin adducts and respiratory tract irritation in mice after inhalation of toluene diisocyanate (TDI) and 4,4'-methylenediphenyl diisocyanate (MDI). Mutat Res 723(1):1-10.

Liss GM, Bernstein DI, Moller DR, et al. 1988. Pulmonary and immunologic evaluation of foundry workers exposed to methylene diphenyldiisocyanate (MDI). J Allergy Clin Immunol 82(1):55-61.

Littorin M, Axmon A, Broberg K, et al. 2007. Eye and airway symptoms in low occupational exposure to toluene diisocyanate. Scand J Work Environ Health 33(4):280-285.

Loeser E. 1983. Long-term toxicity and carcinogenicity studies with 2,4/2,6-toluene-diisocyanate (80/20) in rats and mice. Toxicol Lett 15(1):71-81.

Luckenbach M, Kielar R. 1980. Toxic corneal epithelial edema from exposure to high atmospheric concentration of toluene diisocyanates. Am J Ophthalmol 90(5):682-686.

Lushniak BD, Reh CM, Bernstein DI, et al. 1998. Indirect assessment of 4,4'-diphenylmethane diisocyanate (MDI) exposure by evaluation of specific humoral immune responses to MDI conjugated to human serum albumin. Am J Ind Med 33(5):471-477.

Lyman WJ, Reehl WF, Rosenblatt DH. 1990. Rate of aqueous photolysis. In: Handbook of chemical property estimation methods. Environmental behavior of organic compounds. Washington, DC: American Chemical Society, 8-11 to 18-14.

Maestrelli P, De Marzo N, Saetta M, et al. 1993. Effects of inhaled beclomethasone on airway responsiveness in occupational asthma - placebo-controlled study of subjects sensitized to toluene diisocyanate. Am Rev Respir Dis 148(2):407-412.

Malo JL, Zeiss CR. 1982. Occupational hypersensitivity pneumonitis after exposure to diphenylmethane diisocyanate. Am Rev Respir Dis 125(1):113-116.

Mapp C, Boschetto P, dal Vecchio L, et al. 1987. Protective effect of antiasthma drugs on late asthmatic reactions and increased airway responsiveness induced by toluene diisocyanate in sensitized subjects. Am Rev Respir Dis 136(6):1403-1407.

Mapp CE, Corona PC, De Marzo N, et al. 1988. Persistent asthma due to isocyanates. A follow-up study of subjects with occupational asthma due to toluene diisocyanate (TDI). Am Rev Respir Dis 137(6):1326-1329. 
Mapp CE, Lucchini RE, Miotto D, et al. 1998. Immunization and challenge with toluene diisocyanate decrease tachykinin and calcitonin gene-related peptide immunoreactivity in guinea pig central airways. Am J Respir Crit Care Med 158(1):263-269.

Marczynski B, Merget R, Mensing T, et al. 2005. DNA strand breaks in the lymphocytes of workers exposed to diisocyanates: Indications of individual differences in susceptibility after low-dose and shortterm exposure. Arch Toxicol 79(6):355-362.

Marek W, Potthast J, Marczynski B, et al. 1999. Subchronic exposure to diisocyanates increases guinea pig tracheal smooth muscle responses to acetylcholine. Respiration 66(2):156-161.

Matheson JM, Johnson VJ, Vallyathan V, et al. 2005. Exposure and immunological determinants in a murine model for toluene diisocyanate (TDI) asthma. Toxicol Sci 84(1):88-98.

Matheson JM, Lemus R, Lange RW, et al. 2002. Role of tumor necrosis factor in toluene diisocyanate asthma. Am J Respir Cell Mol Biol 27(4):396-405.

McGregor DB, Brown AG, Howgate S, et al. 1991. Responses of the L5178Y mouse lymphoma cell forward mutation assay. V: 27 Coded chemicals. Environ Mol Mutagen 17(3):196-219.

Meyer SD, Tallman DE. 1983. The determination of toluene diisocyanate in air by high-performance liquid chromatography with electrochemical detection. Anal Chim Acta 146:227-236.

Mikoczy Z, Welinder H, Tinnerberg H, et al. 2004. Cancer incidence and mortality of isocyanate exposed workers from the Swedish polyurethane foam industry: Updated findings 1959-98. Occup Environ Med 61(5):432-437.

MMWR. 1998. Community exposure to toluene diisocyanate from a polyurethane foam manufacturing plant- North Carolina, 1997. U.S. Department of Health and Human Services, Centers for Disease Control. Morbidity and Mortality Weekly Report 47(22):455-457.

Moller DR, Brooks SM, McKay RT, et al. 1986. Chronic asthma due to toluene diisocyanate. Chest 90(4):494-499.

Morselli PL, Franco-Morselli R, Bossi L. 1980. Clinical pharmacokinetics in newborns and infants: Age-related differences and therapeutic implications. Clin Pharmacokinet 5(6):485-527.

Moscato G, Dellabianca A, Vinci G, et al. 1991. Toluene diisocyanate-induced asthma: Clinical findings and bronchial responsiveness studies in 113 exposed subjects with work-related respiratory symptoms. J Occup Med 33(6):720-725.

Musk AW, Peters JM, Diberardinis L, et al. 1982. Absence of respiratory effects in subjects exposed to low concentrations of toluene diisocyanate and diphenylmethyldiisocyanate. J Occup Med 24(10):746750.

NAS/NRC. 1989. Report of the oversight committee. Biologic markers in reproductive toxicology. Washington, DC: National Academy of Sciences, National Research Council, National Academy Press, 15-35. 


\section{REFERENCES}

*NAS/NRC. 2004. Toluene 2,4- and 2,6-diisocyanate. Acute exposure guideline levels. In: Acute guideline levels for selected airborne chemicals: Volume 4. Washington, DC: National Academy of Sciences, National Research Council, National Academy Press, 198-249.

$\mathrm{http}: / / \mathrm{www} . n a p . e d u / c a t a l o g / 10902 /$ acute-exposure-guideline-levels-for-selected-airborne-chemicalsvolume-4. August 26, 2015.

NCDHHS. 2017. NC community TDI report. North Carolina Department of Health and Human Services and Agency for Toxic Substances and Disease Registry.

NIOSH. 1989. Current Intelligence Bulletin 53. Toluene diisocyanate (TDI) and toluenediamine (TDA): Evidence of carcinogenicity. National Institute of Occupational Safety and Health, Centers for Disease Control and Prevention. http://www.cdc.gov/niosh/docs/90-101/. December 31, 2013.

NIOSH. 1994. Isocyanates, monomeric. Method 5521, Issue 2. NIOSH manual of analytical methods (NMAM), Fourth edition. National Institute of Occupational Safety and Health.

http://www.cdc.gov/niosh/docs/2003-154/pdfs/5521.pdf. May 30, 2014.

NIOSH. 1996. Isocyanates. Method 5522, Issue 1. NIOSH manual of analytical methods (NMAM). Fourth edition. National Institute of Occupational Safety and Health.

http://www.cdc.gov/niosh/docs/2003-154/pdfs/5522.pdf. May 30, 2014.

NIOSH. 2003. Isocyanates, total (MAP). Method 5525, Issue 1. NIOSH Manual of Analytical Methods (NMAM). Fourth edition. National Institute of Occupational Safety and Health. http://www.cdc.gov/niosh/docs/2003-154/pdfs/5525.pdf. May 30, 2014.

NIOSH. 2006. NIOSH alert: Preventing asthma and death from MDI exposure during spray-on truck bed liner and related applications. National Institute of Occupational Safety and Health. http://www.cdc.gov/niosh/docs/2006-149/pdfs/2006-149.pdf. May 30, 2014.

NIOSH. 2016a. Methylene bisphenyl isocyanate. NIOSH pocket guide to chemical hazards. Atlanta, GA: National Institute for Occupational Safety and Health, Centers for Disease Control and Prevention. https://www.cdc.gov/niosh/npg/npgd0413.html. February 22, 2018.

NIOSH. 2016b. Toluene-2,4-diisocyanate. NIOSH pocket guide to chemical hazards. Atlanta, GA: National Institute for Occupational Safety and Health, Centers for Disease Control and Prevention. https://www.cdc.gov/niosh/npg/npgd0621.html. February 22, 2018.

Nordqvist Y, Nilsson U, Colmsjo A. 2005. Investigation of a cylindrical chemosorptive denuder for sampling and phase separation of toluene diisocyanate aerosols. Anal Bioanal Chem 382(5):1294-1299.

NRC. 1993. Pesticides in the diets of infants and children. Washington, DC: National Research Council. National Academy Press.

NTP. 1986. NTP Toxicology and carcinogenesis studies of commercial grade 2,4 (80\%)- and 2,6 (20\%)- toluene diisocyanate (CAS No. 26471-62-5) in F344/N rats and B6C3F1 mice (gavage studies). National Toxicology Program Tech Rep Ser 251:1-194.

NTP. 2011. Toluene diisocyanates. Report on carcinogens, twelfth edition. National Toxicology Program, 414-416. 


\section{REFERENCES}

NTP. 2016. Toluene diisocyanates. Report on carcinogens, Fourteenth edition. Research Triangle Park, NC: U.S. Department of Health and Human Services, Public Health Service, National Toxicology Program. https://ntp.niehs.nih.gov/ntp/roc/content/profiles/toluenediisocyanates.pdf. February 22, 2018.

Nuorteva P, Assmuth T, Haahtela T, et al. 1987. The prevalence of asthma among inhabitants in the vicinity of a polyurethane factory in Finland. Environ Res 43(2):308-316.

O'Brien IM, Harries MG, Burge PS, et al. 1979. Toluene di-isocyanate-induced asthma. I. Reactions to TDI, MDI, HDI and histamine. Clin Allergy 9(1):1-6.

Ogawa H, Inoue S, Ogushi F, et al. 2006. Toluene diisocyanate (TDI) induces production of inflammatory cytokines and chemokines by bronchial epithelial cells via the epidermal growth factor receptor and p38 mitogen-activated protein kinase pathways. Exp Lung Res 32(6):245-262.

Olsen GW, Shellenberger R, Bodner KM, et al. 1989. An epidemiologic investigation of forced expiratory volume at 1 second and respiratory symptoms among employees of a toluene diisocyanate production plant. J Occup Med 31(8):664-667.

Omae K, Higashi T, Nakadate T, et al. 1992. Four-year follow-up of effects of toluene diisocyanate exposure on the respiratory system in polyurethane foam manufacturing workers. II. Four-year changes in the effects on the respiratory system. Int Arch Occup Environ Health 63(8):565-569.

OSHA. 1980. Diisocyanates. 2,4-TDI and MDI. Method No. 18. Sampling and analytical methods. Occupational Safety and Health Administration. https://www.osha.gov/dts/sltc/methods/organic/org018/org018.html. December 17, 2013.

OSHA. 1989a. Diisocyanates. 1,6-hexamethylene diisocyanate (HDI), toluene-2,6-diisocyanate (2,6TDI), and toluene-2,4-diisocyanate (2,4-TDI). Organic method \#042. Sampling and analytical methods. Occupational Safety and Health Administration. https://www.osha.gov/dts/sltc/methods/organic/org042/org042.html. December 17, 2013.

OSHA. 1989b. Methylene bisphenyl isocyanate (MDI). Organic method \#047. Sampling and analytical methods. Occupational Safety and Health Administration.

https://www.osha.gov/dts/sltc/methods/organic/org047/org047.html. December 17, 2013.

OSHA. 1992. Report on occupational safety and health for fiscal year 1990 (under Public Law 91-596). Occupational Safety and Health Administration.

https://www.osha.gov/pls/oshaweb/owadisp.show_document?p_table $=$ oshact\&p_id=2743. January 21, 2014.

OSHA. 2017a. Subpart H - Hazardous materials. Process safety management of highly hazardous chemicals. Code of Federal Regulations. 29 CFR 1910.119. Occupational Safety and Health Standards. https://www.gpo.gov/fdsys/pkg/CFR-2017-title29-vol5/pdf/CFR-2017-title29-vol5-sec1910-119.pdf. February 22, 2018.

OSHA. 2017b. Subpart Z - Toxic and hazardous substances. Air contaminants. Code of Federal Regulations. 29 CFR 1910.1000. Occupational Safety and Health Standards. https:/www.gpo.gov/fdsys/pkg/CFR-2017-title29-vol6/pdf/CFR-2017-title29-vol6-sec1910-1000.pdf. January 10, 2018. 


\section{REFERENCES}

Ott MG, Diller WF, Jolly AT. 2003. Respiratory effects of toluene diisocyanate in the workplace: A discussion of exposure-response relationships. Crit Rev Toxicol 33(1):1-59.

Ott MG, Jolly AT, Burkett AL, et al. 2007. Issues in diisocyanate antibody testing. Crit Rev Toxicol 37:567-585.

Ott MG, Klees JE, Poche SL. 2000. Respiratory health surveillance in a toluene di-isocyanate production unit, 1967-97: Clinical observations and lung function analyses. Occup Environ Med 57(1):43-52.

Owen GM, Brozek J. 1966. Influence of age, sex and nutrition on body composition during childhood and adolescence. In: Falkner F, ed. Human development. Philadelphia, PA: WB Saunders, 222-238.

Padoan M, Pozzato V, Simoni M, et al. 2003. Long-term follow-up of toluene diisocyanate-induced asthma. Eur Respir J 21(4):637-640.

Paggiaro P, Bacci E, Talini D, et al. 1987. Atropine does not inhibit late asthmatic responses induced by toluene-diisocyanate in sensitized subjects. Am Rev Respir Dis 136(5):1237-1241.

Paggiaro PL, Innocenti A, Bacci E, et al. 1986. Specific bronchial reactivity to toluene diisocyanate: Relationship with baseline clinical findings. Thorax 41(4):279-282.

Paggiaro PL, Loi AM, Rossi O, et al. 1984. Follow-up study of patients with respiratory disease due to toluene diisocyanate (TDI). Clin Allergy 14(5):463-469.

Paggiaro PL, Vagaggini B, Dente FL, et al. 1993. Bronchial hyperresponsiveness and toluene diisocyanate. Long-term change in sensitized asthmatic subjects. Chest 103(4):1123-1128.

Palikhe NS, Kim JH, Park HS. 2011. Biomarkers predicting isocyanate-induced asthma. Allergy Asthma Immunol Res 3(1):21-26.

Park HS, Nahm DH. 1996. Isocyanate-induced occupational asthma: Challenge and immunologic studies. J Korean Med Sci 11(4):314-318.

Park HS, Nahm DH. 1997. Prognostic factors for toluene diisocyanate-induced occupational asthma after removal from exposure. Clin Exp Allergy 27(10):1145-1150.

Park HS, Kim HY, Nahm DH, et al. 1999. Specific IgG, but not specific IgE, antibodies to toluene diisocyanate-human serum albumin conjugate are associated with toluene diisocyanate bronchoprovocation test results. J Allergy Clin Immunol 104(4 Pt 1):847-851.

Pauluhn J. 2014. Development of a respiratory sensitization/elicitation protocol of toluene diisocyanate (TDI) in Brown Norway rats to derive an elicitation-based occupational exposure level. Toxicology 319:10-22. 10.1016/j.tox.2014.02.006.

Pauluhn J, Gollapudi B, Hammond T, et al. 2001. Bone marrow micronucleus assay in Brown-Norway rats exposed to diphenyl-methane-4,4'-diisocyanate. Arch Toxicol 75(4):234-242.

Peters JM, Murphy RL, Pagnotto LD, et al. 1968. Acute respiratory effects in workers exposed to low levels of toluene diisocyanate (TDI). Arch Environ Health 16(5):642-647. 


\section{REFERENCES}

Peters JM, Murphy RL, Pagnotto LD, et al. 1970. Respiratory impairment in workers exposed to "safe" levels of toluene diisocyanate (TDI). Arch Environ Health 20(3):364-367.

Petsonk EL, Wang ML, Lewis DM, et al. 2000. Asthma-like symptoms in wood product plant workers exposed to methylene diphenyl diisocyanate. Chest 118(4):1183-1193.

Pezzini A, Riviera A, Paggiaro P, et al. 1984. Specific IgE antibodies in twenty-eight workers with diisocyanate-induced bronchial asthma. Clin Allergy 14(5):453-461.

Pham LD, Kim MA, Yoon MG, et al. 2014. Serum specific IgG response to toluene diisocyanate-tissue transglutaminase conjugate in toluene diisocyanate-induced occupational asthmatics. Ann Allergy, Asthma Immunol 113(1):48-54. 10.1016/j.anai.2014.04.022.

Pollaris L, Devos F, De Vooght V, et al. 2016. Toluene diisocyanate and methylene diphenyl diisocyanate: Asthmatic response and cross-reactivity in a mouse model. Arch Toxicol 90:1709-1717. 10.1007/s00204-015-1606-6.

Pons F, Haag M, Corcos L, et al. 2000. Inhalation of toluene diisocyanate affects cytochrome P450 2B1 expression in rat lung. Arch Toxicol 74(7):397-403.

Rando RJ, Poovey HG. 1994. Dichotomous sampling of vapor and aerosol of methylene-bis(phenylisocyanate) (MDI) with an annular diffusional denuder. Am Ind Hyg Assoc J 55(8):716-721.

Rastogi SC. 1989. Analysis of diisocyanate monomers in chemical products containing polyurethanes by high pressure liquid chromatography. Chromatographia 28(1-2):15-18.

Renman L, Sango C, Skarping G. 1986. Determination of isocyanate and aromatic amine emissions from thermally degraded polyurethanes in foundries. Am Ind Hyg Assoc J 47(10):621-628.

RePORTER. 2014. Diisocyanates. National Institutes of Health, Research Portfolio Online Reporting Tools. http://projectreporter.nih.gov/reporter.cfm. April 7, 2014.

Reuzel PGJ, Arts JH, Lomax LG, et al. 1994. Chronic inhalation toxicity and carcinogenicity study of respirable polymeric methylene diphenyl diisocyanate (polymeric MDI) aerosol in rats. Fundam Appl Toxicol 22(2):195-210.

Rosenberg C, Savolainen H. 1986a. Determination in urine of diisocyanate-derived amines from occupational exposure by gas chromatography-mass fragmentography. Analyst 111(9):1069-1071.

Rosenberg C, Savolainen H. 1986b. Determination of occupational exposure to toluene diisocyanate by biological monitoring. J Chromatogr 367(2):385-392.

RTECS. 2009a. Isocyanic acid, methylenedi-p-phenylene ester. RTECS \#: NQ9350000. National Institute for Occupational Safety and Health. Registry of Toxic Effects of Chemical Substances. RTECS: NQ9350000. http://www.cdc.gov/niosh-rtecs/NQ8EAB70.html. December 30, 2013.

RTECS. 2009b. Benzene, 2,3-diisocyanato-1-methyl-. RTECS \# CZ6300000. National Institute for Occupational Safety and Health. Registry of Toxic Effects of Chemical Substances. http://www.cdc.gov/niosh-rtecs/CZ602160.html. December 31, 2014. 


\section{REFERENCES}

RTECS. 2009c. Benzene, 2,6-diisocyanato-1 methyl-. RTECS \#: CZ6310000. National Institute for Occupational Safety and Health. Registry of Toxic Effects of Chemical Substances. http://www.cdc.gov/niosh-rtecs/cz604870.html. December 31, 2013.

Sabbioni G, Dongari N, Kumar A. 2010. Determination of a new biomarker in subjects exposed to 4,4'methylenediphenyl diisocyanate. Biomarkers 15(6):508-515.

Sabbioni G, Gu Q, Vanimireddy LR. 2012. Determination of isocyanate specific albumin-adducts in workers exposed to toluene diisocyanates. Biomarkers 17(2):150-159.

Sabbioni G, Wesp H, Lewalter J, et al. 2007. Determination of isocyanate biomarkers in construction site workers. Biomarkers 12(5):468-483.

Saetta M, Maestrelli P, Turato G, et al. 1995. Airway wall remodeling after cessation of exposure to isocyanates in sensitized asthmatic subjects. Am J Respir Crit Care Med 151(2 Pt 1):489-494.

Sangha GK, Alarie Y. 1979. Sensory irritation by toluene diisocyanate in single and repeated exposures. Toxicol Appl Pharmacol 50(3):533-547.

Saunders NR, Ek CJ, Habgood MD, et al. 2008. Barriers in the brain: A renaissance? Trends Neurosci 31(6):279-286.

Saunders NR, Liddelow SA, Dziegielewska KM. 2012. Barrier mechanisms in the developing brain. Front Pharmacol 3(10.3389/fphar.2012.00046):Article 46.

Scheuplein R, Charnley G, Dourson M. 2002. Differential sensitivity of children and adults to chemical toxicity. I. Biological basis. Regul Toxicol Pharmacol 35(3):429-447.

Schmidt-Nowara WW, Murphy RL, Atkinson JD. 1973. Lung function after acute toluene di-isocyanate inhalation. Chest 63(6):1039-1040.

Schnorr TM, Steenland K, Egeland GM, et al. 1996. Mortality of workers exposed to toluene diisocyanate in the polyurethane foam industry. Occup Environ Med 53(10):703-707.

Schutze D, Sepai O, Lewalter J, et al. 1995. Biomonitoring of workers exposed to 4,4'methylenedianiline or 4,4'-methylenediphenyl diisocyanate. Carcinogenesis 16(3):573-582.

Seel K, Walber U, Herbold B, et al. 1999. Chemical behaviour of seven aromatic diisocyanates (toluenediisocyanates and diphenylmethanediisocyanates) under in vitro conditions in relationship to their results in the Salmonella/microsome test. Mutat Res 438(2):109-123.

Sendijarevic V, Sendijarevic A, Sendijarevic I, et al. 2004. Hydrolytic stability of toluene diisocyanate and polymeric methylenediphenyl diisocyanate based polyureas under environmental conditions. Environ Sci Technol 38(4):1066-1072.

Sennbro CJ, Lindh CH, Mattsson C, et al. 2006. Biological monitoring of exposure to 1,5-naphthalene diisocyanate and 4,4'-methylenediphenyl diisocyanate. Int Arch Occup Environ Health 79(8):647-653. 


\section{REFERENCES}

Sennbro CJ, Lindh CH, Tinnerberg H, et al. 2003. Development, validation and characterization of an analytical method for the quantification of hydrolysable urinary metabolites and plasma protein adducts of 2,4- and 2,6-toluene diisocyanate, 1,5-naphthalene diisocyanate and 4,4'-methylenediphenyl diisocyanate. Biomarkers 8(3-4):204-217.

Sennbro CJ, Lindh CH, Tinnerberg H, et al. 2004. Biological monitoring of exposure to toluene diisocyanate. Scand J Work Environ Health 30(5):371-378.

Sennbro CJ, Littorin M, Tinnerberg H, et al. 2005. Upper reference limits for biomarkers of exposure to aromatic diisocyanates. Int Arch Occup Environ Health 78(7):541-546.

Sepai O, Henschler D, Sabbioni G. 1995. Albumin adducts, hemoglobin adducts and urinary metabolites in workers exposed to 4,4'-methylenediphenyl diisocyanate. Carcinogenesis 16(10):2583-2587.

Shaddock JG, Robinson BY, Casciano DA. 1990. Effect of pretreatment with hepatic mixed-function oxidase inducers on the genotoxicity of four rat carcinogens in the hepatocyte/DNA repair assay. Mutagenesis 5(4):387-391.

Shadnia S, Ahmadimanesh M, Ghazi-Khansari M, et al. 2013. Intestinal obstruction in acute inhalational toluene 2,4-diisocyanate gas toxicity. Int J Occup Environ Med 4(3):164-166.

Sharifi L, Karimi A, Shokouhi Shoormasti R, et al. 2013. Asthma symptoms and specific IgE levels among toluene diisocyanate (TDI) exposed workers in Tehran, Iran. Iran J Public Health 42(4):397-401.

Shimizu H, Suzuki Y, Takemura N, et al. 1985. The results of microbial mutation test for forty-three industrial chemicals. Jpn J Ind Health 27(6):400-419.

Sielken RL, Jr., Bretzlaff RS, Valdez-Flores C, et al. 2012. Statistical comparison of carcinogenic effects and dose-response relationships in rats and mice for 2,4-toluene diamine to those ascribed to toluene diisocyanate. Hum Ecol Risk Assess 18(6):1315-1337. 10.1080/10807039.2012.722853.

Singer R, Scott NE. 1987. Progression of neuropsychological deficits following toluene diisocyanate exposure. Arch Clin Neuropsychol 2(2):135-144.

Skarping G, Brorson T, Sango C. 1991. Biological monitoring of isocyanates and related amines. III. Test chamber exposure of humans to toluene diisocyanate. Int Arch Occup Environ Health 63(2):83-88.

Skarping G, Dalene M, Lind P. 1994. Determination of toluenediamine isomers by capillary gas chromatography and chemical ionization mass spectrometry with special reference to the biological monitoring of 2,4- and 2,6-toluene diisocyanate. J Chromatogr A 663(2):199-210.

Sorahan T, Nichols L. 2002. Mortality and cancer morbidity of production workers in the UK flexible polyurethane foam industry: Updated findings, 1958-98. Occup Environ Med 59(11):751-758.

Sorahan T, Pope D. 1993. Mortality and cancer morbidity of production workers in the United Kingdom flexible polyurethane foam industry. Br J Ind Med 50(6):528-536.

Stingeni L, Bellini V, Lisi P. 2008. Occupational airborne contact urticaria and asthma: Simultaneous immediate and delayed allergy to diphenylmethane-4,4'-diisocyanate. Contact Dermatitis 58(2):112-113. 


\section{REFERENCES}

Sulotto F, Romano C, Piolatto G, et al. 1990. Short-term respiratory changes in polyurethane foam workers exposed to low MDI concentration. Int Arch Occup Environ Health 62(7):521-524.

Suojalehto H, Linstrom I, Henriks-Eckerman ML, et al. 2011. Occupational asthma related to low levels of airborne methylene diphenyl diisocyanate (MDI) in orthopedic casting work. Am J Ind Med 54(12):906-910.

Swierczynska-Machura D, Brzeznicki S, Nowakowska-Swirta E, et al. 2015. Occupational exposure to diisocyanates in polyurethane foam factory workers. Int J Occup Med Environ Health 28(6):985-998. 10.13075/ijomeh.1896.00284.

Swierczynska-Machura D, Nowakowska-Swirta E, Walusiak-Skorupa J, et al. 2014. Effect of inhaled toluene diisocyanate on local immune response based on murine model for occupational asthma. J Immunotoxicol 11(2):166-171. 10.3109/1547691x.2013.818745.

Tarlo SM, Liss GM, Dias C, et al. 1997. Assessment of the relationship between isocyanate exposure levels and occupational asthma. Am J Ind Med 32(5):517-521.

Timchalk C, Smith FA, Bartels MJ. 1994. Route-dependent comparative metabolism of $\left[{ }^{14} \mathrm{C}\right]$ toluene 2,4-diisocyanate and $\left[{ }^{14} \mathrm{C}\right]$ toluene 2,4-diamine in Fischer 344 rats. Toxicol Appl Pharmacol 124(2):181190.

Tinnerberg H, Broberg K, Lindh CH, et al. 2014. Biomarkers of exposure in Monday morning urine samples as a long-term measure of exposure to aromatic diisocyanates. Int Arch Occup Environ Health 87(4):365-372. 10.1007/s00420-013-0872-y.

Tinnerberg H, Spanne M, Dalene M, et al. 1997. Determination of complex mixtures of airborne isocyanates and amines. Part 3. Methylenediphenyl diisocyanate, methylenediphenylamino isocyanate and methylenediphenyldiamine. Analyst 122(3):275-278.

Tossin L, Chiesura-Corona P, Fabbri LM, et al. 1989. Ketotifen does not inhibit asthmatic reactions induced by toluene di-isocyanate in sensitized subjects. Clin Exp Allergy 19(2):177-182.

TRI16. 2017. TRI explorer: Providing access to EPA's toxics release inventory data. Washington, DC: Office of Information Analysis and Access. Office of Environmental Information. U.S. Environmental Protection Agency. Toxics Release Inventory. http://www.epa.gov/triexplorer/. August 2, 2017.

Tury B, Pemberton D, Bailey RE. 2003. Fate and potential environmental effects of methylenediphenyl diisocyanate and toluene diisocyanate released into the atmosphere. J Air Waste Manag Assoc 53(1):6166.

Tse KS, Johnson A, Chan H, et al. 1985. A study of serum antibody activity in workers with occupational exposure to diphenylmethane diisocyanate. Allergy (Copenh) 40(5):314-320.

Tyl RW, Fisher LC, Dodd DE, et al. 1999a. Developmental toxicity evaluation of inhaled toluene diisocyanate vapor in CD rats. Toxicol Sci 52(2):248-257.

Tyl RW, Neeper-Bradley TL, Fisher LC, et al. 1999b. Two-generation reproductive toxicity study of inhaled toluene diisocyanate vapor in CD rats. Toxicol Sci 52(2):258-268. 


\section{REFERENCES}

Vandenplas O, Cartier A, Lesage J, et al. 1992. Occupational asthma caused by a prepolymer but not the monomer of toluene diisocyanate (TDI). J Allergy Clin Immunol 89(6):1183-1188.

Vandenplas O, Delwiche JP, Staquet P, et al. 1999. Pulmonary effects of short-term exposure to low levels of toluene diisocyanate in asymptomatic subjects. Eur Respir J 13(5):1144-1150.

Vandenplas O, Suojalehto H, Aasen TB, et al. 2014. Specific inhalation challenge in the diagnosis of occupational asthma: Consensus statement. Eur Respir J 43(6):1573-1587.

Vena J, McKay C. 2007. Isocyanates and related compounds. In: Haddad and Winchester's clinical management of poisoning and drug overdose. 4th ed. Philadelphia, PA: Saunders Elsevier, 1317-1322.

Vieira I, Sonnier M, Cresteil T. 1996. Developmental expression of CYP2E1 in the human liver: Hypermethylation control of gene expression during the neonatal period. Eur J Biochem 238(2):476-483.

Vock EH, Lutz WK. 1997. Distribution and DNA adduct formation of radiolabeled methylenediphenyl4,4'-diisocyanate (MDI) in the rat after topical treatment. Toxicol Lett 92(2):93-100.

Vock EH, Cantoreggi S, Gupta RC, et al. 1995. 32P-postlabeling analysis of DNA adducts formed in vitro and in rat skin by methylenediphenyl-4,4'-diisocyanate (MDI). Toxicol Lett 76(1):17-26.

Vock EH, Vamvakas S, Gahlmann R, et al. 1998. Investigation of the induction of DNA double-strand breaks by methylenediphenyl-4,4'-diisocyanate in cultured human lung epithelial cells. Toxicol Sci 46(1):83-89.

Wang ML, Petsonk EL. 2004. Symptom onset in the first 2 years of employment at a wood products plant using diisocyanates: Some observations relevant to occupational medical screening. Am J Ind Med 46(3):226-233.

Wegman DH, Main DM, Musk AW. 1981. Chronic pulmonary function loss over 4 years in poly urethane workers exposed to toluene diisocyanate. Am Rev Respir Dis 123(4 Part 2):145.

Wegman DH, Musk AW, Main DM, et al. 1982. Accelerated loss of FEV-1 in polyurethane production workers: A four-year prospective study. Am J Ind Med 3(2):209-215.

Wegman DH, Peters JM, Pagnotto L, et al. 1977. Chronic pulmonary function loss from exposure to toluene diisocyanate. Br J Ind Med 34(3):196-200.

West JR, Smith HW, Chasis H. 1948. Glomerular filtration rate, effective renal blood flow, and maximal tubular excretory capacity in infancy. J Pediatr 32:10-18.

Weyel DA, Schaffer RB. 1985. Pulmonary and sensory irritation of diphenylmethane-4,4'- and dicyclohexylmethane-4,4'-diisocyanate. Toxicol Appl Pharmacol 77(3):427-433.

White WG, Morris MJ, Sugden E, et al. 1980. Isocyanate-induced asthma in a car factory. Lancet 1(8171):756-760.

WHO. 2000. Diphenylmethane diisocyanate (MDI). Concise International Chemical Assessment document 27. Geneva, Switzerland: World Health Organization. 


\section{REFERENCES}

WHO. 2010. Guidelines for indoor air quality: Selected pollutants. Geneva, Switzerland: World Health Organization. http://www.euro.who.int/_data/assets/pdf_file/0009/128169/e94535.pdf. April 25, 2012.

WHO. 2017. Guidelines for drinking-water quality. Fourth edition incorporating the first addendum. Geneva, Switzerland: World Health Organization. http://apps.who.int/iris/bitstream/10665/254637/1/9789241549950-eng.pdf?ua=1. February 28, 2017.

Widdowson EM, Dickerson JWT. 1964. Chemical composition of the body. In: Comar CL, Bronner F, eds. Mineral metabolism: An advance treatise. Volume II: The elements Part A. New York, NY: Academic Press, 1-247.

Wilder LC, Langley RL, Middleton DC, et al. 2011. Communities near toluene diisocyanate sources: An investigation of exposure and health. J Expo Sci Environ Epidemiol 21(6):587-594.

Wisnewski AV. 2007. Developments in laboratory diagnostics for isocyanate asthma. Curr Opin Allergy Clin Immunol 7(2):138-145.

Wisnewski AV, Liu J, Redlich CA. 2013. Connecting glutathione with immune responses to occupational methylene diphenyl diisocyanate exposure. Chem Biol Interact 205(1):38-45.

Woellner RC, Hall S, Greaves I, et al. 1997. Epidemic of asthma in a wood products plant using methylene diphenyl diisocyanate. Am J Ind Med 31(1):56-63.

Wong KL, Karol MH, Alarie Y. 1985. Use of repeated $\mathrm{CO}_{2}$ challenges to evaluate the pulmonary performance of guinea pigs exposed to toluene diisocyanate. J Toxicol Environ Health 15(1):137-148.

Yakabe Y, Henderson KM, Thompson WC, et al. 1999. Fate of methylenediphenyl diisocyanate and toluene diisocyanate in the aquatic environment. Environ Sci Technol 33(15):2579-2583.

Ye YM, Kang YM, Kim SH, et al. 2010. Probable role of beta 2-adrenergic receptor gene haplotype in toluene diisocyanate-induced asthma. Allergy Asthma Immunol Res 2(4):260-266.

Ye YM, Kim CW, Kim HR, et al. 2006. Biophysical determinants of toluene diisocyanate antigenicity associated with exposure and asthma. J Allergy Clin Immunol 118(4):885-891.

Yeh HJ, Lin WC, Shih TS, et al. 2008. Urinary excretion of toluene diisocyanates in rats following dermal exposure. J Appl Toxicol 28(2):189-195.

Yoshizawa Y, Ohtsuka M, Noguchi K, et al. 1989. Hypersensitivity pneumonitis induced by toluene diisocyanate: Sequelae of continuous exposure. Ann Intern Med 110(1):31-34.

Yucesoy B, Johnson VJ, Lummus ZL, et al. 2012. Genetic variants in antioxidant genes are associated with diisocyanate-induced asthma. Toxicol Sci 129(1):166-173.

Yucesoy B, Kashon ML, Johnson VJ, et al. 2016. Genetic variants in TNF $\alpha$, TGFB1, PTGS1 and PTGS2 genes are associated with diisocyanate-induced asthma. J Immunotoxicol 13(1):119-126.

Yucesoy B, Kaufman KM, Lummus ZL, et al. 2015. Genome-wide association study identifies novel loci associated with diisocyanate-induced occupational asthma. Toxicol Sci 146(1):192-201. 
Zammit-Tabona M, Sherkin M, Kijek K, et al. 1983. Asthma caused by diphenylmethane diisocyanate in foundry workers. Clinical, bronchial provocation, and immunologic studies. Am Rev Respir Dis $128(2): 226-230$.

Zeiger E, Anderson B, Haworth S, et al. 1987. Salmonella mutagenicity tests: III. Results from the testing of 255 chemicals. Environ Mutagen 9(Suppl. 9):1-110.

Zeiss CR, Kanellakes TM, Bellone JD, et al. 1980. Immunoglobulin E-mediated asthma and hypersensitivity pneumonitis with precipitating anti-hapten antibodies due to diphenylmethane diisocyanate (MDI) exposure. J Allergy Clin Immunol 65(5):347-352.

Zhao H, Peng H, Cai SX, et al. 2009. Toluene diisocyanate enhances human bronchial epithelial cells' permeability partly through the vascular endothelial growth factor pathway. Clin Exp Allergy 39(10):1532-1539.

Zheng KC, Ariizumi M, Todoriki H, et al. 2001a. Cytokine profiles in airways of rats exposed to toluene diisocyanate. J Occup Health 43:39-45.

Zheng KC, Kouadio K, Tuekpe MK, et al. 2004. Eosinophil infiltration in airways of mice exposed to toluene diisocyanate. J Occup Health 46(4):299-302.

Zheng KC, Nong DX, Morioka T, et al. 2001b. Elevated interleukin-4 and interleukin-6 in rats sensitized with toluene diisocyanate. Ind Health 39(4):334-339.

Zhong BZ, Siegel PD. 2000. Induction of micronuclei following exposure to methylene di-phenyl diisocyanate: Potential genotoxic metabolites. Toxicol Sci 58(1):102-108.

Ziegler EE, Edwards BB, Jensen RL, et al. 1978. Absorption and retention of lead by infants. Pediatr Res 12(1):29-34.

Zissu D. 1995. Histopathological changes in the respiratory tract of mice exposed to ten families of airborne chemicals. J Appl Toxicol 15(3):207-213. 
9. REFERENCES

This page is intentionally blank. 


\section{GLOSSARY}

Absorption-The taking up of liquids by solids, or of gases by solids or liquids.

Acute Exposure-Exposure to a chemical for a duration of 14 days or less, as specified in the Toxicological Profiles.

Adsorption-The adhesion in an extremely thin layer of molecules (as of gases, solutes, or liquids) to the surfaces of solid bodies or liquids with which they are in contact.

Adsorption Coefficient $\left(\mathbf{K}_{\mathbf{o c}}\right)$ - The ratio of the amount of a chemical adsorbed per unit weight of organic carbon in the soil or sediment to the concentration of the chemical in solution at equilibrium.

Adsorption Ratio (Kd) - The amount of a chemical adsorbed by sediment or soil (i.e., the solid phase) divided by the amount of chemical in the solution phase, which is in equilibrium with the solid phase, at a fixed solid/solution ratio. It is generally expressed in micrograms of chemical sorbed per gram of soil or sediment.

Benchmark Dose (BMD) - Usually defined as the lower confidence limit on the dose that produces a specified magnitude of changes in a specified adverse response. For example, a BMD 10 would be the dose at the $95 \%$ lower confidence limit on a $10 \%$ response, and the benchmark response (BMR) would be $10 \%$. The BMD is determined by modeling the dose response curve in the region of the dose response relationship where biologically observable data are feasible.

Benchmark Dose Model—A statistical dose-response model applied to either experimental toxicological or epidemiological data to calculate a BMD.

Bioconcentration Factor (BCF) - The quotient of the concentration of a chemical in aquatic organisms at a specific time or during a discrete time period of exposure divided by the concentration in the surrounding water at the same time or during the same period.

Biomarkers-Broadly defined as indicators signaling events in biologic systems or samples. They have been classified as markers of exposure, markers of effect, and markers of susceptibility.

Cancer Effect Level (CEL) - The lowest dose of chemical in a study, or group of studies, that produces significant increases in the incidence of cancer (or tumors) between the exposed population and its appropriate control.

Carcinogen-A chemical capable of inducing cancer.

Case-Control Study - A type of epidemiological study that examines the relationship between a particular outcome (disease or condition) and a variety of potential causative agents (such as toxic chemicals). In a case-control study, a group of people with a specified and well-defined outcome is identified and compared to a similar group of people without the outcome.

Case Report-Describes a single individual with a particular disease or exposure. These may suggest some potential topics for scientific research, but are not actual research studies.

Case Series-Describes the experience of a small number of individuals with the same disease or exposure. These may suggest potential topics for scientific research, but are not actual research studies. 
Ceiling Value-A concentration that must not be exceeded.

Chronic Exposure-Exposure to a chemical for 365 days or more, as specified in the Toxicological Profiles.

Cohort Study-A type of epidemiological study of a specific group or groups of people who have had a common insult (e.g., exposure to an agent suspected of causing disease or a common disease) and are followed forward from exposure to outcome. At least one exposed group is compared to one unexposed group.

Cross-sectional Study-A type of epidemiological study of a group or groups of people that examines the relationship between exposure and outcome to a chemical or to chemicals at one point in time.

Data Needs-Substance-specific informational needs that, if met, would reduce the uncertainties of human health risk assessment.

Developmental Toxicity-The occurrence of adverse effects on the developing organism that may result from exposure to a chemical prior to conception (either parent), during prenatal development, or postnatally to the time of sexual maturation. Adverse developmental effects may be detected at any point in the life span of the organism.

Dose-Response Relationship-The quantitative relationship between the amount of exposure to a toxicant and the incidence of the adverse effects.

Embryotoxicity and Fetotoxicity-Any toxic effect on the conceptus as a result of prenatal exposure to a chemical; the distinguishing feature between the two terms is the stage of development during which the insult occurs. The terms, as used here, include malformations and variations, altered growth, and in utero death.

Environmental Protection Agency (EPA) Health Advisory-An estimate of acceptable drinking water levels for a chemical substance based on health effects information. A health advisory is not a legally enforceable federal standard, but serves as technical guidance to assist federal, state, and local officials.

Epidemiology-Refers to the investigation of factors that determine the frequency and distribution of disease or other health-related conditions within a defined human population during a specified period.

Genotoxicity-A specific adverse effect on the genome of living cells that, upon the duplication of affected cells, can be expressed as a mutagenic, clastogenic, or carcinogenic event because of specific alteration of the molecular structure of the genome.

Half-life-A measure of rate for the time required to eliminate one half of a quantity of a chemical from the body or environmental media.

Immediately Dangerous to Life or Health (IDLH) — A condition that poses a threat of life or health, or conditions that pose an immediate threat of severe exposure to contaminants that are likely to have adverse cumulative or delayed effects on health.

Immunologic Toxicity-The occurrence of adverse effects on the immune system that may result from exposure to environmental agents such as chemicals. 
Immunological Effects-Functional changes in the immune response.

Incidence-The ratio of new cases of individuals in a population who develop a specified condition to the total number of individuals in that population who could have developed that condition in a specified time period.

Intermediate Exposure-Exposure to a chemical for a duration of 15-364 days, as specified in the Toxicological Profiles.

In Vitro-Isolated from the living organism and artificially maintained, as in a test tube.

In Vivo-Occurring within the living organism.

Lethal Concentration $(\mathbf{L O})\left(\mathbf{L C}_{\mathbf{L O}}\right)$ - The lowest concentration of a chemical in air that has been reported to have caused death in humans or animals.

Lethal Concentration $\left(\mathbf{5 0}_{0}\right)\left(\mathbf{L C}_{50}\right)$ - A calculated concentration of a chemical in air to which exposure for a specific length of time is expected to cause death in $50 \%$ of a defined experimental animal population.

Lethal Dose $\mathbf{L}_{(\mathbf{L O})}\left(\mathbf{L D}_{\mathrm{LO}}\right)$ - The lowest dose of a chemical introduced by a route other than inhalation that has been reported to have caused death in humans or animals.

Lethal Dose $\mathbf{( 5 0 )}_{\mathbf{(})}\left(\mathbf{L D}_{\mathbf{5 0}}\right)$ - The dose of a chemical that has been calculated to cause death in $50 \%$ of a defined experimental animal population.

Lethal Time (50) $_{(\mathbf{L}}\left(\mathbf{L T}_{\mathbf{5 0}}\right)$ - A calculated period of time within which a specific concentration of a chemical is expected to cause death in $50 \%$ of a defined experimental animal population.

Lowest-Observed-Adverse-Effect Level (LOAEL) - The lowest exposure level of chemical in a study, or group of studies, that produces statistically or biologically significant increases in frequency or severity of adverse effects between the exposed population and its appropriate control.

Lymphoreticular Effects-Represent morphological effects involving lymphatic tissues such as the lymph nodes, spleen, and thymus.

Malformations-Permanent structural changes that may adversely affect survival, development, or function.

Minimal Risk Level (MRL) — An estimate of daily human exposure to a hazardous substance that is likely to be without an appreciable risk of adverse noncancer health effects over a specified route and duration of exposure.

Modifying Factor (MF)—A value (greater than zero) that is applied to the derivation of a Minimal Risk Level (MRL) to reflect additional concerns about the database that are not covered by the uncertainty factors. The default value for a MF is 1 .

Morbidity-State of being diseased; morbidity rate is the incidence or prevalence of disease in a specific population.

Mortality-Death; mortality rate is a measure of the number of deaths in a population during a specified interval of time. 
Mutagen-A substance that causes mutations. A mutation is a change in the DNA sequence of a cell's DNA. Mutations can lead to birth defects, miscarriages, or cancer.

Necropsy-The gross examination of the organs and tissues of a dead body to determine the cause of death or pathological conditions.

Neurotoxicity-The occurrence of adverse effects on the nervous system following exposure to a hazardous substance.

No-Observed-Adverse-Effect Level (NOAEL) - The dose of a chemical at which there were no statistically or biologically significant increases in frequency or severity of adverse effects seen between the exposed population and its appropriate control. Effects may be produced at this dose, but they are not considered to be adverse.

Octanol-Water Partition Coefficient $\left(\mathbf{K}_{\mathbf{o w}}\right)$ - The equilibrium ratio of the concentrations of a chemical in $n$-octanol and water, in dilute solution.

Odds Ratio (OR) - A means of measuring the association between an exposure (such as toxic substances and a disease or condition) that represents the best estimate of relative risk (risk as a ratio of the incidence among subjects exposed to a particular risk factor divided by the incidence among subjects who were not exposed to the risk factor). An OR of greater than 1 is considered to indicate greater risk of disease in the exposed group compared to the unexposed group.

Organophosphate or Organophosphorus Compound-A phosphorus-containing organic compound and especially a pesticide that acts by inhibiting cholinesterase.

Permissible Exposure Limit (PEL)—An Occupational Safety and Health Administration (OSHA) regulatory limit on the amount or concentration of a substance not to be exceeded in workplace air averaged over any 8-hour work shift of a 40-hour workweek.

Pesticide-General classification of chemicals specifically developed and produced for use in the control of agricultural and public health pests (insects or other organisms harmful to cultivated plants or animals).

Pharmacokinetics - The dynamic behavior of a material in the body, used to predict the fate (disposition) of an exogenous substance in an organism. Utilizing computational techniques, it provides the means of studying the absorption, distribution, metabolism, and excretion of chemicals by the body.

Pharmacokinetic Model-A set of equations that can be used to describe the time course of a parent chemical or metabolite in an animal system. There are two types of pharmacokinetic models: data-based and physiologically-based. A data-based model divides the animal system into a series of compartments, which, in general, do not represent real, identifiable anatomic regions of the body, whereas the physiologically-based model compartments represent real anatomic regions of the body.

Physiologically Based Pharmacodynamic (PBPD) Model-A type of physiologically based doseresponse model that quantitatively describes the relationship between target tissue dose and toxic end points. These models advance the importance of physiologically based models in that they clearly describe the biological effect (response) produced by the system following exposure to an exogenous substance. 
Physiologically Based Pharmacokinetic (PBPK) Model-Comprised of a series of compartments representing organs or tissue groups with realistic weights and blood flows. These models require a variety of physiological information: tissue volumes, blood flow rates to tissues, cardiac output, alveolar ventilation rates, and possibly membrane permeabilities. The models also utilize biochemical information, such as blood:air partition coefficients, and metabolic parameters. PBPK models are also called biologically based tissue dosimetry models.

Prevalence-The number of cases of a disease or condition in a population at one point in time.

Prospective Study - A type of cohort study in which the pertinent observations are made on events occurring after the start of the study. A group is followed over time.

$\mathbf{q}_{1}$ *-The upper-bound estimate of the low-dose slope of the dose-response curve as determined by the multistage procedure. The $\mathrm{q}_{1} *$ can be used to calculate an estimate of carcinogenic potency, the incremental excess cancer risk per unit of exposure (usually $\mu \mathrm{g} / \mathrm{L}$ for water, $\mathrm{mg} / \mathrm{kg} /$ day for food, and $\mu \mathrm{g} / \mathrm{m}^{3}$ for air).

Recommended Exposure Limit (REL) - A National Institute for Occupational Safety and Health (NIOSH) time-weighted average (TWA) concentration for up to a 10-hour workday during a 40-hour workweek.

Reference Concentration (RfC)—An estimate (with uncertainty spanning perhaps an order of magnitude) of a continuous inhalation exposure to the human population (including sensitive subgroups) that is likely to be without an appreciable risk of deleterious noncancer health effects during a lifetime. The inhalation reference concentration is for continuous inhalation exposures and is appropriately expressed in units of $\mathrm{mg} / \mathrm{m}^{3}$ or $\mathrm{ppm}$.

Reference Dose (RfD)—An estimate (with uncertainty spanning perhaps an order of magnitude) of the daily exposure of the human population to a potential hazard that is likely to be without risk of deleterious effects during a lifetime. The RfD is operationally derived from the no-observed-adverse-effect level (NOAEL, from animal and human studies) by a consistent application of uncertainty factors that reflect various types of data used to estimate RfDs and an additional modifying factor, which is based on a professional judgment of the entire database on the chemical. The RfDs are not applicable to nonthreshold effects such as cancer.

Reportable Quantity (RQ) - The quantity of a hazardous substance that is considered reportable under the Comprehensive Environmental Response, Compensation, and Liability Act (CERCLA). Reportable quantities are (1) 1 pound or greater or (2) for selected substances, an amount established by regulation either under CERCLA or under Section 311 of the Clean Water Act. Quantities are measured over a 24-hour period.

Reproductive Toxicity-The occurrence of adverse effects on the reproductive system that may result from exposure to a hazardous substance. The toxicity may be directed to the reproductive organs and/or the related endocrine system. The manifestation of such toxicity may be noted as alterations in sexual behavior, fertility, pregnancy outcomes, or modifications in other functions that are dependent on the integrity of this system.

Retrospective Study-A type of cohort study based on a group of persons known to have been exposed at some time in the past. Data are collected from routinely recorded events, up to the time the study is undertaken. Retrospective studies are limited to causal factors that can be ascertained from existing records and/or examining survivors of the cohort. 
Risk-The possibility or chance that some adverse effect will result from a given exposure to a hazardous substance.

Risk Factor-An aspect of personal behavior or lifestyle, an environmental exposure, existing health condition, or an inborn or inherited characteristic that is associated with an increased occurrence of disease or other health-related event or condition.

Risk Ratio-The ratio of the risk among persons with specific risk factors compared to the risk among persons without risk factors. A risk ratio greater than 1 indicates greater risk of disease in the exposed group compared to the unexposed group.

Short-Term Exposure Limit (STEL) - A STEL is a 15-minute TWA exposure that should not be exceeded at any time during a workday.

Standardized Mortality Ratio (SMR) — A ratio of the observed number of deaths and the expected number of deaths in a specific standard population.

Target Organ Toxicity-This term covers a broad range of adverse effects on target organs or physiological systems (e.g., renal, cardiovascular) extending from those arising through a single limited exposure to those assumed over a lifetime of exposure to a chemical.

Teratogen-A chemical that causes structural defects that affect the development of an organism.

Threshold Limit Value (TLV)—An American Conference of Governmental Industrial Hygienists (ACGIH) concentration of a substance to which it is believed that nearly all workers may be repeatedly exposed, day after day, for a working lifetime without adverse effect. The TLV may be expressed as a Time Weighted Average (TLV-TWA), as a Short-Term Exposure Limit (TLV-STEL), or as a ceiling limit (TLV-C).

Time-Weighted Average (TWA)—An average exposure within a given time period.

Toxic Dose $\mathbf{( 5 0}_{\mathbf{5 0}} \mathbf{T}_{\mathbf{5 0}}$ - - A calculated dose of a chemical, introduced by a route other than inhalation, which is expected to cause a specific toxic effect in $50 \%$ of a defined experimental animal population.

Toxicokinetic - The absorption, distribution, and elimination of toxic compounds in the living organism.

Uncertainty Factor (UF) - A factor used in operationally deriving the Minimal Risk Level (MRL) or Reference Dose (RfD) or Reference Concentration (RfC) from experimental data. UFs are intended to account for (1) the variation in sensitivity among the members of the human population, (2) the uncertainty in extrapolating animal data to the case of human, (3) the uncertainty in extrapolating from data obtained in a study that is of less than lifetime exposure, and (4) the uncertainty in using lowestobserved-adverse-effect level (LOAEL) data rather than no-observed-adverse-effect level (NOAEL) data. A default for each individual UF is 10; if complete certainty in data exists, a value of 1 can be used; however, a reduced UF of 3 may be used on a case-by-case basis, 3 being the approximate logarithmic average of 10 and 1 .

Xenobiotic-Any substance that is foreign to the biological system. 


\section{APPENDIX A. ATSDR MINIMAL RISK LEVELS AND WORKSHEETS}

The Comprehensive Environmental Response, Compensation, and Liability Act (CERCLA) [42 U.S.C. 9601 et seq.], as amended by the Superfund Amendments and Reauthorization Act (SARA) [Pub. L. 99499], requires that the Agency for Toxic Substances and Disease Registry (ATSDR) develop jointly with the U.S. Environmental Protection Agency (EPA), in order of priority, a list of hazardous substances most commonly found at facilities on the CERCLA National Priorities List (NPL); prepare toxicological profiles for each substance included on the priority list of hazardous substances; and assure the initiation of a research program to fill identified data needs associated with the substances.

The toxicological profiles include an examination, summary, and interpretation of available toxicological information and epidemiologic evaluations of a hazardous substance. During the development of toxicological profiles, Minimal Risk Levels (MRLs) are derived when reliable and sufficient data exist to identify the target organ(s) of effect or the most sensitive health effect(s) for a specific duration for a given route of exposure. An MRL is an estimate of the daily human exposure to a hazardous substance that is likely to be without appreciable risk of adverse noncancer health effects over a specified route and duration of exposure. MRLs are based on noncancer health effects only and are not based on a consideration of cancer effects. These substance-specific estimates, which are intended to serve as screening levels, are used by ATSDR health assessors to identify contaminants and potential health effects that may be of concern at hazardous waste sites. It is important to note that MRLs are not intended to define clean-up or action levels.

MRLs are derived for hazardous substances using the no-observed-adverse-effect level/uncertainty factor approach. They are below levels that might cause adverse health effects in the people most sensitive to such chemical-induced effects. MRLs are derived for acute (1-14 days), intermediate (15-364 days), and chronic (365 days and longer) durations and for the oral and inhalation routes of exposure. Currently, MRLs for the dermal route of exposure are not derived because ATSDR has not yet identified a method suitable for this route of exposure. MRLs are generally based on the most sensitive substance-induced endpoint considered to be of relevance to humans. Serious health effects (such as irreparable damage to the liver or kidneys, or birth defects) are not used as a basis for establishing MRLs. Exposure to a level above the MRL does not mean that adverse health effects will occur.

MRLs are intended only to serve as a screening tool to help public health professionals decide where to look more closely. They may also be viewed as a mechanism to identify those hazardous waste sites that 
are not expected to cause adverse health effects. Most MRLs contain a degree of uncertainty because of the lack of precise toxicological information on the people who might be most sensitive (e.g., infants, elderly, nutritionally or immunologically compromised) to the effects of hazardous substances. ATSDR uses a conservative (i.e., protective) approach to address this uncertainty consistent with the public health principle of prevention. Although human data are preferred, MRLs often must be based on animal studies because relevant human studies are lacking. In the absence of evidence to the contrary, ATSDR assumes that humans are more sensitive to the effects of hazardous substance than animals and that certain persons may be particularly sensitive. Thus, the resulting MRL may be as much as 100 -fold below levels that have been shown to be nontoxic in laboratory animals.

Proposed MRLs undergo a rigorous review process: Health Effects/MRL Workgroup reviews within the Division of Toxicology and Human Health Sciences, expert panel peer reviews, and agency-wide MRL Workgroup reviews, with participation from other federal agencies and comments from the public. They are subject to change as new information becomes available concomitant with updating the toxicological profiles. Thus, MRLs in the most recent toxicological profiles supersede previously published levels. For additional information regarding MRLs, please contact the Division of Toxicology and Human Health Sciences, Agency for Toxic Substances and Disease Registry, 1600 Clifton Road NE, Mailstop F-57, Atlanta, Georgia 30329-4027. 


\section{MINIMAL RISK LEVEL (MRL) WORKSHEET}

Chemical Name: Toluene diisocyanate

CAS Number: $\quad 26471-62-5$

Date: June 2018

Profile Status: $\quad$ Final

Route: $\quad[X]$ Inhalation [ ] Oral

Duration: $\quad$ [X] Acute [] Intermediate [] Chronic

Graph Key: $\quad 1$

Species: Humans

Minimal Risk Level: $1 \times 10^{-5} \quad[$ ] mg/kg/day $[\mathrm{X}] \mathrm{ppm}$

Reference: Vandenplas O, Delwiche J-P, Staquet P, et al. 1999. Pulmonary effects of short-term exposure to low levels of toluene diisocyanate in asymptomatic subjects. Eur Respir J 13:1144-1150.

Experimental design: In this single-blind crossover design study, 17 volunteers ( 8 male, 9 females) were exposed to ambient air or $0.005 \mathrm{ppm}$ TDI for 6 hours followed by a 20 -minute exposure to $0.020 \mathrm{ppm}$ TDI. Pulmonary function testing was conducted prior to exposure and every hour during the 6-hour exposure and at the end of the 20-minute exposure to $0.020 \mathrm{ppm}$ or air. Bronchial lavage (BL) and bronchoalveolar lavage (BAL) were performed 1 hour after the end of the exposure.

Effect noted in study and corresponding doses: None of the subjects reported respiratory symptoms in response to the exposure. TDI exposure was associated with a slight, but significant, decrease in specific airway conductance (sGaw) and maximal expiratory flow at $25 \%$ of forced vital capacity $\left(\mathrm{MEF}_{25 \%}\right)$. No significant alterations in the volume of fluid recovered or total and differential cell counts were observed in the BL and BAL after TDI exposure, as compared to air exposure. Exposure to TDI was associated with a decrease in the proportion of CD19 cells in the BL and BAL, although there was no difference in the absolute number of cells. A slight but statistically significant increase in BAL albumin levels and BL $\alpha$-2-macroglobulin levels were observed.

Dose and end point used for MRL derivation: LOAEL of $0.005 \mathrm{ppm}$ for decreased lung function

[ ] NOAEL [X] LOAEL

Uncertainty Factors used in MRL derivation:

[X] 10 for use of a LOAEL

[ ] 10 for extrapolation from animals to humans

[X] 10 for human variability

Was a conversion factor used from ppm in food or water to a $\mathrm{mg} / \mathrm{body}$ weight dose? Not applicable.

If an inhalation study in animals, list conversion factors used in determining human equivalent dose: Not applicable.

Was a conversion used from intermittent to continuous exposure? Yes. The LOAEL of 0.005 ppm was adjusted for intermittent exposure:

$0.005 \mathrm{ppm} \times 6$ hours $/ 24$ hours $=0.00125 \mathrm{ppm}$ 
Other additional studies or pertinent information that lend support to this MRL: In another acute-duration human study, no alterations in specific air way resistance were observed in healthy or asthmatic subjects exposed to $0.02 \mathrm{ppm}$ TDI for 20 minutes (Chester et al. 1979). Acute-duration animal inhalation studies have reported rhinitis, lung damage, and airway hyperresponsiveness. The severity of rhinitis was concentration-related; moderate rhinitis was observed in mice exposed to $0.07 \mathrm{ppm} 6$ hours/day for 4 days (Zissu 1995), moderate-to-severe rhinitis was observed in mice exposed to $0.4 \mathrm{ppm} 6$ hours/day for 5 days (Buckley et al. 1984), and severe nasal lesions were observed in mice exposed to $1 \mathrm{ppm}$ 6 hours/day for 3 days (Arts et al. 2008). Interstitial inflammation, pleural thickening, and goblet cell hyperplasia were observed in the lungs of guinea pigs exposed to $1.4 \mathrm{ppm}$ TDI 3 hours/day for 3 days (Wong et al. 1985). Airway hyperresponsiveness to methacholine or acetylcholine was also observed in guinea pigs and mice exposed to $\geq 0.01 \mathrm{ppm}$ (Gagnaire et al. 1996; Gordon et al. 1985; Marek et al. 1999); a NOAEL of $0.005 \mathrm{ppm}$ for airway hyperresponsiveness was identified in guinea pigs exposed to TDI 6 hours/day for 5 days (Marek et al. 1999). An increase in the incidence of litters with poorly ossified cervical centrum was observed in the offspring of rats exposed to $0.5 \mathrm{ppm}$ commercial-grade TDI 6 hours/day on GDs 6-15 (Tyl et al. 1999a); this concentration was also associated with maternal toxicity including a marked decrease in body weight gain and signs of nasal irritation and audible respiration.

Support for basing the MRL on a single exposure study comes from chronic occupational exposure studies. The lowest LOAEL values identified in longitudinal studies of workers exposed to TDI were 0.0012 and 0.0019 ppm (Clark et al. 1998; Diem et al. 1982); the effects observed at these concentrations included decreases in lung function $\left(\mathrm{FEV}_{1}\right.$ and/or FVC). These LOAELs are roughly 2-4 times lower than the LOAEL from the Vandenplas et al. (1999) study. However, since there is uncertainty that the MRL would be protective for continuous exposure for 14 days, it is suggested that measured air concentrations should not exceed the MRL of $1 \times 10^{-5} \mathrm{ppm}$ during a 24-hour period. 


\section{MINIMAL RISK LEVEL (MRL) WORKSHEET}

$\begin{array}{ll}\text { Chemical Name: } & \text { Toluene diisocyanate } \\ \text { CAS Number: } & \text { 26471-62-5 } \\ \text { Date: } & \text { June 2018 } \\ \text { Profile Status: } & \text { Final } \\ \text { Route: } & \text { [X] Inhalation [ ] Oral } \\ \text { Duration: } & \text { [] Acute [] Intermediate [X] Chronic } \\ \text { Graph Key: } & 26 \\ \text { Species: } & \text { Humans }\end{array}$

Minimal Risk Level: $3 \times 10^{-6} \quad[$ ] mg/kg/day $[\mathrm{X}] \mathrm{ppm}$

Reference: Clark RL, Bugler J, McDermott M, et al. 1998. An epidemiology study of lung function changes of toluene diisocyanate foam workers in the United Kingdom. Int Arch Occup Environ Health 71:169-179.

Experimental design: A group of 780 (649 males, 131 females) workers employed at 12 flexible foamproducing factories in the United Kingdom were examined over a 5-year period; all subjects had taken at least three pulmonary function tests over a period of at least 1 year. Workers were divided into three groups: (1) the exposed group (472 males and 49 females), which consisted of workers employed in the manufacture of polyurethane foam or were handling freshly manufactured products still emitting measurable quantities of TDI; (2) the handling group (80 males and 43 females), consisting of workers handling cold polyurethane products from which TDI emissions could not usually be detected; and (3) the low-exposure group ( 97 males and 39 females), consisting of shop floor and office workers (control group). The average time in the study was 4.3 years. Workers completed respiratory questionnaires at the start of the study and at the end (or when they left the study); pulmonary function testing was conducted annually at the same time of day, same day of the week, and same month of the year. The mean daily exposure to TDI was 0.0096 -hours ppm (0.0012 ppm 8-hour TWA). The investigators noted that although $4.7 \%$ of the measurements exceeded the 8 -hour TWA concentration limit of $0.0058 \mathrm{ppm}$, most of the subjects were exposed to $<0.00125 \mathrm{ppm}$. Additionally, $19 \%$ of the samples in the exposed group exceeded the 15 -minute short-term limit of $0.02 \mathrm{ppm}$.

Effect noted in study and corresponding doses: Significant increases in the prevalence of wheezing were observed in the handling and exposed groups; however, there were only small differences between the two groups. Longitudinal analysis did not find a significant exposure-related effect on lung function. Twenty-four cases of respiratory sensitization were identified; the $\mathrm{FEV}_{1}$ decline was greater in these subjects than those not sensitized. A study of 157 naïve subjects (workers who entered the study after the first longitudinal measurements were made) showed no difference in $\mathrm{FEV}_{1}$ decline as compared to exposed non-naïves. However, longitudinal regression showed the mean daily exposure to be significant for annual changes in $\mathrm{FEV}_{1}$ and FVC. These declines were more rapid in the early years of employment, frequently during the first few months of employment. Clark et al. (1998) suggested that the decline in lung function may have been due to respiratory irritation.

Dose and end point used for MRL derivation: The MRL was based on the mean daily exposure level for the exposed group of $0.0012 \mathrm{ppm}$ that was associated with a significant decrease in lung function; this concentration was treated as an adverse effect level for the purposes of deriving the MRL.

[ ] NOAEL [X] Adverse Effect Level (AEL) 
Uncertainty Factors used in MRL derivation:

[X] 10 for use of a AEL

[ ] 10 for extrapolation from animals to humans

[X] 10 for human variability

Was a conversion factor used from $\mathrm{ppm}$ in food or water to a $\mathrm{mg} /$ body weight dose? Not applicable.

If an inhalation study in animals, list conversion factors used in determining human equivalent dose: Not applicable.

Was a conversion used from intermittent to continuous exposure? Yes. The AEL of 0.0012 ppm was adjusted for intermittent exposure:

$0.0012 \mathrm{ppm} \times 8$ hours $/ 24$ hours $\times 5$ days $/ 7$ days $=0.00029 \mathrm{ppm}$

Other additional studies or pertinent information that lend support to this MRL: The toxicity of TDI has been examined in a large number of occupational exposure studies that identify the respiratory tract as the primary target of toxicity; they are supported by a number of animal studies. In humans, the primary respiratory effects are occupational asthma, asthma-like symptoms (e.g., wheezing, dyspnea, chest tightness), and decreases in lung function. The occupational asthma and possibly the asthma-like symptoms are observed in individuals sensitized to TDI. Although the prevalence of sensitization is not known, it is likely $<10 \%$ based on older literature when the occupational exposures were higher and may now be as low as $<1 \%$ since the occupational exposure limit was lowered to $0.005 \mathrm{ppm}$ (Ott et al. 2003). Exposure to very low concentrations of TDI can elicit an asthma response in sensitized individuals; in non-sensitized individuals, this concentration would be non-irritating. Although there is some indication of an improvement in asthma symptoms after discontinuing TDI exposure, a fair percentage of sensitized workers still report symptoms $>10$ years after exposure termination (Mapp et al. 1988; Moller et al. 1986; Moscato et al. 1991; Padoan et al. 2003; Paggiaro et al. 1984).

The primary effect observed in non-sensitized workers is a decline in lung function (Adams 1975; Bodner et al. 2001; Butcher et al. 1977; Clark et al. 1998, 2003; Diem et al. 1982; Jones et al. 1992; Omae et al. 1992; Ott et al. 2000; Peters et al. 1970; Wegman et al. 1977, 1982). Based on the results of the Clark et al. (1998) study and a prospective longitudinal study by Diem et al. (1982), it appears that the greatest declines in lung function occur during the first couple of years of exposure to TDI; thereafter, continued exposure to lower TDI levels does not result in further annual declines in lung function.

Chronic exposure to TDI resulted in chronic or necrotic rhinitis with epithelial atrophy and mucous and squamous metaplasia in mice exposed to 0.05 ppm TDI 6 hours/day, 5 days/week for 2 years (Loeser 1983). In the lungs, interstitial pneumonitis and catarrhal bronchitis were observed. 


\section{MINIMAL RISK LEVEL (MRL) WORKSHEET}

$\begin{array}{ll}\text { Chemical Name: } & \text { Polymeric methylenediphenyl diisocyanate } \\ \text { CAS Number: } & 9016-87-9 \\ \text { Date: } & \text { June 2018 } \\ \text { Profile Status: } & \text { Final } \\ \text { Route: } & \text { [X] Inhalation [ ] Oral } \\ \text { Duration: } & \text { [] Acute [ ] Intermediate [X] Chronic } \\ \text { Graph Key: } & 8 \\ \text { Species: } & \text { Rat }\end{array}$

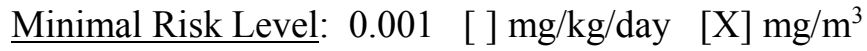

Reference: Reuzel PGJ, Arts JHE, Lomax LG, et al. 1994. Chronic inhalation toxicity and carcinogenicity study of respirable polymeric methylene diphenyl diisocyanate (polymeric MDI) aerosol in rats. Fundam Appl Toxicol 22:195-210.

Experimental design: Groups of 70 male and 70 female Wistar rats were exposed to $0,0.2,1.0$, or $6.0 \mathrm{mg} / \mathrm{m}^{3}$ polymeric MDI for 6 hours/day, 5 days/week for 2 years; after 1 year of exposure, $10 \mathrm{rats} / \mathrm{sex} /$ group were sacrificed for interim evaluation. The test substance contained $44.8-50.2 \%$ monomeric MDI. The mass median aerodynamic diameter (MMAD) particle sizes (and geometric standard deviation [GSD]) were 0.68 (2.93), 0.70 (2.46), and $0.74(2.31) \mu \mathrm{m}$, respectively. The following parameters were used to evaluate toxicity in the rats exposed for 1 year: clinical signs, body weight (weekly for the first 13 weeks and monthly thereafter), hematology (red and white blood cell counts, hemoglobin, packed cell volume, differential white blood cell count, prothrombin time), urinary parameters (volume, density, $\mathrm{pH}$, protein, occult blood, glucose, ketones), clinical chemistry (albumin, alkaline phosphatase, alanine aminotransferase, aspartate aminotransferase, urea nitrogen, total protein, creatinine, electrolytes, inorganic phosphate, cholesterol, triglycerides and glucose), and histopathological examination of major tissues and organs. Histopathological examination of major tissues and organs was also conducted in the control and $6.0 \mathrm{mg} / \mathrm{m}^{3}$ after 2 years of exposure and the nose, lungs, and mediastinal lymph nodes were examined in the 0.2 and $1.0 \mathrm{mg} / \mathrm{m}^{3}$ group after 2 years of exposure.

Effect noted in study and corresponding doses: Sniffing (no additional information provided) was observed in the $6.0 \mathrm{mg} / \mathrm{m}^{3}$ group after removal from the exposure chamber during months 5 and 6 . No treatment-related increases in mortality were observed, and there were no alterations in body weight gain. No alterations in hematological, clinical chemistry, or urinalysis parameters were observed. Significant increases in absolute and relative lung weights were observed in the $6.0 \mathrm{mg} / \mathrm{m}^{3}$ group after 1 and 2 years of exposure. In the rats sacrificed after 1 year of exposure, histological alterations were observed in the nasal cavity, lungs, and mediastinal lymph nodes. In the lungs, the lesions consisted of pneumonitis in the 1.0 and $6.0 \mathrm{mg} / \mathrm{m}^{3}$ males, alveolar duct epithelialization in males at $6.0 \mathrm{mg} / \mathrm{m}^{3}$ and females at 1.0 and $6.0 \mathrm{mg} / \mathrm{m}^{3}$, and minimal to moderate localized fibrosis and accumulation of macrophages with yellow pigment in the $6.0 \mathrm{mg} / \mathrm{m}^{3}$ males and females. An accumulation of macrophages with yellow pigment was also observed in the lymph nodes of male and female rats exposed to $1.0 \mathrm{or} 6.0 \mathrm{mg} / \mathrm{m}^{3}$. In the nasal cavity, minimal to moderate olfactory epithelial disarrangement was observed in males at $6.0 \mathrm{mg} / \mathrm{m}^{3}$. Alterations were also observed in the lungs, mediastinal lymph nodes, and nasal cavity after 2 years of exposure. Lung effects included adenoma in males exposed to $6.0 \mathrm{mg} / \mathrm{m}^{3}$, accumulation of macrophages with yellow pigment in males and females at 1.0 and $6.0 \mathrm{mg} / \mathrm{m}^{3}$, localized fibrosis in males at 1.0 and $6.0 \mathrm{mg} / \mathrm{m}^{3}$ and females at $6.0 \mathrm{mg} / \mathrm{m}^{3}$, alveolar duct epithelialization in males and females at 1.0 and $6.0 \mathrm{mg} /{ }^{3}$, and localized alveolar bronchiolization in males and females at $6.0 \mathrm{mg} / \mathrm{m}^{3}$. An accumulation of macrophages with yellow pigment was observed in the mediastinal lymph nodes in males at 1.0 and $6.0 \mathrm{mg} / \mathrm{m}^{3}$ and females at $6.0 \mathrm{mg} / \mathrm{m}^{3}$. Nasal effects included basal cell hyperplasia and Bowman's gland 
hyperplasia in males at 1.0 and $6.0 \mathrm{mg} / \mathrm{m}^{3}$, basal cell hyperplasia in females at $6.0 \mathrm{mg} / \mathrm{m}^{3}$, and minimal to severe olfactory epithelial degeneration in males and females at $6.0 \mathrm{mg} / \mathrm{m}^{3}$. No significant increases in tumors were observed.

Dose and end point used for MRL derivation: $\mathrm{BMCL}_{10}$ of $0.48 \mathrm{mg} / \mathrm{m}^{3}$ for basal cell hyperplasia

\section{[ ] NOAEL [ ] LOAEL [X] BMCL}

The incidence data (Table A-1) for basal cell hyperplasia in the nasal cavity, Bowman's duct hyperplasia in the nasal cavity, and lung fibrosis were fit to all available dichotomous models in EPA's Benchmark Dose Software (BMDS, version 2.4.0) using the extra risk option. Adequate model fit was judged by three criteria: goodness-of-fit statistics ( $\mathrm{p}$-value $>0.1$ ), visual inspection of the dose-response curve, and scaled residual at the data point (except the control) closest to the predefined benchmark dose response (BMR). Among all of the models providing adequate fit to the data, the lowest BMCL (95\% lower confidence limit on the benchmark concentration) was selected as the point of departure when the difference between the BMCLs estimated from these models were more 3-fold; otherwise, the BMCL from the model with the lowest Akaike's Information Criterion (AIC) was chosen. For all three lesion types, a BMR of $10 \%$ was used. The model predictions for basal cell hyperplasia are presented in Table A-2. The incidence data for Bowman's gland hyperplasia did not fit any of the available dichotomous models. The model predictions for the incidence of lung fibrosis are presented in Table A-3.

\section{Table A-1. Incidence of Nasal and Pulmonary Lesions in Male Rats Exposed to Polymeric Methylenediphenyl Diisocyanate}

\begin{tabular}{lllll}
\hline & \multicolumn{4}{c}{ Exposure concentration $\left(\mathrm{mg} / \mathrm{m}^{3}\right)$} \\
\cline { 2 - 5 } & 0 & 0.2 & 1.0 & 6.0 \\
\hline Basal cell hyperplasia & $14 / 60$ & $13 / 60$ & $26 / 60$ & $32 / 60$ \\
Bowman's gland hyperplasia & $0 / 60$ & $2 / 60$ & $9 / 60$ & $17 / 60$ \\
Lung fibrosis & $1 / 60$ & $0 / 60$ & $9 / 60$ & $44 / 60$ \\
\hline
\end{tabular}

Source: Reuzel et al. 1994 
Table A-2. Model Predictions for Incidence of Basal Cell Hyperplasia in Male Rats Exposed to Polymeric Methylenediphenyl Diisocyanate $\left(\mathrm{mg} / \mathrm{m}^{3}\right)$

\begin{tabular}{|c|c|c|c|c|c|c|c|c|c|}
\hline \multirow[b]{2}{*}{ Model } & \multirow[b]{2}{*}{ DF } & \multirow[b]{2}{*}{$x^{2}$} & \multirow{2}{*}{$\begin{array}{c}x^{2} \\
\text { Goodness } \\
\text { of fit } \\
p-v a l u e^{a}\end{array}$} & \multicolumn{3}{|c|}{ Scaled residuals ${ }^{b}$} & \multirow[b]{2}{*}{$\mathrm{AIC}$} & \multirow[b]{2}{*}{$\begin{array}{c}\mathrm{BMC}_{10} \\
\left(\mathrm{mg} / \mathrm{m}^{3}\right)\end{array}$} & \multirow[b]{2}{*}{$\begin{array}{l}\mathrm{BMCL}_{10} \\
\left(\mathrm{mg} / \mathrm{m}^{3}\right)\end{array}$} \\
\hline & & & & $\begin{array}{l}\text { Dose } \\
\text { below } \\
\text { BMC }\end{array}$ & $\begin{array}{c}\text { Dose } \\
\text { above } \\
\text { BMC }\end{array}$ & $\begin{array}{l}\text { Overall } \\
\text { largest }\end{array}$ & & & \\
\hline Gammac $^{c}$ & 2 & 4.8 & 0.09 & 1.87 & -0.45 & 1.87 & 301.60 & ND & ND \\
\hline Logistic & 2 & 5.76 & 0.06 & 2.01 & -0.28 & 2.01 & 302.55 & ND & ND \\
\hline LogLogistic d.f & 2 & 3.96 & 0.14 & 1.67 & -0.62 & 1.67 & 300.81 & 0.87 & 0.48 \\
\hline LogProbit $^{d}$ & 2 & 7.56 & 0.02 & 2.30 & -0.28 & 2.30 & 304.25 & ND & ND \\
\hline Multistage (1 degree) $)^{\mathrm{e}}$ & 2 & 4.8 & 0.09 & 1.87 & -0.45 & 1.87 & 301.60 & ND & ND \\
\hline Multistage (2 degree)e & 2 & 4.8 & 0.09 & 1.87 & -0.45 & 1.87 & 301.60 & ND & ND \\
\hline Multistage (3-degree) & 2 & 4.8 & 0.09 & 1.87 & -0.45 & 1.87 & 301.60 & ND & ND \\
\hline Probit & 2 & 5.7 & 0.06 & 2.00 & -0.29 & 2.00 & 302.49 & ND & ND \\
\hline Weibullc & 2 & 4.8 & 0.09 & 1.87 & -0.45 & 1.87 & 301.60 & ND & ND \\
\hline Quantal-Linear & 2 & 4.8 & 0.09 & 1.87 & -0.45 & 1.87 & 301.60 & ND & ND \\
\hline
\end{tabular}

AIC = Akaike Information Criterion; BMC = maximum likelihood estimate of the exposure concentration associated with the selected benchmark response; $\mathrm{BMCL}=95 \%$ lower confidence limit on the BMC (subscripts denote benchmark response: i.e., $10=$ exposure concentration associated with $10 \%$ extra risk); DF = degrees of freedom; $\mathrm{ND}=$ not determined , model does not provide adequate fit to the data

a Values $<0.1$ fail to meet conventional goodness-of-fit criteria.

bScaled residuals at doses immediately below and above the BMD; also the largest residual at any dose.

cPower restricted to $\geq 1$.

dSlope restricted to $\geq 1$.

eBetas restricted to $\geq 0$.

fSelected model. The only model that was fit to the data was the LogLogistic model (all other models had a $p$-value $<0.1)$. 


\section{Table A-3. Model Predictions for Incidence of Lung Fibrosis in Male Rats Exposed to Methylenediphenyl Diisocyanate $\left(\mathrm{mg} / \mathrm{m}^{3}\right)$}

\begin{tabular}{|c|c|c|c|c|c|c|c|c|c|}
\hline \multirow[b]{2}{*}{ Model } & \multirow[b]{2}{*}{ DF } & \multirow[b]{2}{*}{$x^{2}$} & \multirow{2}{*}{$\begin{array}{c}x^{2} \\
\text { Goodness } \\
\text { of fit } \\
\text { p-value }\end{array}$} & \multicolumn{3}{|c|}{ Scaled residuals ${ }^{b}$} & \multirow[b]{2}{*}{ AIC } & \multirow[b]{2}{*}{$\begin{array}{r}\mathrm{BMC}_{10} \\
\left(\mathrm{mg} / \mathrm{m}^{3}\right) \\
\end{array}$} & \multirow[b]{2}{*}{$\begin{array}{l}\mathrm{BMCL}_{10} \\
\left(\mathrm{mg} / \mathrm{m}^{3}\right)\end{array}$} \\
\hline & & & & $\begin{array}{c}\text { Dose } \\
\text { below } \\
\text { BMC }\end{array}$ & $\begin{array}{c}\text { Dose } \\
\text { above } \\
\text { BMC }\end{array}$ & $\begin{array}{l}\text { Overall } \\
\text { largest }\end{array}$ & & & \\
\hline Gammac $^{c}$ & 1 & 2.04 & 0.15 & 0.63 & -0.16 & -1.12 & 139.67 & 0.90 & 0.57 \\
\hline Logistic & 2 & 8.46 & 0.01 & 2.23 & -0.20 & 2.23 & 144.69 & ND & ND \\
\hline LogLogistic $^{d, f}$ & 1 & 1.73 & 0.19 & 0.43 & -0.15 & -1.06 & 139.22 & 0.87 & 0.57 \\
\hline LogProbit $^{d}$ & 2 & 1.3 & 0.52 & 0.35 & -0.20 & -0.84 & 136.40 & 0.87 & 0.70 \\
\hline Multistage (1-degree) $)^{\mathrm{e}}$ & 2 & 4.42 & 0.11 & -0.65 & 0.73 & -1.69 & 141.53 & 0.54 & 0.43 \\
\hline Multistage (2-degree) & 1 & 2.64 & 0.10 & 0.67 & -0.07 & -1.36 & 140.83 & 0.89 & 0.51 \\
\hline Multistage (3-degree) & 1 & 2.64 & 0.10 & 0.67 & -0.07 & -1.36 & 140.83 & 0.89 & 0.51 \\
\hline Probit & 2 & 7.46 & 0.02 & 2.11 & -0.23 & 2.11 & 143.53 & ND & ND \\
\hline Weibullc & 1 & 2.2 & 0.14 & 0.64 & -0.12 & -1.19 & 139.99 & 0.90 & 0.55 \\
\hline Quantal-Linear & 2 & 4.42 & 0.11 & -0.65 & 0.73 & -1.69 & 141.53 & 0.54 & 0.43 \\
\hline
\end{tabular}

$\mathrm{AIC}=$ Akaike Information Criterion; $\mathrm{BMC}=$ maximum likelihood estimate of the exposure concentration associated with the selected benchmark response; $\mathrm{BMCL}=95 \%$ lower confidence limit on the BMC (subscripts denote benchmark response: i.e., $10=$ exposure concentration associated with $10 \%$ extra risk); DF = degrees of freedom; ND $=$ not determined, model does not provide adequate fit to the data

aValues $<0.1$ fail to meet conventional goodness-of-fit criteria.

bScaled residuals at doses immediately below and above the BMD; also the largest residual at any dose.

cPower restricted to $\geq 1$.

dSlope restricted to $\geq 1$.

eBetas restricted to $\geq 0$.

fSelected model. All models, except for the Logistic and the Probit $(p<0.1)$ were fit to the data. BMDLs for models providing adequate fit were sufficiently close (differed by <2-3-fold), so the model with the lowest AIC was selected (LogLogistic Model).

The $\mathrm{BMCL}_{10}$ values predicted from the selected models for basal cell hyperplasia and lung fibrosis were 0.48 and $0.70 \mathrm{mg} / \mathrm{m}^{3}$; the LogLogistic and LogProbit models for these effects are presented in Figures A-1 and A-2. The BMCL 10 of $0.48 \mathrm{mg} / \mathrm{m}^{3}$ was selected as the point of departure for the MRL. 
Figure A-1. Fit of LogLogistic Model to Data on Incidence of Basal Cell Hyperplasia in Male Rats Exposed to Polymeric Methylenediphenyl Diisocyanate $\left(\mathrm{mg} / \mathrm{m}^{3}\right)$

Log-Logistic Model, with BMR of 10\% Extra Risk for the BMD and 0.95 Lower Confidence Limit for the E

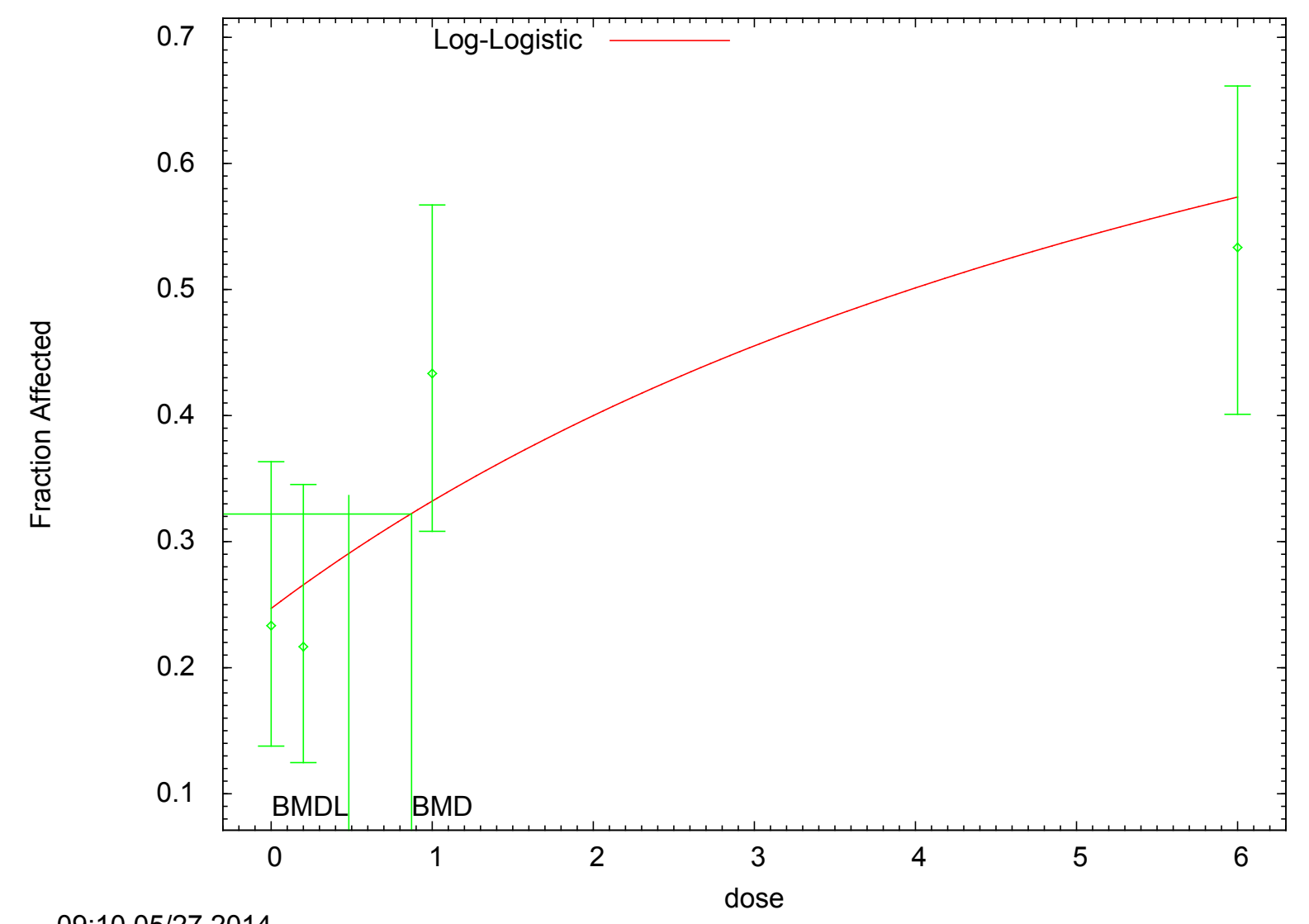


Figure A-2. Fit of LogLogistic Model to Data on for Incidence of Lung Fibrosis in Male Rats Exposed to Polymeric Methylenediphenyl Diisocyanate $\left(\mathrm{mg} / \mathrm{m}^{3}\right)$

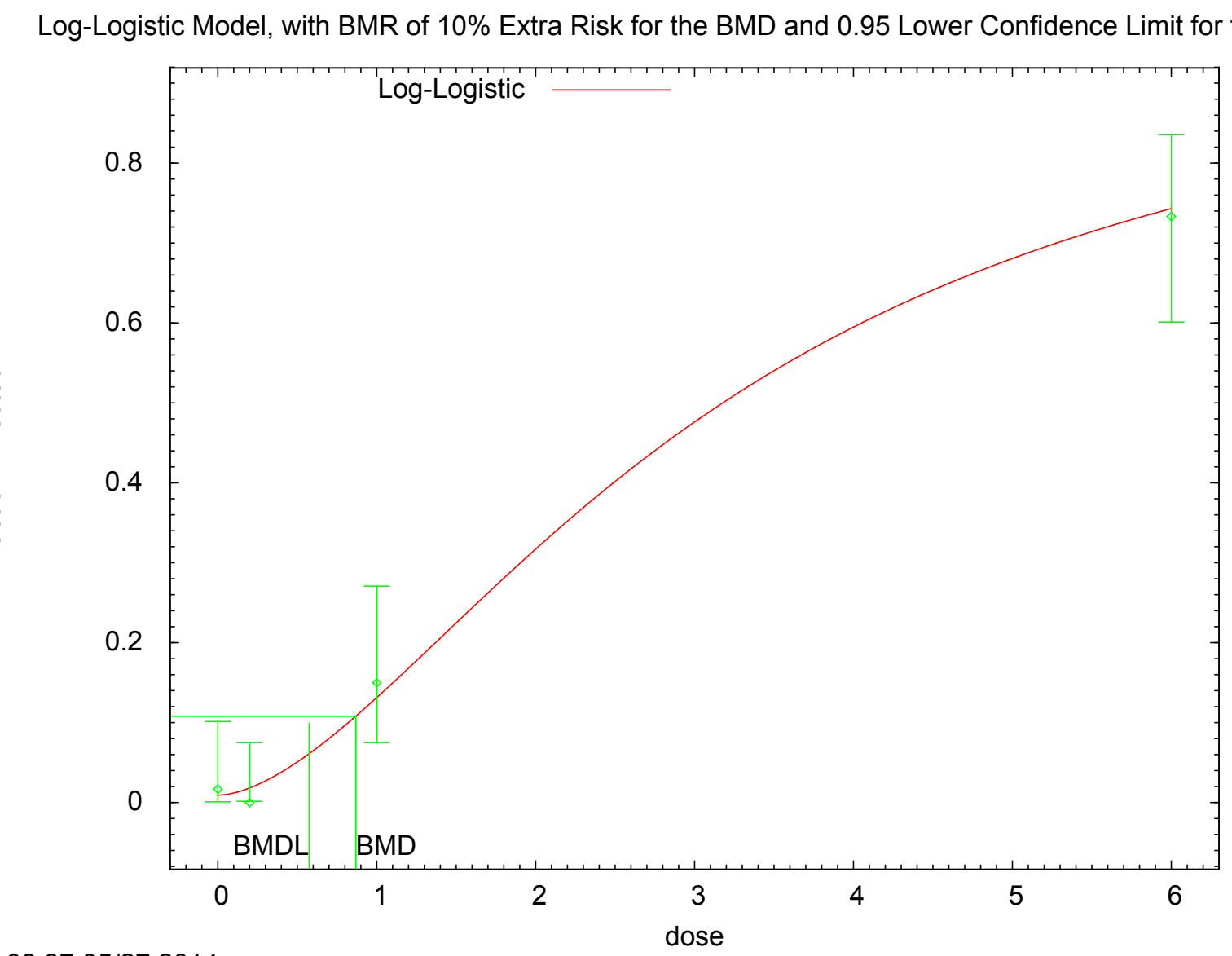

$09: 3705 / 272014$

Uncertainty Factors used in MRL derivation:

[ ] 10 for use of a LOAEL

[X] 3 for extrapolation from animals to humans with dosimetric adjustment

[X] 10 for human variability

Was a conversion factor used from ppm in food or water to a $\mathrm{mg} /$ body weight dose? Not applicable.

If an inhalation study in animals, list conversion factors used in determining human equivalent dose: Yes.

The $\mathrm{BMCL}_{\mathrm{ADJ}}$ of $0.086 \mathrm{mg} / \mathrm{m}^{3}$ was converted to a human equivalent concentration (BMCL $\mathrm{HEC}$ ) of $0.039 \mathrm{mg} / \mathrm{m}^{3}$ using the RDDR program (EPA 1990) as follows:

$\mathrm{BMCL}_{\mathrm{HEC}}=\mathrm{BMCL}_{\mathrm{ADJ}} \mathrm{x}$ RDDR

$\mathrm{BMCL}_{\mathrm{HEC}}=0.086 \mathrm{mg} / \mathrm{m}^{3} \times 0.453$

$\mathrm{BMCL}_{\mathrm{HEC}}=0.039 \mathrm{mg} / \mathrm{m}^{3}$ 
where:

RDDR is a multiplicative factor used to adjust an observed inhalation particulate exposure concentration of an animal to the predicted inhalation particulate exposure concentration for a human. The RDDR multiplier of 0.453 for the extrathoracic region tract was determined using the default chronic body weight of $462 \mathrm{~g}$ for male Wistar rats (EPA 1988) and a particle size $\mathrm{MMAD} \pm \mathrm{GSD}$ of $0.68 \pm 2.93 \mu \mathrm{m}$ reported in the Reuzel et al. (1994) study.

Was a conversion used from intermittent to continuous exposure? Yes.

A BMCL $L_{\mathrm{ADJ}}$ was calculated by adjusting the $\mathrm{BMCL}_{10}$ of $0.48 \mathrm{mg} / \mathrm{m}^{3}$ for intermittent exposure:

$$
0.048 \mathrm{mg} / \mathrm{m}^{3} \times 6 \text { hours } / 24 \text { hours } \times 5 \text { days } / 7 \text { days }=0.086 \mathrm{mg} / \mathrm{m}^{3}
$$

Other additional studies or pertinent information that lend support to this MRL: The respiratory tract is the primary target of MDI toxicity in humans and animals. Occupational asthma, asthma-like symptoms, and decreases in lung function have been reported in occupational exposure studies (Hur et al. 2008; Liss et al. 1988; Musk et al. 1982; Sulotto et al. 1990; Wang and Petsonk 2004; Woellner et al. 1997; ZamitTabona et al. 1983). The occupational asthma and asthma-like symptoms result from sensitization to MDI following a brief exposure to very high concentrations or prolonged exposure to lower concentrations; the prevalence of MDI-sensitization is believed to be low. Liss et al. (1988) reported significant declines in $\mathrm{FEV}_{1}$ levels when pre-shift levels were compared to post-shift levels; however, the study did not provide monitoring data. Sulotto et al. (1990) and Musk et al. (1982) did not find declines in lung function in workers. Sulotto et al. (1990) reported MDI levels ranging from 0.005 to $0.001 \mathrm{ppm}$; the monitoring data provided by Musk et al. (1982) was not considered reliable. 
APPENDIX A

This page is intentionally blank. 


\section{APPENDIX B. USER'S GUIDE}

\section{Chapter 1}

\section{Public Health Statement}

This chapter of the profile is a health effects summary written in non-technical language. Its intended audience is the general public, especially people living in the vicinity of a hazardous waste site or chemical release. If the Public Health Statement were removed from the rest of the document, it would still communicate to the lay public essential information about the chemical.

The major headings in the Public Health Statement are useful to find specific topics of concern. The topics are written in a question and answer format. The answer to each question includes a sentence that will direct the reader to chapters in the profile that will provide more information on the given topic.

\section{Chapter 2}

\section{Relevance to Public Health}

This chapter provides a health effects summary based on evaluations of existing toxicologic, epidemiologic, and toxicokinetic information. This summary is designed to present interpretive, weightof-evidence discussions for human health end points by addressing the following questions:

1. What effects are known to occur in humans?

2. What effects observed in animals are likely to be of concern to humans?

3. What exposure conditions are likely to be of concern to humans, especially around hazardous waste sites?

The chapter covers end points in the same order that they appear within the Discussion of Health Effects by Route of Exposure section, by route (inhalation, oral, and dermal) and within route by effect. Human data are presented first, then animal data. Both are organized by duration (acute, intermediate, chronic). In vitro data and data from parenteral routes (intramuscular, intravenous, subcutaneous, etc.) are also considered in this chapter.

The carcinogenic potential of the profiled substance is qualitatively evaluated, when appropriate, using existing toxicokinetic, genotoxic, and carcinogenic data. ATSDR does not currently assess cancer potency or perform cancer risk assessments. Minimal Risk Levels (MRLs) for noncancer end points (if derived) and the end points from which they were derived are indicated and discussed.

Limitations to existing scientific literature that prevent a satisfactory evaluation of the relevance to public health are identified in the Chapter 3 Data Needs section.

\section{Interpretation of Minimal Risk Levels}

Where sufficient toxicologic information is available, ATSDR has derived MRLs for inhalation and oral routes of entry at each duration of exposure (acute, intermediate, and chronic). These MRLs are not meant to support regulatory action, but to acquaint health professionals with exposure levels at which adverse health effects are not expected to occur in humans. 
MRLs should help physicians and public health officials determine the safety of a community living near a hazardous substance emission, given the concentration of a contaminant in air or the estimated daily dose in water. MRLs are based largely on toxicological studies in animals and on reports of human occupational exposure.

MRL users should be familiar with the toxicologic information on which the number is based. Chapter 2, "Relevance to Public Health," contains basic information known about the substance. Other sections such as Chapter 3 Section 3.9, "Interactions with Other Substances," and Section 3.10, "Populations that are Unusually Susceptible" provide important supplemental information.

MRL users should also understand the MRL derivation methodology. MRLs are derived using a modified version of the risk assessment methodology that the Environmental Protection Agency (EPA) provides (Barnes and Dourson 1988) to determine reference doses (RfDs) for lifetime exposure.

To derive an MRL, ATSDR generally selects the most sensitive end point which, in its best judgement, represents the most sensitive human health effect for a given exposure route and duration. ATSDR cannot make this judgement or derive an MRL unless information (quantitative or qualitative) is available for all potential systemic, neurological, and developmental effects. If this information and reliable quantitative data on the chosen end point are available, ATSDR derives an MRL using the most sensitive species (when information from multiple species is available) with the highest no-observed-adverse-effect level (NOAEL) that does not exceed any adverse effect levels. When a NOAEL is not available, a lowest-observed-adverse-effect level (LOAEL) can be used to derive an MRL, and an uncertainty factor (UF) of 10 must be employed. Additional uncertainty factors of 10 must be used both for human variability to protect sensitive subpopulations (people who are most susceptible to the health effects caused by the substance) and for interspecies variability (extrapolation from animals to humans). In deriving an MRL, these individual uncertainty factors are multiplied together. The product is then divided into the inhalation concentration or oral dosage selected from the study. Uncertainty factors used in developing a substance-specific MRL are provided in the footnotes of the levels of significant exposure (LSE) tables.

\section{Chapter 3}

\section{Health Effects}

\section{Tables and Figures for Levels of Significant Exposure (LSE)}

Tables and figures are used to summarize health effects and illustrate graphically levels of exposure associated with those effects. These levels cover health effects observed at increasing dose concentrations and durations, differences in response by species, MRLs to humans for noncancer end points, and EPA's estimated range associated with an upper- bound individual lifetime cancer risk of 1 in 10,000 to 1 in $10,000,000$. Use the LSE tables and figures for a quick review of the health effects and to locate data for a specific exposure scenario. The LSE tables and figures should always be used in conjunction with the text. All entries in these tables and figures represent studies that provide reliable, quantitative estimates of NOAELs, LOAELs, or Cancer Effect Levels (CELs).

The legends presented below demonstrate the application of these tables and figures. Representative examples of LSE Table 3-1 and Figure 3-1 are shown. The numbers in the left column of the legends correspond to the numbers in the example table and figure. 


\section{LEGEND}

\section{See Sample LSE Table 3-1 (page B-6)}

(1) Route of Exposure. One of the first considerations when reviewing the toxicity of a substance using these tables and figures should be the relevant and appropriate route of exposure. Typically when sufficient data exist, three LSE tables and two LSE figures are presented in the document. The three LSE tables present data on the three principal routes of exposure, i.e., inhalation, oral, and dermal (LSE Tables 3-1, 3-2, and 3-3, respectively). LSE figures are limited to the inhalation (LSE Figure 3-1) and oral (LSE Figure 3-2) routes. Not all substances will have data on each route of exposure and will not, therefore, have all five of the tables and figures.

(2) Exposure Period. Three exposure periods - acute (less than 15 days), intermediate (15364 days), and chronic (365 days or more) - are presented within each relevant route of exposure. In this example, an inhalation study of intermediate exposure duration is reported. For quick reference to health effects occurring from a known length of exposure, locate the applicable exposure period within the LSE table and figure.

(3) Health Effect. The major categories of health effects included in LSE tables and figures include death, systemic, immunological, neurological, developmental, reproductive, and cancer. NOAELs and LOAELs can be reported in the tables and figures for all effects but cancer. Systemic effects are further defined in the "System" column of the LSE table (see key number $18)$.

(4) Key to Figure. Each key number in the LSE table links study information to one or more data points using the same key number in the corresponding LSE figure. In this example, the study represented by key number 18 has been used to derive a NOAEL and a Less Serious LOAEL (also see the two "18r" data points in sample Figure 3-1).

(5) Species. The test species, whether animal or human, are identified in this column. Chapter 2, "Relevance to Public Health," covers the relevance of animal data to human toxicity and Section 3.4, "Toxicokinetics," contains any available information on comparative toxicokinetics. Although NOAELs and LOAELs are species specific, the levels are extrapolated to equivalent human doses to derive an MRL.

(6) Exposure Frequency/Duration. The duration of the study and the weekly and daily exposure regimens are provided in this column. This permits comparison of NOAELs and LOAELs from different studies. In this case (key number 18), rats were exposed to "Chemical x" via inhalation for 6 hours/day, 5 days/week, for 13 weeks. For a more complete review of the dosing regimen, refer to the appropriate sections of the text or the original reference paper (i.e., Nitschke et al. 1981).

(7) System. This column further defines the systemic effects. These systems include respiratory, cardiovascular, gastrointestinal, hematological, musculoskeletal, hepatic, renal, and dermal/ocular. "Other" refers to any systemic effect (e.g., a decrease in body weight) not covered in these systems. In the example of key number 18, one systemic effect (respiratory) was investigated.

(8) NOAEL. A NOAEL is the highest exposure level at which no adverse effects were seen in the organ system studied. Key number 18 reports a NOAEL of $3 \mathrm{ppm}$ for the respiratory system, which was used to derive an intermediate exposure, inhalation MRL of $0.005 \mathrm{ppm}$ (see footnote "b"). 
(9) LOAEL. A LOAEL is the lowest dose used in the study that caused an adverse health effect. LOAELs have been classified into "Less Serious" and "Serious" effects. These distinctions help readers identify the levels of exposure at which adverse health effects first appear and the gradation of effects with increasing dose. A brief description of the specific end point used to quantify the adverse effect accompanies the LOAEL. The respiratory effect reported in key number 18 (hyperplasia) is a Less Serious LOAEL of $10 \mathrm{ppm}$. MRLs are not derived from Serious LOAELs.

(10) Reference. The complete reference citation is given in Chapter 9 of the profile.

(11) CEL. A CEL is the lowest exposure level associated with the onset of carcinogenesis in experimental or epidemiologic studies. CELs are always considered serious effects. The LSE tables and figures do not contain NOAELs for cancer, but the text may report doses not causing measurable cancer increases.

(12) Footnotes. Explanations of abbreviations or reference notes for data in the LSE tables are found in the footnotes. Footnote "b" indicates that the NOAEL of 3 ppm in key number 18 was used to derive an MRL of $0.005 \mathrm{ppm}$.

\section{LEGEND}

\section{See Sample Figure 3-1 (page B-7)}

LSE figures graphically illustrate the data presented in the corresponding LSE tables. Figures help the reader quickly compare health effects according to exposure concentrations for particular exposure periods.

(13) Exposure Period. The same exposure periods appear as in the LSE table. In this example, health effects observed within the acute and intermediate exposure periods are illustrated.

(14) Health Effect. These are the categories of health effects for which reliable quantitative data exists. The same health effects appear in the LSE table.

(15) Levels of Exposure. Concentrations or doses for each health effect in the LSE tables are graphically displayed in the LSE figures. Exposure concentration or dose is measured on the log scale "y" axis. Inhalation exposure is reported in $\mathrm{mg} / \mathrm{m}^{3}$ or $\mathrm{ppm}$ and oral exposure is reported in $\mathrm{mg} / \mathrm{kg} / \mathrm{day}$.

(16) NOAEL. In this example, the open circle designated $18 \mathrm{r}$ identifies a NOAEL critical end point in the rat upon which an intermediate inhalation exposure MRL is based. The key number 18 corresponds to the entry in the LSE table. The dashed descending arrow indicates the extrapolation from the exposure level of $3 \mathrm{ppm}$ (see entry 18 in the table) to the MRL of $0.005 \mathrm{ppm}$ (see footnote "b" in the LSE table).

(17) CEL. Key number $38 \mathrm{~m}$ is one of three studies for which CELs were derived. The diamond symbol refers to a CEL for the test species-mouse. The number 38 corresponds to the entry in the LSE table. 
(18) Estimated Upper-Bound Human Cancer Risk Levels. This is the range associated with the upperbound for lifetime cancer risk of 1 in 10,000 to 1 in 10,000,000. These risk levels are derived from the EPA's Human Health Assessment Group's upper-bound estimates of the slope of the cancer dose response curve at low dose levels $\left(\mathrm{q}_{1}{ }^{*}\right)$.

(19) Key to LSE Figure. The Key explains the abbreviations and symbols used in the figure. 


\section{SAMPLE}

Table 3-1. Levels of Significant Exposure to [Chemical x] - Inhalation

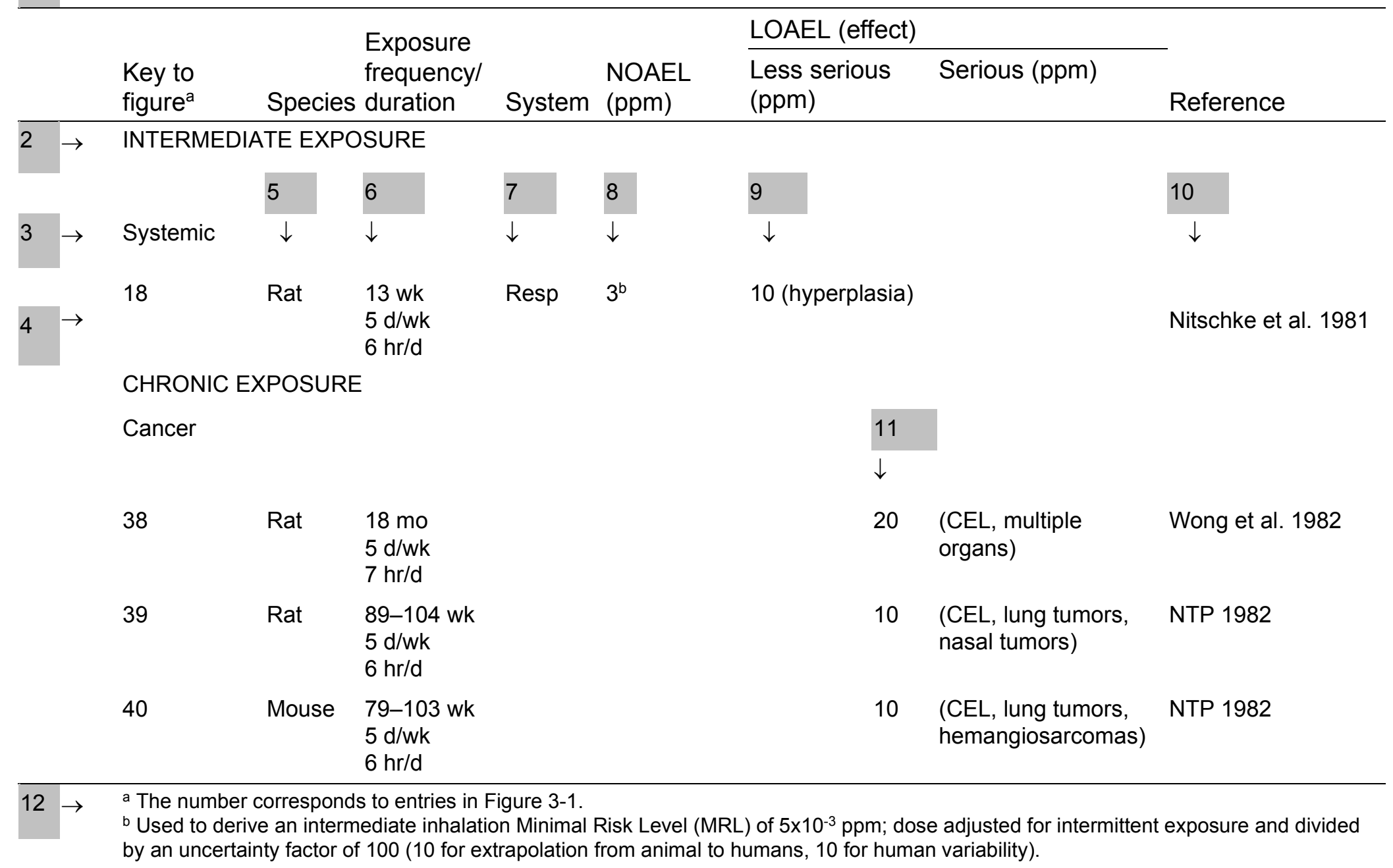




\section{SAMPLE}

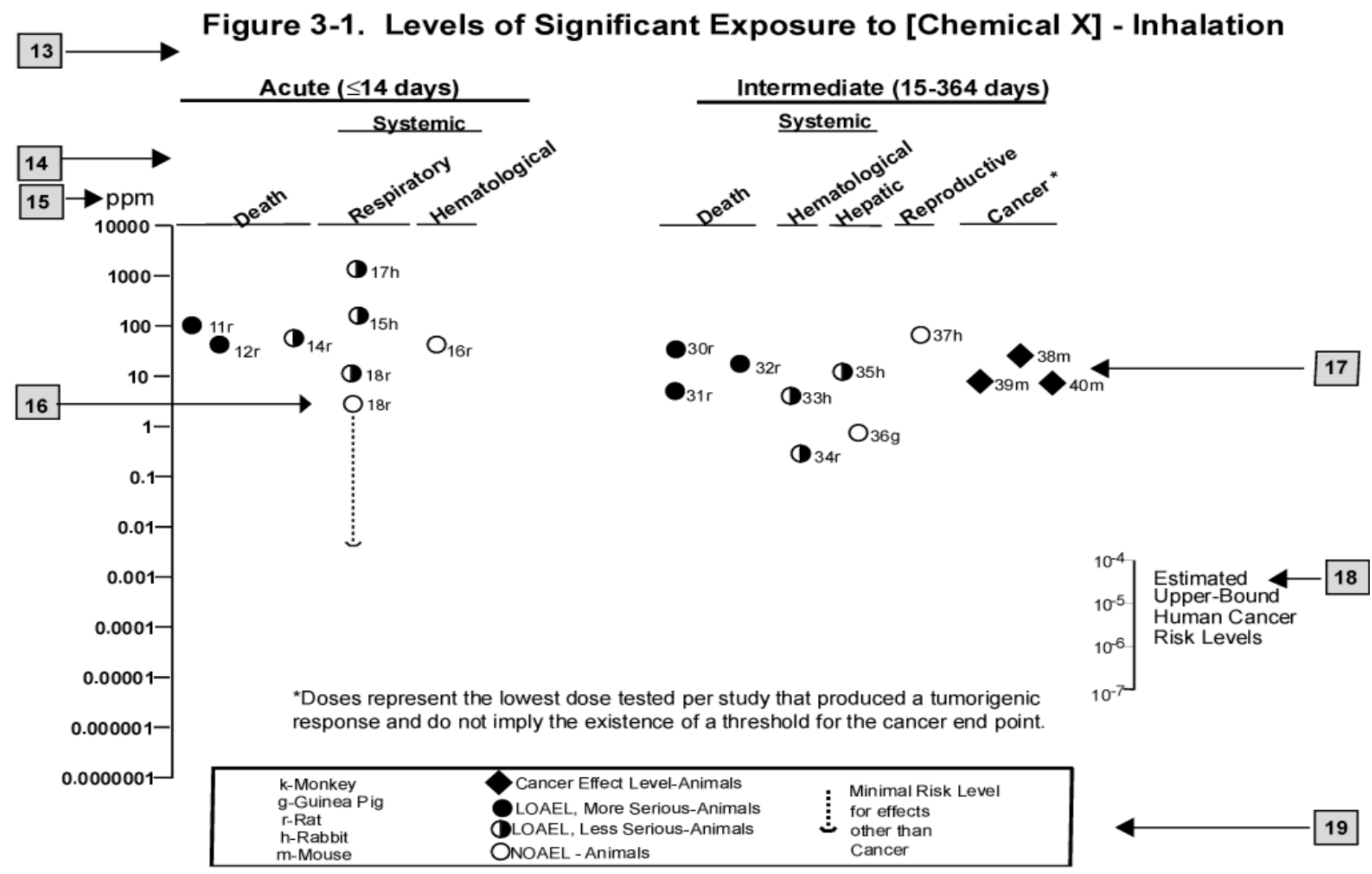


APPENDIX B

This page is intentionally blank. 


\section{APPENDIX C. ACRONYMS, ABBREVIATIONS, AND SYMBOLS}

\begin{tabular}{|c|c|}
\hline ACGIH & American Conference of Governmental Industrial Hygienists \\
\hline ACOEM & American College of Occupational and Environmental Medicine \\
\hline ADI & acceptable daily intake \\
\hline ADME & absorption, distribution, metabolism, and excretion \\
\hline AED & atomic emission detection \\
\hline AFID & alkali flame ionization detector \\
\hline AFOSH & Air Force Office of Safety and Health \\
\hline ALT & alanine aminotransferase \\
\hline AML & acute myeloid leukemia \\
\hline $\mathrm{AOAC}$ & Association of Official Analytical Chemists \\
\hline AOEC & Association of Occupational and Environmental Clinics \\
\hline AP & alkaline phosphatase \\
\hline APHA & American Public Health Association \\
\hline AST & aspartate aminotransferase \\
\hline atm & atmosphere \\
\hline ATSDR & Agency for Toxic Substances and Disease Registry \\
\hline AWQC & Ambient Water Quality Criteria \\
\hline BAT & best available technology \\
\hline $\mathrm{BCF}$ & bioconcentration factor \\
\hline BEI & Biological Exposure Index \\
\hline $\mathrm{BMD} / \mathrm{C}$ & benchmark dose or benchmark concentration \\
\hline $\mathrm{BMD}_{\mathrm{X}}$ & dose that produces a $\mathrm{X} \%$ change in response rate of an adverse effect \\
\hline $\mathrm{BMDL}_{\mathrm{X}}$ & $95 \%$ lower confidence limit on the $\mathrm{BMD}_{\mathrm{X}}$ \\
\hline BMDS & Benchmark Dose Software \\
\hline BMR & benchmark response \\
\hline $\mathrm{BSC}$ & Board of Scientific Counselors \\
\hline $\mathrm{C}$ & centigrade \\
\hline CAA & Clean Air Act \\
\hline CAG & Cancer Assessment Group of the U.S. Environmental Protection Agency \\
\hline CAS & Chemical Abstract Services \\
\hline $\mathrm{CDC}$ & Centers for Disease Control and Prevention \\
\hline CEL & cancer effect level \\
\hline CELDS & Computer-Environmental Legislative Data System \\
\hline CERCLA & Comprehensive Environmental Response, Compensation, and Liability Act \\
\hline CFR & Code of Federal Regulations \\
\hline $\mathrm{Ci}$ & curie \\
\hline $\mathrm{CI}$ & confidence interval \\
\hline CLP & Contract Laboratory Program \\
\hline $\mathrm{cm}$ & centimeter \\
\hline CML & chronic myeloid leukemia \\
\hline CPSC & Consumer Products Safety Commission \\
\hline CWA & Clean Water Act \\
\hline DHEW & Department of Health, Education, and Welfare \\
\hline DHHS & Department of Health and Human Services \\
\hline DNA & deoxyribonucleic acid \\
\hline DOD & Department of Defense \\
\hline DOE & Department of Energy \\
\hline DOL & Department of Labor \\
\hline DOT & Department of Transportation \\
\hline
\end{tabular}




\begin{tabular}{|c|c|}
\hline $\begin{array}{l}\text { DOT/UN/ } \\
\text { NA/IMDG }\end{array}$ & $\begin{array}{l}\text { Department of Transportation/United Nations/ } \\
\text { North America/Intergovernmental Maritime Dangerous Goods Code }\end{array}$ \\
\hline DWEL & drinking water exposure level \\
\hline $\mathrm{ECD}$ & electron capture detection \\
\hline ECG/EKG & electrocardiogram \\
\hline EEG & electroencephalogram \\
\hline EEGL & Emergency Exposure Guidance Level \\
\hline EPA & Environmental Protection Agency \\
\hline $\mathrm{F}$ & Fahrenheit \\
\hline $\mathrm{F}_{1}$ & first-filial generation \\
\hline FAO & Food and Agricultural Organization of the United Nations \\
\hline FDA & Food and Drug Administration \\
\hline FEMA & Federal Emergency Management Agency \\
\hline FIFRA & Federal Insecticide, Fungicide, and Rodenticide Act \\
\hline FPD & flame photometric detection \\
\hline fpm & feet per minute \\
\hline FR & Federal Register \\
\hline FSH & follicle stimulating hormone \\
\hline $\mathrm{g}$ & gram \\
\hline GC & gas chromatography \\
\hline gd & gestational day \\
\hline GLC & gas liquid chromatography \\
\hline GPC & gel permeation chromatography \\
\hline HPLC & high-performance liquid chromatography \\
\hline HRGC & high resolution gas chromatography \\
\hline HSDB & Hazardous Substance Data Bank \\
\hline IARC & International Agency for Research on Cancer \\
\hline IDLH & immediately dangerous to life and health \\
\hline ILO & International Labor Organization \\
\hline IRIS & Integrated Risk Information System \\
\hline Kd & adsorption ratio \\
\hline $\mathrm{kg}$ & kilogram \\
\hline $\mathrm{kkg}$ & kilokilogram; 1 kilokilogram is equivalent to 1,000 kilograms and 1 metric ton \\
\hline $\mathrm{K}_{\mathrm{oc}}$ & organic carbon partition coefficient \\
\hline $\mathrm{K}_{\mathrm{ow}}$ & octanol-water partition coefficient \\
\hline $\mathrm{L}$ & liter \\
\hline $\mathrm{LC}$ & liquid chromatography \\
\hline $\mathrm{LC}_{50}$ & lethal concentration, $50 \%$ kill \\
\hline $\mathrm{LC}_{\mathrm{Lo}}$ & lethal concentration, low \\
\hline $\mathrm{LD}_{50}$ & lethal dose, $50 \%$ kill \\
\hline $\mathrm{LD}_{\mathrm{Lo}}$ & lethal dose, low \\
\hline $\mathrm{LDH}$ & lactic dehydrogenase \\
\hline LH & luteinizing hormone \\
\hline LOAEL & lowest-observed-adverse-effect level \\
\hline LSE & Levels of Significant Exposure \\
\hline $\mathrm{LT}_{50}$ & lethal time, $50 \%$ kill \\
\hline $\mathrm{m}$ & meter \\
\hline MA & trans,trans-muconic acid \\
\hline MAL & maximum allowable level \\
\hline $\mathrm{mCi}$ & millicurie \\
\hline MCL & maximum contaminant level \\
\hline
\end{tabular}




\begin{tabular}{|c|c|}
\hline MCLG & maximum contaminant level goal \\
\hline MF & modifying factor \\
\hline MFO & mixed function oxidase \\
\hline $\mathrm{mg}$ & milligram \\
\hline $\mathrm{mL}$ & milliliter \\
\hline $\mathrm{mm}$ & millimeter \\
\hline $\mathrm{mmHg}$ & millimeters of mercury \\
\hline mmol & millimole \\
\hline mppcf & millions of particles per cubic foot \\
\hline MRL & Minimal Risk Level \\
\hline MS & mass spectrometry \\
\hline $\mathrm{mt}$ & metric ton \\
\hline NAAQS & National Ambient Air Quality Standard \\
\hline NAS & National Academy of Science \\
\hline NATICH & National Air Toxics Information Clearinghouse \\
\hline NATO & North Atlantic Treaty Organization \\
\hline NCE & normochromatic erythrocytes \\
\hline NCEH & National Center for Environmental Health \\
\hline NCI & National Cancer Institute \\
\hline ND & not detected \\
\hline $\begin{array}{l}\text { NFPA } \\
\text { ng }\end{array}$ & $\begin{array}{l}\text { National Fire Protection Association } \\
\text { nanogram }\end{array}$ \\
\hline NHANES & National Health and Nutrition Examination Survey \\
\hline NIEHS & National Institute of Environmental Health Sciences \\
\hline NIOSH & National Institute for Occupational Safety and Health \\
\hline NIOSHTIC & NIOSH's Computerized Information Retrieval System \\
\hline NLM & National Library of Medicine \\
\hline $\mathrm{nm}$ & nanometer \\
\hline nmol & nanomole \\
\hline NOAEL & no-observed-adverse-effect level \\
\hline NOES & National Occupational Exposure Survey \\
\hline NOHS & National Occupational Hazard Survey \\
\hline NPD & nitrogen phosphorus detection \\
\hline NPDES & National Pollutant Discharge Elimination System \\
\hline NPL & National Priorities List \\
\hline NR & not reported \\
\hline NRC & National Research Council \\
\hline NS & not specified \\
\hline NSPS & New Source Performance Standards \\
\hline NTIS & National Technical Information Service \\
\hline NTP & National Toxicology Program \\
\hline ODW & Office of Drinking Water, EPA \\
\hline OERR & Office of Emergency and Remedial Response, EPA \\
\hline OHM/TADS & Oil and Hazardous Materials/Technical Assistance Data System \\
\hline OPP & Office of Pesticide Programs, EPA \\
\hline OPPT & Office of Pollution Prevention and Toxics, EPA \\
\hline OPPTS & Office of Prevention, Pesticides and Toxic Substances, EPA \\
\hline OR & odds ratio \\
\hline OSHA & Occupational Safety and Health Administration \\
\hline OSW & Office of Solid Waste, EPA \\
\hline OTS & Office of Toxic Substances \\
\hline
\end{tabular}




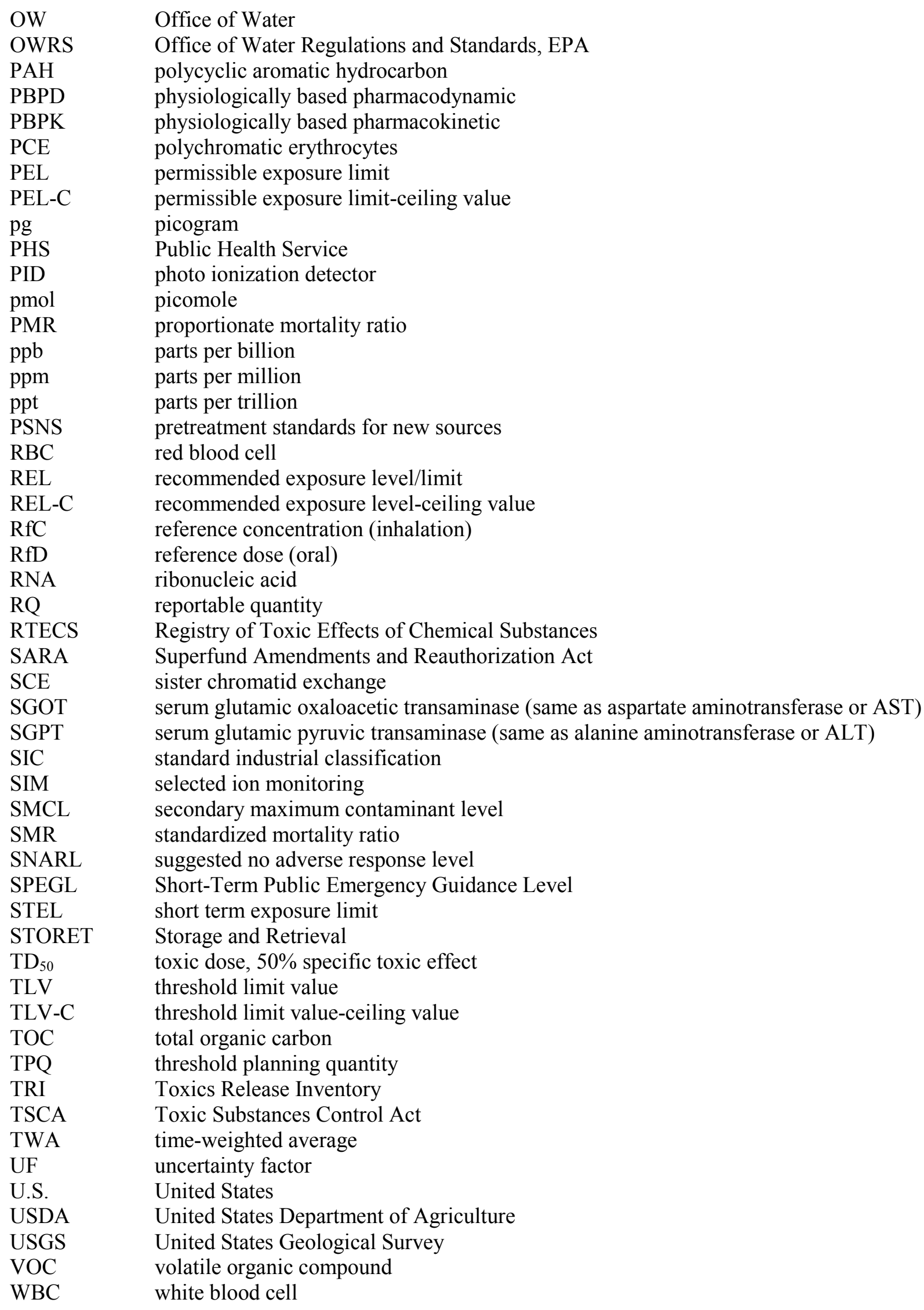




$\begin{array}{ll}\text { WHO } & \text { World Health Organization } \\ > & \\ \geq & \text { greater than } \\ = & \text { greater than or equal to } \\ < & \text { equal to } \\ \leq & \text { less than } \\ \% & \text { less than or equal to } \\ \alpha & \text { percent } \\ \beta & \text { alpha } \\ \gamma & \text { beta } \\ \delta & \text { gamma } \\ \mu \mathrm{m} & \text { delta } \\ \mu \mathrm{g} & \text { micrometer } \\ \mathrm{q}^{*} & \text { microgram } \\ - & \text { cancer slope factor } \\ + & \text { negative } \\ (+) & \text { positive } \\ (-) & \text { weakly positive result } \\ & \text { weakly negative result }\end{array}$

